Francesca Falk · Eine gestische Geschichte der Grenze 
Menschen machen Grenzen.

Grenzen machen Menschen.

Liebe Leserin, lieber Leser,

teilen Sie das Buch in ein Oben und Unten.

Ziehen Sie die Grenzlinie da, wo sie aufhört,

auf der folgenden Doppelseite weiter.

Ad infinitum.

1.6 .2011 
Francesca Falk

\title{
Eine gestische Geschichte der Grenze
}

\author{
Wie der Liberalismus an der Grenze \\ an seine Grenzen kommt
}


Für die finanzielle Förderung der Arbeit beziehungsweise deren Publikation dankt die Autorin dem Schweizerischen Nationalfonds, der Schweizerischen Studienstiftung, der Janggen-Pöhn-Stiftung, der Christine Bonjour-Stiftung, der Hamasil Stiftung, dem Basler Dissertationsfonds und dem Max Geldner-Fonds.

\author{
Umschlagabbildung: \\ Dan Perjovschi: „I am Not Exotic - I Am Exhausted“, \\ Basel 2007
}

Bibliografische Information der Deutschen Nationalbibliothek

Die Deutsche Nationalbibliothek verzeichnet diese Publikation in der Deutschen

Nationalbibliografie; detaillierte bibliografische Daten sind im Internet über http://dnb.d-nb.de abrufbar.

Alle Rechte, auch die des auszugsweisen Nachdrucks, der fotomechanischen

Wiedergabe und der Übersetzung, vorbehalten. Dies betrifft auch die Vervielfältigung und Übertragung einzelner Textabschnitte, Zeichnungen oder Bilder durch alle Verfahren wie Speicherung und Übertragung auf Papier,

Transparente, Filme, Bänder, Platten und andere Medien, soweit es nicht $\$ \$ 53$ und 54 UrhG ausdrücklich gestatten.

(C) 2011 Wilhelm Fink Verlag, München

(Wilhelm Fink GmbH \& Co. Verlags-KG, Jühenplatz 1, D-33098 Paderborn)

Internet: www.fink.de

Einbandgestaltung: Evelyn Ziegler, München

Printed in Germany.

Herstellung: Ferdinand Schöningh GmbH \& Co. KG, Paderborn

ISBN 978-3-7705-5202-3 


\section{INHALTSVERZEICHNIS}

EINLEITUNG. . . . . . . . . . . . . . . . . .

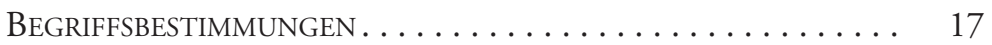

Evidenz.............................. 17

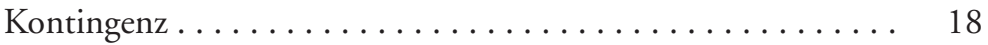

Transparenz............................. 19

ZuR KONSTITUTIVEN FUNKTION DER LEERE IN LOCKES

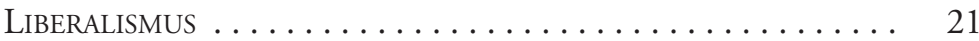

Geldökonomie und die Verknappung des leeren Raumes .... . 24

Grundstücksgrenzen als Folgen der Geldwirtschaft . . . . . . . 27

Exit-Option ............................ 29

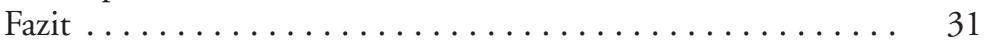

LOCKES LIBERALE STAATSTHEORIE UND WATKINS'

GRENZFOTOGRAFIE $\ldots \ldots \ldots \ldots \ldots \ldots \ldots \ldots \ldots \ldots \ldots \ldots \ldots$

Goldrausch und gefährdete Grundstücksgrenzen. . . . . . . . 39

Amerika als leere Augenweide . . . . . . . . . . . . . . . 43

Friedliche und flexible Frontier . . . . . . . . . . . . . . . 44

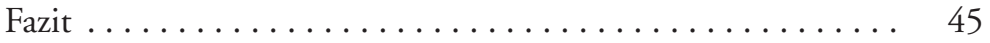

Hobbes' Horror Vacui. . . . . . . . . . . . . . . . . . . . . 47

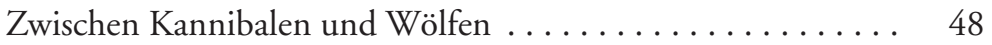

Freiheit als die Abwesenheit von Bewegungshindernissen .... 55

Politische Theorie und postkoloniale Perspektiven........ 58

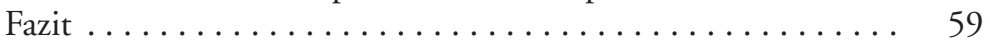


SCHNABElmasken: Sanität, Souveränität, SelekTion . . . . . .

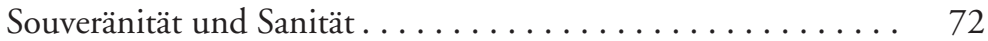

Selektion............................. 75

Wie die Biopolitik ins Bild des Politischen rückt....... 76

Soldaten, Seuchenärzte und Sicherheitsversprechen........ 85

Fazit .......................... 86

BOOTSFLÜCHTLINGE UND BILDGEDÄCHTNIS . . . . . . . . . 91

Das Boot ist voll ........................ 93

Ikonen gefährdeter Grenzen . . . . . . . . . . . . . 95

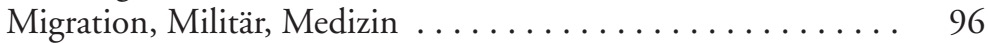

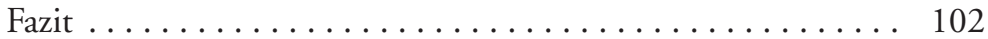

Die Vorgeschichte des Abschiebelagers . . . . . . . . . 105

Lager in kolonialen Konstellationen . . . . . . . . . . . . 107

Abschiebung der Fahrenden . . . . . . . . . . . . . . . 108

Abschiebelager für osteuropäische jüdische Migrierende

in der Weimarer Republik. . . . . . . . . . . . . . . . . . 112

Lager versus Gefängnis . . . . . . . . . . . . . . . . . . 113

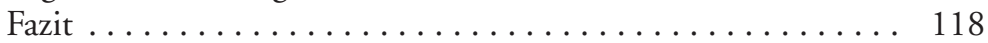

ILLEGALISIERUNG, IDENTIFIZIERUNG UND (IN-)VISIBILISIERUNG . 121

Fingerabdruck und Fotografie . . . . . . . . . . . . . 121

Sichtbarmachung der Sans-Papiers . . . . . . . . . . . . 125

Entgrenzung und Entbildlichung der Grenze . . . . . . . . 128

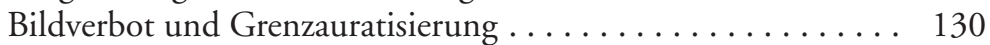

Fazit . . . . . . . . . . . . . . . . . . . . . . 131

Ein Recht auf Migration . . . . . . . . . . . . . . . . 135

Aus- und Einwanderungsrechte. . . . . . . . . . . . . . . . 139

Sozialstaat und freie Migration: (K)eine Aporie? . . . . . . . . . . 142

Grenzen anders sehen ........................ 145 
AnsÄtze Einer Gestischen Geschichte . . . . . . . . . . . . . 149

DANKSAGUNG ........................ 151

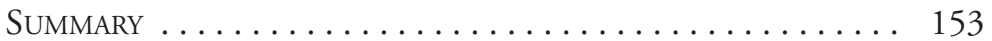

BILDNACHWEISE. . . . . . . . . . . . . . . . . . . . . . . . . . 157

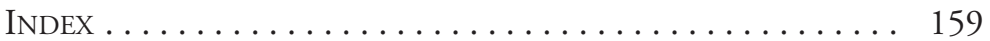

Bibliografie. . . . . . . . . . . . . . . . . . . . . 163 
Urheberrechtlich geschütztes Material! @ 2011 Wilhelm Fink Verlag,

Paderborn, ein Imprint der Brill-Gruppe 


\title{
EINLEITUNG
}

\author{
„Ce sujet', dit le gardien des dieux termes, ou \\ cette façon de le traiter, voilà sans doute qui \\ peut séduire. Mais prends garde, ô éphèbe: ce \\ n'est pas de l'histoire. “"1
}

Am Anfang war die Irritation über die unhinterfragte Legitimität bereits bestehender Grenzen. Ich wurde als Schweizer Staatsbürgerin geboren. Kurz vor meiner Volljährigkeit kam ich über meine Mutter in Besitz einer zweiten, der italienischen Staatsbürgerschaft. ${ }^{2}$ Ein formeller Akt, der von mir keine besondere Mitwirkung erforderte und von mir auch nicht verlangte, dass ich beispielsweise in diesem Land je lebte. Ganz anders verlief die Einbürgerungen meiner Schulkolleginnen und -kollegen. Als Ortsbürgerin von Rheineck - einer Schweizer Kleinstadt direkt an der Grenze zu Österreich - war ich Teil jenes Kreises, der in erster Instanz über die Einbürgerungsgesuche zu entscheiden hatte. Ich erinnere mich, wie bei einer ehemaligen Schulfreundin aus Bosnien aus mir unersichtlichen Gründen nur sie und ihr Bruder, nicht aber ihre Eltern und ihr jüngerer Bruder zur Einbürgerung zugelassen wurden. Solche Entscheidungen brauchten keine Begründung; wer diese staatsbürgerliche Grenze kontrollierte, musste sich nicht rechtfertigen. ${ }^{3}$ In zweiter Instanz befand damals die Einwohnergemeinde über die von der Ortsgemeinde zur Einbürgerung Zugelassenen. Es wurden jeweils Broschüren an alle Wahlberechtigten verschickt, in denen die Einbürgerungswilligen vorgestellt wurden; dass jemand mit den Verwandten in der Heimat noch in Kontakt stand oder nicht

1 Bloch, 1993, S. 81.

21992 war in der Schweiz das Verbot der doppelten Staatsbürgerschaft aufgehoben worden. Studer / Arlettaz und Argast, 2008, S. 403.

3 Allgemein zur Frage der Einbürgerung in der Schweiz siehe u. a. Steiner und Wicker, 2004. Achermann und Gass, 2003. D’Amato, 2001. 
am Vereinsleben teilnahm ${ }^{4}$, wurde dabei negativ zur Kenntnis genommen. ${ }^{5}$

Die Kontingenz des Geburtsortes und der Staatszugehörigkeit entscheidet heute in besonderem Ausmass über die Möglichkeiten der Lebensgestaltung. Die Evidenz, die aus der Existenz bereits bestehender - in diesem Falle staatsbürgerlicher - Grenzen resultiert, frappiert. Wie wird eine solche Grenzevidenz generiert, gerade in liberal verfassten Gesellschaften, in denen die individuellen Freiheitsrechte (worunter auch das Recht auf Bewegungsfreiheit fällt) so hoch veranschlagt werden? Der Ausschluss der Migrierenden vom Bürgerstatus unterminiert die „demokratische Deckungsgleichheit" ${ }^{\text {" }}$ zwischen jenen, die politische Herrschaft ausüben, und jenen, die der politischen Herrschaft unterworfen sind. Doch bereits im liberalen Gesellschaftsvertrag findet sich ein solcher Widerspruch: bei John Locke, dem „Vater" des Liberalismus ${ }^{7}$, und seinem Gesellschaftsvertrag, wie er ihn im „Second Treatise“ entwirft. Demnach sollen sich Individuen freiwillig einem Gesellschaftsvertrag anschliessen. Ich interessiere mich bei dieser Gründungsschrift des Liberalismus für das oft Übersehene: Auch die vom Vertrag Ausgeschlossenen sind von ihm betroffen und werden in ihren Handlungsmöglichkeiten eingeschränkt, können sich aber nicht aktiv dazu verhalten. Politische Grenzen unterliegen somit keiner freien Entschei-

4 Transnationale Forschungsansätze reflektieren gerade die Produktivität solcher Verbindungen zum Herkunftsland, dazu Glick Schiller / Basch und Szanton Blanc, 1995.

5 Heute, 2011, sieht das Einbürgerungsverfahren in Rheineck anders aus. Einbürgerungen finden nicht mehr an der Urne statt, sondern nach der erfolgten $\mathrm{Zu}$ stimmung der Einbürgerungskommission (zusammengesetzt aus Vertretern der Einwohner- und der Ortsbürgergemeinde) durch eine Abstimmung an einer Bürgerversammlung. Doch kommt es immer noch zu ungenügenden und demnach verfassungswidrigen Begründungen bei Einbürgerungsablehnungen. Die staatsrechtliche Literatur spricht gar von einem „Rheineckerproblem“. Auer, 2009, S.69.

2009 veranlasste die kantonale Regierung die Rheinecker Bürgerversammlung zum dritten Mal über sieben Einbürgerungen zu befinden, nachdem der Kanton die Rekurse wegen ungenügender Begründung der ablehnenden Entscheide erneut geschützt hatte. Die von der Einbürgerungsablehnung Betroffenen haben den Fall ans Bundesgericht weiter gezogen. Im Dezember 2009 hat der Kanton St. Gallen erstmals Einbürgerungen gegen den Willen von Gemeindeversammlungen angeordnet; damit setzt er den Entscheid des Bundesgerichts um. Krummenacher, 2009a. Krummenacher, 2009b.

6 Dazu Falk, 2010c.

7 „Liberalismus“ wird hier absichtlich nicht im Vorfeld definiert, sondern induktiv erschlossen: Er soll in seiner begrifflichen Dissensualität offen gehalten werden. 
dung beider Seiten. John Locke muss „leeres Land“ in Amerika postulieren, um sein Konzept der Staatsgründung zu legitimieren.

Bildlich umgesetzt hat diese Leere der Fotograf Carleton Watkins. Im 19. Jahrhundert fotografierte er den Westen der USA und wurde mit Bildern des späteren Yosemite Nationalparks berühmt. Dass Bilder desselben Fotografen vor Gericht bei Grenzstreitigkeiten verwendet wurden, ergibt eine zu John Locke in ihrer Widersprüchlichkeit entsprechende Konstellation. Watkins' Fotografien sollten im wörtlichen Sinne Grenzevidenz generieren.

Für Thomas Hobbes hingegen war Amerika mit seinen Indianern nicht leeres Land, sondern eine Vergegenwärtigung des Naturzustands, was das erste Frontispiz von Hobbes’ „De Cive“ augenfällig verdeutlicht. Hier werden Naturzustand - „Libertas“ - und Staat - „Imperium" - einander dichotomisch gegenübergestellt. In dieser Schrift wird die Freiheit als die Abwesenheit von allem, was die Bewegung hindert, beschrieben.

Eine Kontrolle und Kanalisation der Bewegung entstand wesentlich im Zuge einer Pestpolitik; medizinische Dispositive waren wichtig für die Etablierung und Legitimierung von Grenzen. So riefen Seuchenmassnahmen neue staatliche Strukturen ins Leben, es entstanden neue Formen der Grenz- und Migrationskontrolle. Erinnert sei hier an das Aufkommen der Quarantänestationen. Auch die Schaffung des Passes lässt sich unter anderem auf die in Pestzeiten ab dem 15. Jahrhundert ausgestellten „bollettini di sanità" zurückführen. Beide, Natur- und Pestzustand, erfüllen eine ähnliche und doch auch etwas anders gelagerte Funktion, wie Michel Foucault treffend bemerkte: „Versetzten sich die Juristen in den Naturzustand, um die Rechte und Gesetze in der reinen Theorie funktionieren zu lassen, so träumten die Regierenden vom Pestzustand, um die perfekten Disziplinen funktionieren zu lassen."8

Meine Untersuchung stellt das Frontispiz des „Leviathan“, das Emblem des Body Politic, in neue Zusammenhänge, und zwar in den $\mathrm{Zu}$ sammenhang von Sanität, Souveränität, Selektion sowie einer beginnenden Biopolitik. Die Schnabelmasken der in der Forschung kaum beachteten Pestärzte werden dabei zum Schwer- und Drehpunkt der Interpretation. Als Wahrnehmungsfilter verändern sie die Sicht auf den dargestellten Staatskörper.

Der ikonische Charakter der Schnabelmaske findet seine Fortsetzung in der Mundschutzmaske des Militärpolizisten, der Bootsflücht-

8 Foucault, 1977, S.255. Dazu auch Sarasin, 2008, S. 275. 
linge empfängt. Die Mundschutzmaske deutet auf die Angst vor Ansteckung hin. In solchen Bildern überlagern sich territoriale Grenzen mit Körpergrenzen: Migration erscheint hier als Angriff auf die Integrität des eigenen Körpers.

Bootsflüchtlinge sind in den Medien regelmässig sichtbar, selbst wenn die meisten der zahlreichen Todesopfer für die mediale Öffentlichkeit verborgen bleiben. Im Gegensatz dazu bleiben die Abschiebungsinsassen unsichtbar. Ihre Lager befinden sich meist in der Peripherie der Städte. Bilder, die diese zeigen, zirkulieren selten in den Medien. Stört diese Realität unser Eigenbild einer liberalen Gesellschaft?

Eine Genealogie der Abschiebelager verdeutlicht, dass die „Ursprünge" dieser Institution u. a. auf koloniale Kontexte im In- und Ausland zurückzuführen sind, was die gegenwärtige Illegalisierung der Immigration in neuer Weise auch aus einer postkolonialen Perspektive befragbar macht. ${ }^{?}$

In der politischen Theorie gilt der Akt der Grenzziehung oft als (implizite) Prämisse des Politischen. Gleichzeitig widersprechen geschlossene Grenzen den Grundprinzipien „liberaler" Gesellschaften. ${ }^{10}$ Dieses Spannungsverhältnis manifestiert sich in einer Tendenz zu Grenztransparenz (wobei diese Grenztransparenz immer perspektivenabhängig ist). Die Spannbreite des Begriffs „Grenztransparenz" versuche ich im Konkreten auszuloten. Indes will ich nicht eine geradlinige, lineare Entwicklung postulieren: Die diagnostizierte Tendenz zur Grenztransparenz schliesst nicht aus, dass gleichzeitig gerade in einer sich globalisierenden Welt eine Rückkehr zu militarisierten Mauern und bewachten Grenzbefestigungen zu beobachten ist.

Miliz-Grenzwächter in den USA, Sans-Papiers in Europa, Bootsflüchtlinge in Italien. Zäune, Mauern und Abschiebelager. Grenzen produzieren und legitimieren Gewalt. Grenzen produzieren Widersprüche. Doch sind die zum „medialen Drama der Migration“" führenden Verhältnisse nicht zu ändern, wenn man nur auf die Grenze blickt. Globale Probleme werden an der Grenze augenfällig, erhalten

9 Falk, 2012. Das Anliegen postkolonialer Ansätze besteht gerade in der Thematisierung des Fortbestehens und Nachwirkens von Effekten kolonialer Herrschaft - und nicht in der Proklamation einer erfolgreichen Überwindung des Kolonialismus. Conrad und Randeria, 2002, S. 24. Purtschert, 2008a, S.78.

10 Dazu auch die sehr interessante Arbeit von Wendy Brown, 2009.

11 „Auf Lampedusa findet der Mythos von der grossen Migrantenflut sein mediales Abbild“, meint etwa Charlotte Wiedmann. Wiedemann, 2009. 
hier eine mediale Sichtbarkeit - beispielsweise am Strand von Lampedusa -, sind aber nicht hier produziert.

Konkrete Handlungsanweisungen im Umgang mit politisch-territorialen Grenzen vermag ich nicht zu formulieren. Ziel dieser Arbeit ist, die denkkonstitutive Wirkung von bildlichen wie sprachlichen Prämissen, die Grenzevidenz generier(t)en, sichtbar und damit Grenzkontingenz in Geschichte und Gegenwart wahrnehmbar zu machen. Mögen alle Grenzziehungen letztlich kontingent sein, so werden sie doch meist nicht in ihrer Kontingenz gesehen.

Ausgehend von historischen Fallstudien werden demnach in dieser Studie dringende Fragen verhandelt, so beispielsweise ein (Menschen-) Recht auf Migration. Doch wird heute die Aufnahme von Migrierenden als Entscheidungsbefugnis souveräner Staaten betrachtet: „Illegale Migration" wird aus einer solchen Perspektive als Angriff auf die staatliche Souveränität verstanden.

Der Prototyp der flexiblen Arbeitskraft sind die Sans-Papiers. Ihre Existenz resultiert aus der Tatsache, dass eine programmatisch dichte Grenze in der Tradition der Souveränität proklamiert wird, diese Grenze aber nicht hermetisch funktioniert. Gleichzeitig wird durch die drakonische Abschiebehaft ein Strafexempel statuiert, das wie der Hobbes'sche „Leviathan“ über einen Effekt der Abschreckung wirken soll, und zwar ebenfalls auf die „regularisierten“ Immigrantinnen und Immigranten, die potenziell selbst von Zwangsmassnahmen betroffen sind und ihre Aufenthaltsbewilligung verlieren können.

Die Grenze, die innerhalb eines Staats Illegalisierte von den übrigen Bewohnerinnen und Bewohnern trennt, ist allerdings für gewöhnlich unsichtbar und nur unter gewissen Bedingungen und für bestimmte Personen sichtbar, beispielsweise für die Sans-Papiers selbst.

Wesentliche Pole dieser Arbeit bilden die Begriffe Grenzevidenz, Grenzkontingenz und Grenztransparenz. Gerade weil jede Grenze in einem gewissen Sinne kontingent ist, besteht für die gesellschaftliche Ordnung ein Erfordernis, Grenzevidenz herzustellen. Ein Gefühl des Überzeugtseins in Bezug auf die notwendige Existenz einer Grenze und ein Vertrauen in ihre Anerkennung; dies lässt sich unter dem Begriff der "Grenzevidenz" verstehen. ${ }^{12}$ Grenzevidenz - im Sinne eines wörtlichen „Vor-Augen-Führens der Grenze“ - lässt sich u.a. durch eine Politik der Sichtbarmachung produzieren, doch lässt sich eine „einleuchtende Anschaulichkeit" beispielsweise auch über das Medium

12 Siehe dazu die Begriffsbestimmungen zu Evidenz, Kontingenz und Transparenz im Anschluss an die Einleitung. 
der Sprache herstellen. Scheitern diese Evidenzeffekte, gelten Grenzen als willkürlich, nicht natürlich, als gemacht, nicht gegeben, als kontingent, nicht evident. ${ }^{13}$ Kontingent ist die faktisch vorhandene, doch weder notwendige noch unmögliche, das heisst also historisch wandelbare Grenze: Die Grenze ist, wie sie ist, sie könnte aber auch anders oder gar nicht - sein. Evidenz verdrängt Kontingenz.

Evidenz und Kontingenz sind indes nicht sich auschliessende, sondern verschränkt funktionierende Gegensatzpaare: Jede Evidenzerzeugung kann auf das ihr inhärente Kontingente hin befragt werden. Die Grenze zwischen Grenzevidenz und Grenzkontingenz ist somit stets eine fragile. Da Evidenzeffekte kippen können, möchte ich keine starke Opposition aufbauen zwischen Grenzevidenz und Grenzkontingenz. Vielmehr suche ich jene Orte auf, wo trotz vermeintlich generierter Grenzevidenz, zumindest unter einem bestimmten Blick, die Kontingenz der Grenze sichtbar wird. Anhand konkreter historischer Konstellationen untersuche ich also einerseits, wie verschiedene Arten von Grenzen - die sich allerdings immer in gewisser Weise territorial manifestieren - unter anderem über ein visuelles Programm evident gemacht werden, wie sich andererseits aber auch eine Tendenz zur Grenztransparenz etabliert, auch im Sinne einer Unsichtbarmachung der Grenze. Ich spreche deshalb von einer Tendenz, weil es mir darum geht, Prozesse zu beschreiben und nicht Typologien zu postulieren.

Nicht jede Visibilisierung von Grenzen produziert Evidenzeffekte; jedes Sichtbarmachen birgt auch gewisse Risiken. Die undurchdringbarste Grenze ist deshalb jene, die nicht als Grenze wahrnehmbar ist. Grenzpotenz beruht demnach nicht nur auf Evidenz - im Sinne der Erzeugung von Anschaulichkeit -, sondern auch auf Strategien der Unsichtbarmachung, des Bildverbots und des Blickentzugs, was ich mit dem Begriff der Grenztransparenz fasse. ${ }^{14}$

13 Wobei dabei ein ganz bestimmter Naturbegriff vorausgesetzt wird. Darwin beispielsweise denkt Natur und Kontingenz, Natur und Kultur nicht als Gegensätze; interessanterweise entwickelte er das Prinzip des Zufalls im Medium des Bildes. Dazu die sehr anregende Studie von Voss, 2007. Zum Konzept der natürlichen Grenze siehe Sahlins, 1989. - Sahlins, 1990.

14 Die Begriffsassoziationen von „Transparenz“ oszillieren heute zwischen dem aufklärerischen Impetus einer demokratischen Offenheit, die nichts zu verbergen hat (Transparenz meint hier Durchschaubarkeit der Verhältnisse und gerade nicht Unsichtbarmachung im Sinne einer Vertuschung) und der Vision einer Kontrollgesellschaft, was beispielsweise die Sprechweise vom „gläsernen Menschen“ verdeutlicht. Damit wird ein illegitimer Einblick in die Intimsphäre des Individuums kritisiert. 
Traditionellerweise dient politische Philosophie der Evidenzerzeugung des Staats: Ihre Grundfrage lautet, wie der Staat gegenüber seinen Bürgern legitimiert werden kann. Der Staat ist in einer solchen Denktradition nur gegenüber seinen Mitgliedern begründungsverpflichtet. Doch gerade dies wird in der gegenwärtigen politischen Theorie kritisiert. Diese Arbeit auf der Grenze zwischen Geschichtswissenschaft, Bildanalyse und politischer Theorie steht in dieser Denkrichtung. ${ }^{15}$

Die verfolgte Argumentation mit und gegen Michel Foucault, Thomas Hobbes und John Locke steigt dabei aus der traditionellen politischen Ideengeschichte aus und dringt zur Bildlichkeit der politischen Theorie vor. ${ }^{16}$ Bilder stossen unser Denken an, grenzen es ein, organisieren unsere Argumentationssysteme. Dies wiederum beeinflusst auch das Sehen von Grenzen und damit die Wahrnehmung der Migration. ${ }^{17}$

Noch in der Generation unserer Mütter war in der Schweiz die politische Partizipation der Frauen keine Selbstverständlichkeit, sondern ein Recht, das es zu erkämpfen galt. Für mich Nachgeborene ist ein solcher Ausschluss unvorstellbar, selbst wenn ich mich an die Einführung des Frauenstimmrechts im Appenzell erinnere. Anfang der 1990er Jahre erzwang das Schweizerische Bundesgericht, das vorher die Einführung des Frauenstimmrechts via Verfassungsinterpretation stets abgelehnt hatte, die politische Inklusion der Frauen auch im Kanton Appenzell Innerrhoden. In Bezug auf Einbürgerungsprozesse lassen sich heute in der Schweiz ähnliche Prozesse beobachten. Die Geschichte zeigt: Die Vorstellungen darüber, wer dazugehört und wer nicht, sei es in Bezug auf Aufenthalts-, politische, zivilrechtliche oder soziale Rechte, ändern sich (allerdings nicht zwangsläufig zum Besseren). ${ }^{18}$ Eine historische Betrachtung kann demnach auch für den Umstand sensi-

15 Während in der Wissenschaftsgeschichte die konstituierende Wirkung von sprachlichen und visuellen Bildern vor allem in den letzten Jahren zu einem wichtigen Untersuchungsfeld wurde, ist dies in Bezug auf die politische Theorie meines Erachtens meist noch wenig der Fall. Es erstaunt deshalb nicht, dass die bisher wohl bekanntesten Arbeiten dazu von einem Kunsthistoriker - Horst Bredekamp - stammen. Auf seine faszinierenden und materialreichen Studien werde ich in dieser Arbeit noch an mehreren Stellen zu sprechen kommen; nicht immer teile ich Bredekamps Meinung, doch waren seine Schriften für meine Argumentation ein wichtiger Referenzpunkt.

$16 \mathrm{Zu}$ visual culture siehe Mitchell, 2003. Mitchell, 2005a. - Mitchell, 2005b. Aus einer historischen Perspektive siehe auch Paul, 2008.

17 Dazu auch Mitchell, 2010. Mitchell, 2008, S. 410-411.

18 In meiner Publikation „Grenzverwischer" fragte ich: Wie werden gesellschaftliche Grenzen gezogen, begründet und gedacht? Am Beispiel von Antisemitismus und Homophobie untersuchte ich die Mechanismen der Marginalisierung und die Funktionsweise diskriminierender Diskurse. In dieser Studie ist es nun die Grenze 
bilisieren, dass Demokratiedefizite zeitgenössisch oft nicht als solche wahrgenommen werden.

Grenzen beherrschen seit einigen Jahren gesellschaftliche und politische Debatten und inspirieren zahlreiche künstlerische und wissenschaftliche Arbeiten. Diese Studien sind meist räumlich, zeitlich und sachlich stark fokussiert. Diese Studie wählt einen anderen Ansatz. Da das Abstrakte nicht ohne Rückgriff auf das Anschauliche zu denken ist, nimmt sie mehrere konkrete Konstellationen sowie weiterwirkende Wechselbeziehungen gleichzeitig in den Blick. ${ }^{19}$ Ziel ist es, Themen nicht ab-, sondern aufzuschliessen.

Das Gestische an der Art von Geschichtsschreibung, die ich dabei vorschlage, beruht auf einer Strategie des reduktionistischen Schreibens, auf einem Prinzip der Verdichtung und Unterbrechung. Ohne Unterbrechung kann es eine gestische Geschichte nicht geben. Dabei wird eine bestimmte Zusammenstellung von Konstellationen anvisiert; diese ist kontingent, aber nicht beliebig. Dabei zu schaffende Bilder sind gezwungenermassen sprunghaft und auf das Wesentliche reduziert. Sie sollen zeigen, wie der Liberalismus an der Grenze an seine Grenzen kommt. ${ }^{20}$

selbst - ihre Evidenz, Kontingenz und manchmal auch Transparenz -, auf die ich meinen Blick richte. Falk, 2008c.

19 Ich beschäftige mich dabei mit verschiedenen Arten von Grenzen, die aber immer auch eine territoriale Dimension aufweisen. Die Literatur zum Themenfeld „Gren$z^{\text {" }}$ ist heute kaum zu überblicken; in dieser Studie werde ich deshalb nur jene Arbeiten zitieren, auf die sich meine Argumentation explizit stützt.

20 Dazu auch Cole, 2000. 


\section{BEGRIFFSBESTIMMUNGEN}

\section{Evidenz}

Die rhetorische Lehre von der evidentia, welche Evidenz als rhetorische Operation begreift, als eine „einleuchtende Anschaulichkeit“, welche über das Medium der Sprache hergestellt wird, erfährt im Laufe der Zeit einen beträchtlichen Bedeutungswandel, und so weist heute der Begriff der Evidenz je nach Sprache und Kontext sehr verschiedene Dimensionen auf. ${ }^{1}$ Evidenz wird im Deutschen gerne als Augenscheinlichkeit, Einsichtigkeit oder Offenkundigkeit wiedergegeben. Es soll dasjenige bezeichnen, was ein-leuchtet, weil es sozusagen aus sich herausstrahlt. Cicero bildete das Wort evidentia als Ableitung von evideri, hervorscheinen; Evidenz ist also genauso eine Angelegenheit des Scheins wie des Seins. Cicero übersetzte damit das griechische enargeia beziehungsweise energeia. ${ }^{2}$ In beiden Fällen ist Evidenz ein Effekt von Rhetorik, hergestellt mittels „Verlebendigung der Rede“ (energeia: Lebhaftigkeit) beziehungsweise „ausmalender Detaillierung des Geschilderten" (enargeia: Genauigkeit). Im Moment der Evidenzerfahrung wird ein Sachverhalt plastisch vor Augen geführt. Glückt der Prozess der Evidenzherstellung, stellt sich ein Gefühl des Überzeugtseins und der Gewissheit ein. In der Folge erscheint das Evidente als das Notwendige. Evidenz ist im Gegensatz zur Plausibilität nicht graduierbar oder in Abstufungen darstellbar. Sie wird nach diesem Verständnis stets produziert, doch jeweils ausgehend von spezifisch vorhandenen medialen und materiellen Möglichkeiten, wobei der Herstellungsprozess oft im evidenten Endprodukt verschwindet. Die konkreten Verfahren der Evidenzherstellung sind als historisch kontingent zu verstehen, zudem bleibt im Evidenten seine mediale Erzeugung untilgbar

1 Das englische „evidence“ lässt sich ins Deutsche beispielsweise durch Beleg, Beweis, Hinweis, Nachweis, Zeugnis, Anzeichen, Zeugenaussage oder auch Evidenz übersetzen. Der deutsche Begriff „Evidenz“ ist jedoch im Gegensatz zum englischen „evidence“ gerade nicht ein Synonym für Beweis, sondern unterhält ein komplexeres Verhältnis zu den semantischen Feldern von Wissen, Gewissheit und Vergewisserung. Siebenpfeiffer, 2009.

2 Interessant ist in diesem Zusammenhang auch der Umstand, dass Cicero perspicuitas (Deutlichkeit, Durchsichtigkeit) und evidentia als Synonyme verwendet. 
eingeschrieben. ${ }^{3}$ Weiter können sich zwischen sprachlichen und bildlichen Evidenzverfahren auch Diskrepanzen ergeben. ${ }^{4}$

\section{Kontingenz}

Wie jene der Evidenz, ist auch die Geschichte des Begriffs „Kontingenz" vielfach verschlungen und nicht leicht zu entwirren. ${ }^{5}$ Da es hier vor allem darum gehen soll, die Begriffe Evidenz, Kontingenz und Transparenz in ein bestimmtes Verhältnis zueinander zu bringen, sind die Ausführungen notwendigerweise stark selektiv und simplifizierend. ${ }^{6}$ Aristoteles bezeichnete mit endechómena eine der vier Modalitätsformen: Neben dem Möglichen, Unmöglichen und Notwendigen meinte dieser Begriff das Kontingente. ${ }^{7}$ Johannes von Salisbury ermöglichte es, Kontingenz als das, was nicht unmöglich, nicht notwendig und nicht nur möglich, sondern faktisch ist, zu präzisieren. ${ }^{8}$ Der Begriff der Kontingenz wird ebenfalls von Cicero in die lateinische Sprache eingeführt (contingere: zusammenfallen, sich berühren, ereignen). Bildlichkeit ${ }^{9}$ kann Evidenz und Potenz produzieren, ${ }^{10}$ andererseits aber durch die Risiken der Repräsentation auch Kontingenz wahrnehmbar machen.

3 Jäger, 2009.

4 Büttner / Wimböck und Friedrich, 2007.

5 Siehe der Eintrag zu „Kontingenz“ in Ritter und Gründer, 1971.

6 Rorty, der Ironie als Ausdruck von Kontingenzbewusstsein versteht, fehlt in diesen Ausführungen. Nicht erwähnt werden weiter Luhmanns Arbeiten; bei Luhmann reduzieren soziale Systeme Kontingenz. Ebenso fehlt Darwin und sein Einfluss auf Konzeptionen der Kontingenz - um hier nur einige der nicht auftauchenden Namen zu nennen.

7 Aristoteles, 1992, S. 25 (Buch 1, Kapitel 13).

8 Agamben, 2003, S. 127. Dazu auch Huber und Stoellger, 2008, S. 12.

9 Unter den Begriff der Bildlichkeit lassen sich die verschiedenen Ausprägungsformen von Bildern subsumieren. Bildlichkeit vermag u. a. architektonische Formationen zu umfassen. Die Chinesische Mauer beispielsweise - die sich scheinbar in die Unendlichkeit hineinschlängelt - lässt sich nicht synoptisch überblicken. Sie zeigt sich folglich gerade nicht als ein Bild, wenn ein Bild als etwas klar Begrenztes begriffen wird: „Bilder sind begrenzte und überschaubare Flächen, auf denen sich ein Sinn zeigt." Boehm, 2001, S. 257. Auch lässt sich die Chinesische Mauer dann nicht als ein Bild begreifen, wenn ein Bild als Sichtbarmachung eines nicht Anwesenden verstanden wird. Wiesing, 1997, S. 160. Eine Bildlichkeit der „Grosse Mauer“ lässt sich indes nicht negieren. Von „blosser Sichtbarkeit“ unterscheidet sich Bildlichkeit wiederum durch die - je nach Sichtweise inhärente oder durch die Rezipienten produzierte - Sinngenerierung.

10 Marin, 2005. 


\section{Transparenz}

Dieser lateinische Begriff für das griechische diaphaneitas wird gebildet aus trans (durch) und parere (sich zeigen, scheinen); er wird im 12. Jahrhundert geprägt. Transparenz ist eine optische Eigenschaft des physischen Materials, aber die Bedeutung dieses Begriffs ist nicht darauf beschränkt. In der scholastischen Tradition wird Transparenz mit Geistigkeit und Göttlichkeit gleichgesetzt. Im Kontext der französischen Revolution mutiert Transparenz zu einem politischen Postulat, das an die Lichtmetaphorik der Aufklärung anschliesst. ${ }^{11}$

Transparenz gehört im 19. und 20. Jahrhundert ,zur ,Selbstsymbolisierung' von Wirtschafts- und Verwaltungsorganisationen, die ihr gläsernes Erscheinungsbild ebenso als Zeichen von Sachlichkeit wie von demokratischer Offenheit gedeutet wissen." ${ }^{12}$ In der Nachkriegszeit wird Glas endgültig zum Kennzeichen für Demokratie und Liberalismus. Allerdings steht „Glas“ auch für eine Form der Transparenz, die eine Durchsichtigkeit, aber nicht notwendigerweise eine Durchlässigkeit produziert, erinnert sei an den Ausdruck der "Gläsernen Decke“. Der Begriff der Transparenz ist deshalb äusserst ambivalent. Heutzutage meint die Rede vom gläsernen Menschen meist die „negativ konnotierte Kehrseite jener Durchschaubarkeit“ ${ }^{13}$ Einst jedoch war der „Gläserne Mensch " positiv besetzt als ein Hoffungsträger der Wissenschaft. ${ }^{14}$ In bildtheoretischen Diskursen wird unter Transparenz die mediale Selbstverleugnung des Bildes verstanden. ${ }^{15}$ Opazität bezeichnet im physikalischen Sinne den Grad der Lichtdurchlässigkeit, in bildtheoretischen Diskussionen ist damit die Sichtbarwerdung der materialen und visuellen Eigenlogiken des Bildlichen gemeint: Das Bildliche wird qua Opazität als Darstellung erkennbar.

Das Verhältnis von Transparenz und Opazität lässt sich ähnlich beschreiben wie jenes der Evidenz zur Kontingenz: Durch eine Trübung von Transparenz wird Opazität - und damit gegebenenfalls Reflexivität und Kontingenzbewusstsein - produziert. ${ }^{16}$ Im Begriff der Transparenz lässt sich demnach die Beziehung zwischen Evidenz und Kontingenz

11 Hunt, 1989, S.288. - Baecque, 1993.

12 Roesler, 2007. Dazu auch Münkler, 2009.

13 Ebenda.

14 Jeggle, 1990.

15 Wiesing, 2000.

16 Gleichzeitig werden bei diesem Prozess oft aber auch neue Evidenzen etabliert. Vattimo, 1992. 
auf folgende Weise fassen: Verliert Evidenz ihre angebliche Transparenz, wird Kontingenz sichtbar. ${ }^{17}$ Andererseits kann Transparenz im Sinne einer „perfekten Durchsichtigkeit“ auch zu Unsichtbarkeit führen.

17 Jäger, 2004, S. 62-63. 


\section{ZUR KONSTITUTIVEN FUNKTION \\ DER LEERE IN LOCKES LIBERALISMUS}

„Au coeur de l'évidence, il y a le vide. “1

„Wenn sie [diese Leute] im eigenen Land keine Arbeit haben, sind wir in der Schweiz nicht schuld. "2 So lautet die Aussage eines Passanten in der TV-Sendung „Blickpunkt“ vom 5. Juni 1981. Umgekehrt stellt sich die Frage: Was können Schweizerinnen und Schweizer dafür, dass es für sie Arbeitsmöglichkeiten in „ihrem“ Land gibt? Die Aussage des Passanten verweist auf die in Anspruch genommene Selbstverständlichkeit, Arbeitswilligen den Zutritt zum eigenen Staat in legitimer Weise verwehren zu dürfen. Das nationale Territorium wird dabei in den Kategorien des naturalisierten und legitimierten Privateigentums gedacht: Wie Hausbesitzer den Eintritt in ihr Haus festlegen, so entscheiden folglich allein die Bürgerinnen und Bürger über das Aufenthaltsrecht in ihrem Nationalstaat, wobei dieses Recht - wie heute jenes auf Eigentum - als vererbbar und in gewisser Weise als vorpolitisch begriffen wird. ${ }^{3}$

Wie auch immer eine solche Haltung bewertet wird, so scheint unbestritten: Eine solche Denkweise hat viel mit Vorstellungen von Eigentum zu tun. Die Frage, wie philosophisch begründete Konzeptionen (die wiederum oft auf bestimmten Bildern beruhen) in den Alltag sickern und was für Wirkungen sie dabei entfalten, kann an dieser Stelle nur aufgeworfen werden. Vermag John Lockes Naturalisierung von Eigentum gegenwärtig auch in migrationspolitischen Debatten als stille Referenz Evidenz zu generieren?

Im physikalischen Experiment des 17. Jahrhunderts wurde u.a. von Otto von Guericke oder Robert Boyle der künstlich entleerte und des-

1 Jabès, 1978, S. 55.

2 Siehe der Beitrag „Hintergründe zur massiven Ablehnung der Mitenand-Initiative zur Aufhebung des Saisonnier-Statuts“ auf der DVD „Niemand war schon immer da“, 41:40-41.55, produziert von memoriav für das Projekt „Erlebte Schweiz“.

3 Cole, 2000, S. 154. Siehe auch Miller, 2010, S. 114-115. Und die Replik darauf: Abizadeh, 2010. Zum Aspekt der Vererbbarkeit siehe Shachar, 2009. 
halb stets begrenzte leere Raum - das Vakuum - erzeugt. ${ }^{4} \mathrm{Zu}$ dieser Zeit wurde in John Lockes Gesellschaftsvertrag die Erzeugung eines „leeren Raumes“ für die Begründung von „gewaltfrei“ verfassten Gemeinschaften konstitutiv. ${ }^{5}$

Die Ausweichmöglichkeit für jene Individuen, welche dem Gesellschaftsvertrag nicht zustimmen, ermöglicht nach Locke eine gewaltfreie Gründung der Gesellschaft. Erst unter diesen Bedingungen kann politische Gewalt als selbst geschaffenes Verhältnis begriffen werden, dem jedes Individuum sich freiwillig unterworfen hat. ${ }^{6}$ Das einzelne Individuum darf nach Locke nicht zum Staatseintritt gezwungen werden, denn gerade die Freiwilligkeit der Zustimmung stiftet die Legitimation des Staates. Das Denken eines leeren Raumes ist deshalb bei Locke in engem Zusammenhang mit der postulierten Dichotomie von Gewalt und Gesellschaftsvertrag zu sehen. Die daraus resultierende Exit-Option ${ }^{7}$ ermöglicht die freiwillige Zustimmung zum Gesellschaftsvertrag und somit eine gewaltlose Konstituierung der Gesellschaft. Die Menschen schliessen sich nun vor allem deshalb zum Staat zusammen, so Locke, um durch die Etablierung eines Gewaltmonopols und die Einführung von Gesetzen ihr Eigentum besser zu schützen: „Das grosse und hauptsächliche Ziel, weshalb Menschen sich zu einem Staatswesen zusammenschliessen und sich unter eine Regierung stellen, ist also die Erhaltung ihres Eigentums. "8 Locke geht dabei von einem weiten Eigentumsbegriff aus. Er fasst den Schutz des Lebens, der Freiheit und des Vermögens darunter. ${ }^{9}$ Nach Locke existiert Eigentum indes schon im Naturzustand. Wie den Geldgebrauch, so versteht Locke auch das Eigentum als vorpolitisch. ${ }^{10}$ Locke differenziert zudem zwischen Natur- und Kriegszustand; für ihn zeichnet sich der Naturzustand vor allem durch ein Fehlen von richterlicher Gewalt aus. ${ }^{11}$

4 Zur Geschichte des Vakuums siehe auch Genz, 1994.

5 Locke hat sich u. a. in seinem Essay „Concerning Human Understanding“ zu seinem Verständnis von Raum geäussert; seine diesbezüglichen Überlegungen mit dem „Second Treatise“ systematisch zu vergleichen, wäre sicherlich ein interessantes Unterfangen, das an dieser Stelle allerdings nicht geleistet werden kann. Festgehalten sei nur, dass nach Locke das Konzept der Unendlichkeit nicht seine empirische Denkweise „bedroht“. Dazu kurz Rogers, 1998, S. 73.

6 Locke, 1977, S. 209, 260.

7 Hirschman, 1970.

8 Locke, 1977, S. 278, 286.

9 Locke, 1977.

10 Hobbes hingegen begreift Eigentumsrechte als ein Produkt des Staates. Hobbes, 1966, S. 191.

11 Locke, 1977, S. 255. 
Locke schildert - im Gegensatz zu Hobbes - den Naturzustand als einen der Fülle: „Auch gereichte diese Aneignung irgendeines Stückes Land, indem man es bebaute, niemandem zum Schaden, da noch genügend und gleich gutes Land übrigblieb, und zwar mehr, als die noch Unversorgten nutzen konnten. So stellt in Wirklichkeit die Abgrenzung für den eigenen Bedarf keine Benachteiligung für die anderen dar. "12 Gerade weil der Boden nicht knapp war, ist nach Locke diese „erste Landnahme“ legitimiert. Die Möglichkeit der Auswanderung muss nach Locke stets bestehen bleiben, bildet sie doch die Voraussetzung dafür, dass die Ansiedlung auf einem Staatsterritorium als implizite Zustimmung zum Staat gewertet werden kann. ${ }^{13}$ Der Gesellschaftsvertrag überträgt sich nämlich nicht automatisch auf die Nachkommen der Vertragsgeneration: Er wird von Locke als immer wieder abzuschliessend gedacht. ${ }^{14}$ Deshalb ist es für Locke wichtig zu betonen, dass sich „immer noch grosse Bodenflächen finden, die brach liegen (weil sich die Bewohner nicht der Übereinkunft der übrigen Menschheit über den Gebrauch ihres gemeinsamen Geldes angeschlossen haben) ". ${ }^{15}$ Der Zusammenschluss Einzelner zum Gesellschaftsvertrag beeinträchtigt nach Locke die Freiheit der Übrigen nicht; diese verbleiben "wie vorher in der Freiheit des Naturzustands“. ${ }^{16}$

12 Locke, 1977, S. 220.

13 Eine Kritik zum stillschweigenden Vertrag findet sich bei Adam Smith: „It may indeed be said that by remaining in the country you tacitly consent to the contract and are bound by it. But how can you avoid staying in it? You were not consulted whether you should be born in it or not. And how can you get out of it? Most people know no other language nor country, are poor, and obliged to stay not far from the place where they were born to labour for subsistance. They cannot therefore be said to give any consent to a contract, tho' they may have the strongest sense of obedience. To say that by staying in a country a man agrees to a contract of obedience to government, is just the same with carrying a man into a ship and after he is at a distance from land to tell him that by being in the shop (ship, copyist' error) he has contracted to obey the master." Smith, 1978, Bd. VIII, S. 403.

14 Locke, 1977, S. 274.

15 Locke, 1977, S. 228.

16 Locke, 1977, S. 260. 


\section{Geldökonomie und die Verknappung des leeren Raumes}

Locke selbst räumt zwar ein, dass sich das Menschengeschlecht bis heute in alle Winkel der Welt verbreitet hat ${ }^{17}$ und dass in manchen Gegenden „durch die Zunahme der Bevölkerung, des Viehbestandes und durch den Gebrauch des Geldes das Land knapp" 18 wurde. Die Einführung des Geldes ist nach Locke durch eine stillschweigende und freiwillige Zustimmung legitimiert. Diese Zustimmung zur Geldwirtschaft erfolgt „ausserhalb der Grenzen der Gemeinschaft und ohne Vertrag “. ${ }^{19}$ Der Gesellschaftsvertrag basiert nach Locke bereits auf einem bestimmten Wirtschaftssystem (der Begriff des Wirtschaftsvertrags trifft hier die Sache gerade nicht), der Gebrauch des Geldes geht der politischen Konstituierung voraus. Während der Gesellschaftsvertrag demnach als politische Angelegenheit verstanden wird, wird der Geldgebrauch als natürlich beschrieben. ${ }^{20}$ Wo aber der Geldverkehr eingeführt wurde, wird nach Locke herrenloses Land knapp. Das Vorhandensein von leerem Land ist folglich bei Locke nicht voraussetzungslos; die Vorstellung eines leeren Raumes steht vielmehr in einem Spannungsverhältnis zur geldwirtschaftlichen Doktrin der Knappheit aller Güter. Für Locke ist die Knappheit des Bodens eine Folge der Geldwirtschaft, welche die natürliche Bedürfnisrestriktion sprengt. Die Geldwirtschaft wiederum wurde nach Locke eingeführt, um ein effizienteres Anhäufen von Besitz zu ermöglichen, ohne dass Waren dabei verderben; diese Position findet sich übrigens schon bei Hobbes. ${ }^{21}$ Dass Geld beispielsweise in Form von Muscheln, Fellen oder Tabak schon vor Ankunft der Europäer in Amerika in Gebrauch war (und übrigens von den Neuankömmlingen im Handel mit den Indianern, aber auch untereinander übernommen wurde), erwähnt Locke zwar, er verdrängt diesen Befund aber sogleich. ${ }^{22}$ Anfangs, schreibt Locke, war die ganze Welt „ein Amerika, denn so etwas wie Geld war

17 Locke, 1977, S. 222.

18 Locke, 1977, S. 228. Siehe dazu auch Macpherson, 1973.

19 Locke, 1977, S. 231.

20 Aristoteles hatte in der Nikomachischen Ethik die Entstehung des Geldes als Ergebnis menschlicher Übereinkunft beschrieben. Es trage den Namen „nomisma“, weil es sein Dasein nicht der Natur verdankt, sondern weil man es geltend "gesetzt“ habe. Aristoteles, 2001, S. 209, 1133b. Im Gegensatz zu Locke handelt es sich dabei folglich um eine explizite, nicht implizite Zustimmung.

21 Hobbes, 1966, S. 194.

22 Locke, 1977, S. 318. 
überall unbekannt. " ${ }^{23}$ Nach Lockes Logik ist die weltweite Einführung einer Geldwirtschaft rational, wird doch durch die intensivere Kultivierung des Bodens das Gesamtwohl der Gesellschaft befördert. Durch die Einführung einer Geldwirtschaft wird die Verschwendung und Verrottung von Gütern vermieden: Nichts sei von Gott geschaffen worden, meint Locke, „damit die Menschen es verderben lassen oder vernichten. " ${ }^{24} \mathrm{Da}$ Geld aber nicht verdirbt, kann seine Anhäufung und Aufbewahrung niemanden schädigen; das Geld ist nach Locke somit jenes Gut, das durch die Möglichkeit einer endlosen Akkumulation keinerlei Grenzen kennt. ${ }^{25}$ Vor allem aber bewirkt die Einführung des Geldes nach Locke eine Dynamisierung des Handels, denn durch den Gebrauch des Geldes würde bei allen Menschen ein Antrieb zur Mehrarbeit geschaffen: „Wenn man sich etwas ausdenkt, was bei seinen Nachbarn dem Gebrauch und dem Wert des Geldes entspricht, so wird man sehen, wie derselbe Mensch unverzüglich beginnt, seinen Besitz zu vergrössern. " ${ }^{26}$ Gerade aber diese durch die Geldwirtschaft ausgelöste Tendenz zu einem expansiven globalen Wirtschaftssystem gefährdet Lockes Prämisse des faktisch vorhandenen und normativ notwendigen leeren Raumes. ${ }^{27}$ Hier zeigt sich ein Widerspruch; es ist nicht nur ein Auseinanderklaffen zwischen Geltungs- und Verwirklichungsbedingungen zu beobachten, sondern dieser Gegensatz besteht bereits in Lockes liberalem Denken selbst, und zwar gewissermassen zwischen seinem politischen und ökonomischen Projekt. ${ }^{28}$ Während er im politischen Bereich weiter eine Pluralität verschiedener Systeme voraussetzt (um eine Wegzugs- und damit Wahlmöglichkeit zu garantieren), sieht er im Ökonomischen die Existenz nur eines einzigen rationalen Systems vor. Hier gibt es demnach keine Wahlmöglichkeit, alle sind zur Partizipation gezwungen.

Locke beschreibt den Geldgebrauch als natürlich, den Wert des Geldes jedoch gleichzeitig auch als imaginär. Geld oder ähnliche Reichtümer gehören nach Locke nämlich nicht zu den natürlichen Gütern wie beispielsweise Nahrungsmittel, sondern sie haben nur einen phantastischen, imaginären Wert: „Die Natur hat ihnen diesen Wert nicht verliehen, und ihrem Gehalt nach sind sie nicht mehr wert als die Wamponmuscheln der amerikanischen Bewohner für einen europäischen

23 Locke, 1977, S. 230.

24 Locke, 1977, S. 219.

25 Priddat, 1988, S. 25. Kesselring, 2009.

26 Locke, 1977, S. 230.

27 Armitage, 2004, S. 606.

$28 \mathrm{Zu}$ dieser Art von Widerspruch siehe auch Parekh, 1995. 
Fürsten, oder als es früher das Silbergeld Europas für einen Bewohner Amerikas war. " ${ }^{29}$ Locke macht hier keinen Unterschied zwischen dem Silbergeld Europas und den Wamponmuscheln der Amerikaner; beide gewinnen ihren Wert rein durch menschliche Übereinkunft. ${ }^{30}$ Dies steht in einem Spannungsverhältnis zum Umstand, dass Lockes Argumentation auf einem postulierten fundamentalen Unterschied zwischen dem indianischen und europäischen Geldverkehr basiert. Eine ähnliche Konstellation findet sich bei John Locke in Bezug auf die indianische Landwirtschaft. Aufgrund seiner umfangreichen Literatur über Amerika und den zahlreichen Reiseberichten in seinem Besitz ist es sehr wahrscheinlich, dass er von der Landwirtschaft der nordamerikanischen Indianer erfahren hatte, besass er doch beispielsweise auch die Bände von de Bry. ${ }^{31}$

Diese Verneinung einer indianischen Landwirtschaft ist für Locke deshalb notwendig, weil er dadurch den Indianern Eigentumsrechte am Territorium absprechen kann. Es ist nämlich nicht so, dass Locke den Indianern grundsätzlich Eigentumsrechte abspricht; Eigentum an erlegtem Wild beispielsweise billigt er ihnen zu. Das Gesetz der Vernunft gibt, schreibt Locke, das Wild demjenigen Indianer zum Eigentum, der es getötet hat. ${ }^{32}$ Jeder Mensch habe - und zwar ohne Vertrag - Eigentum am eigenen Körper. Wenn der Mensch nun einen Teil seiner selbst durch Arbeit in bestimmte Gegenstände lege, vollziehe sich sozusagen eine Erweiterung des Selbstbesitzes des Menschen über seinen Körper hinaus auf Naturdinge. ${ }^{33}$ „Die Arbeit seines Körpers und das Werk seiner Hände sind, so können wir sagen, im eigentlichen Sinne sein Eigentum. "34 Durch diese Argumentationsfigur wird Privateigentum so „natürlich“ wie die Körperlichkeit des Menschen selbst, wohingegen gemäss der römisch-biblisch inspirierten „Okkupationstheorie" Privateigentum das kontingente Resultat menschlicher Vereinbarungen war: Aus einem Dialog zwischen den Menschen wurde

29 Locke, 1977, S. 318, 230.

30 Nach Herman Lebovics habe Locke den Gebrauch des Geldes bei den Indianern vor allem als einen zeremoniellen verstanden. Bei dieser Aussage beachtet Lebovics meines Erachtens jedoch zu wenig, dass Locke auch dem europäischen Geld einen imaginären Wert zuwies. Lebovics, 1986, S. 578. Siehe auch Lebovics, 2006.

31 Harrison und Laslett, 1965, S. 96. Dazu auch Banner, 2005, S. 47. Siehe aus einer literaturwissenschaftlichen Perspektive auch Kiening, 2006, S. 37.

32 Locke, 1977, S. 218.

33 Brandt, 1974, S. 22.

34 Locke, 1977, S. 216. 
mit Locke, wie Manfred Brocker treffend schreibt, ein Monolog des Menschen mit der Natur. ${ }^{35}$

\section{Grundstücksgrenzen als Folgen der Geldwirtschaft}

Nach Locke ist es also die Arbeit, die Eigentumsrechte verleiht. ${ }^{36}$ Locke wendet sich in seiner politischen Theorie bekanntlich gegen Robert Filmer. Filmers Hauptwerk „Patriarcha“, das die Monarchie als natürliche Gesellschaftsform legitimierte, ${ }^{37}$ wurde posthum 1680 veröffentlicht. ${ }^{38}$ Locke kritisiert in seiner Schrift Filmers Vorstellung, dass Adam von Gott als oberster Regent eingesetzt und dieses Amt an gegenwärtig herrschende Könige weitervererbt hat. ${ }^{39}$ Eigentum soll nach Locke grundsätzlich nicht durch Gottesgnadentum, sondern durch eigene Arbeit legitimiert werden. ${ }^{40}$ Aber auch dabei verstrickt sich Locke in Widersprüche, da die eigene Arbeit das Recht auf Eigentum begründen soll, gleichzeitig jedoch auch die Arbeit des Knechts nach Locke Eigentum legitimiert: „Das Gras, das mein Pferd gefressen, der Torf, den mein Knecht gestochen, und das Erz, das ich an irgendeiner Stelle gegraben habe, wo ich mit anderen gemeinsam ein Recht dazu habe, werden ohne die Anweisung und Zustimmung von jemandem mein Eigentum. " 41 Als das Land durch eine Zunahme der Bevölkerung, des Viehbestandes, vor allem aber durch den Geldgebrauch knapp wurde, setzten die einzelnen Gemeinschaften „deshalb die Grenzen ihrer verschiedenen Gebiete fest, regelten durch eigene Gesetze das private Eigentum innerhalb ihrer Gesellschaft, und entschieden so durch Vertrag und Übereinkunft die Frage des Eigentums, das seinen Ursprung in der Arbeit und im Fleiss hatte. " 42 In diesem Stadium einigen sich nun die einzelnen Staaten und Königreiche - das gilt allerdings nur für Europa - ausdrücklich oder stillschweigend auf die gegenseitige Anerkennung ihres Besitzes. „Auf diesem Wege setzen sie durch positive Abkommen untereinander ein Eigentum an den verschiedenen Teilen und Stücken der Erde fest. Und dennoch lassen sich immer noch grosse Bodenflä-

35 Brocker, 1992, S. 186, 287.

36 Locke, 1977, S. 228.

37 Schmale, 2000, S. 144.

38 Filmer, 1991.

39 Schochet, 1969.

40 Brocker, 1992, S. 152.

41 Locke, 1977, S. 217.

42 Locke, 1977. 
chen finden, die brach liegen (weil sich die Bewohner nicht der Übereinkunft der übrigen Menschheit über den Gebrauch ihres gemeinsamen Geldes angeschlossen haben). Diese Flächen sind grösser, als die darauf wohnenden Menschen wirklich gebrauchen oder nutzen können, und

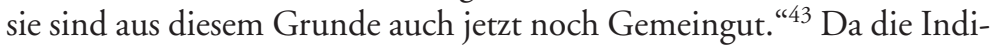
aner ihr Land verschwenden und vernachlässigen, es „nicht durch Arbeit veredeln ${ }^{\text {“44 }}$, haben sie nach Locke keine Eigentumsrechte daran. ${ }^{45}$

Damit Locke diese Schlussfolgerung ziehen kann, muss er wie gesagt die Existenz der indianischen Landwirtschaft negieren: „Locke's account of the Indians is completely at odds with virtually all other accounts of the period, many of which included detailed observations of Indian agricultural techniques and property ownership. What makes Locke's error all the more remarkable is that Locke must have known he was providing inaccurate information about the Indians. " ${ }^{46}$ Locke, der bekanntlich in den Sklavenhandel investierte ${ }^{47}$, vertrat gegenüber den Indianern, wie William Uzgalis bemerkt, eine kulturelle, nicht eine biologisch fundierte Haltung der Überlegenheit, wobei eine solche Unterscheidung insbesondere für das 17. Jahrhundert problematisch ist. ${ }^{48}$ „Locke is saying that all people are essentially the same biologically, and that the significant differences between Englishmen and those in other lands is purely cultural. " 49 In eine ähnliche Richtung

43 Locke, 1977. Ein ähnliches Argumentationsmuster findet sich bereits bei Grotius. Dazu auch Aravamudan, 2009, S. 59.

44 Locke, 1977.

45 William Uzgalis betont, dass es nach Locke die Bearbeitung des Bodens und nicht die Einzäunung sei, welche eine Erschliessung des Bodens charakterisiere und damit Eigentumsrechte generiere. Uzgalis, 2002, S.91. Siehe dazu auch die völkerrechtliche Figur der terra nullius beziehungsweise des Vacuum domicilium, die sich auf das Römische Recht bezog. Sie bedeutete nicht, dass ein Land als vollkommen unbewohnt gesehen wurde, sondern dass seinen Bewohnern, u. a. aufgrund eines Mangels an sichtbaren Grenzziehungen die Staatsfähigkeit - und damit auch Eigentumsrechte - abgesprochen werden konnten. Hier zeigt sich ein Widerspruch zu jenem Argument, welches die Figur der terra nullius in Anlehnung an jene der res nullius legitimieren sollte, wonach bei der Aneignung einer besitzlosen Sache niemand einen Schaden erleiden dürfe. Siehe dazu Fisch, 1984. - Vismann, 1995. Kant verwarf Lockes res nullius These. Dazu Benhabib, 2004, S. 31.

46 Banner, 2005, S. 46-47. Zu den territorialen Rechten der Native Americans siehe auch Tully, 1993, S. 137-176.

47 Arneil, 1996. - Lebovics, 1986, S. 567. Banner, 2005, S. 46. - Ivison, 2003, S. 101. - Farr, 2008. Mills, 1997, S. 68.

48 Mokre, 2000.

49 Uzgalis, 2002, S. 87. Zu dieser Frage siehe auch Bernasconi und Maaza Mann, 2005. Zu Hobbes siehe diesbezüglich Hall, 2005. Ähnlich argumentiert auch Talbot, 2010 . 
argumentiert auch Kathy Sqadrito. Wichtiger als Lockes „Second Treatise" sei bezüglich des Umgangs mit den amerikanischen Indianern Lockes Konzeption der "leeren Leinwand“ beziehungsweise der auf Aristoteles zurückgehenden „tabula rasa“ gewesen: „Since man does not have a real essence, he can be transformed by changing the environment", meint Sqadrito. ${ }^{50}$ Allerdings wird dabei unterschlagen, dass nach Lockes Logik eine kulturelle Angleichung der Indianer zu einer Landknappheit führen muss. Dies wiederum gefährdet nicht nur, sondern verunmöglicht schliesslich Lockes Prämisse des leeren Landes, der Möglichkeit der Auswanderung und damit letztlich der gewaltfreien Gründung der Gesellschaft. Die „tabula rasa“ wird von Locke sozusagen auch räumlich gedacht. Bereits Thomas Morus hatte zwar 1516 in seiner „Utopia“ davon gesprochen, dass bei Überbevölkerung da, wo die Eingeborenen grossen Überfluss an unbebautem Ackerland hätten, Kolonien gegründet werden sollten. Auch Hugo Grotius vertrat die Ansicht, dass Land, welches nicht bearbeitet werde, nicht besessen werde. ${ }^{51}$ Leeres Land fungierte bei beiden aber nicht in gleicher Weise wie bei Locke als konstitutive Prämisse für ihre Argumentation.

\section{Exit-Option}

Wer nach Locke seine Zustimmung zum Gesellschaftsvertrag explizit gegeben hat, ist „auf ewig und unwiderruflich verpflichtet, sein Untertan zu sein und unabänderlich zu bleiben. Er kann niemals wieder in die Freiheit des Naturzustands zurückkehren, es sei denn, die Regierung, der er untertan war, würde sich durch irgendein Unglück auflösen, oder er würde durch einen öffentlichen Beschluss davon ausgeschlossen, länger ihr Mitglied zu sein." 52 Für diese Voll-Bürger der Gesellschaft besteht ausser in den genannten Ausnahmefällen also explizit kein Austrittsrecht, allerdings muss auch da vorher die Austrittsmöglichkeit vorhanden gewesen sein, damit die Zustimmung freiwillig erfolgte. Wer nun aber durch „Erbschaft, Kauf, Erlaubnis oder sonstwie in den Genuss irgendeines Stückes Land kommt", muss sich nach Locke „wie jeder andere Untertan der Regierung dieses Staates unterwerfen, unter dessen Rechtsprechung dieses Stück Land steht. ${ }^{\text {"53 }}$ Der Bodenbesit-

50 Sqadrito, 2002, S. 116. Dazu auch Greenblatt, 1991, S. 160.

51 Brocker, 1992, S. 395. - Pateman und Mills, 2007, S. 47. Boucher, 2009, S. 118.

52 Locke, 1977, S. 277.

53 Locke, 1977, S. 276, 274. 
zer anerkennt also die Gesetze, die auf seinem Territorium gelten, und damit stillschweigend ${ }^{54}$ den Gesellschaftsvertrag. Wer aber stillschweigend seine Zustimmung zum Gesellschaftsvertrag gegeben hat und sich später entschliesst, seinen Besitz aufzugeben, verfügt nach Locke über die Möglichkeit, sich einem anderen Staatswesen einzuverleiben „oder sich mit anderen über die Begründung eines neuen zu verständigen in vacuis locis, in irgendeinem Teil der Welt, den sie frei und herrenlos finden “, 55 oder, wie es im englischen Original heisst: „in vacuis locis, in any part of the world, they can find free and unpossessed. " 56 Im Gegensatz zu Vattel reflektiert Locke nicht die Möglichkeit, dass die Bedingungen des Gesellschaftsvertrages von einer Mehrheit so geändert werden können, dass auch für jene, die ihre Zustimmung zum Staat explizit gegeben haben, ein Recht auf Austritt resultiert. ${ }^{57}$

Die Prämisse des leeren Raumes zeigt Folgen für innergesellschaftliche Grenzziehungen und für den Umgang mit Randständigen im eigenen Land. Da bedürftige Menschen grundsätzlich die Möglichkeit zur Arbeit haben, besteht nach Locke keine politische Pflicht zu ihrer Unterstützung. Zudem haben die Menschen nach Locke mit der Einführung des Geldes ungleiche Besitzverhältnisse bejaht, denn die Menschen haben dadurch einen Weg gefunden, „wie ein Mensch auf redliche Weise mehr Land besitzen darf als er selbst nutzen kann" ${ }^{58}$ Hobbes hingegen nimmt den Souverän viel direkter in die Pflicht: Weil Menschen ohne ihre Schuld arm werden, muss er dafür sorgen, dass diese keine Not leiden. In der lateinischen Fassung des „Leviathan" heisst es in der deutschen Übertragung: „Weil aber auch viele ohne ihre Schuld durch unvorhergesehene Zufälle in einen solchen Zustand geraten können, dass sie sich ihren Unterhalt auf keine Weise selbst zu verschaffen vermögen, muss der Oberherr dafür sorgen, dass diese an den notwendigsten Bedürfnissen keinen Mangel leiden. Nach dem Naturrecht ist es im dringendsten Notfall erlaubt, fremdes Eigentum heimlich oder öffentlich zu beschlagnahmen; damit die Bedürfti-

54 Eine solche Denkfigur findet sich bereits bei Sokrates beziehungsweise Platon: „wir [die Gesetze] haben trotzdem jedem Athener, der will, ausdrücklich freigestellt, er möge, sobald er in die Bürgerliste aufgenommen ist und die Verhältnisse in der Stadt und uns, die Gesetze, kennengelernt hat, mitsamt seiner Habe davonziehen, wohin es ihm beliebt, wenn er mit uns nicht zufrieden ist. Platon, 1994, S. 52.

55 Locke, 1977, S. 277.

56 Locke, 1980, S.65. Dazu auch Ludwig, 2005. Siehe auch Bauböck, 1994. Lockes Prämisse des „leeren Landes“ wird in etwas anderer Form auch von anderen Autoren thematisiert wird, siehe beispielsweise Casas Klausen, 2007.

57 Whelan, 1981, S.649.

58 Locke, 1977, S. 231. 
gen den Bürgern nicht zur Last fallen, müssen sie vom Staate ernährt, nicht aber der etwaigen Wohltätigkeit einzelner Bürger überlassen werden. " ${ }^{\text {"59 }}$ Private Wohltätigkeit ist also nach Hobbes gerade nicht die Lösung des Armutsproblems. Vielmehr ist die Erhebung von Steuern zur Linderung von Not gerechtfertigt; auch diese Massnahme befördert die Stabilität des Staates. ${ }^{60}$

\section{Fazit}

In einer Gegenüberstellung von Hobbes und Locke kann auf die vorhandenen Ähnlichkeiten oder auf die Unterschiede fokussiert werden. Peter Laslett meint dazu, Locke habe Hobbes' Gedankengut übernommen, ohne sich dessen bewusst gewesen zu sein. ${ }^{61}$ Hobbes würde demnach für Locke eine stille, keine explizite Referenz darstellen. Nur einmal zitiert Locke Hobbes' „Leviathan“ übrigens in expliziter Weise, und zwar im Zusammenhang mit einer medizinischen Abhandlung. Er referiert dabei auf Hobbes' Kritik an einer ungeprüften Übernahme von ungenauen oder unsinnigen Definitionen. ${ }^{62}$ In $\$ 98$ des „Second Treatise“ erwähnt Locke weiter den „mächtigen Leviathan“, aber hier taucht kein direkter Bezug zu Hobbes auf. Allerdings wendet sich Locke dabei ja gegen Robert Filmer, der wiederum auf Hobbes reagierte.

Einige der Gemeinsamkeiten zwischen den beiden Autoren wurden bereits erwähnt: Die Vorstellung von Geld als Aufbewahrungsinstrument oder ihre Annahme, Siedler dürften „Einheimische“ zur Sesshaftigkeit zwingen. Nach Carole Pateman schliessen diese Siedler unterei-

59 Hobbes, 1970, S. 287. In der früheren englischen Ausgabe des „Leviathan“ wird die Implikation dieser Aussage nicht gleichermassen deutlich formuliert: „Denn ist es von jedermann hartherzig, wenn er sich um den Schwachen nicht kümmert, so ist es dies auch vom Souverän eines Staates, wenn er sie der zufälligen und so unsicheren Wohltätigkeit überlässt." Hobbes, 1966, S. 264.

60 Bekannt für die Divergenzen zwischen Hobbes und Locke wurde ein weiterer Sachverhalt: Nach Locke widerspricht der absolute Staat dem von Hobbes selbst postulierten Selbsterhaltungsprinzip. Nach Locke befinden sich die Bürger einem absoluten Souverän gegenüber immer noch im Naturzustand, fehlt es doch weiterhin an einer neutralen Schiedsrichterinstanz. Der Souverän dürfe die Individualrechte nicht ausser Kraft setzen, denn diese bildeten sozusagen die raison d'être des Staates. Herrschaftslegitimation und Herrschaftslimitation fallen deshalb bei Locke zusammen. Dazu Cheneval, 2002, S. 288 sowie Kersting, 1996, S. 109. Zu einer liberalen Auslegung von Hobbes siehe auch Cattaneo, 1960.

61 Locke, 1988, S. 72.

62 Dazu Rogers, 1998, S. 73. 
nander einen Gesellschaftsvertrag, der die bereits ansässige Bevölkerung in einer Weise ausschliesst, die wiederum an den konstitutiven Ausschluss der Frauen erinnert. ${ }^{63}$

Gegenüber der Vorstellung eines immer bereits vorhandenen leeren Raumes verhält sich Hobbes skeptischer als Locke, wohingegen Locke den leeren Raum als faktisch gegeben und normativ notwendig voraussetzt. Hobbes wie Locke gehen indes beide von einem Expansionsdrang aus. Bei Hobbes wird dieser Expansionsdrang als anthropologische Konstante gesetzt, bei Locke hingegen als Folge der Geldwirtschaft entwickelt. Beides jedoch führt zu einer territorialen Knappheit. Wenn aber der Raum begrenzt ist und Gesellschaften auf eine territoriale Fundierung nicht verzichten können, verkleinern sich mit jedem realisierten Gesellschaftsvertrag die Möglichkeiten, eine neue Gesellschaft zu gründen, bis schliesslich Neugründungen gänzlich unmöglich werden. Unter dieser Voraussetzung zeigt zudem jeder Gesellschaftsvertrag Auswirkungen sowohl auf die in den Vertrag Ein- als auch auf die Ausgeschlossenen.

Damit wird jene politische Grenze, welche konstituierte Gesellschaften vom „Rest“ abspaltet, in ihrer Legitimität prekär: Die vom Vertrag Ausgeschlossenen sind vom Vertrag betroffen, werden in ihren Handlungsmöglichkeiten dadurch eingeschränkt, können sich aber dazu nicht aktiv verhalten. Sie sind Objekt, nicht Subjekt des Vertrags. Lockes Prämisse, der Gesellschaftsvertrag beeinträchtige die Freiheit der Übrigen nicht, gilt unter diesen Bedingungen nicht.

Doch auch für die im Vertrag „Eingeschlossenen“ ist keine Legitimität des Gesellschaftsvertrages gegeben, wenn die Austrittsmöglichkeit faktisch nicht gegeben ist, weil sie beispielsweise kein Land finden, in welches sie auswandern können. Auch hier zeigt sich die koloniale Logik, denn unter imperialen Verhältnissen ist diese Exit-Option immer gegeben. Während Locke im politischen Bereich für jede neue Generation sozusagen die Situation einer tabula rasa, eines Neuanfanges postuliert (wer sich dem Gesellschaftsvertrag nicht anschliessen will, muss die Möglichkeit haben, auszuwandern), fordert er für ökonomische Belange keine solche Möglichkeit. Wenn weiter nicht nur die eigene Arbeit, sondern auch diejenige der Vorfahren das nationale Eigentum begründet, dann finden wir hier ein ähnliches Spannungsverhältnis wie bei Lockes Passage zum torfstechenden Knecht. ${ }^{64}$ Eigentumsrechte

63 Pateman und Mills, 2007.

64 Die eigene Arbeit soll das Recht auf Eigentum begründen, gleichzeitig kann jedoch auch die Arbeit des Knechts nach Locke Eigentum legitimieren. 
sind historisch variabel und das Resultat von gesellschaftlichen Entscheidungen: Da rechtliche Verhältnisse immer sozialer Natur sind, können sie nicht durch eigenmächtige Akte einseitig konstituiert werden. ${ }^{65}$

Die Grundfrage der traditionellen politischen Philosophie lautet, wie der Staat gegenüber seinen Bürgern legitimiert werden kann. Der Staat ist in einer solchen Denktradition nur gegenüber seinen Mitgliedern begründungsverpflichtet. Doch gerade dies wird durch eine solche Lektüre von der Peripherie her in Frage gestellt. Nach Giorgio Agamben stellt sich die Frage, ob die politische Philosophie, ausgehend von der Figur des Flüchtlings, ${ }^{66}$ neu zu begründen sei. ${ }^{67}$

Francis Cheneval formuliert dies, allerdings mit einem etwas anders akzentuierten Bezug, folgendermassen: „Die politische Philosophie der Moderne ist ausgezogen, um den faktisch im Entstehen begriffenen, neuzeitlichen, souveränen, nationalen Territorialstaat zu legitimieren. Sie nahm zur Legitimation von Staat und Bürgertum aber spätestens seit Thomas Hobbes Prämissen in ihr Rüstzeug auf, die in letzter Konsequenz eben diesen Nationalstaat supranational und kosmopolitisch relativieren." ${ }^{68}$ Es gilt in diesem Sinne nicht nur, die kolonialen Auswirkungen des Gesellschaftsvertrags auf „Einheimische“ zu reflektieren, wie es in den letzten Jahren eingefordert wird. Die Implikationen dieser wirkmächtigen Fiktionen sind auch in Bezug auf sedimentierte Vorstellungen und Denkbilder in Fragen der Migration zu durchdenken. Wer dabei Anachronismen wittert, sei entgegnet, dass manchmal ein bewusst „anachronistischer“ Blick nötig ist, da die Zeit des Schreibens und die Zeit des Wirkens bekanntlich ihren eigenen Logiken folgen.

65 Brocker, 1992, S. 573.

66 Der Begriff des „Flüchtlings“ wird in dieser Arbeit breiter verwendet als nach der Definition der Genfer Flüchtlingskonvention.

67 Agamben, 2001a. Siehe auch Agamben, 1995. Dazu die ausgezeichneten Artikel von Hartle, 2005. - Hartle, 2003.

68 Cheneval, 2002, S. 30. 
Urheberrechtlich geschütztes Material! @ 2011 Wilhelm Fink Verlag,

Paderborn, ein Imprint der Brill-Gruppe 


\title{
LOCKES LIBERALE STAATSTHEORIE und WatKIns’ GRENZFOTOGRAFIE
}

\author{
„The American frontier is sharply distin- \\ guished from the European frontier - a forti- \\ fied boundary line running through dense \\ population. The most significant thing about \\ the American frontier is that it lies at the \\ hither edge of free land."
}

Carleton Watkins' Fotografie von 1865/66 mit dem Titel „Yosemite Valley from the Best General View" zeigt eine weite Wildnis mit Wald und Wasserfall (Bild 1). ${ }^{2}$ Eine hohe Kiefer durchschneidet die Komposition im Vordergrund, den oberen Bildrand durchstossend, während die Umrisse der Berge sich im Hintergrund in immer schwächer werdenden Schattierungen verlieren. Watkins, der Yosemite nach Charles Leander Weed als zweiter Fotograf besuchte, inszenierte diese Landschaft Kaliforniens in der Sierra Nevada als eine jungfräuliche Wildnis. Weite, Stabilisierung und Ruhe sind Merkmale seiner ausbalancierten Bildkompositionen. ${ }^{3}$ Im Gegensatz zu Weed, der in seine Fotografien gerne einen Beobachter integrierte, zeigte Watkins Yosemite als unbevölkert. ${ }^{4}$ In Yosemite schien das Bild eines menschenleeren Amerika besonders wahr, weil einige Jahre zuvor die ansässigen Indianer besiegt

1 Turner, 1998, S.33. Siehe auch Linklater, 2007. Dieses Kapitel stützt sich vor allem auf Watkins' court deposition in Land Case 100 ND, United States v. D. \& V. Peralta, 1861, United States District Court, Northern District of California; San Francisco, p. 945-962, 982-1018; California Land Case Collection, Bancroft Library University of California, Berkeley. Ich danke insbesondere Jack von Euw von der Bancroft Library für seine Hilfe vor Ort.

2 Eine erste Fassung dieses Textes ist bereits erschienen, siehe Falk, 2008a.

3 Christadler, 1993.

4 Naef und Wood, 1975. Bemerkenswerterweise wurden im amerikanischen Westen bis in die 1850er Jahre bei den seltenen Aussenaufnahmen unter freiem Himmel meist Gegenden aufgenommen, die bereits sichtbar in Berührung mit menschlichem Tun gekommen waren, wie z.B. Berg- und Sägewerke, Schuppen, Häuser oder Stadtansichten, was sich aber in den 1860er Jahren änderte. Dazu Adam, 1996. 
36 LOCKES LIBERALE STAATSTHEORIE UND WATKINS' GRENZFOTOGRAFIE

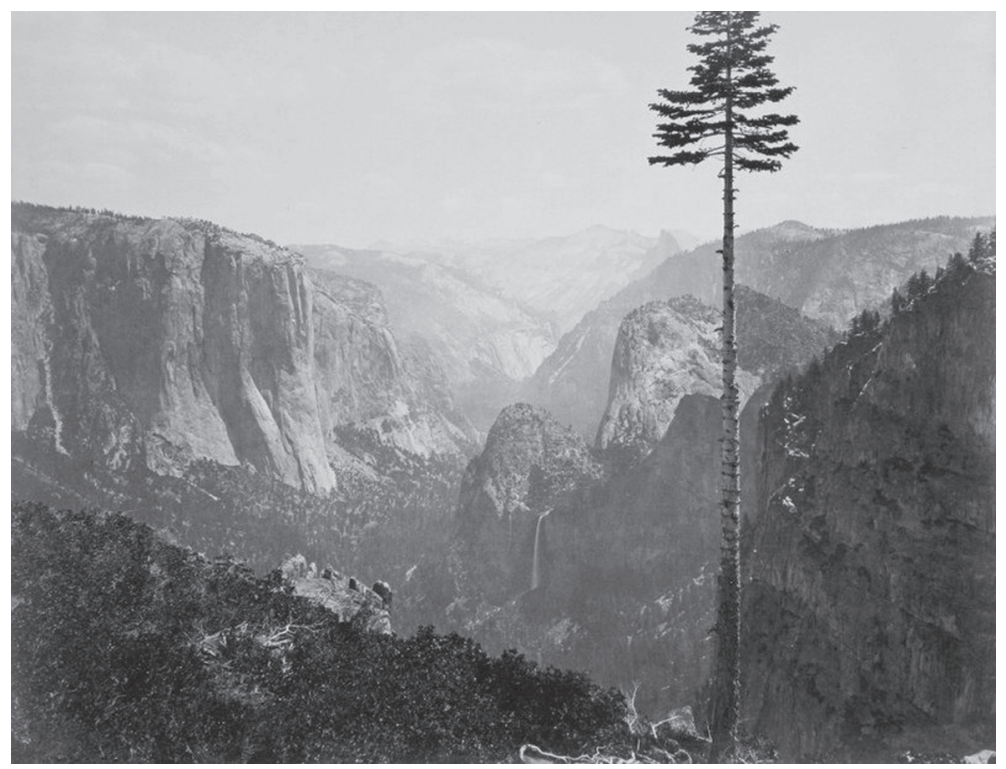

Bild 1: Carleton Watkins:

„Yosemite Valley from the Best General View“, 1865/66

J. Paul Getty Museum, Los Angeles 
und aus Yosemite vertrieben worden waren. ${ }^{5}$ Watkins' Landschaftsfotografien sind ein frühes Beispiel für die fotografische Inbesitznahme des nordamerikanischen Territoriums. Die Entwicklung der Fotografie lief damals parallel zur Entwicklung des amerikanischen Westens: Ausgelöst durch den kalifornischen Goldrausch im Jahre 1848, lockten Fotografien das Geld der Investoren zu den Minen, aber auch zur Eisenbahn. ${ }^{6}$

Bei der emotionalen Besetzung des eroberten Raumes wurde dieser oft mit religiöser Bedeutung aufgeladen: „As a national icon, Yosemite helped justify the country's decision to expand westward, and its edenic qualities added a kind of religious sanction to the expansionist cant. "7 Auch Watkins' fotografische Produktion war eingebunden in die Kolonisierung des Westens. Er fotografierte nicht nur „unberührte Natur", sondern Minen, wachsende Städte und die Eisenbahn, welche 1869 Kalifornien erreichte. ${ }^{8}$ Dennoch ist Watkins heute vor allem für seine menschenleeren Landschaftsfotografien bekannt; seine Bilder spielten eine wichtige Rolle, als es darum ging, Yosemite Valley als Naturschutzgebiet zu deklarieren - oder als touristische Konkurrenz zu den Alpen. Watkins' Fotografien inszenierten indes nicht nur leere Landschaft; auf seine fotografischen Fähigkeiten wurde bei Landstreitigkeiten zurückgegriffen. Land war auch im amerikanischen Westen der 1860er Jahre ein knappes Gut.

Als Kalifornien nach dem Mexikanisch-Amerikanischen Krieg 1849 Teil der Vereinigten Staaten wurde, mussten alle Grundbesitzer die Rechtmässigkeit ihrer Grundstückstitel vor Gericht beweisen. Die Besitzrechte dieser „mexikanischen“ Eigentümer gingen auf den Vertrag von Tordesillas im Jahre 1494 zurück. Kurz nach Kolumbus’ Rückkehr bat Königin Isabella Papst Alexander VI., die neu entdeckten und zu entdeckenden Territorien Spanien zuzusprechen, ohne von der Existenz Amerikas bereits zu wissen. Nach langen Verhandlungen einigten sich Spanien und Portugal darauf, eine Demarkationslinie auf einer Länge von $46^{\circ} 37^{\prime}$ West zu ziehen; alle heidnischen Gebiete westlich davon (Amerika) wurden Spanien, alle östlich gelegenen (Afrika, Asien, aber auch ein Teil des heutigen Brasilien) Portugal zugesprochen.' Weiter wurde vereinbart, dass die Linie, wenn sie auf Land traf, phy-

\footnotetext{
5 Keller und Turek, 1998. Später allerdings kehrten die Indianer zurück, und so sind in einigen später angefertigten Aufnahmen von Watkins auch „Natives“ zu sehen.

6 Von Euw, 2006.

7 Odgen, 2002, S. 378.

8 Berger, 2003.

9 Davenport, 1917. Schneider, 2003.
} 
sisch zu markieren sei, beispielsweise mit Türmen. Diese Grenze sollte also nicht nur auf einer Karte gezogen werden, sondern war, wenn immer möglich, in situ, vor Ort selbst zu markieren. Beide Mächte einigten sich deshalb darauf, in zehn Monaten Schiffe loszuschicken, um den genauen lokalen Verlauf dieser Linie zu bestimmen. Später wurde jedoch der Entschluss gefasst, dass eine Linie auf einer Karte genug Evidenz erzeuge; Portugal und Spanien haben in der Folge die erwähnten Schiffe nie losgeschickt. ${ }^{10}$

Einer der grössten spanischen und mexikanischen „land grants“ war Rancho San Antonio. 1822 hatte Sola, der letzte spanische und zugleich erste mexikanische Gouverneur, dem Offizier Peralta in Anerkennung seiner militärischen Verdienste - vor allem im Kampf gegen die Indianer - Rancho San Antonio zugesprochen. Dieses umfasste den Grossteil jenes Gebietes, das heute als East Bay bei San Francisco bekannt ist. Während des Übergabezeremoniells des Grundstücks wurde eine Proklamation verlesen, es wurden Steine in die vier Himmelsrichtungen geschleudert und es wurde ein Schuss abgegeben, zudem wurde eine grobe Skizze produziert, aber das Land wurde nicht vermessen. ${ }^{11}$

Nach dem Mexikanisch-Amerikanischen Krieg hatten die Vereinigten Staaten im Friedensvertrag garantiert, dass sie alle Landzuteilungen, welche die spanische oder mexikanische Regierung vorgenommen hatten, respektieren würden. Zugleich verlangte jedoch ein Gesetz von 1851, dass alle Grundbesitzer die Rechtmässigkeit ihrer Titel vor Gericht beweisen sollten. Viele dieser Territorien waren aber vom rechtlichen Prozedere her unvollständig dokumentiert, selten umzäunt und oft ungenau kartografiert. ${ }^{12}$ Auch wenn die Grenzen dieser Grundstücke rechtlich nur unzureichend definiert waren, so hatten die Land-

10 Eine sehr ähnliche Vorstellung findet sich diesbezüglich noch bei Petty: „The last gasp of Hobbesian and Seldenian ideas concerning mare clausum was William Petty's evocative idea of signal ships demarcating oceanic boundaries manned by convicts who would be knitting stockings and communicating by semaphores." Armitage, 2000, S. 68.

11 Fox, 1975, S.35. Leider ging die erste Skizze von Rancho San Antonio verloren. Es wäre aber ein interessantes Unterfangen, alle vom Grundstück noch erhaltenen Bilder - seien es Skizzen, Karten oder auch Fotografien - in systematischer Weise miteinander zu vergleichen.

12 Ebenso ergaben sich bei der Grenzziehung zwischen Mexiko und den Vereinigten Staaten Schwierigkeiten, weil die Landschaft teilweise nicht mit den Befunden jener Karten übereinstimmte, die für den Friedensvertrag benutzt worden waren, u. a. auch weil der Verlauf des Rio Grande sich oft änderte. Prescott, 1978, S. 8487. 
besitzer - die vorwiegend Viehwirtschaft ${ }^{13}$ betrieben, was sich auf die Art und Weise der praktizierten Grenzziehung auswirkte - offenbar im praktischen Umgang wenig Probleme, ihr Land von demjenigen ihrer Nachbarn zu unterscheiden. Bis die Goldgräber kamen. ${ }^{14}$

\section{Goldrausch und gefährdete Grundstücksgrenzen}

In den Zeiten des Goldrauschs war das Leben in Kalifornien weniger berauschend denn ernüchternd hart; nur wenige machten ihr Glück in den Minen, die meisten kehrten ärmer zurück als zuvor. Oft respektierten diese desillusionierten Goldgräber die ehemals mexikanischen Grundstückszuteilungen nicht. Wie einst die Indianer, so verloren in dieser Zeit viele vormals in der mexikanischen Gesellschaft führende Familien ihr Eigentum und ihren Einfluss. Auch auf Rancho San Antonio siedelten Squatters; sie verbrauchten das Holz der Peraltas und töteten deren Vieh. In dieser Situation gewann ein Anwalt namens Carpentier grossen Einfluss auf die Familie. ${ }^{15}$ Der spätere Bürgermeister von Oakland erwarb als Abgeltung für seine Anwaltsdienste einen grossen Teil ihres Eigentums. Es war derselbe Carpentier, der 1861 Carleton Watkins den Auftrag gab, die nördliche Grundstücksgrenze zu fotografieren. ${ }^{16}$ Die dabei entstandenen Fotografien gehören zu den ersten, auf die in einem amerikanischen Gerichtsfall zurückgegriffen wurde. ${ }^{17}$ Laut den Peraltas bildeten ein Hügel, ein Bach und ein markanter Felsen die nördliche Grundstücksgrenze; diese topografischen Gegebenheiten sollte Watkins festhalten. Die fotografischen Aufnahmen folgten also in gewisser Hinsicht der Logik der spanischen und mexikanischen Landvergabe, nach der bestimmte augenfällige Landschaftsformationen zur Grenzmarkierung ausgewählt wurden. Diese wurden in einfachen, funktionalen Skizzen festgehalten, wobei die

13 Interessant ist in diesem Zusammenhang die Tatsache, dass aus einer solchen Perspektive auch diese mexikanischen Familien Lockes Gebot, wonach Landwirtschaft Eigentum begründe, nur ungenügend nachkamen, was sich wohl auf die Anerkennung ihrer Ansprüche auswirkte.

14 Hornbeck, 1979.

15 Pitt, 1998.

16 Watkins' court deposition in Land Case 100 ND, United States v. D. \& V. Peralta, 1861, United States District Court, Northern District of California; San Francisco, p. 945-962, 982-1018; California Land Case Collection, Bancroft Library University of California, Berkeley.

17 Es war allerdings nicht das erste Mal, dass Watkins einen solchen juristischen Auftrag annahm. Siehe Palmquist, 1981. 
schriftliche Beschreibung des Grundstücks im Vordergrund stand. ${ }^{18}$ Barbara Mundy spricht gar von einem ,anti-image bias in New Spain“, da das primitive Bild den Indios, die alphabetische Schrift hingegen den kultivierten Spaniern zugeschrieben wurde. ${ }^{19}$ Wohl auch aufgrund dieses empfundenen Defizits gegenüber dem nordamerikanischen kartografischen System sollten Watkins' Fotografien nun auf visuelle Weise den von den Peraltas postulierten Verlauf der Grundstücksgrenze evident machen.

Am 1., 8. und 10. Mai 1861 musste folglich der damals 31-jährige Fotograf vor Gericht erscheinen: $\mathrm{Zu}$ den dreizehn verhandelten Bildern $^{20}$ wurden ihm über einhundertfünfzig Fragen gestellt. ${ }^{21}$ Diese muten repetitiv an; meistens ging es um eine Identifizierung des Dargestellten; eine eventuelle Manipulation der Fotografien war kein Thema. Als der Staatsanwalt fragte, ob Watkins auch jenen Bach fotografiert habe, der die Grundstücksgrenze markiere, bejahte der Fotograf die Frage. Er verwies auf sein Bild Nummer 8 (Bild 2), das eine hügelige, zum Teil bewaldete Landschaft zeigt, die ins Meer ausläuft. Nachdem geklärt worden war, von welchem Standort aus der Fotograf die Aufnahme angefertigt hatte, wurde Watkins aufgefordert, jene dunklere, feine Zick-Zack-Linie zu identifizieren, die sich zwischen den beiden Hügeln über die Ebene zog. Dies sei der Bach, war seine Antwort. Watkins wurde allerdings nicht nur in seiner Funktion als Fotograf ins Kreuzverhör genommen, sondern auch als Augenzeuge, der über die Beschaffenheit der Landschaft Auskunft zu geben hatte; so wurde er beispielsweise über das Alter dieses Baches ausgefragt, obwohl er in diesem Bereich über kein Expertenwissen verfügte. Bemerkenswert ist vor allem aber der Umstand, dass auf der Fotografie der Grenzbach fast nicht zu sehen ist; man muss bereits wissen, wo er sich befindet, um ihn zu erkennen. Dies war wohl auch eine Folge der Wetterverhältnisse zum Zeitpunkt der Aufnahme. Da Watkins seine Bilder sofort entwickeln musste, benötigte er eine sperrige Ausrüstung, deren Transport über die hügelige Landschaft selbst mit Pferdewagen anstrengend war. Aufgrund der schweren Glasplatten konnte Watkins jeweils nur eine beschränkte Zahl von Bildern anfertigen. Zweimal fotografiert hat er -

18 Becker, 1969. Endfield, 2001.

19 Mundy, 1996.

20 Die Bildergrösse variiert leicht, die Fotografien sind ca. $34 \mathrm{~cm}$ breit und $42 \mathrm{~cm}$ lang, oben gerundet und jeweils durchnummeriert von 1-10 und von A-C (die letztgenannten Fotografien A-C wurden später auf Geheiss des Staatsanwalts angefertigt), wobei sich die Fotografien B und 3 aus zwei Bildern zusammensetzen.

21 Davon kann hier nur ein kleiner Ausschnitt wiedergegeben werden. 


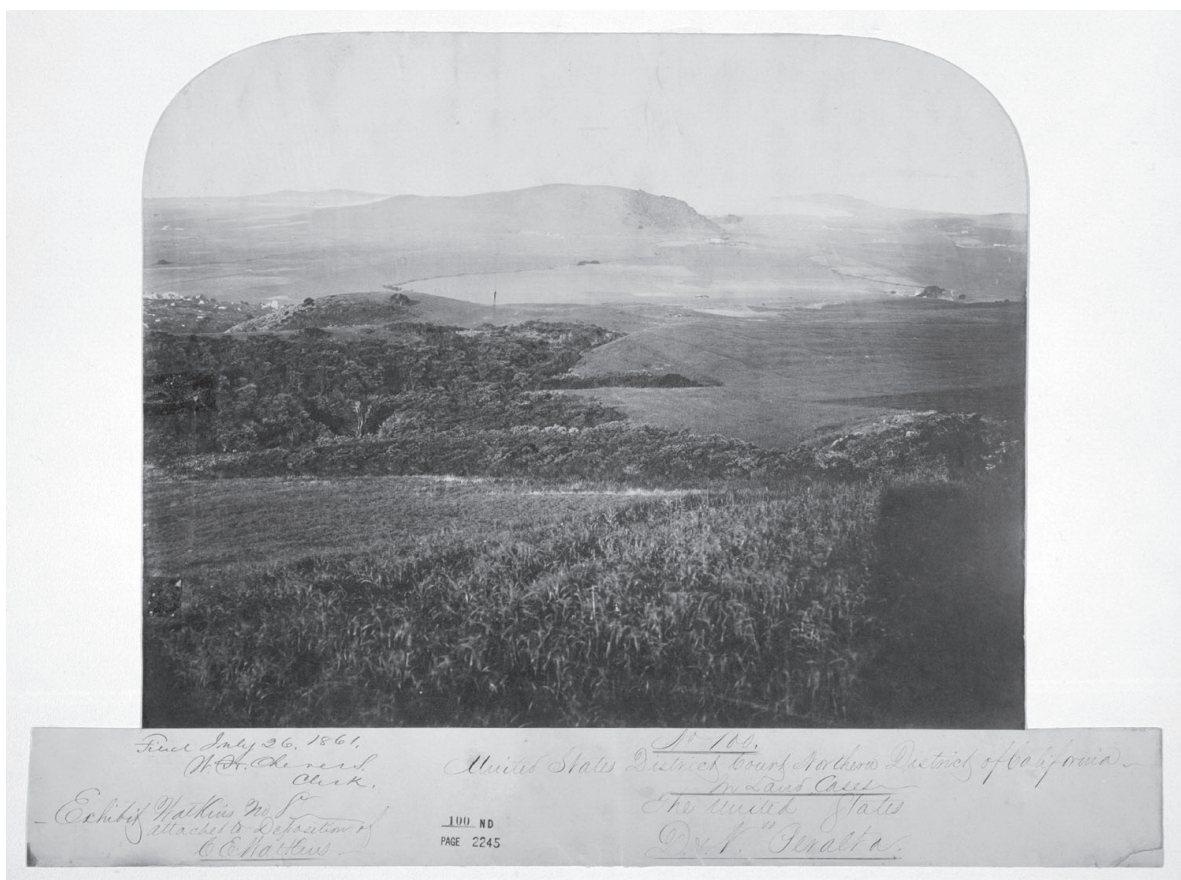

Bild 2: Carleton Watkins: „Rancho San Antonio“,1861 Courtesy of The Bancroft Library University of California, Berkeley 
und zwar auf Geheiss des Staatsanwalts - nur jenen roten Felsen, den der Staatsanwalt im Gegensatz zur Peralta-Partei als die ursprüngliche Grenzmarkierung betrachtete. Damit wurde aber die Meinung des Staatsanwalts bestätigt, dass sich die abzeichnende Kontur und die Grösse des Felsens durch die Aufnahmeposition und -distanz beträchtlich beeinflussen liessen. ${ }^{22}$

Die im Verlauf des Verhörs immer wieder auftauchende Frage nach der Position des Fotografen zeugt von einem erstaunlich hohen Bewusstsein für die Standortgebundenheit und Ausschnitthaftigkeit der Fotografie. ${ }^{23}$ In Zusammenhang mit den verschiedenen Felsformationen musste Watkins die „Farbechtheit“ seiner Schwarzweiss-Fotografien bezeugen: „If I could color in water colors, I do not think I could make it much nearer correct", antwortete der Fotograf mit $\mathrm{Zu}$ versicht. ${ }^{24}$ Trotz des hier geäusserten Optimismus entwickelten seine Bilder nicht die persuasive Kraft, die sich Domingo und Vicente Peralta (beziehungsweise ihr Anwalt Carpentier) versprochen hatten; es dauerte noch weitere sechzehn Jahre, bis ihre Landrechte anerkannt wurden. ${ }^{25}$ In der hier beschriebenen Zeit, um 1861, wurde in Nordamerika die Fotografie nicht als eigenständiges, sondern als illustratives Beweismittel betrachtet. ${ }^{26}$ Dieser Status war aber durchaus ambivalent; so wurde die Fotografie andererseits in Gerichtsprozessen von Anfang an als besonders wirkungsvolles Beweismittel gesehen. ${ }^{27}$ Bereits zwanzig Jahre zuvor hatte William Henry Fox Talbot in „The Pencil of Nature" die Fotografie als objektive Selbstabbildung der Natur begriffen und ihren Einsatz als Beweismittel vor Gericht ausgemalt. ${ }^{28}$

Es ist schwierig abzuschätzen, wie die Fotografien den Prozessverlauf im erwähnten „land case“ tatsächlich beeinflussten - sei es im Sinne der Peraltas oder des Staatsanwalts, der von den neuen Möglichkeiten sofort Gebrauch machte und Watkins mit der Herstellung von

22 Dazu auch Sexton, 1982.

23 Wie die Vorstellung eines nicht durch menschlichen Eingriff vermittelten fotografischen Abbilds zu einem mechanischen Objektivitätsbegriff führte, der wiederum in einem Spannungsverhältnis stand zu einem a-perspektivischen Objektivitätsverständnis, zeigt sehr schön Daston, 1999.

24 Siehe Watkins' court deposition in Land Case 100 ND.

25 Die Anwaltskosten verschlangen in der Folge einen grossen Teil ihres Territoriums. Weniger lange dauerte es übrigens bei den beiden anderen Brüdern Ygnacio und Antonio Peralta; deren südlicher gelegene Grundbesitze wurden 1858 bzw. 1874 „patentiert“ (1841 hatte der Vater das Land unter seinen Söhnen aufgeteilt).

26 Golan, 2002.

27 Mnookin, 1998.

28 Talbot, 1969 (1844-46). 
Gegenbildern beauftragte. Auch wenn das fotografische Experiment für Antonio und Vicente Peralta nicht sonderlich erfolgreich war, so lohnte sich der Auftrag für Watkins; kurz darauf hatte der damals noch unbekannte Fotograf jedenfalls genug Geld, um Yosemite zu besuchen und dieses Gebiet als leere Landschaft zu inszenieren.

\section{Amerika als leere Augenweide}

Der Widerspruch in Watkins' fotografischem Werk - die Inszenierung des amerikanischen Westens als leere Augenweide bei gleichzeitiger Verwicklung in Grundstücksstreitigkeiten (was auf eine Knappheit des Landes verweist) - findet sich in ähnlicher Weise in John Lockes Staatstheorie und der ihr zugrunde liegenden Vorstellung vom leeren Raum, wie sie bereits im vorhergehenden Kapitel herausgearbeitet wurde: Wenn der Gesellschaftsvertrag ohne Gewaltanwendung etabliert werden soll, müssen Individuen, die sich diesem nicht anschliessen wollen, die Freiheit haben, zu gehen, entweder indem sie sich einem anderen Staatswesen anschliessen oder sich mit anderen über die Begründung eines neuen Staates verständigen, in vacuis locis, in irgendeinem Teil der Welt, den sie frei und besitzlos finden. ${ }^{29}$

Leere Bodenflächen finden sich allerdings nach Locke nur bei jenen Völkern, die sich nicht dem Gebrauch eines gemeinsamen Geldes angeschlossen haben. ${ }^{30}$ Den Umstand, dass Geldsysteme schon vor Ankunft der Europäer in Gebrauch waren, reflektiert Locke nicht (beziehungsweise er bedenkt nicht die Konsequenzen), obwohl er die Wamponmuscheln der Indianer erwähnt. ${ }^{31}$ John Locke lokalisierte den für seinen Gesellschaftsvertrag notwendigen leeren Raum in Amerika. Dass Indianerstämme auch Landwirtschaft betrieben, zudem Jagdrechte ebenfalls territoriale Besitzansprüche fundierten, wurde von Locke mit Verweis auf die angebliche Landverschwendung der Indianer ignoriert.

Nicht nur politisch-juristische Diskurse schufen die Vorstellung eines leeren Amerikas. Ebenso wichtig waren bildliche Imaginationen. Die Kartografie - selbst zwischen Bild und Sprache siedelnd ${ }^{32}$ - spielte eine wichtige Funktion bei der Produktion eines „menschenleeren

29 Locke, 1980, S. 65.

30 Locke, 1977, S. 228. Dazu auch Macpherson, 1973, S. 263.

31 Locke, 1977, S. 318.

32 Zur raumkonstituierenden Funktion der Kartografie siehe Krämer, 2007. 
Amerikas". ${ }^{33}$ In der amerikanischen Landschaftsmalerei waren indes „Einheimische“ oft dann noch visuell präsent, als sie aus den entsprechenden Gebieten bereits verdrängt worden waren. ${ }^{34}$ Es waren demnach vor allem Fotografen, welche Amerika visuell als leere Augenweide inszenierten. ${ }^{35}$ Allerdings kann der Topos des leeren Raumes als Rechtfertigungsmotiv auch abgelöst beziehungsweise ergänzt werden, so beispielsweise von der Leitidee einer zum Wohle aller gereichenden Modernisierung. ${ }^{36}$

\section{Friedliche und flexible Frontier}

Einige Jahrzehnte nach Watkins' fotografischen Aufnahmen, die den Westen Amerikas als leere Augenweiden zeigten, formulierte der Historiker Frederick Jackson Turner seine berühmte, aber auch umstrittene Frontier-These. ${ }^{37}$ Die Auseinandersetzung mit einer unberührten und wilden Natur hätte aus verweichlichten Europäern starke, demokratische, individualistische und initiative Amerikaner gemacht. Gleichzeitig postulierte Turner einen grundsätzlichen Unterschied zwischen den militarisierten, scharf definierten und linearisierten Grenzen Europas und der friedlichen und flexiblen amerikanischen Frontier: „The American frontier is sharply distinguished from the European frontier - a fortified boundary line running through dense population. The most significant thing about the American frontier is that it lies at the hither edge of free land. “38 Allerdings war der Osten Amerikas von den ersten Entdeckern als dicht besiedelt beschrieben worden. ${ }^{39}$ Die Strategie, ein leeres Land mystifizierend aufzurufen - bei Turner der Garant einer vermeintlichen Chancengleichheit -, ist indes nicht auf Amerika beschränkt. Es findet sich in anderen Kontexten unter anderem auch in Afrika, Australien, Osteuropa, China oder in

33 Dazu Harley, 2001. Zu weissen Flecken auf Karten siehe auch Laboulais-Lesage, 2004. - Hölscher, 2009, S. 16.

34 Kornhauser und Fluck, 2007, S. 15.

35 In den frühen Tagen der Fotografie erschienen aufgrund der langen Belichtungszeit belebte Städte als menschenleere Schauplätze (was zu Watkins' Zeiten allerdings nicht mehr der Fall war). Geimer, 2002. Nicht vergessen werden sollte hier jedoch der Umstand, dass „Menschenleere“ auch als ein Merkmal einer bestimmten Tradition der malerischen Landschaftsdarstellung gesehen werden muss.

36 Weiand, 2010.

37 Osterhammel, 2009, S. 468-471.

38 Turner, 1998, S. 133.

39 Denevan, 1992. 
Israel/Palästina und zeigt auch da wirkmächtige Folgen für Eigentumslegitimationen. ${ }^{40}$ Gerade in solchen expansionistischen Kontexten kann nun nicht nur eine möglichst scharf definierte und eindeutig markierte Grenzlinie Evidenz erzeugen; auch eine unklar gehaltene Umgrenzung vermag zuweilen Grenzpotenz zu generieren. ${ }^{41}$ Dass dabei die gleichzeitig geschaffenen militärischen Grenzbefestigungen mit ihrer Undurchdringlichkeitssymbolik ${ }^{42}$ - die je nach Sichtweise als offensiv oder defensiv, als Ausdruck von Stärke oder von Schwäche gesehen werden kann - durch ihr oft bildmächtiges Bauwerk und ihre spektakuläre Sichtbarkeit zur Ikone werden, ist nicht als Widerspruch zu werten. Grenzregimes leben auch davon, dass sie gewisse Aspekte sichtbar, andere aber unsichtbar machen - und dass dieses Verhältnis wieder verändert werden kann.

\section{Fazit}

In der hier untersuchten Konstellation präsentiert die imaginierte Leere den spannungsreichen Hintergrund für eine Fotografie der Grenze als juristisches Beweismittel, deren Bedeutungspotenzial sich jedoch nicht im Sinne der Auftraggeber realisieren liess. Nur wer bereit war, die Grenze zu sehen, konnte durch den eigenen Blick ein vieldeutiges Bild zu einem eindeutigen Beweis formen, die Grenze im gezeigten Bach tatsächlich erkennen. ${ }^{43}$ Den Drehpunkt der Argumentation bildet dabei der Umstand, dass sich bei Watkins in ähnlicher Weise wie bei Locke eine in ihrer Widersprüchlichkeit entsprechende Konstellation findet: Watkins war mit seinem Werk nicht nur daran beteiligt, die Vorstellung Amerikas als leeres Land zu etablieren, vielmehr waren seine Arbeiten auch bei Landstreitigkeiten und den damit zusammenhängenden Grenzverhandlungen von Gewicht.

40 Afrika bespielsweise wird gerne als „leer“ inszeniert, so beispielsweise im Schweizer Kinderbuch Globi, vor allem in älteren Ausgaben. Dazu Purtschert, 2008b. Purtschert, 2012.

41 Weizman, 2007. Allerdings ist Grenze nicht einfach gleich „Grenze“; was für Grundstücksgrenzen gilt, muss nicht zwangsläufig für nationalstaatliche zutreffen - und umgekehrt.

42 Osterhammel, 2001, S. 210.

43 Indes hätte selbst ein gestochen scharfes Bild nicht bedeutet, dass der fotografierte Bach vor Gericht automatisch auch als „authentische“ Grenze anerkannt worden wäre. 
Indes ist dies nicht nur die Erzählung eines gescheiterten Evidenzeffekts; der Umstand, dass der Staatsanwalt sofort selbst Fotografien herstellen liess, bezeugt zugleich deren potenzielle „power of persuasion“. ${ }^{4}$ Beachtenswert ist in diesem Zusammenhang zudem das ähnliche argumentative Muster in Bezug auf die Fotografie wie auf Grenzen: Je nach Perspektive konnten beide jeweils als gegeben beziehungsweise gemacht, evident oder kontingent, natürlich oder willkürlich gesehen werden.

44 Mnookin, 1998. 


\section{HOBBES' HORROR VACUI}

„Die Freiheit ist (um sie zu definieren) nichts anderes als die Abwesenheit von allem, was die Bewegung hindert. ${ }^{\text {1 }}$

Thomas Hobbes malt im „Leviathan“ das Bild des Naturzustands in kräftigen Farben: Im Naturzustand ist nach Hobbes das Leben einsam, armselig, ekelhaft, tierisch und kurz. ${ }^{2}$ Der Naturzustand soll dem von ihm entwickelten Souveränitätsprinzip Evidenz verschaffen. Die Naturzustandsmetaphorik strukturiert den Hobbes'schen Gesellschaftsvertrag $^{3}$ in grundlegender Weise. Die nachfolgenden Kontraktualisten streiten darüber, wie der Naturzustand konkret zu konturieren und kolorieren sei; dass ein (sprachliches) Bild als Prämisse fungiert, wird jedoch nicht grundsätzlich kritisiert. ${ }^{4}$

Doch wird die visuelle Bildlichkeit dieser Naturzustandsprämisse in Hobbes' Schriften gewissermassen verdrängt: Nicht ein Bild des Naturzustands ziert den „Leviathan“, sondern jenes des gewaltigen und gewaltausübenden Souveräns; das Vorhandensein eines Naturzustands zwischen den Staaten wird hier u. a. mit den abgebildeten Soldaten nur angedeutet. Dies war allerdings nicht immer so.

1 Hobbes, 1994, S. 170. Dieses Kapitel wird in anderer Fassung in der Zeitschrift „Historische Anthropologie“ erscheinen. Falk, 2011 b.

2 Hobbes, 1966, S. 96.

3 Hobbes spricht in Bezug auf „Vertrag“ allerdings häufiger von covenant, der sich auch auf den Bund mit Gott beziehen lässt, als von contract, in dem die ökonomische Sphäre stärker präsent ist.

4 Doch selbst wenn der Naturzustand mit Thomas Hobbes zur normativ-analytischen Basis der politischen Theorie wird, so ist die Vorstellung vom Naturzustand als literarisch-politischem Topos sehr viel älter. Medick, 1973, S. 31. Hugo Grotius beispielsweise verwendet den Begriff des Naturzustands, aber es findet sich bei ihm keine allgemeine Beschreibung eines solchen vorrechtlichen Zustandes. Siehe dazu Spyk, 2005, S.62. Dazu auch Skinner, 1978, S. 155. Siehe auch Medick, 1973, S.31. Allerdings hat Hobbes den wohl entscheidenden Beitrag zur Etablierung dieses Konzeptes geleistet. 


\section{Zwischen Kannibalen und Wölfen}

1642 erschien in Paris anonym Thomas Hobbes' „De Cive“. Diese zuerst auf Latein verfasste Schrift nahm in weiten Teilen Hobbes' späteres Werk „Leviathan“ vorweg. Ein heute wenig bekanntes Frontispiz, angefertigt durch Jean Matheus, zierte die erste Druckfassung (Bild 3). ${ }^{5}$ Das Titelbild operiert mit Oppositionspaaren. Der Bildraum ist klar aufgeteilt zwischen oben und unten, links und rechts: einem irdischen unteren und einem jenseitigen oberen Bereich sowie einer positiven linken und einer negativen rechten Seite. Im linken unteren Teil sehen wir eine üppig gekleidete, jung aussehende und bekrönte Frauenstatue, die - wie wir dem Sockel entnehmen können - für das „Imperium“ und damit nach Hobbes' Logik auch für den Staat und die Zivilisation steht. Sie trägt eine Waage und ein Schwert, das nach oben zeigt. Ihr gegenüber finden wir eine mit einem Federrock und Armschmuck bekleidete Indianerfigur: die „Libertas“. Diese verkörpert den Naturzustand. Bei der Indianerfigur ist die Geschlechtszugehörigkeit nicht eindeutig zu bestimmen, was auf eine Verwischung der Geschlechtergrenzen im Naturzustand verweist. ${ }^{6}$ Der Indianer wirkt alt und erschöpft, auffallend sind seine runzelige Stirn und der gebeugte Rücken. Der Wilde wird hier als degeneriert und deformiert gezeigt. Der Pfeil des Indianers zeigt nach unten und am Sockel nagt der Zahn der Zeit - der Indianer steht auf wackligem Grund. Im Hintergrund sehen wir, wie sich nackte oder halbnackte Wilde mit Pfeil, Bogen und Keule jagen; zwei Kannibalen sind dabei, die zergliederten Reste eines Menschen zuzubereiten. ${ }^{7}$ Auf der Gegenseite leben die Ackerbauern in friedlichen Verhältnissen; das Leben besteht aus Arbeit, aber ebenso aus wohlverdienter Erholung. Zwei Bauern sind mit dem Dreschen der auffallend hochgewachsenen Ähren beschäftigt, während sich weiter hinten zwei Menschen mit Gehstock und Bündel in Richtung einer Stadt bewegen. Ein binärer Aufbau findet sich ebenfalls in der oberen Bildhälfte. Hier markiert Jesus die Grenze zwischen den Verdammten, die von Teufeln in die Hölle geschubst oder mit dem Dreizack malträtiert werden und den Erlösten,

5 Dieses Frontispiz wurde als Zeichnung bereits 1641 dem Pergamentmanuskript beigefügt. Bredekamp, 1999, S. 144.

6 Zum Topos des Grenzverwischens siehe Manow, 2007. Falk, 2008c. Hobbes selbst denkt die Geschlechterdifferenz graduell und nicht prinzipiell; er begreift die Vorherrschaft des Mannes nicht als natürlich, sondern als ein Produkt von Konventionen. Siehe Bürgin, 1998, S. 257. Dazu vor allem aber auch die mittlerweile klassischen Studien von Carol Pateman, 1988. - Pateman und Mills, 2007.

7 Bredekamp, 1999, S. 144. 


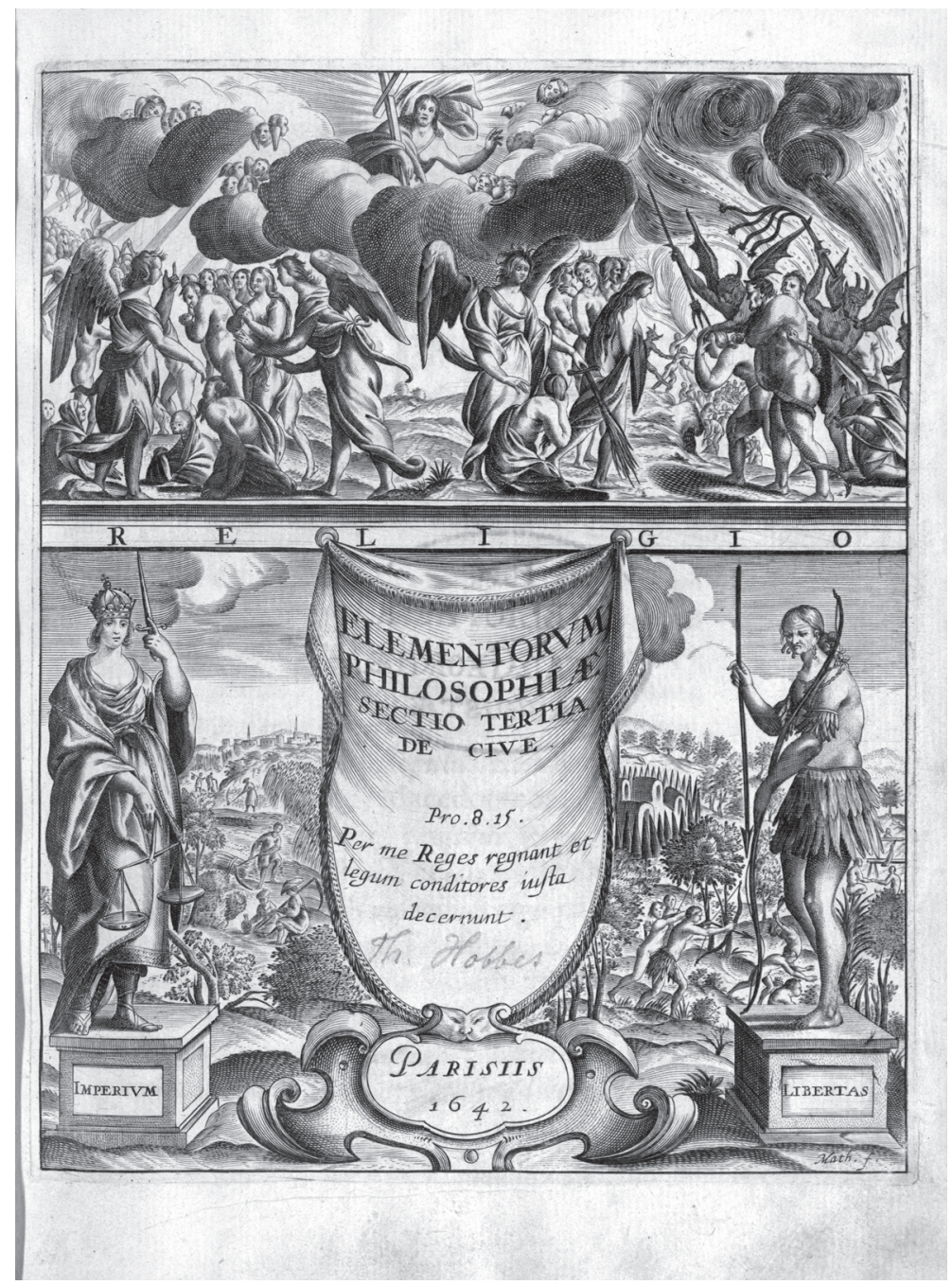

Bild 3: Jean Matheus: Frontispiz von „De Cive“, 1642

Universitätsbibliothek Göttingen 
die in ihrem Körper zum Himmel aufsteigen. Die gleiche grenzziehende Funktion wie das Jüngste Gericht übernimmt im irdischen Bereich jener Vorhang, auf dem der Titel des Werkes zu lesen ist, weiter der nachträglich eingefügte Autorenname sowie der biblische Leitspruch „Durch mich regieren die Könige, und entscheiden die Urheber der Gesetze, was Recht ist" (Sprüche Salomons 8,15). Hier ist es also Hobbes' Schrift, welche eine quasigöttliche Funktion übernimmt und die Grenze markiert, und zwar jene zwischen „Libertas“ und „Imperium“, Naturzustand und Staat, friedlichen und kriegerischen Verhältnissen. Gleichzeitig verdeckt der Vorgang aber auch die Grenze zwischen dem Zustand des „Imperiums“ und jener der „Libertas“ und er verheimlicht, auf welche Weise diese zwei Bereiche zusammengehören. Zudem wird durch den sich vor dem Bild befindenden Vorhang visuell verdeutlicht, dass es sich beim Naturzustand um ein Bild im Bild handelt - und nicht um unvermittelte Realität.

Die beiden sich jeweils auf Sockeln gegenüberstehenden Figuren erinnern an die Kupferstiche der ab 1590 publizierten America-Serie des Verlegers Theodor de Bry, insbesondere an das Titelbild des ersten Bandes zu Virginia (Bild 4). ${ }^{8}$ Diese Reiseberichtsammlung gehörte zu den bedeutendsten der Frühen Neuzeit; das dabei entstandene Bilderarchiv prägt noch heute, wie Susanna Burghartz und Maike Christalder gezeigt haben, unsere Vorstellung von der frühen Kolonialgeschichte. Auf dem Titelbild des ersten Bandes zu Virginia wird allerdings einiges anders dargestellt als auf unserem Frontispiz. Die männlichen Indianer werden hier als „kräftige Kerle“ gezeigt. ${ }^{9}$ Die Gegenüberstellung von Frau und Mann erinnert an Adam und Eva und damit an paradiesische Zustände. ${ }^{10}$ Die von Thomas Harriot verfassten Kom-

8 Burghartz, 2004b. Skinner, 2008, S. 102. Christadler, 2004. Die America-Serie wiederum stützt sich auf Zeichnungen des Koloniegouverneurs John White, die sich jedoch zum Teil stark von der Darstellung de Brys unterscheiden. Siehe dazu Kuhlemann, 2007.

9 Jedoch taucht der Topos der Geschlechterverwirrung auch bei de Bry auf, allerdings in etwas anderer Form, und zwar beim Titelblatt des neunten Bandes von 1601: „Die Magellanstrassen-Bewohner können als Zeichen einer ,verkehrten Welt' gelesen werden, denn der Mann trägt nun einen kurzen (Feder-) Rock und lange Haare, während die Frau nackte Beine und kurze Haare hat. "Dazu Christadler, 2004, S. 67. Auch beim Titelblatt des dreizehnten Bandes von 1627 erscheint die Indianerin als hässliche Alte mit männlichen Zügen, was an Hexendarstellungen erinnert. Die Sexualorgane sind jedoch deutlich sichtbar, so beispielsweise die übergrossen, hängenden Brüste. Siehe auch Burghartz, 2008.

10 Burghartz, 2008. Zur Thematik, dass der Gesellschaftsvertrag „Fülle“ hervorbringe, siehe Balke, 2007. 


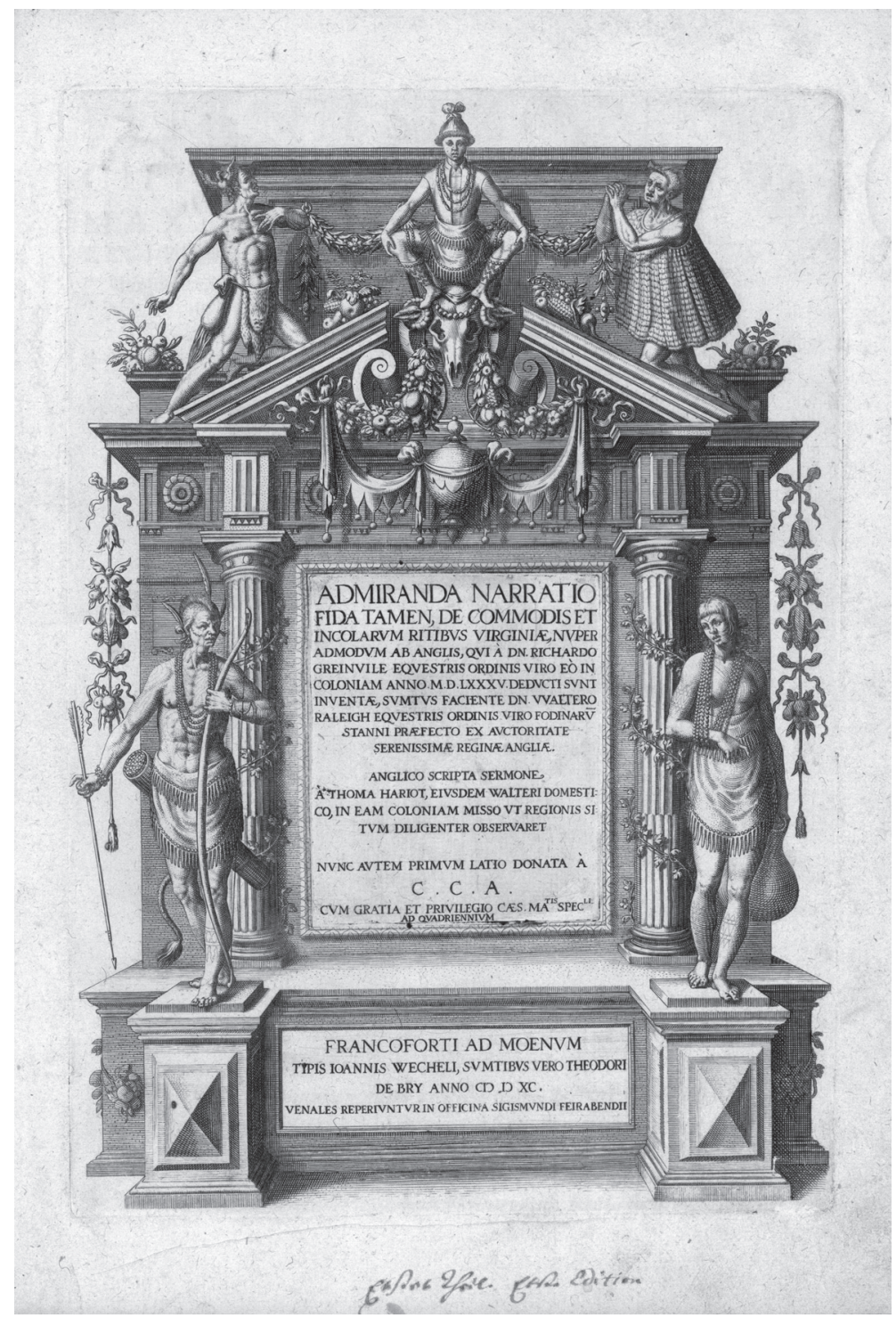

Bild 4: „America-Serie“ des Verlegers Theodor de Bry, Frontispiz des ersten Bandes von 1590, Herzog August Bibliothek Wolfenbüttel 
mentare für den Virginia-Band beschreiben in leuchtenden Farben die Fruchtbarkeit der Landschaft. ${ }^{11}$ Diese Anspielungen an die Fülle der Natur wie der Umstand, dass sich in diesem Band - im Gegensatz zum Titelbild von „De Cive“ - Darstellungen der indianischen Landwirtschaft finden, sollten im Folgenden, wenn ich auf Hobbes' Beschreibung des Naturzustandes eingehe, im Kopf behalten werden. Allerdings erweckt auch bei de Bry der abgebildete Tierschädel Assoziationen ans Morbide, und die Anbetung des darauf sitzenden Herrschers durchbricht das Bild des Paradiesischen.

In Hobbes' Schriften oszilliert der Status des Naturzustands: Ambivalent sind seine Ausführungen in Bezug auf die Frage, ob der Naturzustand und die daraus resultierende Einsetzung einer unbeschränkten Gewalt als vergangene Begebenheit, als noch herrschender Zustand oder als hypothetisches Konstrukt zur Analyse der Bedingungen staatlicher Ordnung zu verstehen sei. ${ }^{12}$ Die Figur des Naturzustands wird dabei, wie Patricia Purtschert schreibt, zwischen fiktivem Gedankenspiel, historischer Rekonstruktion und ethnografischem Ausgriff in der Schwebe gehalten. ${ }^{13}$ In „De Cive“ verortet Hobbes den Krieg aller gegen alle, was den Naturzustand charakterisiert, sowohl bei den Indianern wie auch in der Vergangenheit: „Als ein Beispiel dafür zeigt uns das jetzige Jahrhundert die Amerikaner; frühere Zeiten zeigten andere Völker" ${ }^{14}$ Hier wird der Naturzustand sowohl als ein vergangener wie auch als ein gegenwärtig herrschender Zustand beschrieben. Auch im „Leviathan" wird der Naturzustand mit den Indianern in Verbindung gebracht: „Denn die wilden Völker verschiedener Gebiete Amerikas besitzen überhaupt keine Regierung, ausgenommen die Regierung über kleine Familien, deren Eintracht von der natürlichen Lust abhängt und die bis zum heutigen Tag auf jene tierische Weise leben, die ich oben beschrieben habe. " ${ }^{15}$ Hobbes setzt hier die Existenz von Familien im Naturzustand voraus. ${ }^{16}$ Selbst wenn der Naturzustand u. a.

11 Burghartz, 2008.

12 Dazu auch Jahn, 2000.

13 Purtschert, Unveröffentlichtes Manuskript (2009). Dazu auch Fink-Eitel, 1994.

14 Hobbes, 1994, S. 84. Auch bei de Bry sind die Indianer jenen Völkern, die früher in England gelebt haben, sehr ähnlich - und umgekehrt. Burghartz, 2004a, S. 196.

15 Hobbes, 1966, S. 97.

16 Hobbes' Ausführungen zur Existenz von Familienstrukturen im Naturzustand sind allerdings ambivalent, denn in „De Cive“ wiederum heisst es: „Wir wollen nun wieder auf den Naturzustand zurückgehen und annehmen, dass die Menschen gleichsam wie Pilze - plötzlich aus der Erde hervorwachsen und erwachsen wären, ohne dass einer dem andern verpflichtet wäre." Hier zielt Hobbes auf die analytische Funktion des Naturzustands und das als autonom konzipierte Individuum ab, 
wohl auch aufgrund von Familienverbänden niemals allgemein auf der ganzen Welt als ein Krieg aller gegen alle existiert hätte, schreibt Hobbes im „Leviathan “17, kenne man gegenwärtig viele Gebiete, wo Menschen im Naturzustand lebten, so eben in Amerika. Zudem zeige der Bürgerkrieg, zu welchem Leben ein Fehlen einer allgemeinen Gewalt führe; dies könne im Übrigen selbst jenen Menschen widerfahren, die früher unter einer friedlichen Regierung gelebt hätten. Für Thomas Hobbes ist Amerika nicht leeres Land, sondern wie bereits Carl Schmitt bemerkte ${ }^{18}$, eine Vergegenwärtigung des Naturzustands.

Nach Francis Cheneval bildet der kriegerische Zustand zwischen den Staaten den Ausgangspunkt bei der Hobbes'schen Konzeption des Naturzustands. ${ }^{19}$ Die Menschen befinden sich bei Hobbes zudem nicht einfach im Naturzustand oder ausserhalb, sondern sie können sich demnach durchaus zur gleichen Zeit im Hinblick auf einige Menschen im Naturzustand, im Hinblick auf andere aber ausserhalb des Naturzustands befinden. ${ }^{20}$ Auf dem Titelbild des später publizierten „Leviathan“ wird der Naturzustand mit den Soldaten als zwischen den einzelnen Staaten auch in Europa andeutungsweise als gegenwärtig existierend gezeigt; auf dem Frontispiz von „De Cive“ wird er hingegen in prominenter Weise mit dem Kannibalismus der Indianer veranschaulicht.

Gegenüber der Vorstellung eines leeren Raumes verhält sich Hobbes skeptisch; er lässt sich in die Denktradition des Horror Vacui einreihen. Die vorsokratischen Atomisten hatten hingegen noch keine Angst vor dem Nichts. Die Leere galt ihnen als Bedingung der Möglichkeit dafür, dass die Atome kompakte Einheiten bilden können. ${ }^{21}$ Sie ermöglichte sowohl Fülle wie auch Bewegung. Aristoteles bekämpfte diese Auffassung. Er empfand als Widerspruch, dass Leere nichts sei, gleichzeitig aber existieren müsse, also ein Seiendes und ein Nicht-Seiendes sei. Nach Aristoteles übertrug das feinstoffliche Medium Äther die Bewegungsimpulse; es sicherte so das Prinzip der Fülle. Auch die scholastische Denktradition verneinte die Existenz eines leeren Raumes. Nach dem Prinzip des Horror Vacui durfte die Schöpfung keine Diskontinuität aufweisen. Zwischen allem Seienden vermittelt ein Übergängli-

weshalb er in diesem Gedankenexperiment auf die Annahme von Familienstrukturen verzichtet. Hobbes, 1994, S. 161. Dazu auch Pateman, 1988, S. 46.

17 Hobbes, 1966, S. 97.

18 Schmitt, 1997, S. 64-65.

19 Cheneval, 2002, S. 31.

20 Eggers, 2008, S. 58.

21 Böhme, 2003, S. 44. 
ches, weshalb immer eine Beziehung des Zusammenhangs und der Benachbarung besteht: „Gott garantiert kosmologisch das Prinzip der Lückenlosigkeit und der Fülle des Seins. " 22 Die materialisierte Schöpfung Gottes durfte keine in der Leere verschwindende Minderheit sein. ${ }^{23}$ Auch Hobbes bestreitet in „De Corpore“ die Existenz eines Vakuums und erklärt in seinem „Dialogus Physicus, sive de Natura Aeris“ (1661) die experimentellen Ergebnisse von Robert Boyle für irrig. ${ }^{24}$ Auch der Vorstellung eines geografisch gedachten leeren Raums steht Hobbes kritischer gegenüber als Locke: Die daraus resultierende Eroberungslust führe, schreiben Shapin und Schaffer, nach Hobbes zu Krieg. ${ }^{25}$ In seiner Argumentation geht Hobbes bekanntlich von einer Mangelsituation aus. Da alle Menschen eine ähnliche Konstitution haben, streben sie nach ähnlichen Gütern, was im Naturzustand eine permanente Bedrohungssituation produziert. Das Prinzip der Knappheit gilt bei Hobbes auch in Bezug auf das Territorium. Im „Leviathan“ spricht Hobbes in Bezug auf die Gründung von Kolonien allerdings auch von Land, das ,vorher unbewohnt war oder durch Krieg menschenleer gemacht wurde“ “ ${ }^{26}$ Vorhanden sind nach Hobbes weiter „unterbesiedelte Länder". ${ }^{27}$ Bei Überbevölkerung sollen arme, kräftige Leute dorthin verpflanzt werden, wobei „Einheimische“ zu Sesshaftigkeit und zu einer bestimmten Arbeits- und Produktionsweise gezwungen werden dürfen. Siedler sollen indes, meint Hobbes, nicht die Menschen, die sie antreffen, ausrotten, „sondern sie müssen sie zwingen, enger zusammenzuwohnen und nicht weite Teile des Landes zu durchstreifen, um zu sammeln, was sie finden, sondern sich jedes Fleckchens mit Geschick und Arbeit anzunehmen, damit es ihnen in der entsprechenden Jahreszeit ihre Nahrung gibt. Ist indes die ganze Welt von Bewohnern überfüllt, so bleibt als letztes Mittel der Krieg, der für jedermann Sieg oder Tod bereit hat. " 28

Die Gewalt, die hinter solchen Entleerungsprozessen steht, wird hier nicht unsichtbar gemacht. ${ }^{29}$ Es gebe „kaum einen Staat auf der

22 Böhme, 2003, S. 46.

23 Böhme, 2003, S. 58.

24 Hingegen war Locke mit Boyle befreundet, siehe dazu Short, 2004. Siehe auch Latour, 1995. In Bezug auf die europäische Expansion spricht Colin M. MacLachlan von einem juristischen Vakuum. MacLachlan, 1988.

25 Shapin und Schaffer, 1985, S. 108.

26 Hobbes, 1966, S. 195.

27 Hobbes, 1966, S. 264.

28 Hobbes, 1966, S. 264.

29 Wie Gewalt im Liberalismus unsichtbar gemacht wird, thematisiert auch Chantal Mouffe, Mouffe, 1993. 
Welt, dessen Anfänge mit gutem Gewissen zu rechtfertigen sind." ${ }^{30}$ Die Gründung des Staats zur Beendigung des latenten Kriegs aller gegen alle durch die Etablierung eines Gesellschaftsvertrags liegt nach Hobbes allerdings auch im rationalen Selbstinteresse jedes Einzelnen. ${ }^{31}$ Zwar differenziert Hobbes zwischen einem Staat durch Aneignung und einem Staat durch Einsetzung. ${ }^{32} \mathrm{Ob}$ die Unterwerfung unter den Souverän historisch gesehen durch freiwillige Zustimmung oder Gewaltanwendung zustande kommt, macht für Hobbes aber letztlich keinen Unterschied. Gerade dies ist der Grund, weshalb Hobbes die Konzeption eines leeren Raumes für jene, die sich dem Gesellschaftsvertrag nicht anschliessen wollen, nicht in gleicher Weise wie Locke benötigt. ${ }^{33}$

\section{Freiheit als die Abwesenheit von Bewegungshindernissen}

„De Cive“ erschien in einer nur sehr kleinen Auflage und war nicht zum Verkauf vorgesehen. Hobbes liess die Schrift zuerst unter Freunden kursieren, um so allfällige Kritik in einer neuen Fassung einarbeiten zu können, wie er selbst im Vorwort der zweiten Auflage bemerkte. ${ }^{34}$ Auch hat sich nicht dieses erste Frontispiz durchgesetzt, sondern die Amsterdamer Version von 1647. Hier ist das „Imperium“ als Widerpart der niederländischen Freiheit charakterisiert, trägt dieses doch einen Doppeladler auf der Brust; die Staatsgewalt tritt also in Gestalt des in den Niederlanden ungeliebten Habsburgerreiches auf. Auch die „Libertas" hat, wie Horst Bredekamp minutiös aufzeigt, ihren Charakter vollständig verändert. ${ }^{35}$ Bredekamp bemerkt zu Recht, dass dieses Bild eher vom Text ablenke als dass es diesen bekräftige: „Die erörter-

30 Hobbes, 1966, S. 539.

31 Höffe, 1979, S. 202.

32 Hobbes, 1966, S. 135.

33 Auf diesem Hintergrund erscheint mir deshalb auch Srinivas Aravamudans Einschätzung nicht ganz treffend: „There is no better explanation of why Hobbes, as the founder of modern political philosophy, needed to see America as terra nullius to be able to build an integrated defence of conquest and positive law using natural-law premises." Aravamudan, 2009, S. 70.

34 Hobbes, 1994, S. 73.

35 „Sie ist nicht mehr durch einen halbnackten Indianer, sondern durch eine züchtig bekleidete, sich der Religio zuwendende Frau repräsentiert, die mit der Rechten ein Szepter über die Schulter legt und mit der Linken einen niederländischen Bürgerhut, Gegenstück zum antiken pileum der Freiheit, hochhält, um ihn vom Halo bescheinen zu lassen." Bredekamp, 1999, S. 147. 
ten Abbildungen bilden keine Illustrationen, sondern Antipoden zum Text. "36 Es lassen sich nach Bredekamp indes keine Hinweise darauf finden, dass Hobbes gegen dieses Titelbild protestiert habe, was darauf hindeute, dass auch diese Version als gezielte Strategie verstanden werden kann, um so von Inhalten der Schrift abzulenken, die bei einem niederländischen Publikum hätten Anstoss erregen können, insbesondere einer negativen Darstellung der „Freiheit“.

In „De Cive“ beschreibt Hobbes die Freiheit als „die Abwesenheit von allem, was die Bewegung hindert". ${ }^{37}$ In der lateinischen Fassung heisst es: „Libertas, ut eam definiamus, nihil aliud est quam absentia impedimentorum motûs; ut aqua vase conclusa, ideò non est libera, qui vas impedimento est ne effluat, quae fracto vase liberatur. "38 Auf dem Frontispiz korrespondiert diese Definition mit dem abgebildeten Krug auf der linken Seite, doch zugleich lässt sich sagen, dass das abgebildete Dorf auf der rechten mit spitzen Palisaden gesichert ist, was die Bewegungsfreiheit auch im Zustand der „Libertas“ einschränkt und darauf verweist, dass hier auch den Indianern Grenzziehungen zugeschrieben werden. ${ }^{39}$

Es ist nicht bekannt, inwieweit Hobbes die Gestaltung des Titelblattes geprägt hat, obwohl dies durchaus wahrscheinlich erscheint, selbst wenn sich an gewissen Stellen ein Spannungsverhältnis zwischen Bild und Text ausmachen lässt. So wird beispielsweise eine gewisse Kritik am römischen Reich ersichtlich, wenn Hobbes in der Widmung an den Grafen Wilhelm von Devonshire in „De Cive“ kritisch fragt, ob das römische Volk nicht ein reissendes Tier gewesen sei, das beinahe den ganzen Erdkreis geplündert habe. ${ }^{40}$ Der Umstand, dass das gegenwärtige Imperium (das zugleich die Staatsherrschaft im allgemeinen symbolisiert) in der Tradition des römischen steht, wird hingegen auf dem Titelbild durch die römischen Schnürsandalen verdeutlicht, welche die Imperiumsstatue trägt. Allerdings war im antiken Rom die Freiheitskonzeption eine deutlich andere als bei Hobbes: „The Roman

36 Bredekamp, 1999, S. 153.

37 Hobbes, 1994, S. 170.

38 Hobbes und Warrender, 1983, S.167. „LIBERTY, that we may define it, is nothing else but an absence of the lets, and hinderances of motion, as water shut up in a vessell is therefore not a liberty, because the vessell hinders it from running out, which the vessell being broken, is made free."Hobbes, 2004, S. 41. Dazu auch Brett, 1997.

39 Nach Petrus Martyr von Anghiera beispielsweise lebten die Indianer in einem Goldenen Zeitalter ohne Gräben, Mauern und Zäunen und in Gärten ohne Grenzen. Zitiert nach Thumfart, 2010, S. 203.

40 Hobbes, 1994, S. 59. 
idea of liberty (libertas) was a civic right acquired under positive law; namely, it was a constituent of the membership of the civic body (citizenship). [...] Roman liberty was by definition a positive right that was guaranteed (but could also be withdrawn) by the law. " ${ }^{11}$ Hier stehen also Freiheit und Staat nicht im Gegensatz zueinander, sondern ermöglichen sich erst gegenseitig. Hobbes wiederum unterscheidet zwischen Freiheit im Naturzustand und Freiheit unter staatlichen Verhältnissen und beschreibt das zweite folgendermassen: „Aber auch hier hat ein Mensch um so grössere Freiheit, auf je mehr Bahnen er sich bewegen kann. Und hierhin besteht die bürgerliche Freiheit; denn kein Untertan oder Familiensohn oder Sklave wird durch die Strafen, welche ein noch so strenger Staat oder Vater oder Herr ihm auferlegt, gehindert, alles zu tun und von allen Mitteln, die zur Erhaltung des Lebens und der Gesundheit notwendig sind, Gebrauch zu machen. Ich wüsste also nicht, in welchem Punkte sich der Sklave beklagen könnte, dass ihm die Freiheit fehle; er müsste denn für ein Elend halten, dass er gehindert ist, sich selbst zu verletzen, und dass er das Leben, das er durch den Krieg oder ein unglückliches Geschick oder gar durch seine Trägheit verwirkt hatte, samt allem zur Ernährung Nötigen und allem zum Leben und der Gesundheit Erforderlichen unter der Bedingung zurückempfangen habe, dass er sich leiten lasse. " ${ }^{42}$ Der Unterschied zwischen einem Sklaven und einem Bürger liege darin, führt Hobbes seine Legitimation der Sklaverei weiter, dass der Freie nur dem Staate, der Sklave aber auch einem Mitbürger diene. „Jede andere Freiheit ist eine Befreiung von den Gesetzen des Staates und gebührt nur den Herrschern. " ${ }^{43}$ Auch in Bezug auf die Staatsform negiert Hobbes im „Leviathan“ unterschiedliche Freiheitsgrade: „Ob ein Staat monarchisch oder demokratisch ist - die Freiheit bleibt dieselbe." ${ }^{44}$ Ziel des Staates ist nach Hobbes bekanntlich nicht das Garantieren von Freiheit, sondern von Sicherheit.

Daniel Eggers weist in seiner sehr genauen Studie auf die Komplexität des Hobbes'schen Freiheitsbegriffes hin $^{45}$, und Roland Pennock meint zu Hobbbes' Definition der „Libertas“: „I would be inclined to argue that he is so inconsistent that it is impossible to construct a single, coherent argument and defend the proposition that it represents

41 Shogimen, 2005, S. 1272.

42 Hobbes, 1994, S. 170-171.

43 Hobbes, 1994.

44 Hobbes, 1966, S. 167.

45 Eggers, 2008, S. 128. Siehe auch Mezzadra, 1998. 
the real Hobbes.“ ${ }^{6}$ Wie Hobbes’ Ausführungen zur „Freiheit“ zu verschiedenen Auslegungen Anlass geben, so ist dies auch in Bezug auf Lockes Passagen zur Sklaverei der Fall: Er rechtfertigt einerseits die Versklavung von Gegnern als Folge eines gerechten Krieges und kritisiert andererseits die Vererbbarkeit des Sklavenstatus. Zudem delegitimiert er den Absolutismus mit der Metapher der Sklaverei, so dass auf seine Schriften auch von Abolitionisten zurückgegriffen wurde: „Locke has written himself into the institutions of both slavery and abolition“, meint Wayne Glausser dazu. ${ }^{47}$

\section{Politische Theorie und postkoloniale Perspektiven}

Charles W. Mills deutet Hobbes' ambivalente Ausführungen zur „Libertas" und zum Naturzustand in die Richtung, dass der wörtliche $\mathrm{Na}$ turzustand für Nichtweisse reserviert sei, während für Weisse der Naturzustand nur hypothetisch vorhanden sei. ${ }^{48}$ Mills sieht deshalb den Naturzustand „as a nonwhite figure“. Dagegen hält Tommy L. Lott fest, dass die Gegenüberstellung von „wild“ und „zivilisiert“ bei Hobbes nicht grundsätzlich rassisch gedacht sei. ${ }^{49}$ Ich folge Lotts Sichtweise, betont doch Hobbes an mehreren Stellen, dass einst auch europäische Völker ohne Staatsgewalt gelebt hätten. ${ }^{50}$ Ein weiteres Argument von Mills lautet, das imperiale Projekt Grossbritanniens sei Mitte des 17. Jahrhunderts noch nicht in der Weise ausgebildet gewesen, „that the intellectual apparatus of racial subordination had been completely elaborated." 51 Auch wenn diese Differenz nicht in rassischen Kategorien formuliert werden sollte, wird ein unterschiedlicher Referenzrahmen deutlich, wenn man Hobbes' Argumentation mit jener des 44 Jahre jüngeren John Locke in seiner Schrift "Zwei Abhandlungen über die Regierung“ von 1690 vergleicht. „By the time the Treatises ap-

46 Pennock, 1965, S. 101.

47 Glausser, 1990, S. 215.

48 Mills, 1997, S. 66. Wie diese Imaginationen des Naturzustands aus einer postkolonialen Perspektive befragbar werden, untersucht auch Patricia Purtschert in ihrem Projekt: „Beyond the State of Nature: Gender, Culture, and the Constitution of European Modernity“. Zu einer postkolonialen Perspektive auf die politische Theorie siehe Persram, 2007. Exemplarisch auch Buck-Morss, 2009. Siehe auch Cole, 2000, S. 198-202.

49 Lott, 2002, S. 72.

50 Dazu auch Skinner, 2008, S. 98.

51 Mills, 1997, S. 66. 
peared, English colonization efforts were in full swing", schreibt Mark Michael. ${ }^{52}$ Locke denkt demnach in einer kolonialen Logik, weigert sich aber, die daraus resultierenden Konsequenzen - die im Gesellschaftsvertrag postulierte Erschaffung von friedlichen und gewaltlosen Verhältnissen in Europa auf Kosten der Bevölkerung in den europäischen Kolonien - zu denken. ${ }^{53}$

\section{Fazit}

Postkoloniale Ansätze interessieren sich dafür, wie Kolonialherrschaft nicht nur durch physische und ökonomische Gewaltanwendung etabliert, sondern vor allem auch durch Kultur- und Konsensproduktion legitimiert wird. ${ }^{54}$ Für eine postkoloniale Perspektive ist demnach der Gesellschaftsvertrag, dessen Funktion es ja gerade ist, Herrschaft zu legitimieren, ein prädestiniertes Untersuchungsfeld. Die politische Theorie gegen den Strich beziehungsweise von ihrer Peripherie her zu lesen, um diese auf ihren kolonialen Gehalt hin zu befragen, war hier das Ziel. ${ }^{55}$ Beide, Hobbes wie Locke, beteiligten sich an kolonialen Geschäften; ${ }^{56}$ Locke geht in seiner Rechtfertigung kolonialer Landnahme weiter als Hobbes, ${ }^{57}$ selbst wenn sich bereits in der Hobbes'schen Argumentation eine Verteidigung der europäischen Kolonisierung fin$\operatorname{det}^{58}$ und sich in den beiden Argumentationen auch deutliche Parallelen zeigen. Doch gerade im Vergleich der Vorstellungen eines leeren Raumes werden interessante Unterschiede deutlich. Für Thomas Hobbes sind die amerikanischen Indianer eine Vergegenwärtigung des $\mathrm{Na}-$ turzustands. Auch für John Locke stellt Amerika „ein Muster für die frühesten Zeiten in Asien und Europa“ dar, „als das Land zu wenige Einwohner hatte und der Mangel an Bevölkerung und Geld die Menschen nicht in Versuchung führte, ihren Landbesitz zu vergrössern oder

52 Michael, 1998, S. 408.

53 Dazu auch Schmitt, 1997.

54 Paradigmatisch dazu Said, 2003.

55 Die Stimmen von afrikanischen, arabischen, südamerikanischen oder asiatischen Philosophinnen und Philosophen systematisch in die Argumentation einzubeziehen, wäre unbestritten sehr wichtig, konnte hier aber nicht geleistet werden.

56 Dazu beispielsweise Bernasconi und Maaza Mann, 2005, S.89. Aravamudan, 2009. - Arneil, 1996. - Malcolm, 2002a. Aravamudan, 2009. Hobbes war zwischen 1622 und 1642 an den Geschäften der Virginia Company beteiligt.

57 Arneil, 1996. - Lebovics, 1986, S. 567. Siehe dazu auch Banner, 2005, S. 46. - Ivison, 2003, S. 101. - Farr, 2008. Mills, 1997, S. 68. Bauböck, 2008.

58 Dazu auch Walzer, 1998, S. 85. 
um eine weitere Ausdehnung ihres Gebietes zu kämpfen“, weshalb für ihn „die Könige der Indianer kaum mehr sind als die Anführer ihrer Heere. Und obwohl sie im Kriege die absolute Befehlsgewalt haben, so üben sie zu Hause und in den Zeiten des Friedens doch eine sehr unbedeutende Herrschaft aus und verfügen nur über eine sehr beschränkte Souveränität. " ${ }^{59}$ Vor allem aber imaginiert Locke Amerika als leeres Land.

Gegenüber der Vorstellung eines leeren Raumes verhält sich Hobbes skeptischer als Locke, wohingegen Locke den leeren Raum als faktisch gegeben und normativ notwendig voraussetzt. Hobbes wie Locke gehen indes beide von einem Expansionsdrang aus. Bei Hobbes wird dieser Expansionsdrang als anthropologische Konstante gesetzt, bei Locke hingegen als Folge der Geldwirtschaft entwickelt. Beides jedoch führt zu einer territorialen Knappheit.

Wenn aber der Raum begrenzt ist und Gesellschaften auf eine territoriale Fundierung nicht verzichten können, verkleinern sich mit jedem realisierten Gesellschaftsvertrag die Möglichkeiten, eine neue Gesellschaft zu gründen, bis schliesslich Neugründungen gänzlich unmöglich werden. Unter dieser Voraussetzung zeigt jeder Gesellschaftsvertrag Auswirkungen sowohl auf die in den Vertrag Ein- als auch auf die Ausgeschlossenen, was für Hobbes nicht zwingend ein Problem darstellt, aber für Locke. Für die im Vertrag „Eingeschlossenen“ ist nach Lockes Logik keine Legitimität des Gesellschaftsvertrages gegeben, wenn die Austrittsmöglichkeit faktisch nicht gegeben ist, weil sie beispielsweise kein Land finden, in welches sie „auswandern“ können.

Hier zeigt sich die koloniale Begründungslogik, denn unter imperialen Verhältnissen ist diese Exit-Option immer gegeben. Gerade weil innerhalb der europäischen Staaten gewaltfreie Verhältnisse postuliert werden, wird in Lockes politischer Theorie eine Rechtfertigung des Kolonialismus notwendig, was auf die inhärenten Ambivalenzen beziehungsweise Aporien der "Aufklärung“ verweist. Bei Hobbes muss hingegen die Gewalt des Gesellschaftsvertrages nicht unsichtbar gemacht werden, deshalb ist er auf die Locke'sche Prämisse des normativ notwendigen und faktisch vorhandenen leeren Raumes weniger angewiesen.

Lockes Schrift trägt nicht zufälligerweise kein Titelbild; der „Liberalismus" inszeniert sich gerne als ikonoklastisch. ${ }^{60}$ Bei John Locke bleibt deshalb die koloniale Grundierung in visueller Weise unsichtbar,

59 Locke, 1977, S. 268.

60 Allerdings ist Lockes Sprache sehr bildmächtig. Dazu auch Bredekamp, 2003, S. 152. Brandt, 1982, S. 213. 
sie strukturiert dennoch in grundsätzlicher Weise dessen Argumentation und führt damit den liberalen Gesellschaftsvertrag in Aporien. Bemerkenswert ist, dass bei „De Cive“ die Naturzustandsimagination mit dem Kannibalismus der Indianer visuell verdeutlicht wird, ${ }^{61}$ während auf dem Frontispiz des später publizierten „Leviathan“ der Naturzustand mit den Soldaten und den Schnabelmasken nur andeutungsweise ins Bild gesetzt wird.

Auch wurden in Bezug auf den Hobbes'schen Naturzustand nicht die amerikanischen Indianer weltbekannt, sondern dessen in seiner Widmung von „De Cive“ geäussertes und übrigens von Plautus inspiriertes Diktum: „homo homini lupus“. Hier heisst es wörtlich: „Nun sind sicher beide Sätze wahr: Der Mensch ist ein Gott für den Menschen, und: Der Mensch ist ein Wolf für den Menschen; jener, wenn man die Bürger untereinander, dieser, wenn man die Staaten untereinander vergleicht. " ${ }^{2}$ Mit der Metaphorik des Wölfischen wird hier u.a. charakterisiert, dass sich die souveränen Staaten nach Hobbes in einem permanenten Kriegszustand befinden, denn nach Hobbes überlebt die Gewaltsamkeit des Naturzustands in der souveränen Gewalt. ${ }^{63}$ Der Naturzustand wird demnach nicht nur historisch gedacht, was daran ersichtlich ist, dass er zwischen den Staaten stets präsent bleibt. ${ }^{64}$

Auf dem Titelbild des „Leviathan“, das zu einer Ikone der politischen Philosophie wurde, bleibt dieser koloniale Referenzrahmen - der viel mit den Logiken gegenwärtiger Migrationen zu tun hat - unsichtbar, oder zumindest: fast, wie wir im nächsten Kapitel sehen werden.

Eher implizit denn explizit aufgerufen und nicht beantwortet wurde schliesslich die Frage, was die Ansicht, „illegale Migration“ sei als Angriff auf die staatliche Souveränität zu verstehen, mit Hobbes - dem Vater $^{65}$ der Souveränität - zu tun habe. ${ }^{66}$

61 Interessant ist, dass auch bei Horst Bredekamp dieses Bild (das Frontispiz von „De Cive") gewissermassen verdrängt wird: In seiner ersten Publikation zum Frontispiz des „Leviathan“ ist davon sehr ausführlich und genau die Rede, in der überarbeiteten Auflage verschwinden diese Ausführungen. Siehe Bredekamp, 1999. - Bredekamp, 2003.

62 Hobbes, 1994, S. 59.

63 Agamben, 2002, S. 46.

64 König, 1992, S.29-32.

65 Jean Bodin müsste dementsprechend als Grossvater der Souveränität wahrgenommen werden.

66 Siehe dazu auch das Kaptiel „Ein Recht auf Migration“. 
Urheberrechtlich geschütztes Material! @ 2011 Wilhelm Fink Verlag,

Paderborn, ein Imprint der Brill-Gruppe 


\section{SCHNABELMASKEN: SANITÄT, SOUVERÄNITÄT, SELEKTION ${ }^{1}$}

„das Gewesene mit dem Jetzt blitzhaft zu einer

Konstellation zusammentritt ${ }^{\text {“2 }}$

Dieses Bild des „Leviathan“ hat im Laufe der Geschichte zahlreiche Denkräume produziert - und ist zugleich ein Produkt derselben. Ein Bild, welches die Betrachter bannt und das politische Denken bahnt. Ein Bild aber auch, welches auf einigen Buchausgaben nicht zu finden ist $^{3}$ und das erst im Zusammenwirken von Text und Bild zu einer Ikone wurde. Über eine biopolitische Lektüre und die Rekonstruktion ihres Kontextes rücken, wie wir sehen werden, der koloniale Referenzrahmen und die Gewalt der Grenze auch auf diesem Frontispiz ins Bild.

Diese Ikone der politischen Philosophie soll, so Horst Bredekamp, wahrscheinlich vom Pariser Künstler Abraham Bosse stammen (Bild 5). Es zeigt einen die Landschaft überragenden Riesen, dessen Oberkörper aus lauter Menschen zusammengesetzt ist. Die versammelten Menschen - es sind auch einige Frauen dabei - richten ihren Blick auf den Kopf des Kolosses. Der Gigant wiederum erwidert den Blick der Bildbetrachter. Dieser Riese ist der „Leviathan“, die höchste Entscheidungsgewalt im Lande. In der Inskription heisst es in Anspielung an das biblische Ungeheuer: „Non est potestas super terram quae comparetur ei“, es gibt keine Macht auf Erden, die sich mit seiner vergleichen liesse. ${ }^{4}$ Doch es sind die Menschen, die diesem sterblichen Gott Subs-

1 Dieses Kapitel wird als umgearbeiteter Beitrag in „Leviathan. Berliner Zeitschrift für Sozialwissenschaft" erscheinen.

2 Benjamin, 1983, Bd. I, S. 576-577. Zu Benjamins Geschichtsthesen siehe von Müller und von Ungern-Sternberg, 2004.

3 So beispielsweise in der Suhrkamp Taschenbuchausgabe Hobbes, 1966. Achatz von Müller bezeichnet Werke, die zugleich Text und Bild sind, als Figurationen. Zum Begriff der Figuration insbesondere in Bezug auf die politische Theorie siehe auch Balke, 2009.

4 Zum Bibelzitat siehe auch Matala de Mazza, 1999, S. 75. 


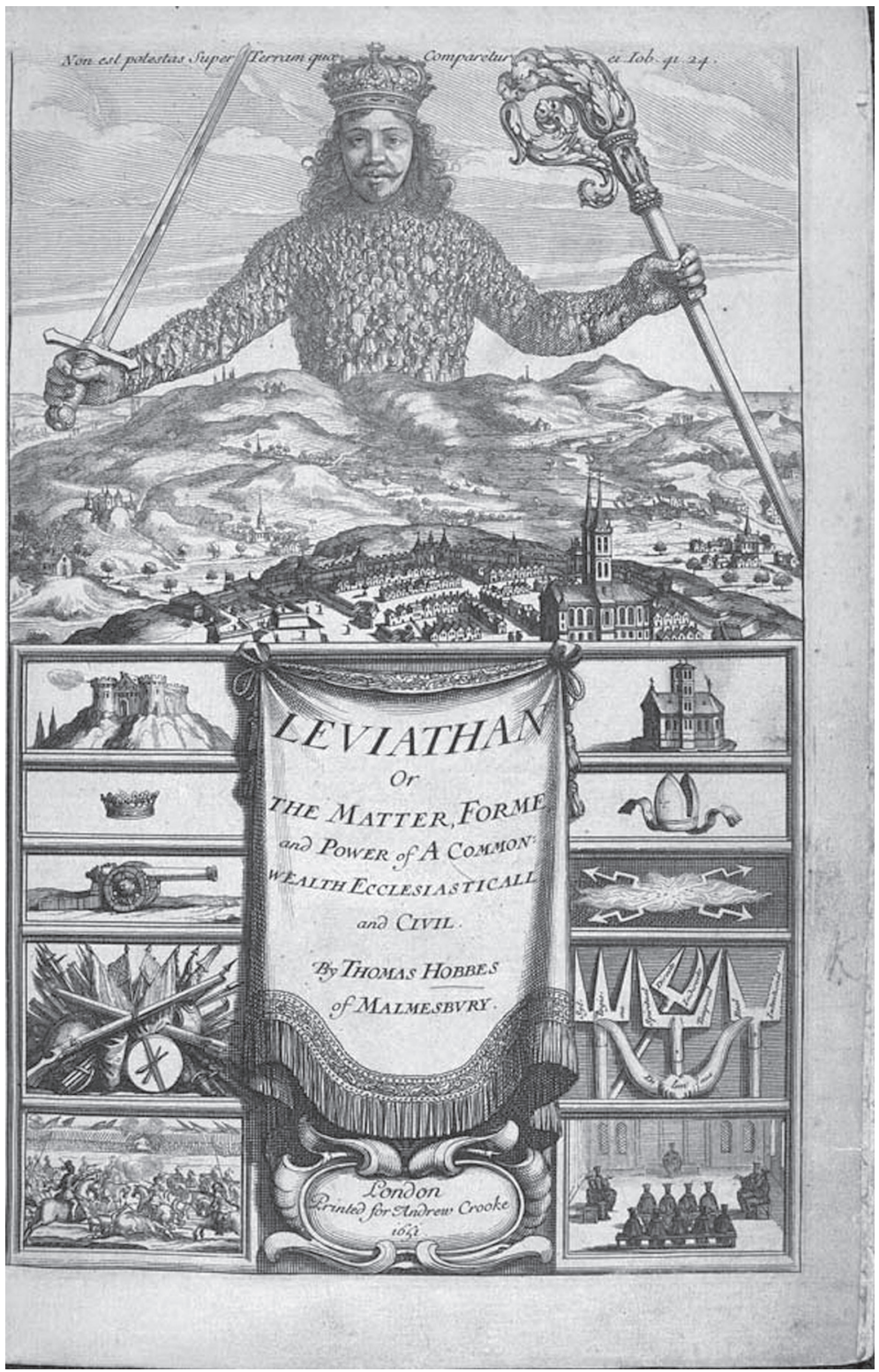

Bild 5: Abraham Bosse: Frontispiz des „Leviathan“, 1651 Britisch Library 
tanz verschaffen. ${ }^{5}$ Die Quelle der politischen Autorität ist nicht die natürliche Überlegenheit des Souveräns oder der Wille Gottes, sondern die Zustimmung der Herrschaftsunterworfenen. Wenn das Naturzustandsindividuum sich selbst erhalten will, ist es für den Einzelnen rational, durch Vertrag ${ }^{6}$ einer Staatserrichtung, d.h. der Etablierung eines Gewaltmonopols, zuzustimmen; damit wird der Krieg aller gegen alle beendet. Während der Naturzustand, wie bereits gezeigt wurde, nach Hobbes nicht als ein rein ahistorisches Argument gesehen werden kann, ist der Augenblick der Vertragsschliessung eher als ein Gedankenexperiment denn im Sinne eines geschichtlichen Vorgangs zu verstehen. Gerade das Titelbild verwandelt dieses hypothetische Konstrukt jedoch sozusagen in ein historisches Ereignis, wodurch es, wie Helmut König treffend bemerkt, anschaulich gemacht und im Gedächtnis der Betrachter verankert wird. ${ }^{7}$ Die Faszination des imposanten Bildes liegt im Umstand begründet, dass darin die Übermacht des Souveräns wie auch das Moment der Übereinkunft der Staatsangehörigen, potenzieller Zwang wie Zustimmung gesehen werden können. Der Souverän, so Hobbes, ist dabei nicht eine vertragsabschliessende Partei, sondern der durch den Vertrag eingesetzte Dritte. ${ }^{8}$ Der Kopf des „Leviathan“, der wie eine Sonne am Himmel ragt, ist nicht mit Menschen ausgefüllt: Die Menschen haben sich aus eigener Entscheidung im „Leviathan“ versammelt, dennoch kontrollieren sie ihn nicht. Jeder hat sich mit jedem verpflichtet, dem Willen des Souveräns, dem er sich untergeordnet hat, keinen Widerstand zu leisten. ${ }^{9}$ Das Frontispiz führt uns die Beziehung zwischen Schutz und Gehorsam vor Augen: Als Gegenleistung für Gehorsamkeit liefert der „Leviathan“ Schutz. Dieser Schutz ist indes nicht nur militärisch gedacht, sondern ebenfalls sozial.

5 Philip Manow interpretiert den „Leviathan“ als Parlamentsverkörperung. Manow, 2008, S. 42. Allerdings wird bei dieser Interpretation Hobbes' kritische Sicht auf das Parlament unterschlagen. Dazu König, 1992, S. 41.

6 Hobbes spricht wie gesagt in Bezug auf „Vertrag“ allerdings häufiger von covenant, der sich auch auf den Bund mit Gott beziehen lässt, als von contract, in dem die ökonomische Sphäre stärker präsent ist.

7 König, 2008, S. 332.

8 Hobbes, 1966, S. 137.

9 Hobbes, 1966, S.248. Der Souverän hat also keine Verträge mit den Subjekten geschlossen; er könnte dies gar nicht, denn dann müsste eine höhere Instanz Richterin über die Einhaltung der Verträge sein, dies würde aber zu einem unendlichen Regress führen. Die Absetzung des Souveräns ist wiederum gleichbedeutend mit der Auflösung des politischen Körpers; der Rückfall in einen vorstaatlichen $\mathrm{Zu}$ stand droht. Münkler, 2001. 


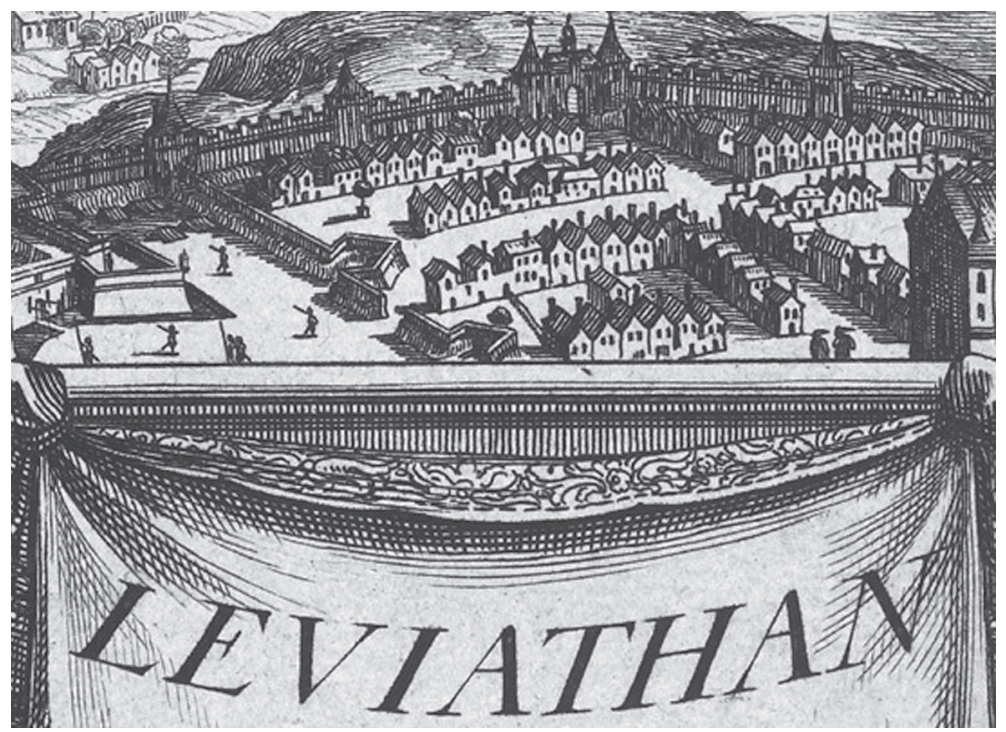

Bild 6: Detailaufnahme „Leviathan“, 1651 Britisch Library 
Der Schutz des „Leviathan“ weist noch eine weitere Dimension auf. Damit wir diese sehen können, müssen wir uns näher ans Bild heranwagen. Mich interessieren dabei vor allem die beiden Figuren der Seuchenärzte (Bild 6) ${ }^{10}$ Deren Schnabelmasken sind zumindest zeitweise im wörtlichen wie metaphorischen Sinn aus dem Bild gefallen. Im holländischen Frontispiz von 1667 und in der Ausgabe von $1750^{11}$ beispielsweise stellen die Gestalten vor der Kirche nicht mehr Seuchenärzte, sondern Besucher dar (Bild 7). ${ }^{12}$ Im Folgenden werde ich indes nicht danach fragen, weshalb diese Seuchenärzte in einigen Ausgaben nicht vorhanden sind, sondern weshalb sie auf dem Frontispiz von 1651 überhaupt auftauchen, zwar als unscheinbares Detail, ${ }^{13}$ als etwas, das da, aber kaum sichtbar ist, sich dem Blick entzieht und erst jenen Betrachtern auffällt, die das Bild sezieren. Die Seuchenärzte befinden sich am äussersten Rand des oberen Bildabschnittes, auf der Grenze des gerade noch Sichtbaren und über jenem Vorhang stehend, der nach Carl Schmitt andeutet, „dass hier nicht nur viel gesagt, sondern ausserdem auch einiges verborgen ist ". ${ }^{14}$ Schmitt fügte jedoch seiner mit antisemitischen Untertönen versehenen „Leviathan“-Publikation von 1938 das erwähnte Frontispiz von 1750 bei; hier fehlen die Seuchenärzte. ${ }^{15}$

Die Schnabelmasken sind nicht nur aus dem Bild herausgefallen, sondern auch aus den Bildanalysen. Horst Bredekamp beispielsweise erwähnt die Schnabelmasken, entwickelt aber daraus kein eigenes Argument. ${ }^{16}$ Reinhard Brandt wiederum hat die in der Stadt dargestellten Menschen als Bürger interpretiert. Er schreibt: „Historisch pointiert

10 Auf der französischen Version von 1651 finden wir ebenfalls die Pestärzte, wie mir Marianne Pieper (Warburg-Haus) freundlichst mitteilte.

11 Dieses wurde allerdings auch mit der Jahreszahl 1651 beschriftet.

12 Es bestehen noch weitere Unterschiede zwischen den verschiedenen TitelblattVersionen. So hat sich 1750 die Zahl der Soldaten halbiert, was darauf hindeutet, dass die Bedrohungssituation „heruntergefahren“ wurde. Weiter wird der Souverän als ein gerahmter gezeigt, sein Schwert ist kürzer und seine Krone durchstösst nicht mehr das Bibelzitat, was die imposante Wirkung des „Leviathan“ schmälert und damit dem Text entgegenläuft. Dazu auch Bredekamp, 2003, S. 27.

13 Zum Detail bei Warburg siehe Jussen, 2000. Zur Interpretation des Details sind in letzter Zeit einige Publikationen erschienen, siehe beispielsweise Futscher, 2007. - Schäffner, 2003. Arasse, 1992. Klassisch dazu ist auch die Studie von Ginzburg, 1995. Ginzburg zeigt, wie sich das Indizienparadigma gegen Ende des 19. Jahrhunderts als gemeinsames epistemologisches Modell in verschiedenen Wissenschaften artikulierte, und zwar inspiriert durch die Medizin.

14 Schmitt, 2003, S. 151.

15 Schmitt, 1938, S. 27. Zu Carl Schmitts Bildgebrauch siehe Bredekamp, 2009.

16 Bredekamp, 2003, S. 27. 


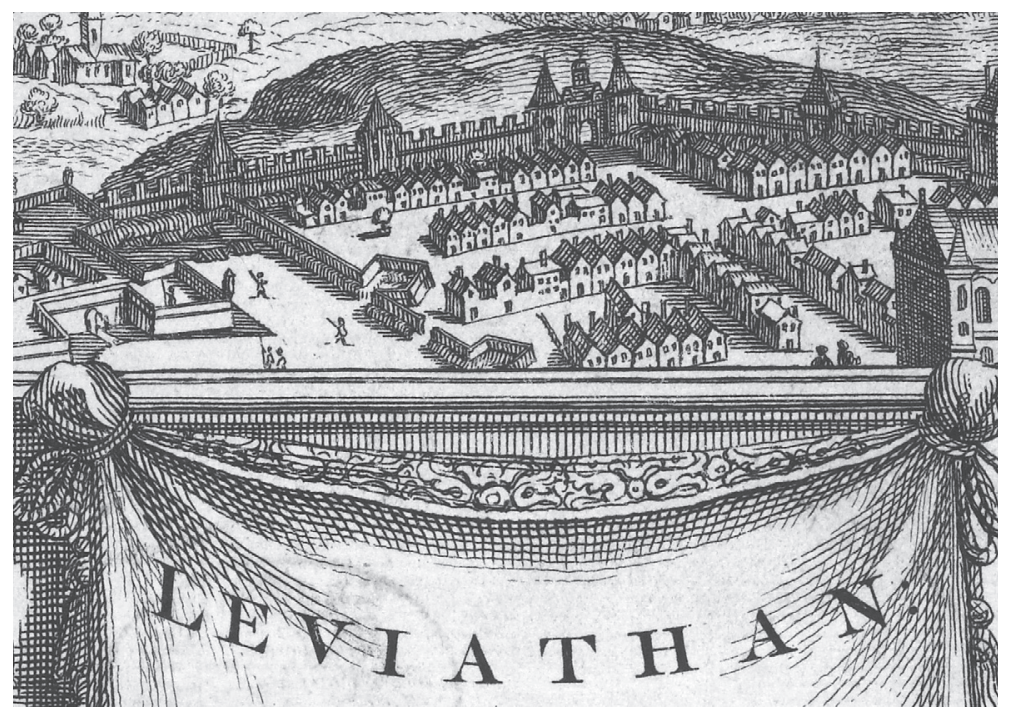

Bild 7: Detailaufnahme Frontispiz des „Leviathan“, 1750 Britisch Library 
könnte man von einer Zäsur zwischen Bourgeois und Citoyen sprechen: es werden die Menschen in ihrer privat-gesellschaftlichen Tätigkeit von der Person im Staat getrennt. "17 Die staatliche Funktion der Seuchenärzte und damit ebenso die Schnabelmasken fallen hier aus dem Blick. Carlo Ginzburg, der auf den Zusammenhang von Sanität und Souveränität bei Hobbes in einem aufschlussreichen Artikel aufmerksam macht, erwähnt ebenfalls nicht die Schnabelmasken, die sein Argument stützen würden. ${ }^{18}$

Erstaunlich ist jedoch, dass ein so winziges Detail wie die beiden dreimillimetergrossen Schnabelmasken auf dem Frontispiz von 1651 bei genauem Hinsehen klar erkennbar ist. Die Schnabelmaske besitzt eine sehr auffällige Form, ja sie ist im Laufe der Geschichte selbst gewissermassen zur Ikone geworden. Wieso aber sieht das Kostüm des Pestdoktors so eigentümlich aus? Schauen wir uns dessen Entstehung etwas genauer an.

Der Anzug des Seuchenarztes bestand aus einem Mantel aus luftundurchlässigem Material, Schutzhandschuhen, einer Kopfbedeckung und einer Maske mit Augenschutz und schnabelartiger Nase, die manchmal vor der Pest schützende Räucherstoffe enthielt. ${ }^{19}$ Diese Duftstoffe konnten tatsächlich auch Flöhe fernhalten. ${ }^{20}$ Um 1651 - als das Frontispiz entstand - war das Pestkostüm in dieser Form noch recht neu. ${ }^{21}$ Der spätere Leibarzt von Ludwig dem XIV., Charles de l'Orme, soll sich 1619 beim Ausbruch der Pest in Paris als einer der ersten ein solches Pestkostüm angefertigt haben. ${ }^{22}$ Offenbar hat sich das Pestkleid von Frankreich aus erfolgreich in andere Länder ausgebreitet. ${ }^{23}$ Es weist dabei eine apotropäische Dimension auf; die Schna-

17 Brandt, 2000, S. 318.

18 Ginzburg, 2008.

19 Ulbricht, 2005.

20 Die Schnabelform steht vielleicht auch in einem Zusammenhang mit der den Vögeln zugeschriebene Immunität gegen die Pest.

21 Bemerkenswerterweise habe ich kein Bild eines so gekleideten Seuchenarztes gefunden, welches vor 1651 datiert. Andererseits findet sich dieses Frontispiz, soweit ich gesehen habe, auch nicht in medizinischen Bilddatenbanken, siehe beispielsweise auf medphoto.wellcome.ac.uk (März 2007).

Leprakranke mussten sich übrigens durch Ton (Glocke oder Signalhorn) und Farbe markieren, dazu Riha, 2007, S. 408.

22 Broquet, 1911, S. 11. Brossollet, 1979, S. 64.

23 „In dieser schlechten Grippe war die Stadt Lucca die erste, die, den Gebrauch der französischen Ärzte nachahmend, verordnete, dass sich die Ärzte mit einem langen Wachstuch zu bekleiden hätten; mit einer Kapuze über dem Kopf und Kristallen vor den Augen, eilten sie so den Infizierten zur Hilfe." Salzmann, 1932, S. 11. Übersetzung aus dem Italienischen durch die Autorin 
belmaske soll die Pest selbst erschrecken. Dieses Kostüm kennt jedoch viele Vorformen, wobei sich die dahinter stehenden Ansteckungs- und Miasmentheorien nicht scharf voneinander trennen lassen. Die Schnabelmaske beispielsweise verweist auf die Angst, dass die Pest über die Luft übertragen wie durch giftige Dämpfe ausgelöst werden könne. ${ }^{24}$ Das Kostüm des Seuchenarztes bewirkt zwei Dinge: Es macht die Funktion des Pestdoktors sichtbar und gleichzeitig seine Person unerkennbar. Der Pestarzt ist in seiner meist dunklen Montur und mit dem weissen Stock $^{25}$ von weitem identifizierbar, doch bleibt sein Gesicht hinter der Maske verborgen.

Eine der zumindest im deutschsprachigen Raum bekanntesten Pestarztdarstellungen ist heute der Kupferstich „Der Doctor Schnabel von Rom" (1656) des Kunsthändlers und Verlegers Paulus Fürst (nach I. Columbina) (Bild 8). Akzentuiert wird die Schnabelmaske durch die Worttrennung im Titel. Die beflügelte Sanduhr verkörpert Vergänglichkeit: tempus fugit. Die deutsch-lateinischen Verse erzeugen eine satirische Wirkung; der Pestdoktor erscheint hier vor allem als geldgieriger Kinderschreck. Pestärzte gingen ein hohes Risiko ein, weshalb nicht nur gutes Geld (wie in den Versen evoziert wird), sondern des Öfteren auch ein freies Bürgerrecht lockte. Der Doctor Schnabel von Rom ist einige Jahre nach dem Frontispiz entstanden. Schnabelmasken tauchen auch im venezianischen Karneval auf. Es stellt sich hier auch die Frage, ob hier auch ein Bezug vorhanden ist zum Klischee der (tropfenden) Judennase, das schon früher (spätestens ab dem 13. Jahrhundert) auftaucht. ${ }^{26}$

24 Zuerst etabliert sich die Idee, dass gewisse Stoffe wie Seide für den Pestarzt besonders geeignet seien, da die krankheitsbringende Luft daran weniger hafte, dazu Bazin, 1971, S. 84. Aus dem 15. Jahrhundert finden sich erste Darstellungen, wo sich der Arzt zum Schutz vor der Krankheit einen Schwamm oder ein Tuch unter oder vor die Nase hält. So beispielsweise im „Consilium pro peste evitanda“ von Pietro Tossignano, der Holzstich wird Gentile Bellini zugeschrieben. Diese Schrift wurde 1480 von Johannes Ketham im „Fasciculus Medicinae“ zusammengestellt. Tossignano, Medizinprofessor aus Bologna, spricht in seinem Traktat von Ansteckung und rät zur Flucht, er sieht aber auch astrologische und klimatische Gründe, die zum Ausbruch der Pest führen. Zudem soll zur Pestprävention während des Tages nicht geschlafen werden, hier wird also ein Moment der Disziplinierung sichtbar. De Ketham, 1925. Siehe auch Salzmann, 1932, S.7.

25 Besteht hier auch ein Bezug zum weissen Blindenstock?

26 Im venezianischen Karneval waren auch Judennasen ein beliebtes Motiv. Bekanntlich wurden Juden, die in Venedig im Ghetto lebten, immer wieder für Pestausbrüche verantwortlich gemacht. Weist die Schnabelmaske des Pestarztes, die ja die Krankheitsübertragung verhindern soll, auch einen Bezug zum Klischee der früher erscheinenden (tropfenden) Judennase auf, die spätestens ab dem 13. Jahrhundert 


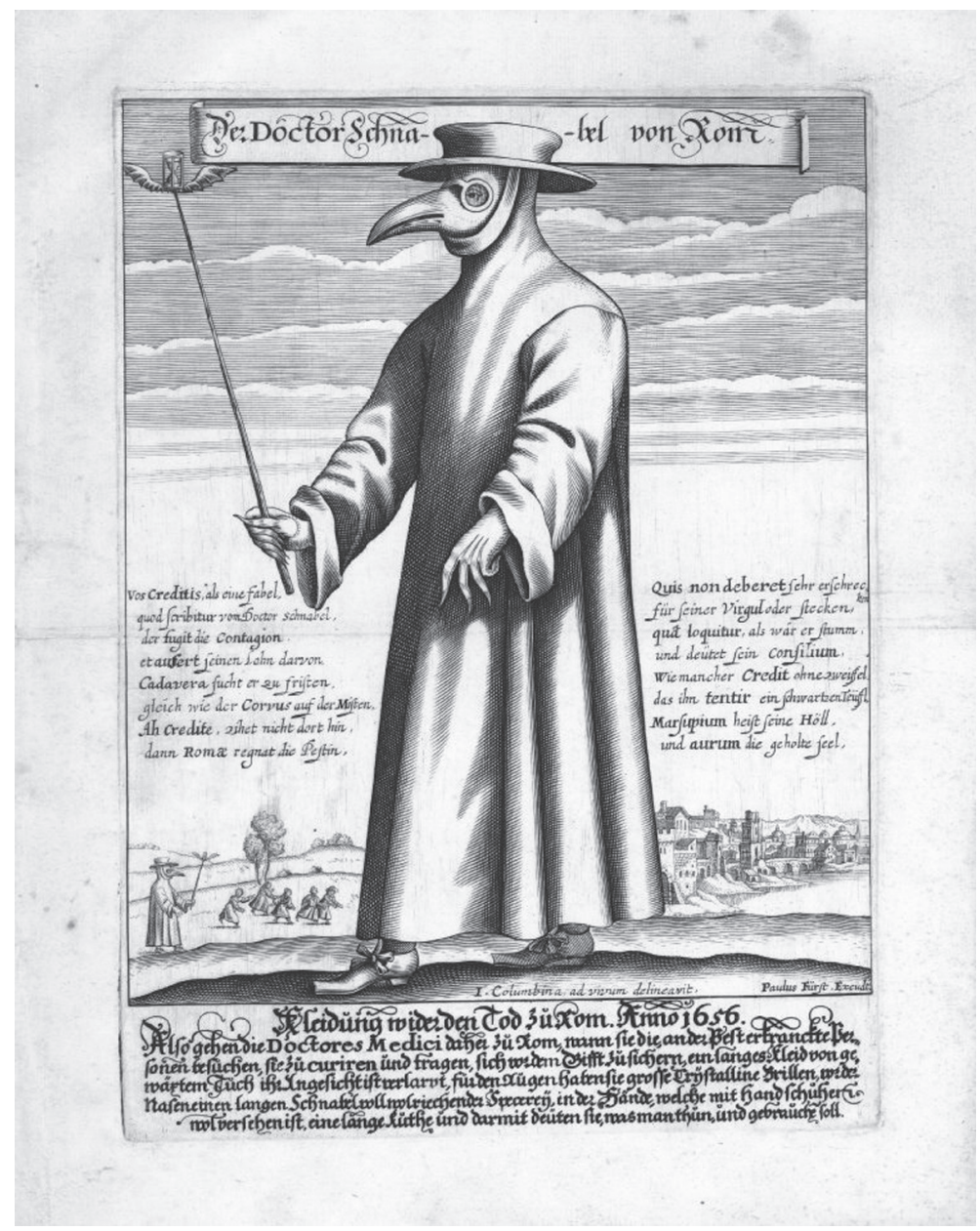

Bild 8: Paulus Fürst nach I. Columbina:

„Der Doctor Schnabel von Rom“, 1656 
Bereits die griechische Theatermaske sollte zeigen, dass der Ausdruck der Theaterfigur vom Ausdruck des Schauspielers unabhängig gemacht werden kann. Dies entspricht in gewisser Weise der Differenz zwischen Amt und Amtsinhaber beziehungsweise Funktion und Person, wie sie Ernst Kantorowicz in seiner klassischen, aber nicht unumstrittenen Studie zu den zwei Körpern des Königs formulierte. ${ }^{27}$

In Zeiten des „Ausnahmezustandes“ wurde eine Verhüllung oft als Gefahr wahrgenommen. ${ }^{28}$ So wurde in Italien im 16 . Jahrhundert das Tragen von Karnevalsmasken in Zeiten der Pest mit dem Argument kritisiert, dadurch könne sich der Kranke ungesehen unter die Gesunden mischen. ${ }^{29}$ Der Karneval dient der Selbstrepräsentation einer Gesellschaft in ihren Grenzen; in der ritualisierten Ausgelassenheit und Entgrenzung wird die gesellschaftliche Ordnung scheinbar auf den Kopf gestellt und dennoch gleichzeitig bekräftigt. Der Karneval selbst kann dabei als ein lebendiges, ephemeres Bild der „begrenzten Entgrenzung" begriffen werden.

\section{Souveränität und Sanität}

Das Frontispiz betont die kompakte Ganzheit und Abgeschlossenheit des Staatskörpers, denn „nur im Bild und nirgendwo sonst kann das Ganze des modernen Staats unmittelbar zur Anschauung kommen“. ${ }^{30}$ Die Schnabelmasken unterlaufen aber gerade diese bildliche Suggesti-

auftaucht? Prominente Nasenformen sind sllerdings auch bei anderen Masken zu beobachten, zudem bezeugt eine visuelle Verwandtschaft nicht zwingend eine geteilte Geschichte. So ist äusserliche Ähnlichkeit einer japanischen Pestuniform von 1910 und einer Schnabelmaske aus einem venezianischen Lazarett aus dem 14. Jahrhundert insofern auch irreführend, als das, was dazwischen liegt, dabei vielleicht zu leicht vergessen wird, so beispielsweise die entdeckte Ausbreitung über den Rattenfloh und die Isolierung des Pesterregers, was während der Pestpandemie der 1890er Jahre möglich wurde. Ein wesentlicher Unterschied besteht schliesslich weiter darin, dass sich in der Maske von 1910 der symbolbeladene Schnabel nicht mehr findet. Dazu Padoan Urban, 1986. Siehe auch Blumenkranz, 1965, S. 25. Mellinkoff, 1999, S. 24. Schreckenberg, 1996.

27 Kantorowicz, 1992. Weiter ist der Begriff der Person, der ja unter anderem auf die Maske des Schauspielers (persona) zurückgeführt wird, insofern beachtenswert, als Hobbes den Staat als „persona ficta“ denkt.

28 Von Müller, 1984, S. 126-132.

29 Bazin, 1971, S.76. Im Schweizer Sarganserland war im Zweiten Weltkrieg während der Fastnacht das Tragen von Masken verboten, siehe Gassner, 2008.

30 König, 2008, S.328. Allerdings kann es sich meiner Meinung nach hierbei auch um metaphorische Bilder handeln. 
on einer totalen Inklusion. Sie erinnern an Selektionen und Exklusionen und sie bringen den Zusammenhang von Seuche, Sanität und Souveränität ins Bild.

Mit der Pestpolitik etablierten sich neue städtische bzw. staatliche Strukturen; George Rosen postuliert eine Parallele zwischen PublicHealth-Massnahmen und the "great Leviathan, the modern state, whose outlines slowly appear out of the storm sea of politics like a whale coming to the surface "31. Die Stadt diente dabei als Vorbild für den Staat. ${ }^{32}$ So entstanden neue Formen von Grenzkontrollen: Erinnert sei hier an das Aufkommen von Quarantänemassnahmen ab dem 14. Jahrhundert, welche jedoch nicht eine hermetische Abriegelung zum Ziel hatten, sondern vielmehr als Membrane wirken sollten, die den Handel nicht blockieren, sondern sicher zu ermöglichen hatten. ${ }^{33}$ Auch die Entstehung des Passes lässt sich u. a. auf die in Pestzeiten ab dem 15. Jahrhundert ausgestellten „bollettini di sanitä“ zurückführen. ${ }^{34}$ Der Pestbrief diente als Grundlage für die Entscheidung, ob ein Reisender in die Stadt eingelassen wurde - oder eben nicht. Neben diesen Identifikationstechnologien etablierten sich zur gleichen Zeit neue Formen der Bewegungskontrolle. So wurde beispielsweise im Venedig des 15. Jahrhunderts die Migration aus dem heutigen Balkan mit der Begründung der Pestprävention verboten. ${ }^{35}$ Diesen Befund teilt Ann Carmichael: „With the proclamation of plague that summer and the next, the council found it relatively easy to rid the city of immigrants on the grounds that they had brought the plague to Venice. ${ }^{\text {" }} 6$ In Perugia mussten 1460 alle Albaner, die in den vergangenen drei Jahren angekommen waren, die Stadt innerhalb dreier Tage verlassen.

31 Rosen, 1958, S. 109. Dazu auch Dinges, 1995.

32 Dazu auch Foucault, 2004a, S. 483.

33 Zur Geschichte der Quarantäne entsteht zurzeit eine viel versprechende Dissertation an der Universität Bern. Luise Müller: „Die Bedrohung kommt übers Meer: Maritime Quarantäne auf der Iberischen Halbinsel als Selbstvergewisserungs- und Abgrenzungsmechanismus" (Arbeitstitel).

34 Dazu Groebner, 2002. Siehe auch Bohn, 2006.

35 „Immigration of this kind was therefore banned, and a close watch kept for illegal immigrants at the Lido and other landing places, and on the mainland." Palmer, 1978, S. 54. In Basel kam es im 14. Jahrhundert noch vor Ausbruch der Pest zu Pogromen gegen Juden. Jene, die nicht geflohen waren, wurden zusammengetrieben und in ein Holzhaus auf einer Sandbank im Rhein gesperrt. Das Haus wurde angezündet, die Menschen verbrannten. Als Folge dieser nicht zuletzt wirtschaftlich motivierten und geplanten Verfolgung wurden auch die Schulden von Basler Bürgern getilgt. Erkens, 1999. Dazu auch Graus, 1987.

36 Carmichael, 1986, S. 118. 
Wer sich weigerte, riskierte ein Jahr Gefängnis, was an die heutige Abschiebungshaft erinnert. ${ }^{37}$

Zwangsmassnahmen richteten sich vielerorts auch gegen die Armen. 1490 verboten die Provveditori alla Sanità den Fährmännern den Transport von Bettlern nach Venedig. Zudem wurden ab 1526 Bettler regelmässig aus der Stadt vertrieben. ${ }^{38}$ Und ab 1550 wurden als Folge dieser zunehmend restriktiven Politik bettelnde Kinder als Schiffsjungen verdingt. Für Schiffe ab einer bestimmten Grösse wurde es sogar zur Pflicht, solche Betteljungen anzuheuern. ${ }^{39}$ Zur Disziplinierung von Bettlern schuf man 1594 in Venedig zudem aus einer verfallenen Leprastation eine Bettleranstalt. ${ }^{40}$ Disziplinierungs- und Kontrollmassnahmen betrafen - allerdings in etwas anderen Dimensionen - auch die Bürger der Städte. Besondere Rechte wurden in Venedig den Provveditori alla Sanità beispielsweise in Bezug auf ihre Untersuchungsmethoden zugestanden. So wurde ihnen zu Beginn des 16. Jahrhunderts gestattet, Folter einzusetzen, um die Wahrheit über die Ursache von Seuchenausbrüchen aufzudecken. ${ }^{41}$ In diesem seuchenpolitischen Ausnahmezustand ${ }^{42}$ gewannen städtische Strukturen an Stärke; es ist kein Zufall, dass die Polizei in der frühneuzeitlichen Gesundheitspolizey u. a. ihre Anfänge findet. ${ }^{43}$ Doch Verordnungen garantieren noch nicht deren Umsetzung. Während die italienischen Stadtstaaten bezüglich Seuchenpolitik eine Vorreiterrolle einnahmen, wurden in Frankreich nach Richard Palmer solche Strukturen erst ab Mitte des 17. Jahrhunderts permanent etabliert, England war noch später dran: „In 1626 a former ambassador to Venice, Sir Dudley Carleton, argued in the English Par-

$37 \mathrm{Zu}$ den historischen Vorläufern der Abschiebung siehe auch Walters, 2002.

38 Palmer, 1978, S. 215.

39 Palmer, 1978.

40 Jütte, 2000, S. 229.

41 Palmer, 1978, S. 84. Siehe auch Prantl, 2008, S. 54-58.

42 Zur Geschichte des Ausnahmezustandes siehe Agamben, 2004. Interessant ist Agambens Figur der ausschliessenden Einschliessung: „Wichtig ist zu bemerken, dass bei Hobbes der Naturzustand in der Person des Souveräns überlebt, der als einziger sein natürliches ius contra omnes bewahrt. Die Souveränität stellt sich somit wie eine Einverleibung des Naturzustands der Gesellschaft dar oder, wenn man will, wie eine Schwelle der Unterschiedenheit zwischen Natur und Kultur, zwischen Gewalt und Gesetz, und genau in dieser Ununterscheidbarkeit liegt das Spezifische der souveränen Gewalt." Agamben, 2002, S.46. Dies trifft auch für den Ausnahmezustand zu, der an der Schwelle der Rechtsordnung zu verorten ist: Im Ausnahmezustand wird das Recht durch das Recht ausser Kraft gesetzt, weshalb es sich dabei nicht einfach um einen rechtsfreien Raum handelt.

43 Foucault, 2004a, S. 451-481. 
liament for a bill on plague control, pointing out the success of plague measures in Paris and Venice. " 44

\section{Selektion}

Seuchenpolitik war unter anderen Faktoren wichtig für die Ausbildung von Souveränität, für die Kontrolle gegen innen und aussen. ${ }^{45}$ Die Provveditori alla Sanità konnten in Pestzeiten verbieten, Messen abzuhalten, denn die Zusammenkunft von Menschenmassen galt als „Ansteckungsgefahr" ${ }^{46}$ Auch nach Hobbes gehört es zu den Rechten des Souveräns, religiöse Ansammlungen zu verbieten; ${ }^{47}$ er vergleicht unrechtmässige Menschenversammlungen mit Geschwüren, die durch $\mathrm{Zu}-$ sammenfluss übler Säfte erzeugt werden.

Hobbes greift oft auf eine medizinische Metaphorik zurück. Bereits in der Einleitung schreibt er, Eintracht im Staat sei Gesundheit, Aufruhr führe zu Krankheit, Bürgerkrieg aber bedeute den Tod des Staates. ${ }^{48}$ Später vergleicht er das Geld mit dem Blutkreislauf; das ist einer der Ausgangspunkte der so erfolgreichen Metapher der ökonomischen Zirkulation. Gleichzeitig wird durch diese Metaphorik das Geld (ähnlich wie bei Locke) naturalisiert. ${ }^{49}$

Explizit von Seuchen spricht Hobbes im Kapitel „Von Wundern, und wozu sie bewirkt werden". So habe Moses seine Hand aussätzig gemacht und anschliessend wieder geheilt, um die Israeliten von seiner Auserwähltheit und Macht zu überzeugen $;{ }^{50}$ dies erinnert auch an die Stelle aus dem Buch Hiob, die dem "Leviathan“" seinen Namen gab. ${ }^{51}$ Gott habe eine Seuche über Ägypten geschickt, um den Pharao zu

44 Palmer, 1978, S. 148.

45 Ein weiterer wichtiger Faktor sind beispielsweise dauerhafte Steuern, siehe dazu beispielsweise Schwennicke, 1996.

46 Palmer, 1978, S.300. Allerdings haben städtische Behörden oft selbst Prozessionen angeordnet.

47 Hobbes, 1966, S. 357.

48 Hobbes, 1966, S. 5.

49 Dazu auch Scholz, 1998, S. 471. Auch Henry Robinson vergleicht 1652 den Staat mit einem Körper (und mit einer Uhr, was ein noch etwas anders gelagertes Bedeutungsfeld eröffnet): Die Gesundheit sei vom funktionierenden Geldkreislauf abhängig, die Umlaufrate sei der Index für die Gesundheit. Dohrn-van Rossum, 1977, S. 245.

50 Hobbes, 1966, S. 336.

51 Gott liess dem zweifelnden Hiob das Seeungeheuer „Leviathan“ in einem Unwetter erscheinen, um die eigene Macht zu offenbaren. 
zwingen, die Israeliten ziehen zu lassen. Dieser Eingriff Gottes hatte laut Hobbes indes nicht zum Ziel, den Pharao zu bekehren, denn der Kirche sollten nicht alle Menschen zugeführt werden, sondern nur jene, die erlöst werden sollten, das gelobte Volk. ${ }^{52}$

Interessant ist, dass hier die Seuche ebenfalls in eine enge Verbindung mit Selektionsprozessen gebracht wird; die magische Heilung der aussätzigen Hand richtet sich als Signal nur an Auserwählte. Allerdings sollte gleichzeitig im Auge behalten werden, dass Hobbes im „Leviathan", wie auch Carlo Ginzburg feststellt, zwar auf Seuchen, ${ }^{53}$ nie aber auf eine eigentliche Seuchenpolitik zu sprechen kommt. Der von Hobbes übersetzte Thukydides schilderte die Folgen der Pest als „anomia“, als Gesetzlosigkeit, was natürlich an die Beschreibung des Naturzustands erinnert.

\section{Wie die Biopolitik ins Bild des Politischen rückt}

Im Zusammenhang mit der Seuchenabwehr entdeckte die städtische Gewalt den Nutzen der Statistik. ${ }^{54}$ Ein wichtiger Vordenker der Bevölkerungsstatistik war William Petty. Dieser hatte eine politische Arithmetik entworfen, in der die Bevölkerung, so Achim Landwehr, nicht als gegeben, sondern als gemacht konzeptualisiert worden sei. ${ }^{55}$ Petty, der in Holland medizinische Vorlesungen besucht hatte, kam 1645 nach Paris. Hier traf er Hobbes - der zwischen 1640 und 1651 im Pariser Exil war - und wurde dessen Assistent. ${ }^{56}$ Petty fertigte Zeichnungen für Hobbes' Studien der Optik an, zusammen studierten die beiden Vesalius' „Fabrica“, ja Hobbes soll sogar anatomischen Zergliederungen beigewohnt haben, die Petty durchführte. ${ }^{57}$ Später wurde

52 Hobbes bietet folgende Definition des Wunders: „Ein Wunder ist ein Werk Gottes, das neben seinem in der Schöpfung festgelegten Wirken auf natürlichem Wege steht und bewirkt wird, um seinen Auserwählten kundzutun, dass er zu ihrer Erlösung einen auserwählten Diener gesandt habe." Hobbes, 1966, S.337. Wunder sind also Zeichen, signs, damit die Menschen den Propheten glauben. Zum Begriff des signs bei Hobbes siehe Bredekamp, 2007.

53 Ginzburg, 2008. Dazu auch Fach, 2010. Es wäre interessant, systematisch der Frage nachzugehen, wo Hobbes sich in anderen Schriften zu Seuchen und insbesondere der Pest äussert. Bei seiner Übersetzung des Thukydides sind Seuchen jedenfalls ein Thema. Dazu Leven, 2001, S. 84. Siehe auch Orwin, 1988.

54 Fazzini, 2004. Dazu auch Brusatin, 1981. Landwehr, 2007, S. 278.

55 Landwehr, 2007, S. 292.

56 Jordan, 2007, S. 35 .

57 Zimmer, 2004, S. 99. 
Petty Professor der Anatomie in Oxford und Gründungsmitglied der Royal Society. ${ }^{58}$ Petty war noch auf anderen Gebieten tätig. So beteiligte er sich unter Cromwells Regierung an der Kolonisierung Irlands. Als Arzt der britischen Armee traf er 1652 zum ersten Mal in Irland ein. Er hatte hier u.a. den Auftrag, die Pest zu bekämpfen und kartografische Studien auszuführen, welche der Aneignung des Landes durch die englischen Eroberer dienten; eroberte irische Territorien wurden damals englischen Anspruchsstellern zugeteilt. ${ }^{59}$ Auch Petty selbst eignete sich in dieser Zeit grosse Grundstücke an. ${ }^{60}$ Fast vierzig Jahre später, 1691, vier Jahre nach Pettys Tod, wurde dessen Studie „Political Anatomy of Ireland" publiziert. ${ }^{61}$ Petty schreibt in der Einleitung, er habe im ersten Essay zur Politischen Anatomie ${ }^{62}$ in Anlehnung an Francis Bacon dessen Assistent wiederum womöglich Hobbes gewesen war - zwischen dem „Body Natural“ und dem „Body Politick“ eine scharfsinnige Parallele gezogen. ${ }^{63}$ Als Versuchskaninchen habe ihm dabei das junge Irland gedient, denn hier seien die Machenschaften des Staats nicht sehr kompliziert, zudem sei er mit Irland vertraut, seit dieses ein Embryo gewesen sei, führt Petty seine kolonial inspirierte Körpermetaphorik fort. Petty eröffnete einen statistischen Zugang zu ökonomischen Fragen, wobei er zugleich eine politische Perspektive auf die Bevölkerung entwarf. Seiner Meinung nach hätte der ärmliche und kränkliche Zustand Irlands durch eine günstigere Proportion zwischen englischer und irischer Bevölkerung verbessert werden können, weshalb er zur Verheiratung englischer Frauen mit irischen Männern riet. Um die irische Arbeitskraft zu vergrössern, schlug Petty die Reduzierung von Feiertagen, Klöstern und Bierstuben vor. ${ }^{64}$ Vor allem aber sollten Emigrationswillige einen Vorteil darin erblicken, nach Irland zu ziehen, um so dem Mangel an Menschen abzuhelfen, dem nach Petty

58 McCormick, 2006.

59 Jordan, 2007, S. 5, 45.

60 Zimmer, 2004, S. 111.

61 Petty, 1899. Petty vergleicht in seiner Studie unter anderem auch die Stärke des Pestausbruches in Irland und London um 1650. Er hatte zudem in London die Etablierung von Pestspitälern postuliert. Dazu Rosen, 1958, S. 115.

62 Zum Begriff der politischen Anatomie siehe auch Manow, 2008.

63 Petty, 1899, S. 129. Vergleiche zwischen dem Körper und dem Staat sind natürlich nicht Petty's Erfindung und gehen u. a. auf Platon zurück. Zudem veröffentlichte beispielsweise der französische Kleriker Johannes Michaelis 1564 ein Traktat mit dem Titel „Anatome Corporis Politici.“ Dohrn-van Rossum, 1977, S. 188. Auch die Anfänge einer Gesundheitspolitik lassen sich zeitlich weit zurückführen.

64 Petty, 1899, S. 223. 
grössten und fundamentalsten Mangel dieses Landes. ${ }^{65}$ Andererseits forderte Petty, die Iren seien nach England zu transplantieren. ${ }^{66}$ David Armitage meint dazu: „This would have left some 300000 people in Ireland to administer the country as a cattle-ranching dependency of England. "67 Mit seiner Vision der Säuberung Irlands von den Iren als notwendige Vorbedingung einer Produktivitätssteigerung kann er als „Vordenker" für Selektion gesehen werden. Er begriff die Bevölkerung als Ressource, allerdings vertrat er nicht einen biologischen Determinismus (der sich historisch gesehen auch erst später durchsetzte), können doch beispielsweise irische Männer durch die Verheiratung mit englischen Frauen umerzogen werden. Andererseits ist die biologische Grundierung seiner Sprache im wörtlichen Sinne frappierend.

Foucault, der die politische Theorie von ihrer Fixierung auf die Souveränität befreien wollte, gilt als einer der Präger des Begriffes Biopolitik. ${ }^{68}$ Nach Michel Foucault wurde die Vorstellung, dass die Kraft eines Staats von der Anzahl seiner Bewohner abhänge, früh im Mittelalter formuliert, sie habe indes erst im 17. Jahrhundert einen genauen Sinn angenommen und zwar in dem Masse, in dem man das Problem aufstellte, wie viele Menschen ein bestimmtes Territorium tatsächlich brauche. ${ }^{69}$

Die Geburt der Biopolitik im Sinne einer Regulierung und Verbesserung der Bevölkerung verortet er im 18. Jahrhundert. ${ }^{70}$ Die biopolitisch optimierte Bevölkerung wiederum ist nach Foucault ein Ziel gouvernementaler Führung, was er als eine Art des Regierens begreift, welches u.a. auf das Einverständnis der Regierten setzt. ${ }^{71}$ Den Begriff der Gouvernementalität führte Foucault in seiner gegenwärtigen Verwendung Ende der 1970er Jahre ein. Er grenzte dabei Souveränität, Disziplinarmacht und Gouvernementalität analytisch voneinander ab. Doch meint Foucault, es handle sich bei diesem Prozess nicht um eine

65 Petty, 1899, S. 223.

66 Petty, 1986, S. 559, 568.

67 Armitage, 2000, S. 151.

68 Foucault, 2001, S. 200.

69 Foucault, 2004a, S. 465.

70 Foucault, 2004a, S. 27, 145-147, 159, 164, 245. Zwar kann aus historischer Perspektive die von Foucault diagnostizierte Akzentverschiebung vom Territorium auf die Bevölkerung so nicht mitgemacht werden, denn lange wurde dieser Vorgang gerade in umgekehrter Richtung beschrieben. Gegenwärtig wird jedoch auch die strenge Abfolge vom Personenverbands- zum territorialen Flächenstaat in Frage gestellt, siehe dazu Sieber-Lehmann, 1996, S. 81.

71 Opitz, 2004, S. 38. 
Ersetzung, sondern um eine Akzentverschiebung. ${ }^{72}$ Die jeweils voneinander differenzierbaren Modelle sind demnach nicht als chronologisch folgend zu denken. ${ }^{73}$

Nach Foucault findet sich nun die letzte Staatstheorie bei Hobbes: „Locke entwickelt nicht mehr eine Theorie des Staats, sondern der Regierung. ${ }^{\text {" }} 44$ Auf Hobbes folge Locke, und bei diesem werde die Begründungsbedürftigkeit des Staats von den Naturgesetzen der Ökonomie abgelöst. ${ }^{75}$ Foucault bringt dabei den Begriff der Gouvernementalität in Verbindung mit Locke, genauer gesagt mit dessen Schrift "Two Treatises of Government".

Allerdings kann das Frontispiz des „Leviathan“- ausgehend von unseren Überlegungen zu Hobbes’ Assistenten Petty, zur Schnabelmaske und der Seuchenpolitik - als Einsatzstelle gesehen werden, wo ein sanitarischer Schutz des Staatskörpers und damit ein Blick auf die Bevölkerung ins „Bild des Politischen“ rückt. In Bezug auf den „Leviathan“ sollte allerdings nicht vergessen werden, dass hier die Metaphorik des Körpers einerseits gebraucht, andererseits aber in bestimmter Hinsicht auch gebrochen wird. Es handelt sich nach Hobbes zwar um einen Körper, aber um einen künstlichen. Hobbes denkt den Staat gewissermassen gleichzeitig als natürlich und künstlich, beschreibt ihn auch als Maschine. ${ }^{76}$ Er versteht Natur und Kultur nicht als Gegensätze. ${ }^{77}$

Foucault stellte dem Modell des Ausschlusses, wie es auf Leprakranke angewendet wurde, jenes des Einschlusses gegenüber, das er in der Pestpolitik verwirklicht sah: Die Kranken würden nun nicht mehr verbannt, vielmehr weise man ihnen einen festen Platz zu. ${ }^{78}$ Dabei werde nicht mehr eine dichotomisch operierende Grenze zwischen Kranken und Gesunden gezogen, sondern es werde ein System von feinen Differenzen etabliert. Dies führe zu einer ständigen Kontrolle des einzelnen Individuums, so dass beispielsweise die noch gesunden Familienmitglieder unter ständige Beobachtung gestellt würden. Mit diesem Modell, das sich an der Pestpolitik orientiere, sei es gleichzeitig zur Erfindung der „technologies positives du pouvoir“ gekommen. „On est

72 Foucault, 2004a, S. 520.

73 Bröckling / Krasmann und Lemke, 2000, S. 13. Dazu auch Pieper und Gutiérrez Rodríguez, 2003. - Pieper, 2007.

74 Foucault, 2004b, S. 133.

75 Foucault, 2004b, S. 133.

76 Dazu auch Skinner, 1996, S. 387.

77 „Die Kunst des Menschen erscheint als mimesis der Natur, die indessen ihrerseits Kunst ist, nämlich die Kunst Gottes." Stollberg-Rilinger, 1986, S. 49.

78 Foucault, 1999, S. 42. 
passé d'une technologie du pouvoir qui chasse, qui exclut, qui bannit, qui marginalise, qui réprime, à un pouvoir qui observe, un pouvoir qui sait et un pouvoir qui se multiple à partir de ses propres effets. " ${ }^{\text {"79 }}$ Später wiederum wurde diese Pestpolitik nach Foucault von einem „PockenModell der Macht" abgelöst. Dieses basiere, so Philipp Sarasin, im Wesentlichen darauf, „dass die Macht den Traum aufgibt, die Pathogene, die Eindringlinge, die Krankheitskeime vollständig auszumerzen. " ${ }^{80}$ Damit wird auch die Vorstellung von der Notwendigkeit hermetischer Grenzen relativiert; das Prinzip der Impfung funktioniert durch Integration, nicht durch Isolierung. ${ }^{81}$ Diese soll Zirkulation ermöglichen, eine solche Sanitätspolitik dient hier also gerade einer territorialen Öffnung. Die Logik dieses Sicherheitsmechanismus bringt Alison Bashford treffend auf den Punkt: „That is, far from working on a preventive model of separation and the maintenance of lines of hygiene, vaccination was precisely about contact, mixing and dissolving the foreign ,other" within the self." 82 Gouvernementalität und Biopolitik können dabei durchaus in einem Spannungsverhältnis zueinander stehen: Eine Form liberaler Staatlichkeit, die sich mit der Freiheit der Individuen inhärente Grenzen setzt, steht dabei einer totalen Verwertung der Biomasse entgegen. ${ }^{83}$

Hobbes - der ja Herrschaft gerade mit dem Verweis auf den Schutz des Lebens legitimierte ${ }^{84}$ - wurde übrigens nach seiner Rückkehr aus dem französischen Exil mit dem Londoner Pestausbruch von 1666 in Verbindung gebracht. Als Folge der damals geäusserten Atheismusvorwürfe wurden Neudrucke des „Leviathan“ verboten. ${ }^{85}$ Selbst wenn aber Hobbes bereits früher mit der Pest konfrontiert worden war, bleibt die Frage allerdings offen, ob das Detail der Schnabelmaske auf dem Frontispiz Hobbes' eigener Vorschlag war.

In seiner „Critique du De mundo de Thomas White“ schreibt Hobbes, die Zergliederung eines Objektes verlängere den Genuss, wohingegen die immer gleiche Sicht oder die Wiederholung des gleichen musikalischen Tons bald die Ohren und Augen beleidige. ${ }^{86}$ Hobbes

79 Foucault, 1999, S. 44.

80 Sarasin, 2005/2006, S. 162.

81 Foucault, 2004a, S. 93.

82 Bashford, 2001, S. 40.

83 Sarasin, 2005, S. 180.

84 Dazu auch Bürgin, 2008, S. 171.

85 Deshalb wurde auf später gedruckten Ausgaben oft ein falsches Erscheinungsdatum angegeben.

86 Hobbes, 1976, S. 464. Siehe auch Daston und Park, 1998, S. 314. 
vertritt die These, dass ein Objekt, welches zu klein sei, um bewusst gesehen zu werden, dennoch auf die Sehorgane wirke: Selbst wenn ein einzelnes Sandkorn aus Distanz nicht wahrnehmbar sei, würde der Sandhaufen als Ganzes dennoch sichtbar. Hobbes erklärt diesen Umstand damit, dass von jedem Einzelteil eine Aktivität, eine Wirkung ausgehe. ${ }^{87}$ Hobbes war also von der Wirkmächtigkeit kaum wahrnehmbarer Details überzeugt. ${ }^{88}$ Die Frage, ob und inwieweit er selbst Einfluss genommen hat auf die Gestaltung des Titelblattes, ist zwar nicht definitiv zu klären. Doch es lassen sich Argumente aufführen, die eine solche Annahme plausibel erscheinen lassen. Hobbes betrieb selbst optische Studien. ${ }^{89}$ In Zusammenhang mit seiner "politischen Optik“ ist die vor allem in einem Briefwechsel von 1650 mit dem Schriftsteller William Davenant genannte Beschreibung eines Experiments wichtig, in welchem verschiedene menschliche Figuren durch Speziallinsen zu einer ganzen Person zusammengefügt wurden. ${ }^{90}$ „I believe, Sir, you have seen a curious kind of perspective, where he that looks through a short hollow pipe upon a picture containing diverse figures sees none of those that are there painted, but some one person made up of their parts, conveyed to the eye by the artificial cutting of a glass." ${ }^{\text {"1 }}$ Dieses Kompositionsbild, das Hobbes bei seiner Arbeit am „Leviathan“ wahrscheinlich inspirierte, existierte nicht als ein Bild mit einem physisch konkreten Körper, sondern als ein visuelles Konstrukt und Resultat eines optischen Experiments. ${ }^{92}$ Diese Analogie darf indes nicht dahingehend verstanden werden, dass Souveränität das Resultat einer Sinnestäuschung sei, vielmehr kann damit die Tatsache betont werden, dass der Staat gemacht, nicht gegeben ist: „like the optical scientist who shows that illusions are created by the operation of natural laws, not demons, Hobbes shows that the sovereign power exists not as a supernatural entity or sacral authority but as a consequence of the rational

87 Hobbes, 1839, Bd. I, S. 342.

$88 \mathrm{Zu}$ Athanasius Kircher, dem Mikroskop und der Vorstellung vom contagium vivum siehe Asmussen, 2009.

89 Prins, 1996.

90 Malcolm, 2002b. - Bredekamp, 2003, S. 89. Ob es sich dabei um Sultane handelte, die optisch zum französischen Souverän zusammengefügt wurden und diesem damit als untergeordnet erschienen, ist nicht restlos geklärt.

In Bezug auf das Denken von der Einheit in der Vielheit, von mehreren Personen als einer Substanz, könnte auch auf Hobbes Verständnis der Trinität eingegangen werden, was hier indes nicht geleistet werden kann. Siehe dazu beispielsweise Matheron, 1990.

91 Hobbes, 1840, Bd. IV, S. 457.

92 Malcolm, 2002b, S. 222. 
acts of will of the people. “93 Hobbes kommt im „Leviathan“ auf diese optischen Instrumente zu sprechen, indem er schreibt, dass Menschen von Natur aus in ihrer Leidenschaft und Selbstliebe über „multiplying glasses" verfügten, wodurch jede Steuer als grosse Belastung erscheine, ihnen jedoch "prospective glasses " ${ }^{\text {"9 }}$ fehlten - nämlich die Wissenschaft von der Moral und vom Staat - „um von ferne die elenden $\mathrm{Zu}$ stände zu sehen, die über ihnen hängen und ohne diese Abgaben nicht abgewendet werden können “95, sprich: Ohne Steuern kann der Souverän keinen Schutz gewährleisten. Allerdings folgt die politische Macht nicht nur dem Gebot der Sichtbarkeit, sondern auch dem Prinzip der Arcana imperii. Die Formel bezeichnet die geheimen, verborgenen und unsichtbaren Mittel der Macht, deren Verschleierung mit Vorhang auf dem Frontispiz angedeutet ist. Nach Horst Bredekamp ist dieser nach dem Vorbild jenes Schleiers gestaltet, welcher das Tabernakel des Alten Testaments verborgen gehalten habe. ${ }^{96}$

„Ohne das Bild des ,Leviathan' bleibt Hobbes politische Theorie so missverständlich wie die Dunkelheit jener Sprache, die er als Verfall der semantischen Verbindlichkeit kritisiert", schreibt Horst Bredekamp. ${ }^{97}$ Seine bekannte Argumentation folgt der Hobbes'schen Rhetorik, die vor der Macht der Metaphern, der (missbräuchlichen) Rhetorik und der Schrift warnt. Zugleich jedoch insistiert Bredekamp auf die politische Notwendigkeit von Bildern. Ohne Schwert seien Verträge blosse Worte; es brauche aber nebst den Waffen auch ein Bild, um die Rhetorik des Gesellschaftsvertrags zu bändigen. Tatsächlich spricht Hobbes von der Notwendigkeit einer sichtbaren Gewalt, um die Menschen im Zaum zu halten..$^{98}$ Eine Sichtbarkeit der Macht bedeutet aber nicht zwangsläufig, dass diese über Bilder erzeugt wird. Auch macht Brede-

93 Malcolm, 2002b, S. 227.

94 Multiplying glasses" wird in den deutschen Übersetzungen als Vergrösserungsund „prospective glasses“ als Ferngläser wiedergeben, ich meine aber, dass es sich beim Erstgenannten um jenen optischen Effekt handelt, wo ein Objekt durch ein „Vervielfältigungsglas" visuell multipliziert wird, beim Zweitgenannten hingegen um jenen soeben beschriebenen, wo verschiedene Figuren durch Speziallinsen zu einem Ganzen zusammengefügt werden. Auf die unpassende Übersetzung von „prospective glasses“ macht auch Horst Bredekamp aufmerksam, er übersetzt aber „multiplying glasses“ wiederum mit „Fernrohr“ statt wie ich vorschlage mit „Vervielfältigungsglas" Bredekamp, 2003a, S. 85. Interessant ist auch die Doppeldeutigkeit von „prospective glass“, kann damit doch auch eine magische Kristallkugel bezeichnet werden.

95 Hobbes, 1966, S. 144. Dazu ist sehr einschlägig auch Windisch, 1997, S. 129.

96 Bredekamp, 2007, S. 32.

97 Bredekamp, 2003, S. 131.

98 Hobbes, 1966, S. 131. 
kamp die Notwendigkeit einer Sichtbarkeit der Macht im „Leviathan“ prominenter, als sie von Hobbes explizit verhandelt wird. Denn meiner Meinung nach liegt die Betonung in Hobbes' Formulierung - „wenn es keine sichtbare Gewalt gibt, die sie im Zaume zu halten und durch Furcht vor Strafe an die Erfüllung ihrer Verträge und an die Beachtung der natürlichen Gesetze zu binden vermag " auf „sichtbar“: Hobbes spricht im „Leviathan“ nur sehr selten von einer notwendigen Sichtbarkeit, während er das Erfordernis eines physischen Gewaltmonopols sehr stark betont. Während also Hobbes vor allem verdeutlicht, dass Worte für Verträge nicht genügen, dass vor allem Waffen nötig seien, um die Einhaltung der Verträge zu erzwingen, akzentuiert Bredekamp die Wichtigkeit des Bildes. Wenn auch die Angst vor dem Einsatz der Gewalt nach Hobbes eine Notwendigkeit ist, so wird diese Angst laut „Leviathan“ nicht primär in visueller Weise erzeugt.

Mir scheint, dass Bredekamp Hobbes hier vielleicht zu sehr durch die Brille von Louis Marin liest. ${ }^{100}$ Es könnte allerdings argumentiert werden, die Annahme einer radikalen Abhängigkeit des Souveräns von seiner Repräsentation strukturiere implizit die Hobbes'sche Argumentation.

Hobbes entwarf im „Leviathan“ selbst eine „Bildtheorie“. Entweder sei ein Bild ein Abbild eines sichtbaren Gegenstands - wie beispielsweise bei einer Spiegelung im Wasser; hier bestehe ein Ähnlichkeitsverhältnis - oder ein Bild vertrete ein Ding; da gelte hingegen keine Ähnlichkeitsbeziehung. ${ }^{101}$ Hobbes schreibt: „So kann ein irdischer Souverän als das Bild Gottes bezeichnet werden ". ${ }^{102}$ Hobbes geht weiter auf den Unterschied zwischen Sichtbarkeit und Bildlichkeit kurz ein, als er ausführt, „Gott dienen aber heisse, seine Vorstellung von ihm anderen

99 Hobbes, 1966, S. 131.

100 Marin, 2005. Louis Marin hat gezeigt, wie eine permanente Präsenz des Monarchen auch bei physischer Absenz durch zirkulierende Bilder produziert werden sollte. Der Repräsentationseffort des Sonnenkönigs beispielsweise wäre somit auch als Antwort auf jene Krise zu verstehen, die durch die Kollision von absoluten Staatsvorstellungen und aufklärerischen Tendenzen provoziert wurde: Bildpotenz sollte sozusagen reale Impotenz verdecken.

101 Meistens allerdings fungieren Bilder laut Hobbes sowohl als Abbild wie auch als Vertretung. Als Kriterium für Bildlichkeit wird sowohl der Begriff der Ähnlichkeit wie auch jener der Repräsentation heute kritisch hinterfragt.

102 Hobbes, 1966, S. 496. Zum Umstand, dass sich absolute Souveräne als Porträt Gottes bezeichnen, siehe auch Marin, 2005. 
sichtbar zu machen", so beispielsweise im Gottesdienst. ${ }^{103}$ Dies wiederum bedeutet nicht, dass man sich von Gott ein „mimetisches“ Bild machen und dieses als authentische Darstellung ansehen dürfe. Hobbes kritisiert vielmehr diese Art von religiöser Bildverehrung an mehreren Stellen. ${ }^{104}$ Jede Vorstellung ist begrenzt - Gott aber sei das Unbegrenzte. ${ }^{105}$ Das Bild des „Leviathan“ könnte nach Hobbes` Logik ebenfalls weniger als Abbild, denn als Stellvertreter verstanden werden. Selbst wenn der bildlich dargestellte Souverän allerdings als sehr mächtig und auf dem Frontispiz von 1651 als oben ungerahmter erscheint, zeichnet sich der von Hobbes begründete souveräne Einzelstaat durch (gewisse) Grenzen aus, die allerdings selten explizit verhandelt werden. Implizit erschliesst sich jedoch eine klare Trennung zwischen den souveränen Einzelstaaten (die Autorität des Staats wird dabei als territorial begrenzt gedacht, geht doch Hobbes davon aus, dass sich die Staaten untereinander im Naturzustand befinden), zwischen innen und aussen, privatem Glauben und öffentlichen Äusserungen. Auch das Frontispiz des „Leviathan“ 106 operiert durchgehend mit Oppositionspaaren: Der Bildraum ist klar aufgeteilt zwischen oben und unten, links und rechts, staatlicher und kirchlicher Macht, wobei der Souverän auch Oberhaupt der Kirche ist und sich die Religion nicht über staatlich gesetzte Grenzen hinwegsetzen darf. ${ }^{107}$ Gleichzeitig ist Hobbes ein

103 Hobbes, 1970, S. 299. Ich habe mich hier auf die Übersetzung der jüngeren lateinischen Fassung gestützt. Hingegen wird in der englischen "Leviathan-Ausgabe“ noch deutlicher, dass ein Sichtbarmachen nicht zwangsläufig visuell zustande kommen muss. Hier heisst es: „the external signs appearing in the words, and actions of men, are called worship“. Hobbes, 1996, S.238. Die Hobbes'sche Definition von signs, auf die Bredekamp rekurriert, um eine Bildakttheorie zu formulieren, bezieht sich bei Hobbes demnach auf vieles, beispielsweise auch Worte und Handlungen und nicht spezifisch auf Bilder.

104 Hobbes, 1966, S. 279, 497, 498, 501, 502, 505.

105 Hobbes, 1966, S.495. Siehe auch folgende Aussage: „Genau so kann man auf Grund der sichtbaren Dinge dieser Welt und ihrer wunderbaren Ordnung begreifen, dass es eine Ursache hiervon geben muss, die man Gott nennt und doch keine Idee oder Abbild von ihm im Geiste besitzen." Hobbes, 1966, S. 81. Siehe auch Hobbes, 1994, S. 251.

106 Wie übrigens auch jenes von „De Cive“.

107 Allerdings darf bei solchen Betrachtungen nicht vergessen werden, dass Grenzen im Laufe der Geschichte unterschiedlich gesehen bzw. konzeptualisiert wurden. In zahlreichen Bereichen waren strikte, linear gedachte Unterscheidungen, die heute selbstverständlich erscheinen, in dieser Form nicht vorhanden. In diesem Zusammenhang ist bemerkenswert, dass auf dem Titelbild die Kontur des Körpers als fixe Grenze gezeigt wird, der Leib insgesamt als hermetisch abgeschlossen erscheint. Körpergrenzen sind nicht einfach als konstant zu denken und die Haut wurde bei- 
Denker, der Grenzen zuweilen abzubauen vermag, so beispielsweise in Bezug auf innergesellschaftliche Grenzziehungen. ${ }^{108}$

\section{Soldaten, Seuchenärzte und Sicherheitsversprechen}

Es sind nun nicht nur Seuchenärzte, sondern auch Soldaten in der menschenleeren Stadt zurückgeblieben. Soldaten und Seuchenärzte üben eine verwandte Funktion aus: Beide sollen den Staatskörper schützen. Der Gesellschaftsvertrag sorgt zwar innerhalb eines Staats für Frieden, dennoch ist der Krieg nicht aufgehoben, sondern nur an die Grenzen gedrängt. Zwischen den Staaten herrscht nach Hobbes der Naturzustand. Diese verhalten sich wie Gladiatoren: „sie richten ihre Waffen gegeneinander und lassen sich nicht aus dem Auge - das heisst, sie haben ihre Festungen, Garnisonen und Geschütze an den Grenzen ihrer Reiche und ihre ständigen Spione bei ihren Nachbarn. " ${ }^{109}$ Im „Leviathan“ ächtet Hobbes zwar den Bürgerkrieg, hingegen bewertet er die Anarchie im zwischenstaatlichen Bereich nicht als negativ, denn es könne dabei der Fleiss der Staatsangehörigen aufrechterhalten werden, ja sogar noch gefördert werden, weshalb daraus nicht das Elend resultiere, „das die Freiheit von Einzelmenschen begleitet“. 110

Auseinandersetzungen im internationalen Bereich sind also immer noch möglich, ja sogar wahrscheinlich, und dieser Umstand bedroht das Leben des Individuums weiterhin. Der Staat kann sein Sicherheitsversprechen nicht vollständig einlösen. ${ }^{111}$ „Jedermann ist von Natur aus verpflichtet, soweit es in seiner Macht steht, im Krieg die Autorität

spielsweise nicht von jeher als lineare Grenze gesehen, welche den Körper abschottet. Dazu einschlägig ist Benthien, 1999.

108 In der Begründung des Gesellschaftsvertrags muss von einer Gleichheit aller Staatsangehörigen ausgegangen werden, denn jeder vermöge jeden umzubringen. Und selbst wenn Gleichheit nicht gegeben wäre, müsste um des Friedens willen eine solche angenommen werden. So lautet Hobbes neuntes Gesetz der Natur: „Jedermann soll den anderen für Seinesgleichen von Natur aus ansehen." Hobbes, 1966, S. 118.

Treffend schreibt Jenny Edkins, allerdings nicht direkt in Bezug auf den Hobbes'schen Leviathan: „Sovereign power is happy to negotiate the boundaries of the distinctions that it makes; what it could not tolerate would be the refusal to make any distinctions of this sort." Edkins, 2007, S.76. Siehe dazu auch Edkins und Pin-Fat, 2004 .

109 Hobbes, 1966, S. 97, 98.

110 Hobbes, 1966, S. 98.

111 Eine scharfe Analyse dazu mit einer etwas anderen Stossrichtung findet sich bei Cheneval, 2002. Das mittelalterliche Verständnis von Schutz und Schirm, das 
zu schützen, durch die er in Friedenszeiten geschützt wird"112, schreibt Hobbes. Die Verpflichtung der Staatsangehörigen gegenüber dem Souverän dauert nach Hobbes allerdings nur so lange, wie dieser sie aufgrund seiner Macht schützen kann, und nicht länger. ${ }^{113}$ Für den angeworbenen Soldaten sieht die Situation etwas anders aus. Dieser ist zwar zur Verteidigung des Souveräns verpflichtet, ${ }^{114}$ jedoch schreibt Hobbes an anderer Stelle, selbst dieser sei nicht zum Opfertod gezwungen. ${ }^{115}$ Die Figur des „Leviathan“ ist demnach nicht ohne innere Spannung; kann der individuelle Körper nicht geschützt werden, zerfällt der Souverän.

Hier zeigt sich allerdings auch eine interessante Differenz zwischen der Schrift des „Leviathan“ und seinem Bild: Während in der Schrift des „Leviathan“ die potenzielle Aufösung des Leviathan angelegt ist, wird im Titelbild die potenzielle Aufösung des Individuums im Staatskörper betont, verschwinden die Menschen doch zum Teil in der Schraffur, so beispielsweise im Unterarm. In gewisser Weise erscheint so die Schrift liberaler, stärker auf die Individualrechte abstützend als das Bild des „Leviathan“. Vielleicht hat sich auch Michel Foucault in seiner Interpretation stärker vom Bild als von der Schrift des „Leviathan" beeindrucken lassen?

\section{Fazit}

Ob ein Detail als trivial oder aufschlussreich gesehen wird, ist kontextabhängig. Dieser Kontext ist jedoch nicht gegeben, kann nicht vorausgesetzt werden, sondern muss geschaffen werden. In der hier vorgeschlagenen Sichtweise wurden die Schnabelmasken zum Schwer- und Drehpunkt der Interpretation. Als Wahrnehmungsfilter verändern sie die Sicht auf den dargestellten Staatskörper. Sie lenken den Blick auf die Gewaltsamkeit der Grenzziehung, die nötig war, um die souveräne Ganzheit und Abgeschlossenheit des Staatskörpers herzustellen. ${ }^{116}$ Die

auch an die geschilderte Konstellation erinnert, wurde kritisch beleuchtet von Algazi, 1996. Zu Kants Kosmopolitismus siehe Eberl, 2008.

112 Hobbes, 1966, S. 536.

113 Hobbes, 1966, S. 171, 254, 537.

114 Hobbes, 1966, S. 169.

115 Hobbes, 1966, S. 159.

116 Passend zu dieser Politik der Grenzziehung ist übrigens die für das Titelbild verwendete Technik des Tiefdrucks, wo selbst Einheiten durch abgrenzende Linien, Einschnitte oder Einätzungen geschaffen werden. Auch diese durch Schnittope- 
bildlich suggerierte inkorporierende Inklusion auf dem Frontispiz lässt diese biopolitischen Exklusionen auf den ersten Blick nicht erahnen. ${ }^{117}$ Der von den Schnabelmasken gelenkte Blick macht weiter den programmatischen Zusammenhang von Souveränität und Sanität sichtbar: Städtische bzw. staatliche Strukturen begannen sich u.a. oft im Krieg und im seuchenpolitischen Ausnahmezustand auszubilden. ${ }^{118}$ Medizinische Dispositive waren unter anderen Faktoren (militärischen, ökonomischen etc.) wichtig für die Etablierung und Legitimierung von Grenzen. Ich begreife die Schnabelmaske folglich als einen Ort, der etablierte Sichtweisen sowohl auf das Titelbild wie auch den Text irritiert. Beides kann von hier aus mit neuen Kontexten kurzgeschlossen und so mit neuer Bedeutung aufgeladen werden. Und hier wird das Bild des „Leviathan“ bzw. des Staatskörpers wichtig, weil sich die Schnabelmasken ja nur hier zeigen, nicht aber in Hobbes' Text.

Auf dem Emblem des Body Politic werden demnach in einem Spannungsverhältnis Souveränität, Disziplinarmacht und eine beginnende Biopolitik sichtbar. Die Machtformation der Souveränität zeichnet sich nach Foucault durch ein Ausüben von Zwang aus, sie funktioniert als Zugriffsrecht. Die Disziplinarmacht wirkt auf die einzelnen Körper und diszipliniert diese; dies ist auf dem Frontispiz sehr schön ersichtlich, der Soldat steht hier als Sinnbild für den disziplinierten Körper. ${ }^{119}$ Unter Biopolitik wiederum versteht Foucault eine Politik, die auf das Leben zielt, und zwar der Gesamtbevölkerung; dieses Leben gilt es zu steigern, zu verbessern. Es ist nun die Machtformation der Gouvernementalität, die nach Foucault mit dem Modus der Biopolitik operiert, auch wenn sich die Gouvernementalität nicht auf Biopolitik beschränken lässt. In gouvernementalen Machtstrukturen verbindet sich das Regieren anderer mit der Selbstregierung. Foucault bringt dies im Speziellen mit einer liberalen Form des Regierens in Verbindung, die auf das Einverständnis der Regierten setzt und auf deren Freiheit: Gerade

rationen ermöglichte Fokussierung auf das Detail der Schnabelmaske trägt ein Moment der Gewalt in sich. Im italienischen „dettaglio“ (taglio, Schnitt) sind übrigens jene Schnittoperationen, welche das Detail erst sichtbar machen, im Begriff selbst besonders augenfällig. Dazu Pichler, 2007, S. 10.

117 Hier böte sich auch ein Vergleich zu Jean Bodin an, der die Geschlechterdifferenz nicht wie Hobbes graduell, sondern prinzipiell denkt. Siehe dazu Opitz-Belakhal, 2006.

118 Slack, 1985.

119 Auf anderen Varianten des Titelblattes ist die Disziplinierung hingegen weniger präsent (wir finden da einzelne, grössere Köpfe, die uns anblicken, und die einen viel ungeordneteren Eindruck hinterlassen) Bredekamp, 2003, S. 19. 
diese wird auch ökonomisch produktiv gemacht. ${ }^{120}$ Für Hobbes ist hingegen nicht Freiheit, sondern Sicherheit das Ziel des Staates, auch wenn nach Hobbes rationale Individuen dem Gesellschaftsvertrag freiwillig zustimmen.

Foucault sieht in „Les Anormaux“121 die Pestpolitik als Beginn einer Machtformation, die nicht nur als Unterdrückungsinstanz, sondern produktiv wirkt, lebensverlängernd, auch wenn er da noch nicht auf den Begriff der Gouvernementalität zurückgreift und seine Analyse dabei noch stärker vom Individuum ausgeht und weniger von der Gesamtbevölkerung. Später bringt Foucault gouvernementale Sicherheitsdispositive vor allem mit der Bekämpfung der Pocken in Verbindung (als Beispiel wären hier das Prinzip der Impfung und die Statistik zu nennen). ${ }^{122}$ Die Ausführungen zu Hobbes' Assistenten Petty zeigen indes, dass bereits dieser u. a. durch das Fördern einer bestimmten Heiratspolitik die Bevölkerung in ihrer Qualität zu verbessern trachtete; Petty betrachtete die Bevölkerung als etwas Gemachtes und nicht einfach Gegebenes. Was mir nun besonders erscheint, ist, dass ausgehend von einer solchen Betrachtungsweise auf dem Emblem des Body Politic eine beginnende Biopolitik 1651 wortwörtlich ins Bild des Politischen rückt. ${ }^{123}$ Das ist auch insofern bemerkenswert, als der Beginn des biopolitischen Zeitalters in Foucault-Rezeptionen oft erst auf ein- bis zweihundert Jahre später datiert wird. Die Schnabelmasken auf dem Frontispiz des „Leviathan“ könnten damit als Aufhänger für eine anders akzentuierte Lektüre sowohl von Foucault wie auch von Hobbes dienen. Es war dabei insbesondere die symbolische Dimension der Sanitätspolitik, die hier interessierte: Das ikonische Kostüm des Pestarztes verbreitete sich in jener Zeit, als auch das Frontispiz entstand. Die Schnabelmasken und Soldaten wollen Sicherheit garantieren, signalisieren gleichzeitig aber auch potenzielle Unsicherheit. Auch sollen die Widersprüche und Spannungsverhältnisse nicht unsichtbar gemacht werden, die gerade auch in Bezug auf Grenzziehungen zwischen Souveränität, Disziplinar- und Biomacht bestehen: „Whereas disciplinary power isolates, concentrates and is essentially pro-

120 Um hier nur eine Stelle zu nennen: Foucault, 2004a, S. 162.

121 Foucault, 1999, S. 41-44.

122 Es besteht vielleicht auch ein gewisses Spannungsverhältnis zwischen den idealtypischen Denkmodellen, die Foucault generiert - dass eben die Bekämpfung der Lepra, der Pest und der Pocken paradigmatisch verstanden werden kann - und der historischen Konkretisierung seiner Arbeit.

123 Agamben postuliert eine notwendige (kritisierte) Verbindung zwischen Souveränität und Biopolitik. Dazu Sarasin, 2003. - Muhle, 2008. Zum Verhältnis von Souveränität und Ökonomie siehe Agamben, 2010. 
tectionist, by contrast biopower is said to be centrifugally oriented in favour of expansion, circulation and movement. "124 Verschwiegen werden soll hier auch nicht, dass gerade nach der grossen Pest von 1665 Immigration als Mittel gesehen wurde, um die Bevölkerungszahl wieder zu erhöhen. In diesem Zusammenhang sprachen sich sowohl Petty wie auch Locke für eine erleichterte Einbürgerung der (wirtschaftlich rentablen) hugenottischen Flüchtlinge aus, ${ }^{125}$ was wiederum mit einer durchaus auch inkludierenden Dynamik gouvernementaler Machtstrukturen in Verbindung gebracht werden kann.

Ich bin mir bewusst, dass die hier vorgeschlagene Sichtweise erst durch den Kurzschluss verschiedener Zeitlichkeiten möglich wird, mit Benjamin gesprochen: wenn „das Gewesene mit dem Jetzt blitzhaft zu einer Konstellation zusammentritt" ${ }^{126}$ Erst in der Jetztzeit, vor dem Hintergrund zeitgenössischer Diskurse, sind die Schnabelmasken auf dem Frontispiz offenbar zur Lesbarkeit gelangt, wobei Lesbarkeit hier metaphorisch verstanden werden soll und sich gerade nicht auf die Lektüre eines Textes beschränkt. ${ }^{127}$ Der biopolitische Kontext, der aus einer solchen Perspektive insbesondere über Hobbes' Assistenten William Petty und die Eroberung Irlands in den Blick rückt, weist dabei von Anfang an einen kolonialen Referenzrahmen auf. Die Schnabelmaske findet dabei ihr Pendant im Soldaten; beide Figuren verweisen auf die Fragilität des Staats, sie markieren dabei die unfreiwilligen Grenzen des „Leviathan“: Kann der Schutz des Lebens nicht gewährleistet werden, sei es durch Kriege, ausgelöst durch den Naturzustand zwischen den Staaten, sei es durch den seuchenpolitischen Ausnahmezustand, zerfällt der Staat.

Ich habe bei weitem nicht alles ausgeführt, was zum Frontispiz oder der Schrift des „Leviathan“ gesagt werden könnte; so bin ich beispielsweise nicht auf die Entstehungsbedingungen des Titelbildes eingegangen und auch nicht auf seine Vor- und Nachbilder; Horst Bredekamp hat ja bereits in seinen paradigmatischen Studien die verschiedenen Variationen des Titelblattes nachgezeichnet und die Vor- und Nachbilder des „Leviathan“ aufgezeigt.

124 Vaughan-Williams, 2009, S. 80.

125 Casalini, 2008. Statt, 1990.

126 Benjamin, 1983, Bd. I, S.576-577. Siehe auch Buck-Morss, 1989. Dazu auch Buck-Morss, 1977. Eine sehr klare Darstellung zu Benjamins Bildbegriff findet sich in Zumbusch, 2004. Zu Benjamins „Jetztzeit" siehe Hamacher, 2005.

127 Pichler, 2007, S. 10. Die Schnabelmasken lassen sich dabei als etwas beschreiben, dessen Relevanz unabhängig von Hobbes' eigener Intention gegeben ist. 
Aber auf Bilder lassen sich bekanntlich ganz verschiedene Blicke werfen; am spannendsten schien mir hier ein Wechselspiel zwischen grosser Nähe und weiter Distanz. In Hinblick auf das nächste Kapitel ist eine weitere Überlegung bedenkenswert. „Sovereign power is the consequence of trading individual freedom for collective safety " ${ }^{128}$, schreibt Catherine Dauvergne. Doch für illegalisierte Immigrierende, die, wenn sie an den Grenzen Europas stranden, oft mit Mundschutzmasken empfangen werden, ${ }^{129}$ gilt dieser Tauschhandel zwischen individueller Gehorsamsverpflichtung und staatlichem Sicherheitsversprechen so nicht. 


\section{BOOTSFLÜCHTLINGE UND BILDGEDÄCHTNIS}

„Dafür gibt es inzwischen eine neue Seuche, die den Planeten bedroht: die Armut. Und wer von ihr befallen ist, muss unter strenge Quarantäne gestellt werden. Auch die Länder, deren Bevölkerung überproportional mit dieser scheusslichen Krankheit infiziert ist, werden unter Quarantäne gestellt."

„Ein Carabiniere mit Mundschutz, heute im Hafen von Brindisi bei der Ankunft eines Fischkutters beladen mit Illegalen aus Albanien“, lautet die Bildlegende einer Fotografie der Nachrichtenagentur AP aus dem Frühjahr 1997 (Bild 9). ${ }^{2}$ Mit einem weissen, durchsichtigen Handschuh drückt sich der elegant gekleidete Militärpolizist die schneeweisse Mundschutzmaske aufs Gesicht. Hinter ihm befindet sich der vollbeladene Fischkutter, der Carabiniere kehrt ihm den Rücken zu. Auf dem rostigen, einst weissgetünchten Schiff die „Clandestini“: Männer, einige Frauen, wenige Kinder. Sie warten im Stehen, die Bildbetrachter anblickend. 1997 ging mit dem so genannten Lotterieaufstand in Albanien der Zusammenbruch der staatlichen Strukturen einher. Dieses Bild von '97 erinnert an die Situation von 1991, als nach dem Fall des Staatssozialismus die Massenauswanderung aus Albanien begann.

1 Faciolince, 2008. Eine erste und kürzere Fassung dieses Textes ist erscheinen in Falk, 2010a.

2 Zum Kontext der Situation siehe Türke, 2008. - Dal Lago, 2006. - Azzelini und Gleitze, 2002. 


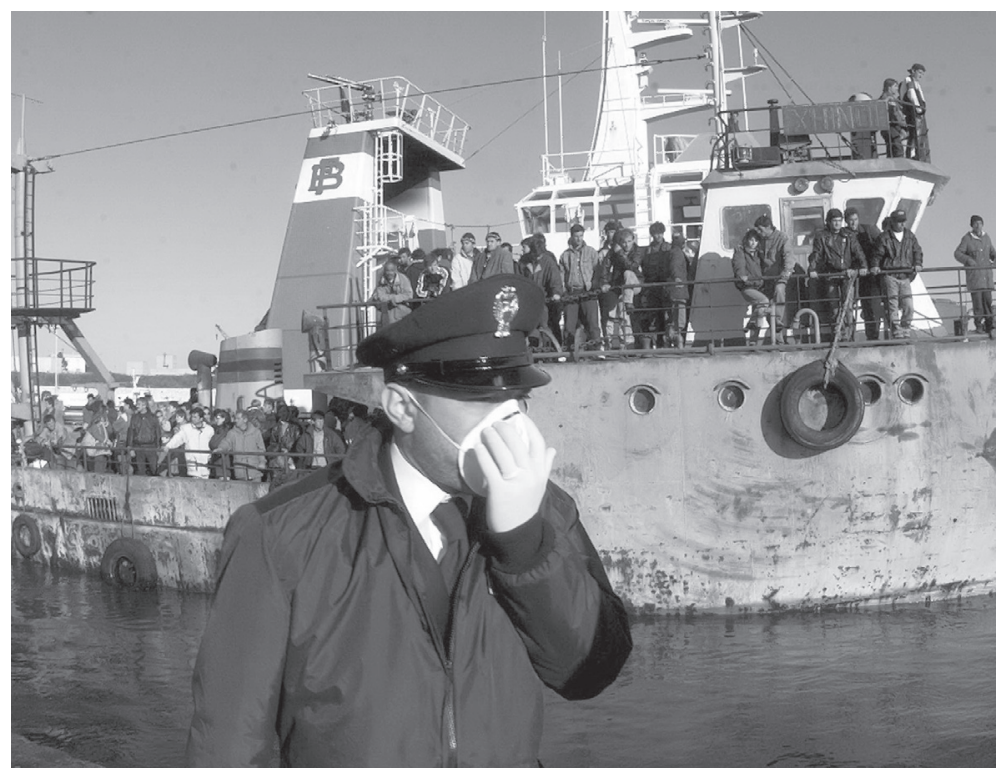

Bild 9: Luca Bruno, 18.03.1997 KEYSTONE AP 


\section{Das Boot ist voll}

Oliviero Toscani wählte im Jahr darauf für seine provozierende Benetton-Kampagne eine Agenturfotografie eines übervollen Bootes als Werbesujet. ${ }^{3}$ Das Bild des vollen Bootes ist jedoch nicht auf den visuellen Bereich beschränkt. Bundesrat von Steiger bezeichnete während des Zweiten Weltkriegs die Schweiz als ein Rettungsboot in grosser Seenot, das nur noch beschränkten freien Platz und nur noch begrenzte Vorräte habe. ${ }^{4}$ Indem ein Mangel an Platz und Ressourcen ausgerufen wurde, sollte einer äusserst restriktiven Flüchtlingspolitik Evidenz und Legitimation verschafft werden: „Fehlende Leere“ wurde im Dienste einer Strategie der „Völle“ benutzt: Sowohl im visuellen wie im metaphorischen Bild des vollen Bootes werden nicht die einzelnen Flüchtlinge gesehen; sie erscheinen vielmehr als anonyme Menschenmasse.

Dennoch präsentierte und imaginierte sich die Schweiz nach dem Krieg als Hort der Humanität, der den Verfolgten grosszügig Schutz geboten hatte. ${ }^{5}$ So beispielsweise 1946 in einem zweiteiligen Plakat von Victor Surbek (Bild 10). Angefertigt wurde es für eine Ausstellung, die in mehreren Schweizer Städten kurz nach dem Krieg gezeigt wurde, um Geld für das zerstörte Europa zu sammeln. Das Bild inszeniert die Schweiz und vor allem die Schweizer Armee in heroischer Weise: Die behelmten Wehrmänner lassen sich von der rauen See nicht aus der Ruhe bringen und halten das Boot auf Kurs. Auch wenn das Rettungsboot schon (fast) voll erscheint, zögert ein Bootsinsasse nicht, einem Ertrinkenden seinen starken Arm entgegenzustrecken.

In den 60er Jahren stiess der 2009 verstorbene Alfred Häsler mit seinem Buch „Das Boot ist voll“ eine Diskussion über die Schweizer Flüchtlingspolitik im Zweiten Weltkrieg an. ${ }^{6} 1980$ kam Markus Imhoofs gleichnamiger Film ins Kino, welcher für einen Oscar nominiert und von Friedrich Dürrenmatt gelobt wurde. 1979 veröffentlichte Häsler in der „Weltwoche" einen Artikel zu den Flüchtlingen aus Indo-

3 Italien und Albanien sind übrigens nicht nur geografisch, sondern auch historisch gesehen eng verbunden, hatte doch u. a. Italien unter dem Faschismus Albanien annektiert.

4 Zitiert nach Häsler, 1989, S. 180.

5 Kreis, 1995.

6 Häsler, 1996, S.324. 


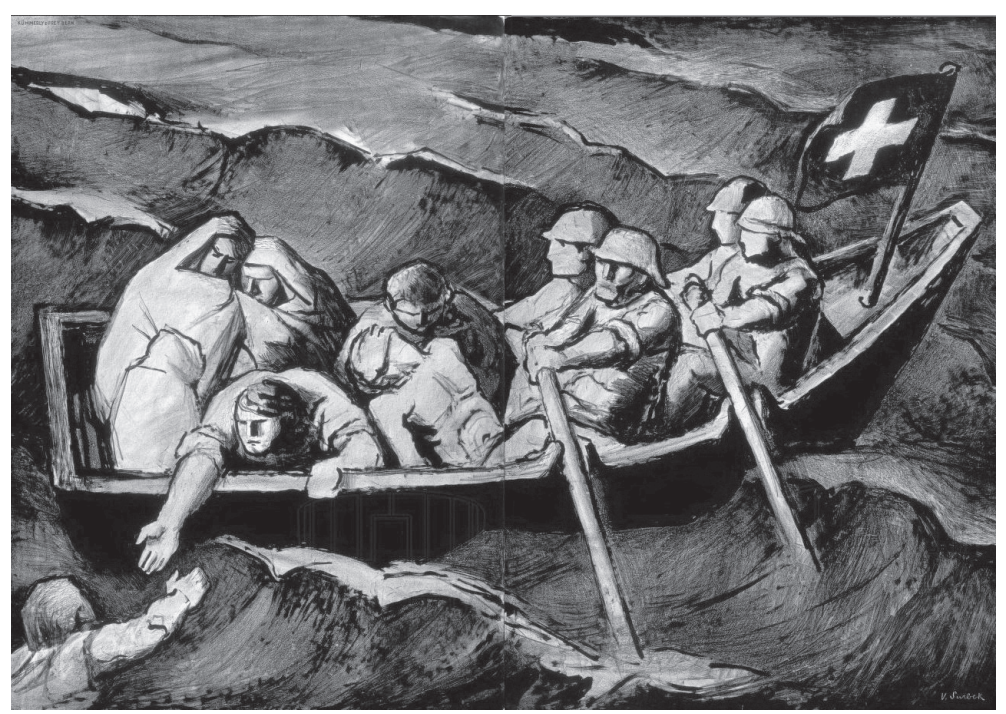

Bild 10: Viktor Surbek, Plakat für die Schweizer Spende $128 \times 271 \mathrm{~cm}, 1945$ oder 1946, Basler Plakatsammlung 
china unter dem Titel „Unser Boot ist nicht voll“. ${ }^{7}$ Damals wurden Flüchtlinge aus Vietnam als „Boat people“ bezeichnet. ${ }^{8}$

Zumindest in der Schweiz gehörte die Wendung des „vollen Bootes" in den 1980er Jahren zur migrationspolitischen Debatte: 1983 demonstrierte das Schweizerische Arbeiterhilfswerk zum Flüchtlingstag gegen die schon damals geläufige Parole: „Das Boot ist voll“.? Auf diesen Slogan griff mit einer anderen Absicht zu Beginn der 1990er Jahre in Deutschland auch die politische Partei der Republikaner zurück; ihr Wahlplakat zeigte Deutschland als eine mit Einwanderern überfüllte Arche Noah. ${ }^{10}$ Die Lega Nord wiederum warb 2002 mit dem Sujet eines überfüllten Bootes und der Bildüberschrift „L'ORDA NO!“ („Nicht die Horde!) “.11 Die Metaphorik des Bootes entfaltet eine Logik, der es schwierig zu entrinnen ist. So wird beispielsweise argumentiert, Chaos und Panik könnten auch ein halbvolles Boot zum Kentern bringen. ${ }^{12}$

\section{Ikonen gefährdeter Grenzen}

Bootsflüchtlinge sind heute in den europäischen Medien regelmässig sichtbar, selbst wenn die zahlreichen Todesopfer meist ungesehen bleiben. Die übervollen Boote sind zu einer Ikone „gefährdeter Grenzen“ geworden. ${ }^{13}$ Der Begriff der Ikone bezieht sich hier allerdings nicht auf eine einzelne Fotografie. Vielmehr handelt es sich dabei meist um "ganz normale " 14 , in ähnlicher Form zahlreich vorhandene Bilder; das Unauffällige kann in seiner Selbstverständlichkeit wirkmächtiger sein als das Auffällige und Aussergewöhnliche. In ihrer Gesamtheit konstituieren diese Bilder visuelle Erinnerungsorte. Das bedeutet aber nicht, dass sie nur als Bilder wirken; bereits in Byzanz waren Ikonen durch

7 Häsler, 1979 .

8 Pugh, 2004.

9 Dazu auch der ausgezeichnete Artikel von Pagenstecher, 2008. Zur Migrationspolitik in der Schweiz siehe auch Skenderovic und D'Amato, 2008. - Wicker I Fibbi und Haug, 2004.

10 Pagenstecher, 2008. Auch zum Teil bewusst erzeugte Überfüllungszustände in Asyllagern werden zuweilen als Beweis einer Überflutung der Gesellschaft durch Ausländer benutzt. Pieper, 2008, S. 18.

11 Hoppe, 2007, S. 133.

12 Jäger, 2007, S. 44.

13 Ich habe allerdings nicht mit quantitativen Methoden gearbeitet. Siehe diesbezüglich Van Gorp, 2005. - Gabrielatos und Baker, 2008.

14 Orland und Gugerli, 2002. 
das Zusammenwirken von Bild und Bildbeschriftung charakterisiert, denn Bild und Schrift leisten je Unterschiedliches und sind deshalb aufeinander angewiesen. Dabei ist die Grenze zwischen Bild und Schrift selbst als historisch variabel zu denken. ${ }^{15}$ Die hier behandelten Bilder beispielsweise sind als Agenturfotografien meist bereits mit einer Beschriftung versehen. ${ }^{16}$

Weiter verfügen Ikonen nicht per se über einen stabilen Status; eine Ikone ist nicht für alle und zu jeder Zeit eine Ikone. ${ }^{17}$ Ihre Bedeutung kann je nach Blick der Betrachtenden stark variieren; je nach Kontext können die gleichen Bilder verschiedene Evidenzen produzieren. So können Bilder, die suggerieren, dass die Grenze ausser Kontrolle geraten sei, zu einer militärischen Verstärkung der „Festung Europa“ führen, weil mit ihrer Hilfe Immigration in öffentlichen Diskursen zur Invasion stilisiert wird, die entsprechende migrationspolitische Forderungen nach sich zieht. Wird indes die Gewaltsamkeit dieser Grenzziehungen sichtbar, können unter Umständen die gleichen Bilder zur Forderung nach einer Welt mit offeneren Grenzen führen.

\section{Migration, Militär, Medizin}

Es fällt auf, dass auf Fotografien von Bootsflüchtlingen häufig Uniformierte mit Mundschutzmasken zu sehen sind. In diesen Bildern treffen Migration, Militär und Medizin aufeinander. So in einer Fotografie der European Pressphoto Agency vom 20. Oktober 2003 (Bild 11). In der Bildbeschriftung heisst es: „In den frühen Stunden von Montag dem 20. Oktober sind Carabinieri einem schwer dehydrierten und hungernden somalischen Immigranten behilflich, als er zum Hafen der Insel Lampedusa gebracht wird - eine Insel auf halbem Wege zwischen Tunesien und Sizilien. Küstenwächter zählten 13 tote Körper auf dem Holzschiff, als es in der letzten Nacht in einiger Entfernung der Insel entdeckt wurde. "18 Die hier geschilderte und gezeigte Situation unterscheidet sich deutlich vom Sujet des überfüllten Bootes; nun richtet sich der Blick auf ein einzelnes, geschwächtes Individuum, das nicht

15 Dazu auch Foucault, 1997.

16 Drechsel, 2006.

17 Perlmutter, 1998, S. 10.

18 Übersetzung aus dem Englischen ff. Auf beide Bilder bin ich durch Recherchen im Keystone Schweiz online-Archiv gestossen. Der Frage, in welchen Zusammenhängen diese Bilder publiziert worden sind, bin ich nicht systematisch nachgegangen, ich werde deshalb dazu keine Ergebnisse präsentieren. 


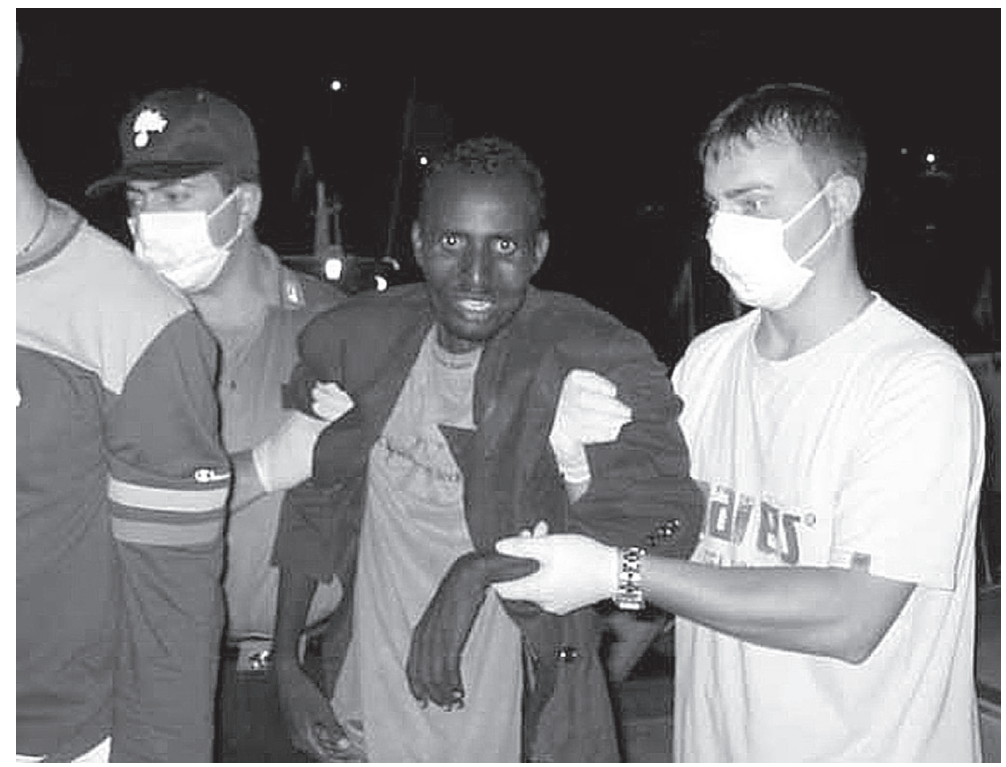

Bild 11: Franco Lannino, 20.10.2003

EPA/Keystone 
mit einem grossen Fischkutter angekommen ist, sondern mit einem Holzboot, in welchem zahlreiche Menschen ihr Leben verloren haben. ${ }^{19}$ Die Entkräftung des hageren Bootsflüchtlings wird hier besonders durch die schlaffen Arme und die herunterhängende Hand deutlich. Im Kontrast dazu stehen die starken Arme der stützenden Helfer, die wiederum weisse Handschuhe und Mundschutzmasken tragen. ${ }^{20}$ Eine solche Bildkomposition erinnert an unzählige Darstellungen des Schmerzensmannes oder der Engelspietà. ${ }^{21}$ So beispielsweise etwa an jene von Giovanni Bellini, wie er sie u.a. im Dogenpalast oder in der Dominikanerkirche „Santi Giovanni e Paolo“ in Venedig realisierte. ${ }^{22}$ Auf einem dort zu findenden Altarbild für den heiligen Vinzenz Ferrer, einen spanischen Dominikaner, wird Jesus in sehr ähnlicher Weise gestützt wie auf unserer Fotografie der Somalier (Bild 12). Ein Engel hält den angewinkelten Arm Jesu, so dass die Wundmale deutlich sichtbar sind. Eine solche Handstellung findet sich, allerdings seitenverkehrt, auch bei unserem (allerdings lebendigen) Bootsflüchtling. ${ }^{23} \mathrm{Ob}$ der Fotograf oder der Mitarbeiter der Bildagentur, der diese Fotografie unter anderen auswählte, eine Engelspietà als visuelles Vorbild im Kopf hatte, vermag ich nicht zu sagen. Unabhängig davon können solche Bildtraditionen durch ein Dispositiv des „inszenierten Déja vu“ - wie Claus Leggewie dies treffend formulierte ${ }^{24}$ - die Ökonomie der Auf-

19 Die Holzboote mit ihren oft bunten Planken entsprechen zynischer Weise dem Klischee vom romantischen Fischerleben. Boesch, 2008, S. 21.

20 Nicht ganz klar ist, ob der Bootsflüchtling von den beiden Helfern nur gestützt oder gleichzeitig auch abgeführt wird.

21 Kritische Bemerkungen zum Verfahren der Ikonologie finden sich bei Mitchell, 1994, S. 30.

22 Das Werk wurde um 1460 realisiert. Die Zuschreibung ist allerdings nicht unumstritten. Für meine Argumentation macht es indes keinen Unterschied, von welchem Künstler das Werk letztlich stammt. Zu Bellini siehe beispielsweise Bätschmann, 2008.

23 Bellinis Pietà wird flankiert von Christophorus und dem Heiligen Sebastian. Dieser ertrug sein Leiden als Märtyrer stoisch; auch auf dem Bild scheint er keinen Schmerz zu spüren. Sebastian ist neben Rochus einer der wichtigsten Pestheiligen. Er, der als christlicher Märtyrer von Bogenschützen mit Pfeilen durchbohrt worden war, sollte die Pfeile der Pest auf sich ziehen und damit die Menschen vor der Seuche schützen. Leven, 2001, S.78.

Bellini, beeinflusst von byzantinischen Bildtraditionen, lebte und arbeitete in jener Zeit in Venedig (1430-1516), in der etwa das "Lazzaretto Nuovo" als Quarantänestation zur Pestprävention etabliert wurde. Pestpolitik war, wie ich in meinen Ausführungen zu den Schnabelmasken zeige, sehr wichtig für die Etablierung und Legitimierung von Grenzen.

24 Leggewie, 2000. 


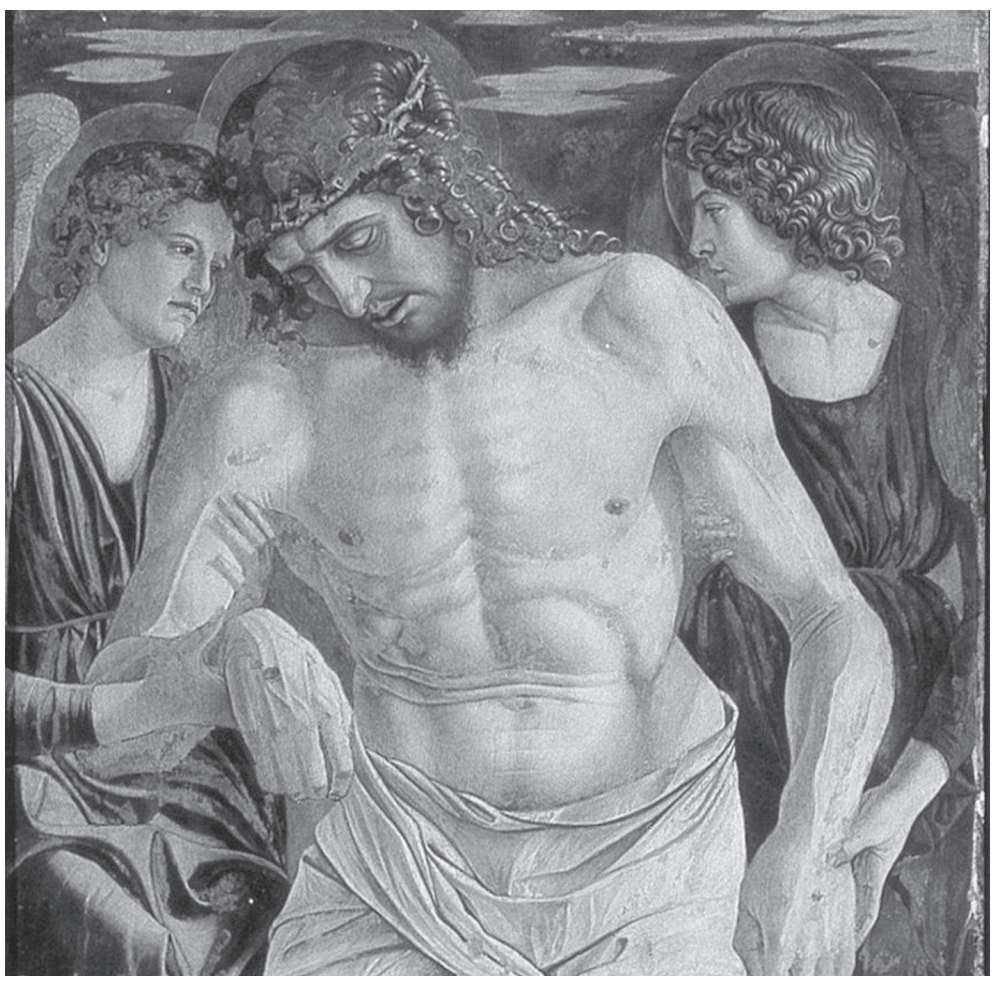

Bild 12: Giovanni Bellini, Polyptychon hl. Vincent Ferrer

$72 \times 67 \mathrm{~cm}$, „Santi Giovanni e Paolo“ in Venedig, 1465-68 
merksamkeit ${ }^{25}$ und damit die Wahrnehmung dieser Fotografien prägen; latente Erinnerungsgehalte können dabei unbewusst wirken, so Aleida Assmann. ${ }^{26}$ Der Immigrant aus Somalia ${ }^{27}$ erscheint hier in visueller Anlehnung an die Engelspietà als Opfer. Bilder von Flüchtlingen, die in der Tradition der christlichen Ikonografie ${ }^{28}$ stehen, sind übrigens weit verbreitet, man denke etwa an Dorothea Langes berühmte Fotografie „Migrant Mother“ von 1936, die stark an Darstellungen der Madonna erinnert, oder auch an das Titelbild von Seyla Benhabibs Buch "The Rights of Others“ ${ }^{29}$ Auch im Plakat von Surbek erinnert der halbliegende Flüchtling an die berühmte Pietà von Michelangelo.

"Opferbilder" sind indes insofern einseitig, als diese Migrantinnen und Migranten selbst Akteure und nicht nur passive Opfer sind, wie solche Bilder suggerieren. Sie handeln, um ihre Situation zu verbessern, selbst wenn der Preis dafür sehr hoch sein kann. Allerdings irritiert, dass der (lebende) Bootsflüchtling aus Somalia im Gegensatz zum Bild von Bellini unseren Blick auf verstörende Art erwidert und damit in gewisser Weise aus seiner Opferrolle ausbricht; ob ein solches Detail wahrnehmbar wird, hängt allerdings auch vom Kontext der Betrachtenden ab. Doch das hier behandelte „Opferbild“ kann neben Mitleid auch Angst auslösen. Denn die Mundschutzmaske deutet auf die Möglichkeit einer Ansteckung. Bei einer etwas genaueren Betrachtung dieser Masken - beispielsweise in italienischen oder spanischen Fernsehnachrichten - fällt auf, dass jeweils einige Uniformierte einen Mundschutz tragen, andere jedoch nicht, obwohl sie in den gezeigten Aufnahmen die gleiche Aufgabe ausführen und sich in gleich engem Kontakt zu den Ankommenden befinden; der Grund für ein Tragen oder Nichttragen einer Mundschutzmaske wird jeweils nicht ersichtlich. ${ }^{30}$ Dies zeigt, dass das Tragen auch hier nicht nur auf medizinische Gründe zurückgeführt werden kann.

25 Franck, 1998.

26 Assmann, 1998, S. 30.

27 Dieses Gebiet befand sich einst übrigens unter britischer sowie italienischer Kolonialherrschaft.

28 Panofsky, 1975.

29 Benhabib, 2004. Auch Josef und Maria waren Flüchtlinge, was in diesem Zusammenhang nicht vergessen werden sollte. Eine starke Präsenz von biblischen Motiven findet sich in diesem Zusammenhang beispielsweise auch in den beiden Filmen „Children of Men“ (2006) und „La Forteresse“ (2008).

30 Diese Beobachtung machte ich im Sommer und Herbst 2008, so beispielsweise in Bezug auf den spanischen Telediario TVE am 26. August (15:23), 2. September (15:20), 4. September (15:10), 14. September (15:15), 22. September (15:22). 
Die Mundschutzmaske besitzt einen ikonischen Charakter, doch ihre Konnotation variiert beträchtlich. So galt in Zeiten von SARS in Hongkong das Tragen der Maske auch als ein Ausdruck von Solidarität: „The mask symbolized a rule of conduct - namely an obligation to protect the wider community - and an expectation regarding how one was to be treated by others [...]. More simply, the mask was the emblematic means by which people communicated their responsibilities to the social group of which they were members. " 31

Hier steht die Maske demnach für Solidarität und Verantwortlichkeit. Zudem sind Mundschutzmasken im chinesischen Raum allgemein sehr viel präsenter, so beispielsweise bei Strassenputzerinnen oder bei Radfahrern, die sich auf diese Weise vor der verschmutzten Luft schützen wollen. Auf jenen Bildern in den europäischen Medien hingegen, in denen Uniformierte mit Mundschutzmasken Bootsflüchtlinge empfangen, ist die Bedeutung der Maske eine andere. ${ }^{32}$ Hier überlagern sich territoriale Grenzen mit Körpergrenzen; Migration erscheint hier auch als Angriff auf die Integrität des eigenen Körpers. ${ }^{33}$ Diese Überlagerung zeigt sich übrigens auch in den verwendeten Begrifflichkeiten; so konnotiert der „Schlepper“ das Einschleppen von Krankheiten. ${ }^{34}$

Es geht hier allerdings nicht darum, die medizinischen Gefahren, die durch die Bewegung von Menschen entstehen können, zu negieren. Philipp Sarasin schreibt dazu: „Es gibt unbestreitbar einen verstärkten Austausch und eine weltweite Verbreitung von pathogenen Mikroorganismen entlang der Routen von Migrationsströmen - allein, gibt es diesen Austausch nicht ebenso, möglicherweise noch viel ausgeprägter im weltweiten touristischen Verkehr? “35

31 Baehr, 2008, S. 150.

32 Seit dem Ausbruch der Schweinegrippe sind Mundschutzmasken allerdings in den europäischen Medien noch präsenter, siehe beispielsweise das Titelbild der Westschweizer Illustrierten L'illustré vom 22. Juli 2009, das Prominente wie Roger Federer mit Mundschutzmaske zeigt.

$33 \mathrm{Zu}$ einer nicht unproblematischen Analogisierung zwischen Körper- und Staatsgrenzen siehe Ratzel, 1903, S.605. Dazu auch Ebeling, 1997.

34 Und der Schleuser das Einsickern von Fluten. Gerhard, 1993, S. 245.

35 Sarasin, 2004, S. 176-177. SARS habe etwas Anderes gelehrt. Deshalb gelte es zu zeigen, „how quickly fact and fiction melt in this area“. Sarasin, 2006, S.217. Es geht auch nicht darum, wie Nancy Tomes zu Recht kritisiert, Krankheiten nur als kulturelle Konstrukte verstehen zu wollen. Tomes, 1999, S. 16. 


\section{Fazit}

Die übervollen Boote sind wohl auch deshalb zu einem beliebten Sujet der Berichterstattung zum Thema Migration geworden, weil sie nebst einer dramatischen Struktur in ihrer Bedeutung vielschichtig sind. ${ }^{36}$ Solche Bilder, die sowohl Angst wie auch Mitleid zu evozieren vermögen, erinnern an das Konzept der Katharsis: Die Betrachter werden in eine Zuschauerrolle verwiesen, die Katastrophe erscheint dabei als unausweichlich, was die Zuschauenden in problematischer Weise von Verantwortung befreit.

Das Boot weist weiter ein sehr breites Bedeutungsspektrum auf, im Prinzip kann es ebenso auf die Beschränktheit des Platzes verweisen wie an Solidarität appellieren; erinnert sei hier an den Ausspruch „wir sitzen alle im gleichen Boot" oder an das Schiff als Metapher für den Staat. Ein Boot beziehungsweise Schiff - das wiederum etwas anders konnotiert ist als das Boot - vermag noch weitere Assoziationen aufzurufen, so beispielsweise an die zumindest in christlichen Kontexten positiv konnotierte Arche Noah. Andererseits können Bilder dieser Boote auch die mythologische Todesfähre erinnern. Ein Schiff voll mit winkenden Flüchtlingen, wie es beispielsweise in einem Schulbuch verwendet wird, kann hingegen einen anderen Eindruck erwecken ${ }^{37}-\mathrm{ob}$ das allerdings tatsächlich der Fall ist, bestimmt sowohl das konkrete Bild wie der Kontext der Rezeption. Gegenwärtig stehen die Bilder von Bootsflüchtlingen für eine bestimmte Art der Migration, nämlich junger afrikanischer Männer nach Europa. Solche Bilder suggerieren, dass die Grenzen nicht geöffnet werden dürfen, weil es sonst zu einer Invasion der Immigrierenden käme.

Schiffe waren das Transportmittel im Zeitalter des Kolonialismus; dass auf dem Bild des Bootsflüchtlings aus Somalia auch ein Carabiniere erscheint, ist in diesem Kontext nicht unrelevant, waren doch während der repressiven Kolonialpolitik des faschistischen Italiens gerade die Carabinieri in Italienisch-Somaliland für Gewalttaten verantwortlich.

Durch ein Abkommen zwischen Italien und Libyen wurde verhindert, dass Boote überhaupt ins Meer stachen. Der finanzielle Betrag,

36 Allerdings waren im Jahre 2009 die Bootsflüchtlinge meiner Meinung nach aufgrund der in den Medien sehr präsenten Wirtschaftskrise, der Schweinegrippe und einer Politik, die vermehrt versucht, die Boote gar nicht erst in europäische Gewässer zu lassen, medial weniger stark präsent.

37 Argast / Binnenkade / Boller und Gautschi, 2005, S. 152. 
den ein europäisches Land für das in Kolonialzeiten ausgeübte Unrecht überwies, war demnach in paradoxer Weise zugleich eine Belohnung für die Unterbindung illegalisierter Immigration, wurde doch damit Gaddafi bezahlt, dass er keine Schiffe mehr in Richtung Lampedusa aufbrechen liess. ${ }^{38}$ Seit dem arabischen Frühling im Jahre 2011 sind die Bootsflüchtlinge wieder zurück. ${ }^{39}$

In der hier untersuchten Konstellation ist das Bild des vollen Bootes und jenes der christlich inspirierten Engelspietà „typologisch“ interpretiert worden: Die beiden Sujets sind zwar jeweils anders konnotiert, beide Bilder weisen aber in der Mundschutzmaske - die in den letzten Jahren vor allem in Zusammenhang mit der Vogel- und Schweinegrippe medial sehr präsent war und dabei vielleicht auch ihre Konnotation veränderte - ein gemeinsames Merkmal auf: die Angst vor Ansteckung. ${ }^{40}$ Die dabei erzeugte Verbindung von Immigration und Infektion ist weit verbreitet; beispielsweise wurde damit auch operiert, als die Räumung des so genannten Dschungels von Calais und die polizeiliche Zerstörung der Notunterkünfte u. a. mit hygienischen Gründen legitimiert wurden. ${ }^{41}$

Solche Bilder werden Teil des kollektiven und kulturellen Gedächtnisses und prägen dadurch die Wahrnehmung von Grenzen und den Umgang mit ihnen. ${ }^{42}$ Es kommen allerdings die wenigsten der illegalisierten Immigrantinnen und Immigranten als Bootsflüchtlinge nach Europa; die meisten reisen über Land- oder Luftwege ein. Der Grossteil der Illegalisierten in der EU hat zudem nie illegal eine Grenze überquert, sondern aus unterschiedlichen Gründen die Aufenthaltserlaubnis verloren. ${ }^{43}$ Wenn also Europa unter gewissen Aspekten einer Festung ${ }^{44}$ gleicht, dann einer mit Dienstboteneingang. ${ }^{45}$

Metaphern zeichnen sich bekanntlich dadurch aus, dass sie erfolgreich gewisse Ähnlichkeitsbeziehungen etablieren oder erfolglos suggerieren. Dabei ergibt sich ein Spannungsfeld möglicher Sichtweisen. Die Metapher der Festung Europa weist gewisse Implikationen und Konnotationen auf: Eine Festung darf im Kriegsfall auch nicht verlas-

38 Falk, 2012. Dazu auch Triulzi, 2006.

39 Falk, 2011a.

40 Eine Verbindung des Motivs des vollen Bootes mit einer Pietà findet sich übrigens auch auf Géricaults „Das Floss der Medusa“ von 1819.

41 Siehe dazu Calame, 2010.

42 Dazu auch Von Osten, 2007.

43 Schwenken, 2006, S. 13.

44 Leuthardt, 1994. - Leuthardt, 1999.

45 Marischka und Pflüger, 2006, S. 152. 
sen werden; sie funktioniert im Innern durch ein strenges Kontrollregime. Festungen können weiter auch religiös aufgeladen werden, erinnert sei hier nur an Luthers Kirchenlied: „Ein(e) feste Burg ist unser Gott".

Gerade die Metaphorik der Festung Europas, die das Bild einer klaren und scharfen Grenze zwischen innen und aussen evoziert, verdeckt allerdings mit der von ihr produzierten Evidenz die Existenz der illegalisierten Immigrierenden; sie verbirgt den Umstand, dass auch innerhalb der Festung (oft unsichtbare) Grenzen verlaufen und dass sich die Grenzen Europas heutzutage in einem gewissen Sinne bereits in Nordafrika oder in der Türkei befinden. ${ }^{46}$ Während einige die Abschottung Europas betonen, überwiegt bei anderen in Bezug auf die europäische Entwicklung eine optimistische Einschätzung; sie verstehen Europa als Konzept für die schrittweise Öffnung der Welt. ${ }^{47}$

46 Euskirchen, 2009, S. 75. Kreis, 2004.

47 Thränhardt, 2010. 


\title{
Die Vorgeschichte Des AbSCHIEBELAGERS
}

\author{
„Ihr sollt wissen, dass kein Mensch illegal ist. \\ Das ist ein Widerspruch in sich. Menschen \\ können schön sein oder noch schöner. Sie \\ können gerecht sein oder ungerecht. Aber ille- \\ gal? Wie kann ein Mensch illegal sein?"1
}

Die für Nichtbetroffene meist nicht wahrnehmbare Grenze innerhalb Europas, welche Legalisierte von Illegalisierten trennt, ist für den Alltag der Sans-Papiers prägend. Diese Grenze zeigt sich beispielsweise, wenn Illegalisierte in Abschiebungshaft genommen werden; hierbei handelt es sich um ein Zwangsmittel, mit dem der Aufenthalt in einem Staat beendet werden soll. ${ }^{2}$ Von den illegalisierten Immigrierenden wird die Abschiebung (in der Schweiz spricht man von Ausschaffung) als Gewalterfahrung empfunden. ",The boundary between ,insiders and ,outsiders" can only be created and policed in an illiberal way. " ${ }_{4}$ Die Abschiebelager sind für die „Normalbevölkerung“ kaum sichtbar, da sie sich meist in der Peripherie der Städte befinden, in der Nähe von Bahngeleisen oder Flughäfen. Eine wichtige administrative Strategie ist die Anordnung dieser Unterkünfte ausserhalb des Sichtfeldes der Bevölkerung. ${ }^{5}$ Mediale Bilder von Abschiebelagern zirkulieren nur in spektakulären Situationen, und dann nur aus der Aussenperspektive: Für Journalistinnen und Journalisten ist es schwierig, eine Besichtigungserlaubnis zu erhalten ${ }^{6}$, und meist darf aus Sicherheitsgründen wie es heisst - innen nicht fotografiert werden. ${ }^{7}$

1 „You shall know that no one is illegal. It is a contradiction in itself. People can be beautiful or even more beautiful. They may be just or unjust. But illegal? How can someone be illegal?"“ Elie Wiesel, jüdischer Holocaust-Überlebender und NobelPreisträger, sagte dies in Tucson, Arizona, auf einer Konferenz über Asyl in den USA. Siehe Heck, 2008, S. 123.

2 De Genova und Peutz, 2010.

3 Düvell, 2005b, S. 194.

4 Cole, 2003, S. 199.

5 Pieper, 2008, S. 18.

6 Dazu auch Shuler, 2008. Kost, 2008.

7 Dazu eindrücklich Gatti, 2010. „Während im Panopticon die Gefangenen stets sichtbar sein sollten, machen die Lager ihre Gefangenen permanent unsichtbar." 
Die Abschiebungsinsassen können dabei mit Gayatri Spivak als "Subalterne"8 gesehen werden, die meist über keine Sprechposition verfügen und deshalb zuweilen mit Brandstiftung antworten, was beispielsweise 2007 im Basler „Bässlergut“ nach einer Verschärfung der Bestimmungen oder im Februar 2009 auf Lampedusa im „Centro di identificazione ed espulsione " geschah. ${ }^{9}$ Die Aussage, dass Subalterne nicht "sprechen“ können, bedeutet aber nach Spivak nicht, dass diese über keine Handlungsmacht verfügen, sondern dass das „Zuhören“ hegemonial strukturiert ist. ${ }^{10}$ Nach Spivak gehöre zur Subalternität geografische und soziale Immobilität, weshalb Migrierende, so Nikita Dhawan, nach Spivaks Definition nicht als subaltern zu bezeichnen seien. ${ }^{11}$ Allerdings kann zwischen illegalisierten und anderen Migrierenden unterschieden werden, da sich die Möglichkeiten einer solchen Mobilität jeweils ganz anders gestalten und das Ausschaffungslager gerade die erzwungene Immobilität verkörpert. ${ }^{12}$

In der Geschichtswissenschaft befinden sich die Abschiebelager am Rand. Hier folgt deshalb der Versuch einer knappen genealogischen Beschreibung der Abschiebehaft. ${ }^{13}$ Genealogie soll hier allerdings in Anlehnung an Nietzsche und Foucault nicht als Teleologie verstanden werden und auch nicht ontologisch als Suche nach dem genau abgegrenzten Wesen, einer „ahistorischen Essenz" einer Sache. ${ }^{14}$ Meine Verwendung des Begriffs „Lager" bezieht sich dabei explizit nicht auf die Konzentrationslager des Nationalsozialismus. ${ }^{15}$ Mich interessiert die Vorgeschichte des Lagers, weshalb ich nicht auf die nationalsozialistischen KZs und Vernichtungslager ${ }^{16}$ zu sprechen komme, weiter auch

Mirzoeff, 2008, S. 126. Allerdings sind die Gefangenen im panoptischen Gefängnis auch da nur von innen, nicht von aussen sichtbar.

8 Zum Begriff der Subalternen siehe Spivak, 1988.

9 Dazu http://www.telebasel.ch/php/videoarchiv/index.php?site=vcat\&cat=7\&so $\mathrm{rt}=\mathrm{ID} \&$ order=DESC\&show=20\&page=10\&lang=de (23. 3. 2009) sowie http:// www.corriere.it/cronache/09_febbraio_18/lampedusa_incendio_cie_scontri_ immigrati_forze_ordine_43a1d466-fdb2-11dd-aa50-00144f02aabc.shtml (23. 3 . 2009).

10 Siehe dazu Castro Varela und Dhawan, 2005. - Castro Varela und Dhawan, 2009/2010. - Castro Varela und Dhawan, 2010.

11 Dhawan, 10.2.2011. Dazu weiter Spivak, 1997.

12 Doch wenn Subalterne sich selbst als solche begreifen, sind sie es nicht mehr. Dhawan, 2008.

13 Siehe dazu auch Schwarte, 2007.

14 Foucault, 1987.

15 Es geht mir nicht darum, das nationalsozialistische $\mathrm{KZ}$ zu relativieren. Zur Problematik des Begriffs Konzentrationslager siehe Wieviorka, 1997.

16 Benz und Distel, 2005-2009. 
nicht auf die Kriegsgefangenenlager des Ersten Weltkrieges oder auf die Internierungslager, die beispielsweise während des Zweiten Weltkriegs in der Schweiz für Flüchtlinge und Soldaten errichtet worden sind. ${ }^{17}$

Im Deutschen weist der Begriff des Lagers sehr viele Bedeutungen auf. Bei den folgenden aufgeführten sehr verschiedenen Lagern ist das gemeinsame Merkmal, dass Zivilisten gegen ihren Willen gemeinsam an einem Ort festgehalten, „konzentriert“ werden: Die Funktion des Lagers besteht hier darin, Mitglieder gesellschaftlicher Gruppen, die als verdächtig oder schädlich angesehen werden, massenhaft zu konzentrieren. Die Lagergesellschaft ist eine Mangelgesellschaft - „und sei es nur der Mangel an Platz, Bewegungsfreiheit, Rückzugsmöglichkeiten für den Einzelnen “. ${ }^{18}$ Der provisorische Charakter des Lagers - Menschen sollten sich da vorübergehend aufhalten - kann dabei zum Dauerzustand werden.

\section{Lager in kolonialen Konstellationen}

Es ist umstritten, wo die Erscheinung der Lager ihren Anfang nahm. In der Literatur wird die Entstehung des Lagers oft auf die "campos de concentraciones" zurückgeführt, welche die Spanier 1896 in Kuba errichteten. Hier wurde der Begriff der „Konzentration“ geprägt. ${ }^{19}$ Es ging darum, die Landbevölkerung zwangsweise an einem vorgegebenen, von der Armee kontrollierten Ort zu versammeln, meist in einer Stadt oder in der Nähe einer Stadt, um so den Aufständischen die Nahrungsmittel zu entziehen und Spionage zu verhindern. Dieser Raum wurde aber nicht abgesperrt. Zivilisten, die sich ausserhalb der bewilligten Zonen aufhielten, galten als Straftäter. Allerdings waren bereits in den 1830er Jahren in Nordamerika Indianer zum Zwecke der Zwangsumsiedelungen in Lagern zusammengetrieben worden; in $\mathrm{Al}$ gerien wurden von den Franzosen ebenfalls bereits in diesen Jahren Lager zur Zwangsumsiedelung errichtet. Auch während des Burenkriegs (1899-1902), in welchem die Engländer die Buren in „concentration camps “ zusammenpferchten, ${ }^{20}$ war die Absicht, die Zivilbevölkerung zu isolieren, nicht, sie zu vernichten, selbst wenn damals

17 Erlanger, 2006.

18 Herbert, 1987, S. 34.

19 Im Folgenden siehe Kotek und Pierre, 2001, S. 45.

20 Agamben, 2002, S. 175. 
Tausende, vor allem Frauen und Kinder, ihr Leben verloren. Die vollständige Vernichtung der Herero als Nation war hingegen das Ziel der Deutschen im heutigen Namibia. Hier erfuhr ab 1905 auch das Lagersystem eine entscheidende Veränderung in der Verbindung von Inhaftierung und Zwangsarbeit. ${ }^{21}$

Eine eindeutige Datierung des „ersten“ Lagers ist für meine Zwecke nicht nötig. Entscheidend ist, dass die Institution des Lagers in kolonialen Kontexten entstand, was übrigens bereits Hannah Arendt konstatierte. ${ }^{22}$ „Die Lager gehen also nicht aus dem gewöhnlichen Recht hervor (und noch weniger, wie man hätte vermuten können, aus einer Verwandlung und Entwicklung des Strafvollzugsrechts)“, schreibt Giorgio Agamben, „sondern aus dem Ausnahmezustand und

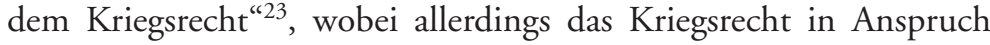
nimmt, den Ausnahmezustand des Kriegs in die gesellschaftliche Ordnung zu integrieren. Der Ausnahmezustand wird sich allerdings, so Agamben, von der Kriegssituation emanzipieren und zur Polizeimassnahme mutieren; er ist dann „kein Sonderrecht (wie das Kriegsrecht), sondern er bestimmt, indem er die Rechtsordnung suspendiert, deren Schwelle oder Grenzbegriff." ${ }^{24}$ Wichtig ist dabei, dass der Ausnahmezustand nach Agamben aus einer demokratischen Tradition hervorgeht. ${ }^{25}$ Agamben geht indes nur kurz auf den kolonialen Kontext der Lager ein. ${ }^{26}$

\section{Abschiebung der Fahrenden}

Nicht nur als Akteurin im europäischen Wirtschaftssystem war auch die Schweiz Teil von kolonialen Konstellationen. Doch in Bezug auf die Schweiz ist zu beachten, dass hier koloniale Gewalt schon im Zeitalter des Kolonialismus wohl weniger sichtbar war als in jenen Natio-

21 Dazu auch Krüger, 1999, S. 127.

22 Arendt, 2008, S.911. Auf die in diesem Zusammenhang von Hannah Arendt initiierte Debatte über die Verbindungen von Imperialismus, Kolonialismus und Nationalsozialismus sei an dieser Stelle hingewiesen. Dazu auch Gerwarth und Malinowski, 2007. Dazu auch Krüger, 1999, S. 68.

23 Agamben, 2002, S. 175. Dazu auch Panagiotidis und Tsianos, 2007, S. 78.

24 Agamben, 2004, S. 10,11.

25 Agamben, 2004.

26 Siehe dazu Mbembé, 2003. Auch bei Foucault sind koloniale Konstellationen in der Analyse wenig explizit präsent. Dazu Lemberg-Pedersen, 2010. 
nalstaaten, die sich explizit als Kolonialmächte verstanden. ${ }^{27}$ Doch lässt sich die „Herkunft“ des Lagers ebenfalls in innereuropäischen Verdrängungs- und Kolonisierungsprozessen festmachen, so beispielsweise in der Schweiz gegenüber den Fahrenden. ${ }^{28}$

1887 beschlossen die Kantone, ausländische Fahrende an der Einreise in die Schweiz zu hindern. Diese restriktive "Zigeunerpolitik“, die von den Kantonen praktiziert wurde, indem sie u. a. Fahrende von einem Kanton in den anderen abschoben, wurde vom Bund bereits auch schon früher kritisiert, so 1872 in einem Schreiben an den Kanton Uri: „Uebrigens ist hierbei nicht zu übersehen, dass es einigermassen schwer fällt, das richtige Mass der Kontrolle zu treffen. Es ist nicht möglich, und auch nicht statthaft, ganze Klassen von Personen von dem persönlichen Verkehr auszuschliessen, weil Einzelne sich Ungebührlichkeiten zu Schulden kommen lassen können. Es würde ein solches Verfahren bei dem mehr und mehr entwickelten Eisenbahnverkehr auch nicht möglich und zudem im Widerspruch sein mit dem allseitig und zumal in der Republik anerkannten Grundsatz der freien Zirkulation der Individuen. "29 Eine rechtliche Legitimation der Abschiebung war allerdings bereits in der Bundesverfassung von 1848 im Artikel 57 verankert worden: „Dem Bunde steht das Recht zu, Fremde, welche die innere oder äussere Sicherheit der Eidgenossenschaft gefährden, aus dem schweizerischen Gebiete wegzuweisen. " ${ }^{30}$ Während aber 1872 die Einschränkung der Bewegungsfreiheit für „ganze Klassen von Personen“ beanstandet wurde, billigte der Bund gegen Ende des 19. Jahrhunderts das Vorgehen der Kantone. Am 27. Juni 1906 stellte der Vorsteher des Justiz- und Polizeidepartements, Bundesrat Ernst Brenner, den Antrag, den Transportanstalten die Beförderung von "Zigeunern“ zu verbieten. Dieser Antrag wurde gutgeheissen und es wurde ein Kreisschreiben an die Kantonsregierungen erlassen. Darin heisst es, die Landesgrenze solle gegen die Einwanderung von Zigeunern aufs Sorgfältigste abgeschlossen werden und die eingedrungenen Zigeuner seien so rasch als möglich dahin auszuschaffen, woher sie gekommen seien. ${ }^{31}$ Angestrebt wurde ausserdem ein gemeinsames Vorgehen mit anderen Staaten, was jedoch nicht zustande kam. 1911 erarbeitete deshalb die Schweiz ein „Programm betreffend Bekämpfung der Zigeunerplage“ im Allein-

27 Dazu auch Guex, 2007.

28 Siehe dazu auch Falk, 2012.

29 Egger, 1982, S. 53.

30 Bundesverfassung der Schweizerischen Eidgenossenschaft, vom 12. Herbstmonat 1848,1848, S. 23.

31 Egger, 1982, S. 58. 
gang: „Da eine Regelung der Zigeunerfrage auf internationalem Boden sich zur Zeit als unmöglich erweist, müssen wir versuchen, die Zigeuner auf dem Wege der Abschreckung und womöglich der Ausweisung unserem Lande fernzuhalten. "32 Kantone sollten weiter Anstalten zur Verfügung stellen, „wo die Zigeuner gegen Kostgeld interniert werden können“. Drei solcher Anstalten würden genügen, wenn sie sich auf die verschiedenen Landesgegenden richtig verteilten. ${ }^{33}$ Zudem sollte eine „Zigeunerregistratur" geschaffen werden, in der deren Personalien gesammelt würden. Die bernische Zwangsarbeitsanstalt Witzwil erklärte sich bereit, die über 16 Jahre alten männlichen Fahrenden während dieser Identifikationshaft aufzunehmen. ${ }^{34}$ Der Bund übernahm ein tägliches Kostgeld von 1.50 Fr. Die Frauen wurden in dieser Zeit in Heime gesperrt, die von der Heilsarmee geführt wurden. War die Identifikation abgeschlossen, wurden die Fahrenden auf Anweisung des Justiz- und Polizeidepartements heimlich über die Schweizergrenze abgeschoben. Da verschiedene bilaterale Niederlassungsverträge die heimliche Abschiebung von Personen ausdrücklich untersagten, nahm diese Praxis bald groteske Formen an. Um die schweizerisch-deutsche Grenze nicht zu sehr zu belasten, schob man die Fahrenden zur Abwechslung nach Frankreich ab, obwohl sie nach eigenen Angaben aus Deutschland stammten. ${ }^{35}$ Diese Internierung, die ab 1913 bis 1921 erfolgte (nach 1921 wurden aufgegriffene Gruppen von ausländischen Sinti, Roma oder Jenischen in lokalen Polizeigefängnissen untergebracht und nicht mehr alle nach Witzwil geschickt), ${ }^{36}$ kann in gewisser Hinsicht als Folge eines Kooperations- und „Verrechtlichungsprozesses" gesehen werden, denn eine unproblematische Abschiebung wurde zunehmend erschwert. Doch eine Abschiebung von papierlosen Personen wurde auch damals praktiziert, selbst wenn dies internationalen Verträgen widersprach. Die Abschiebung als armenpolizeiliche Massnahme hat eine lange Tradition. ${ }^{37}$ In der Schweiz schoben die Kantone Bettler über die Kantonsgrenze, manchmal sogar nach Amerika ab. ${ }^{38}$ Die Kontinuität zur Gegenwart ist augenfällig, und zwar nicht nur, weil sich seit Ende der 1990er Jahre ein Abschiebelager in Witzwil befindet. Wie bei den illegalisierten Immigrienden finden wir auch im

32 Egger, 1982, S. 65.

33 Egger, 1982.

34 Egger, 1982, S. 67. Dazu auch Huonker, 2004. Huonker, 2001.

35 Egger, 1982, S. 69.

36 E-Mail-Auskunft von Thomas Huonker 9. Dezember 2009.

37 Dazu auch Hahn / Komlosy und Reiter, 2006.

38 Hauser, 1995, S. 117. 
Umgang mit Fahrenden das Prinzip der Abschreckung, die Identifikationshaft und den Umstand, dass die Zugehörigkeit zu einer bestimmten Gruppe für die Inhaftierung ausschlaggebend ist.

Es wäre ein wichtiges Unterfangen, aus einer transnationalen Perspektive zu untersuchen, wie dieser Umgang mit Fahrenden zustande kam. In Indien, wo es um 1860 schätzungsweise 5000 weisse Landstreicher gab, wurde 1869 von der Kolonialregierung ein Gesetz verabschiedet, das die Landstreicherei für Europäer unter Strafe stellte. ${ }^{39} \mathrm{Ab}$ 1871 wurden Arbeitshäuser für diese weissen Landstreicher eingerichtet; damit wurden sie für die indische Bevölkerung weitgehend unsichtbar. Das war wichtig, weil die Existenz eines weissen „Lumpenproletariats" die Grenze zwischen Kolonialisierten und Kolonisierenden auf unerwünschte Weise verwischte.

Häufig musste man deshalb, so Fischer-Tiné, die „Unverbesserlichen " auf Staatskosten nach Europa abschieben, um grösseren Schaden für das Ansehen der „ruling race“ abzuwenden. Auffallend ist in diesem Kontext weiter, dass in Indien 1871 und 1911 „Criminal Tribes Acts“ verabschiedet wurden. Die so genannten „Criminal Tribes“ waren mobile Gruppen der ländlichen indischen Bevölkerung, die als Bedrohung der britischen Autorität betrachtet wurden. Die erwähnten Gesetze regelten deshalb ihre Segregation in abgeschlossenen und bewachten Reservaten (Criminal Tribes Settlements) und ihre schrittweise Umerziehung in Arbeitslagern (Industrial Homes) zu einem sesshaften und „zivilisierten“ Lebensstil. Für die Einweisung in die Lager waren Fragen individueller Schuld völlig unerheblich: Was zählte, war einzig die Zugehörigkeit zu einer Gemeinschaft, deren Lebensweise pauschal als nicht-konform und deren Mitglieder kollektiv als asozial und gefährlich eingestuft wurden. Bemerkenswert ist vor allem der Umstand, so Fischer-Tiné, dass gewisse Ähnlichkeiten mit der Wahrnehmung und Sozialdisziplinierung von Fahrenden in Europa keineswegs zufällig seien. In einigen offiziellen Dokumenten der britischen Kolonialverwaltung finden sich klare Belege, dass man beide Gruppen als regionale Varianten der gleichen Problemgruppe ansah. Das „Wissen“, das in Indien in Bezug auf „criminals by birth “ produziert wurde (gerade auch von der Heilsarmee, die mit der Führung dieser Heime beauftragt war), zirkulierte und kam so auch nach Europa. ${ }^{40}$

39 Fischer-Tiné, 2007a. Fischer-Tiné, 2007b.

40 In diesem Zusammenhang ist weiter bemerkenswert, dass den Einwohnern von Kolonien oft keine Bewegungsfreiheit zugestanden wurde. Cornellise, 2010, S. 135145. 


\section{Abschiebelager für osteuropäische jüdische Migrierende in der Weimarer Republik}

Sinti, Jenische und Roma wurden auch in Deutschland interniert. ${ }^{41}$ Hier kam es in der Weimarer Republik zudem zu einer besonders restriktiven Politik gegenüber Osteuropäern und insbesondere osteuropäischen Juden. Schon im Deutschen Reich, in den Jahren 1885/86, wurden etwa 15000 Juden und weitere 20000 polnische Einwanderer aus Preussen ausgewiesen, wie dies vom „Deutschen Volksverein“ in seiner 1881 eingebrachten und von 250000 Deutschen unterzeichneten Antisemitismuspetition gefordert worden war. ${ }^{42}$

Im Zuge des Ersten Weltkriegs benötigte allerdings die deutsche Wirtschaft, insbesondere die Rüstungsindustrie, Arbeitskräfte, weshalb massiv ausländische, vor allem ostjüdische Arbeiter angeworben bzw. zwangsweise nach Deutschland verschleppt wurden. Parallel dazu entzündete sich an der „Ostjudenfrage“ eine andauernde Diskussion über die deutsche Fremdenpolitik; 1915 wurde beispielsweise in den „Preussischen Jahrbüchern" vor den gesundheitlichen Gefahren gewarnt, die Deutschland durch die ostjüdische Einwanderung drohten, und eine Grenzsperre für Ostjuden empfohlen. ${ }^{43} 1918$ wurde schliesslich ein Anwerbestopp für ostjüdische Arbeitskräfte verhängt, u.a. auch mit der Begründung der Fleckfiebergefahr, die von den verlausten Arbeitern ausgehe. ${ }^{44}$ In Preussen kam es in der Folge zu Ausweisungen, wöchentlich soll eine Gruppe von 50 bis 70 Personen nach Polen abgeschoben worden sein. ${ }^{45}$ Zwei Jahre später, 1920, trieb Bayern alle Ostjuden über die Grenzen des Freistaats. Zum gleichen Zeitpunkt wurde im bayrischen Ingolstadt das erste Abschiebungslager errichtet. „Preussen wollte sich offenbar dem bayerischen Vorbild anpassen. Am 23. Januar 1921 kündigte der preussische Innenminister Dominicus (DDP) an, dass man nun mit der Internierung von unerwünschten Ausländern, womit vornehmlich ,Ostjuden' gemeint waren, in ,Konzentrationslagern' beginnen werde. “46

Zur Auffindung der zu Inhaftierenden praktizierte man schon damals eine Art von Schleierfahndung, welche eine Kontrolle auf der

41 Lucassen, 1996.

42 Wippermann, 1999, S. 26. Dazu auch Flam, 2007, S. 217.

43 Heid, 1995, S. 564.

44 Dazu auch Berger, 2009.

45 Heid, 1995, S. 212.

46 Wippermann, 1999, S. 27. 
rückwärtigen Linie ermöglichte, die bis zu 30 Kilometer ins Land hineinreichte: „Dies geschah insbesondere durch Streifen in den Zügen,

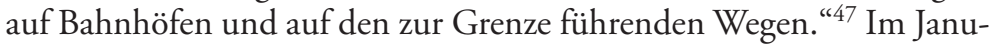
ar 1921 kündigte der preussische Innenminister an, dass jetzt mit der Internierung unerwünschter Ausländer in Konzentrationslagern begonnen werden könne, im Februar wurden die beiden Lager Stargard und Cottbus-Sielow eröffnet. ${ }^{48}$

Kritische Stimmen merkten an, das einzige Verbrechen der Internierten bestünde darin, dass sie Ausländer seien. ${ }^{49}$ Schon damals wurde die abschreckende Wirkung der Abschiebungshaft als Legitimation für eine solche Politik benutzt. So meinte der preussische Innenminister Dominicus 1925: „Meine zuständigen Berater sind aber der Meinung, dass diese Einrichtung indirekt ein Vielfaches von dem bewirkt, was sie tatsächlich bewirkt. Durch das blosse Bestehen dieser Einrichtung werden eben eine ganze Menge von Ausländern auf die Idee gebracht, wirklich nunmehr auszuwandern und den Befehlen der Polizeiverwaltung zu entsprechen. " 50

Diese Politik hat längerfristig allerdings nicht funktioniert; die Finanzlage des Staates Preussen zwang ihn dazu, diese Lager abzuschaffen, da er die dadurch entstehenden Kosten in der Wirtschaftskrise nicht mehr tragen konnte; dasselbe galt 1924 auch für Bayern. ${ }^{51}$ Doch schon bald wurden im Nationalsozialismus neue Lager eröffnet, die sich von den alten bekanntermassen wesentlich unterschieden. ${ }^{52}$

\section{Lager versus Gefängnis}

Die Grenze zwischen Lager und Gefängnis ist selbst eine verwischte. Ein Unterschied zum Gefängnis liegt im juristischen Rahmen: „Das Gefängnis ist im Allgemeinen für rechtskräftig verurteilte Delinquen-

47 Maurer, 1986, S. 266.

48 Siehe http://www.abschiebehaft.de/reader/r8.htm (4. 4. 2009).

49 Maurer, 1986, S. 429.

50 Maurer, 1986, S. 430.

51 Maurer, 1986, S.435. Siehe auch Walter, 1999, S. 75.

52 Bereits vor der Errichtung der ersten Abschiebelager (also vor 1920) waren in der Weimarer Republik Ausländer, die ausgewiesen werden sollten, auf Polizeiwachen oder in Gefängnissen festgenommen und inhaftiert worden, wie es in Bayern übrigens auch nach 1924 mit den verbliebenen Internierten geschah. Diese frühen Formen der Abschiebungshaft waren aber offenbar nicht im grossen Umfang praktiziert worden und zudem oft nur von kurzer Dauer. 
ten bestimmt. Der Gefangene sitzt in ihm eine Strafe ab. Die Insassen der Lager dagegen sind keine verurteilten Rechtsverbrecher. Ihre Haft ist meist behördlich verordnet. " ${ }^{33}$ Es handelt sich bei der Abschiebungshaft um einen administrativen Freiheitsentzug. „Persons are placed in such camps often on the basis of identification with a particular ethnic or political group rather than as individuals and mostly without benefit either of indictment or fair trial." ${ }^{4}$ Die Grenze zwischen Lager und Gefängnis ist indes wie gesagt unklar. So spricht man in der Schweiz oft von Ausschaffungsgefängnissen. „Ein Gefängnis, das so heisst, aber keines sein soll, und eine Haft, die nichts mit Kriminalität zu tun hat: Derart verwirrend ist die Situation, sobald es um Ausschaffungshaft geht. ${ }^{~}{ }^{55}$ Das Schweizer Bundesgericht kritisiere beim Abschiebelager im Flughafen Kloten beispielsweise, dass dieses zwar räumlich vom Untersuchungsgefängnis getrennt sei, sich jedoch in der Ausgestaltung der Haft in verschiedener Hinsicht kaum von einer Strafvollzugsanstalt unterscheide: „Neben der problematischen Dauer der Ausschaffungshaft (zwei Jahre unbedingten Freiheitsentzug kassieren in der Schweiz sonst nur Schwerkriminelle) ist auch der geeignete Ort für diese ausländerrechtliche Zwangsmassnahme umstritten." ${ }^{56}$ Mindestens in einem Punkt unterscheiden sie sich allerdings: „Die speziellen Disziplinierungsmassnahmen in der Strafhaft wie Lern- und Arbeitsprogramme sind auf Resozialisierung ausgerichtet; das Strafmass wird aufgrund eines Urteils auf eine bestimmte Dauer festgelegt. Die exklusiv den AusländerInnen vorbehaltene Ausschaffungshaft, die eigentlich eine mildere Form der Haft sein sollte, kennt keine solche erleichternden Bedingungen. Sie ist auf endgültige Exklusion ausgerichtet. Die häufig zu Erwerbszwecken eingereisten Personen werden mit erzwungener Untätigkeit bestraft. "57 Die Selbstmordrate ist unter Abschiebungsinsassen europaweit hoch. ${ }^{58}$

Auch Quarantänestationen sind Orte der leeren Zeit. Und sie sind ein weiterer "Vorfahre" der Lager, ,historic precedents for the current detention of asylum-seekers".59 Während die heutigen Abschiebelager

53 Kotek und Pierre, 2001, S. 12.

54 Mühlhahn, 2010, S. 544.

55 Hürlimann, 2008.

56 Hürlimann, 2008.

57 Lanz, 2008, S. 111.

58 Cornellise, 2010, S.2-5.

59 Bashford und Strange, 2002, S. 509. 
wenig sichtbar sind - „non-lieux de mémoire“60 - wurden in Nordamerika bestimmte Orte der Grenzsanität zu nationalen Gedenkstätten.

In Ellis Island vor New York fanden ab 1892 die Gesundheitsprüfungen für Immigrierende statt, allerdings nicht für Erstklasspassagiere; diesen Zusammenhang von Migration und Medizin in den USA zeichnet Barbara Lüthi nach. ${ }^{61}$ Nur 2 Prozent der Auswanderer wurden aus Ellis Island abgeschoben, das bedeutet dennoch insgesamt um die zweihundertfünfzigtausend Personen: „Und von 1882 bis 1924 gab es dreitausend Selbstmorde auf Ellis Island." "62 Mit der Hinwendung zu einer rassistisch motivierten Quotierung der Einwanderung durch den "Johnson-Reid Act" (1924) wurden die medizinischen Untersuchungen auf Ellis Island weniger wichtig. ${ }^{63} \mathrm{Da}$ Migrierende in der Nachkriegszeit immer öfter mit Flugzeugen und nicht mehr mit Schiffen ankamen, wurde der Ort 1954 schliesslich geschlossen. Touristische Besuche sind seit 1976 möglich. In den letzten Jahren ist Ellis Island zu einer Ikone der amerikanischen Einwanderungsgesellschaft geworden. ${ }^{64}$ Es steht für die Integration der Migrationserfahrung ins kollektive Gedächtnis der Vereinigten Staaten.

Doch das Sichtbarmachen dieser Erinnerung war nur um den Preis einer Verdunkelung zu haben. ${ }^{65}$ Ellis Island ist als "positives Symbol“ der Einwanderungsnation viel besser geeignet als das vor San Francisco gelegene Angel Island, dafür nimmt Angel Island in Bezug auf die Illegalisierung der Immigration wiederum eine paradigmatische Position ein. ${ }^{66}$

Auf Angel Island (die Insel hatte vorher u.a. als Stützpunkt für die Kämpfe gegen die indianische Bevölkerung gedient) kamen 1891 zum ersten Mal Schiffspassagiere des Dampfers „China“ wegen Pocken an Bord in Quarantäne. ${ }^{67}$ Die Passagiere wurden mit karbolischer Seife gewaschen und ihre Kleider und Gepäckstücke desinfiziert. Sie blieben

60 Diesen Begriff entlehne ich von Noiriel, 1988. Dazu auch Motte und Ohliger, 2006.

61 Lüthi, 2009.

62 Perec und Bober, 1997, S. 17.

63 Heck, 2008, S. 239.

64 Im Folgenden siehe Green, 2007. - Baur, 2006.

65 Dazu Ute Sperrfechter: Ellis Island oder Das Vorzimmer zur Freiheit. http://www. atopia.tk (1. 10. 2008).

66 Die Frage, ab wann in Bezug auf Migration von Ilegalisierung gesprochen werden kann, ist umstritten, hängt es doch davon ab, wie Illegalisierung definiert wird.

67 Allgemein zur amerikanischen Grenzsanität siehe auch Fairchild, 2003. - Stern, 2007. 
vierzehn Tage auf der Insel. Es ist wohl kein Zufall, dass auf Angel Island ein Schiff namens „China“ zum ersten Mal den Quarantänemassnahmen unterzogen wurde. Ab den 1880er Jahren suspendierte der "Chinese Exclusion Act" die chinesische Einwanderung in die USA mit ein paar Ausnahmen; auch hier wurde eine enge Verbindung zwischen staatlicher Souveränität und dem Ausschluss von Fremden postuliert: „If it could not exclude aliens it would be to that extent subject to the control of another power. "68 Durch Nachtragsgesetze wurde der "Chinese Exclusion Act" verschärft, verlängert und ausgedehnt. Es war das erste Immigrationsgesetz in der Geschichte der USA, das auf eine einzelne ethnische Gruppe zielte. ${ }^{69}$ Die Illegalisierung der chinesischen Migration hatte einen Handel mit Identitäten zur Folge. 1906 ereignete sich in San Francisco ein verheerendes Erdbeben. „Danach wütete tagelang ein Feuersturm durch das Geschäftsviertel der Stadt, in dem sich die Stadtverwaltungsgebäude befanden. Nahezu alle offiziellen Akten und Unterlagen der Stadt wurden zerstört. Tausende der illegalisierten chinesischen Einwohner San Franciscos nutzten diesen Moment und behaupteten, in den USA geboren und mithin Staatsbürger zu sein und ihre Dokumente im Feuer verloren zu haben. " ${ }^{70}$ Ferner etablierte sich ein System der so genannten „Paper Sons“: Chinesen, deren amerikanische Staatsbürgerschaft anerkannt worden war, konnten diese für ihre Nachkommen, die noch in China lebten, einfordern. Das führte dazu, dass zum Teil nichtexistente Söhne angemeldet wurden. Auf der Überfahrt lernten diese „Paper Sons“ anhand von „Coaching Documents" wie Fotografien von angeblichen Verwandten, Stammbäumen oder Plänen von Dörfern, die vor der Ankunft zu vernichten waren, ihre neue Biografie auswendig. ${ }^{71}$ Zudem wurden sie bei ihrer Ankunft von ihren Helfern instruiert, was sie auf welche Frage zu antworten hatten. Da der einzige Weg, um einen Zugang zum Einwanderungsland Amerika zu erhalten, war, sich eine fremde Biografie zuzulegen, entwickelte sich ein raffiniertes Vermittlungssystem, das zahlreichen Chinesen (die meisten waren Männer) zu einer neuen Identität verhalf. Um die Umgehung des „Chinese Exclusion Act“ zu verhindern, wurde auf Angel Island 1905 mit dem Bau einer „Immigration

68 Justice Field 1889 zitiert nach Scanlan und Kent, 1988, S. 69.

69 Zum „Chinese Exclusion Act“ siehe auch Ruskola, 2006.

70 Mayer, 2005, S. 137.

71 Siehe National Archives and Records Administration San Bruno, Records of the Immigration and Naturalization Service RG 85, San Francisco District, Chinese Coaching Material (Densmore Investigation), 1906-1940, Entry 232, Box 1 Folder 6 . 
Station" begonnen. Hier wurden von 1910 bis 1940 zum Teil bis zu zwei Jahre lang jene Migrierenden aus China untergebracht, die trotz der widrigen Umstände versuchten, in den Vereinigten Staaten ein neues Leben aufzubauen. Familien wurden dabei getrennt, Frauen und Männer in verschiedenen Baracken untergebracht. In der „Immigration Station" wurden die Ankömmlinge einer strikten medizinischen Untersuchung unterzogen: „Because immigration officials believed that Chinese routinely lied about their ages in order to conform to the life histories documented in bought papers, they ordered immigrants to be examined by doctors to verify them. " 72

Erst seit einigen Jahren wird Angel Island als wichtige nationale Gedenkstätte, als „National Historical Landmark“, wahrgenommen. Angel Island ist ein beliebtes Ausflugsziel: Die kleine Insel ist malerisch in der Bucht von San Francisco gelegen, an Wochenenden strömen Touristen, aber auch zahlreiche Bewohnerinnen und Bewohner der Bay Area dorthin. Vor allem auf Druck der chinesischen Diaspora wurde hier ein Erinnerungsort für die Erfahrung der Illegalisierung etabliert. Dies wurde möglich, weil sich die chinesische Gemeinschaft in und um San Francisco erfolgreich organisierte, um der Diskriminierung mit rechtlichen Mitteln entgegenzuwirken, so auch im Jahre 1900 (im Jahr des Boxerkriegs), als die Chinesen in Zusammenhang mit einem Pestausbruch zum Sündenbock gemacht wurden. ${ }^{73}$ Die Chinesen, die vor allem während und nach der Zeit des Goldrauschs um 1848 nach Kalifornien gekommen waren (einige waren allerdings auch schon vorher eingetroffen), hatten sich in San Francisco im dicht besiedelten Chinatown zusammengefunden, vor allem deshalb, weil ihnen andernorts keine Wohnungen vermietet wurden.

Chinatown war den Behörden seit je ein Dorn im Auge. In einem offiziellen Report wurde 1880 empfohlen, das chinesische Krebsgeschwür aus dem Herzen der Stadt zu entfernen. ${ }^{74}$ Es erstaunt deshalb nicht, dass im März 1900, als ein chinesischer Pesttoter gefunden wurde, ganz Chinatown unter Quarantäne gestellt wurde. Häuser, die sich in diesem Gebiet befanden, aber von Weissen bewohnt waren, wurden davon ausgenommen. ${ }^{75}$ Es wurden Gebiete unter Quarantäne gestellt, in denen keine Krankheitsfälle vorkamen, hingegen wurden befallene

72 Lee, 2003, S. 211. Solche biografischen Befragungen und Altersprüfungen werden auch gegenwärtig bei Abschiebungsinsassen durchgeführt.

73 Im Folgenden siehe Craddock, 2000, S. 15.

74 Committee to Investigate Chinatown 1880: „Chinatown Declared a Nuisance“. Craddock, 2000, S. 80.

75 Craddock, 2000, S. 126-133. 
Häuser innerhalb von Chinatown nicht nochmals isoliert. Einige Stimmen forderten noch radikalere Massnahmen, so die Zeitung „Call“, die am 31. Mai 1900 verlangte, Chinatown auszubrennen. ${ }^{76}$

Die Chinesen litten unter der Quarantäne; sie gingen deshalb gegen die Bestimmung gerichtlich vor - mit Erfolg. Am 15. Juni erklärte ein Richter das Vorgehen für ungerechtfertigt und verlangte dessen Aufhebung. Dennoch war es zu diesem Zeitpunkt bereits zu einer Stigmatisierung der Bewohnerinnen und Bewohner von Chinatown gekommen. An den befallenen Häusern waren gelbe Aushänge angebracht worden, das abgesperrte Gebiet durfte von Autos nicht durchfahren werden. ${ }^{77}$ Zahlreiche Wachen wurden zur Kontrolle dieser Sanitätsgrenze stationiert, nach den überlieferten Fotografien ${ }^{78}$ war aber offenbar dennoch ein Kontakt zwischen den Menschen drinnen und draussen möglich. ${ }^{79}$

Die zur Markierung dieser Grenze zum Teil benutzen Seile erinnern an den Eruv, den jüdischen Sabbatzaun: Dass damit eine Analogisierung von Juden und Chinesen bewusst bewirkt werden sollte, will ich nicht behaupten. Aber die Parallelen der Stigmatisierung - auch in Bezug auf den Vorwurf der Verweiblichung und der Homosexualität - sind erstaunlich. ${ }^{80}$

\section{Fazit}

Die heutigen Ausschaffungslager befinden sich in der Geschichtswissenschaft zwar noch immer „am Rand“, doch ist ein wachsendes Interesse am Thema der illegalisierten Immigration zu beobachten. Die Lager der „Illegalisierten“ sind auch geografisch gesehen wenig sichtbar, befinden sie sich doch meist in der Peripherie der Städte. Es handelt sich hier allerdings nicht nur um eine Invisibilisierungsstrategie,

76 McClain, 1994, S. 262.

77 McClain, 1994, S. 265.

78 Siehe beispielsweise Chinatown: A Conversation Across the Ropes. The Wave. v. 21, Jan. - July 1900. No. 21, page 7. Scenes Outside the Chinatown Quarantine Lines, San Francisco. Identifier: xffF850.W186 v. 21:no.21: 07 [4]. The Bancroft Library: Collection: Chinese in California http://oac.cdlib.org/findaid/ark:/13030/ kt5p3019m2\&brand=oac (22.9. 2009).

79 Chase, 2003, S. 62.

80 Pfaelzer, 2007, S. 13, 139. Zum Vorwurf der Verweiblichung bzw. der Grenzverwischung zwischen den Geschlechtern in Bezug auf Antisemitismus und Homophobie siehe auch Falk, 2008c. 
sondern auch um eine ambivalente Dialektik der Unsichtbar- und Sichtbarmachung: Im Dienste einer Abschreckungspolitik sollen die Abschiebelager für die Sans-Papiers selbst möglichst sichtbar sein. ${ }^{81}$ Auch wird durch die Präsenz der Abschiebelager signalisiert, dass aktiv gegen „illegale Immigration“ vorgegangen wird. Zugleich widerspricht die Präsenz der Abschiebelager offenbar „liberalen“ Empfindungen der regularisierten Bevölkerung.

Ich habe den Begriff des Lagers hier vor allem deshalb benutzt, um den bisher übersehenen kolonialen Kontext der Abschiebelager sichtbar zu machen. Dieser zeigt sich auch bei innereuropäischen Kolonisierungsprozessen, so beispielsweise gegenüber den Fahrenden: Die Ähnlichkeit im Umgang gegenüber den Fahrenden und den heutigen illegalisierten Immigrierenden ist dabei frappierend. Weiter spreche ich von Lagern und nicht von Abschiebungsgefängnissen, um damit auch die Kriminalisierung der Illegalisierten auch begrifflich zu reflektieren $^{82}$ (weshalb ich auch den Begriff der illegalisierten und nicht der illegalen Immigration verwende). Allerdings hat die Bezeichnung des Abschiebelagers den Nachteil, durch diese Begriffssetzung zu verdrängen, dass die Abschiebungshaft in vielen Aspekten tatsächlich einer Gefängnisstrafe gleicht. In einigen Ländern ist die Behandlung von Abschiebungsinsassen zudem oft schlechter als jene von Häftlingen, die aufgrund einer kriminellen Handlung in Haft genommen wurden. ${ }^{83}$

Im Beispiel von Angel Island und dem Pestausbruch in San Francisco wurde schliesslich die Erzeugung der Verbindung von Illegalisierung und Infektion augenfällig, auf die bereits in den beiden letzten Kapiteln aufmerksam gemacht worden war. Für HIV-Positive war übrigens die Einreise in den USA bis Januar 2010 nur zu besonderen Zwecken und mit einem speziellen Vermerk im Pass möglich.

Die Bekämpfung ansteckender Krankheiten ermöglicht(e) im Namen des öffentlichen Interesses Zwangsmassnahmen - selbst gegenüber „Nichtkriminellen“. ${ }^{84}$ Zwangsmassnahmen wurden und werden demnach sowohl bei der illegalisierten Immigration als auch bei der Bekämpfung von Krankheiten wirksam. ${ }^{85}$

81 Dazu auch Walters, 2002, S. 287.

82 Dazu auch Rodier und Saint-Saëns, 2007.

83 Cornellise, 2010, S.2-5.

84 Müller, 1992.

85 Müller, 1992. 
Doch 1900 machte die Kontingenz der Sanitätsgrenze die Isolierung von ganz Chinatown angreifbar; der diskriminierende Charakter dieser Quarantänemassnahme konnte so erfolgreich nachgewiesen werden. Interessant ist in diesem Zusammenhang schliesslich auch, dass inzwischen auf Angel Island eine Musealisierung der ehemals illegalisierten Immigration stattgefunden hat. 


\title{
ILLEGALISIERUNG, IDENTIFIZIERUNG UND (IN-)VISIBILISIERUNG
}

\section{Fingerabdruck und Fotografie}

\author{
„Der Pass ist der edelste Teil \\ von einem Menschen." 1
}

1892, im Jahr der Einweihung von Ellis Island und zehn Jahre nach der Einführung des „Chinese Exclusion Act“, wurde dieser durch den „Geary Act" abgelöst. Er war noch strenger als sein Vorläufer, für Chinesinnen und Chinesen wurde eine obligatorische Registrierung verlangt. Dabei wurde der Einsatz der Fotografie als Identifikationstechnologie gefordert: Da alle Chinesen sehr ähnlich aussähen, würde nur die Fotografie die unauffälligen Unterschiede sichtbar machen, die durch schriftliche Beschreibungen nicht fassbar seien, argumentierte ein Parlamentarier: „The registration of a Chinaman without a photograph is not worth the paper it is written on. "2 Die chinesische Gemeinschaft in San Francisco galt als „distinctly visible but individually indistinguishable and indecipherable". ${ }^{3}$ Die Chinesen wehrten sich gegen diesen Identitätsausweis, der in diskriminierender Weise nur auf ihre Bevölkerungsgruppe zielte. Zudem gab es in ländlichen Gebieten, so beispielsweise im kalifornischen Mono and Inyo, wo Hunderte von Chinesen lebten, noch gar keine Fotografen. ${ }^{4}$ Im September 1892 rief der Präsi-

1 Brecht, 1961, S.7.

2 Zitiert nach Pegler-Gordon, 2006.

3 Gordon, 2002, S. 178. Eine ähnliche Argumentationsfigur findet sich übrigens in mittelalterlichen und frühneuzeitlichen Texten in Bezug auf die Frauen, die nach galenischer Lehre als kalt und feucht in ihrer körperlichen Natur und deshalb als besonders befähigt galten, ihr Äusseres zu verändern. Wegen dieser Fähigkeit zur Simulation und Dissimulation wurden ihre Körper als nicht lesbar beschrieben. Ein Topos, der nach Valentin Groebner von physiognomischen Traktaten des 13. Jahrhunderts über die Erziehungstraktate der Humanisten bis zu moralischen Abhandlungen über die lasterhafte weibliche Fähigkeit des Schminkens wanderte. Groebner, 2004, S. 180.

4 Pfaelzer, 2007, S. 331. 
dent der „Chinese Six Companies“5 zum zivilen Ungehorsam gegen dieses „Hundemarkengesetz“ (Dog Tag Law) auf, das die Chinesen in die Nähe von Tieren rückte: Alle Chinesen wurden aufgefordert, auf das Tragen eines Identitätsausweises, der ihren legalen Status nachweisen sollte, zu verzichten. Tausende folgten diesem Ruf und riskierten dadurch eine sofortige Deportation. ${ }^{6}$

Zwischen 1896 und 1905 wurden um die 4000 Chinesen deportiert, selbst wenn der Kongress vorerst kein Geld für die Umsetzung des "Geary Acts“ gesprochen hatte. ${ }^{7}$ Der „Geary Act" bewirkte zudem zum ersten Mal, dass die ,illegale Immigration“ eine Straftat wurde, die eine Bestrafung bis zu einem Jahr mit „hard labor" möglich machte. ${ }^{8}$

Eine fotografische Identifizierung wurde in den Vereinigten Staaten zuerst von Chinesen verlangt, dann von Mexikanern und schliesslich von Europäern. In Bezug auf den Fingerabdruck lässt sich eine ähnliche Entwicklung beobachten: „Fingerprinting was first considered for application in controlling Chinese immigration into the country through Western ports. " Schon 1883 schlug ein Detektiv namens Morse vor, Daumenabdrücke zur Identifikation jener chinesischen Immigranten zu verwenden, die nach einem Aufenthalt in China wieder in die USA einreisen wollten. ${ }^{10}$ Chinesen, die bereits in Amerika lebten, war nämlich trotz des „Chinese Exclusion Act“ eine Wiedereinreise möglich. Dafür brauchten sie allerdings ein „return certificate“: „Departing Chinese nationals would apply at the Custom House, where they had their ,height, physical marks, and pecularities' recorded and were issued a ,white tag'. This could be exchanged abord ship for a ,red certificate", which would authorize reentry. "11 Um die Identifizierung noch sicherer zu machen, sollten gemäss Morse zusätzlich noch Fingerabdrücke gemacht werden. Woher Morse die Idee des Fingerabruckes

5 Die chinesische Bevölkerung von San Francisco war in den „Chinese Six Companies" nach Herkunftsort organisiert.

6 Pfaelzer, 2007, S. 291.

7 Pfaelzer, 2007, S. 303.

8 Pfaelzer, 2007, S. 292.

9 Cole, 2001, S. 121. Nicole Schwager geht in Bezug auf die Schweiz der Geschichte des Fingerabdruckes in ihrem Dissertationsprojekt nach: „Mit Massstab und Druckerschwärze gegen das Verbrechen. Zur Praxis der polizeilichen Identifikationstechniken Bertillonage und Daktyloskopie in der Schweiz, 1890-1925“ (Arbeitstitel).

10 Das war übrigens auch die Zeit, als Alphonse Bertillon sein portrait parlé entwickelte.

11 Cole, 2001, S. 122. 
hatte, ist nicht geklärt. ${ }^{12}$ Drei Jahre zuvor, 1880 , hatte Herschel in der Zeitschrift „Nature“ berichtet, dass Fingerabdrücke nach 17 Probejahren im bengalischen Bezirk Hooghly offiziell eingeführt worden waren und seit drei Jahren mit bestem Erfolg angewendet wurden. Die Funktionäre des britischen Empire hatten sich das Wissen der Bengalen angeeignet und es gegen sie gewendet, denn bei den Bengalen war es Brauch gewesen, Briefe mit Fingerabdrücken zu versehen. ${ }^{13}$ Auch die Chinesen hatten seit Jahrhunderten den Fingerabdruck als Unterschrift benutzt. Verträge mit chinesischen Prostituierten, die in den USA gefunden wurden und die von 1886 datierten, waren beispielsweise mit Fingerabdruck unterzeichnet.

1885 stellte Isaiah West Taber vergrösserte Fotografien von Fingerabdrücken her. Dazu hiess es in einem Bericht im "San Francisco Daily Report": „The tumb marks of Mong Shing, a Chinese laundryman, are more easily recognizable than his face. " ${ }^{14}$ Taber war übrigens jener Fotograf, der Carleton Watkins' Werk zum Teil unter seinem Namen vermarktete, da er nach Watkins' Bankrott im Jahre 1881 dessen Negative erworben hatte. Auch die Schweiz spielte bei der visuellen Identifikation eine unrühmliche Vorreiterrolle. Bereits in den 1850er Jahren kam es zu einer gross angelegten Polizeiaktion, in deren Verlauf Hunderte von mehrheitlich nicht-sesshaften Familien und Einzelpersonen in der ganzen Schweiz verhaftet, verhört und fotografiert wurden. Hintergrund der vom schweizerischen Generalanwalt geleiteten Aktion bildete ein 1850 erlassenes Bundesgesetz, mit dem die so genannte „Heimatlosenfrage" durch Zwangseinbürgerung endgültig gelöst werden sollte: „Im Jahr 1850 beschloss der Bundesrat, so genannte Heimatlose, die über keinen festen Wohnort verfügten, zwangsweise in verschiedenen Gemeinden einzubürgern. Die meisten fahrenden Korbmacher, Mäusejäger, Kesselflicker, Messerschleifer und andere heimatlose Gruppen widersetzen sich jedoch dem Gesetz. Sie wurden daher 1852 in einer beispiellosen Polizeiaktion auf dem ganzen Gebiet der Eidgenossenschaft aufgespürt und zwecks Abklärung ihrer Identität in Berner Gefängnisse eingesperrt, wo sie fotografiert wurden. Die Fotos wurden an die kantonalen Polizeicorps verteilt, damit diese die, Vaganten' schneller identifizieren konnten." ${ }^{15}$ Carl Durheim wurde deshalb 1852/53 vom Bundesanwalt beauftragt, fotografische Aufnahmen von Heimat-

12 Cole, 2001, S. 124-125.

13 Ginzburg, 1995, S.35-36. Dazu auch Sengoopta, 2003.

14 Zitiert nach Cole, 2001, S. 126.

15 Schär, 2008, S. 108. 
losen und Fahrenden anzufertigen, um ihre Identifikation bei späteren Wiederaufgriffen oder illegalen Grenzübertritten durch die Polizei zu erleichtern. Damit wurde in der Schweiz zum ersten Mal die Fotografie zu polizeilichen Zwecken eingesetzt. ${ }^{16}$ Die bereits erwähnten Massnahmen gegen ausländische Fahrende, die in der Schaffung einer zentralen "Zigeunerregistratur" gipfelten, wurde demnach durch die anthropometrische Vermessung und Fotografierung der in der Schweiz verhafteten Fahrenden in die Wege geleitet. „Durheims rund 220 Porträts von Heimatlosen aus der Zeit von Oktober 1852 bis Ende 1853 sind die frühesten Zeugnisse der Polizeifotografie in der Schweiz und das erste, grössere und von einer staatlichen Institution in Auftrag gegebene Projekt dieser Art überhaupt. " ${ }^{17}$ Drei Jahre später schrieb Eduard Osenbrüggen, Professor für Handelsrecht und Kriminalistik in der Monatsschrift des wissenschaftlichen Vereins in Zürich: „Soviel ich weiss, hat man zuerst in der Schweiz von der Daguerrotypie für polizeiliche Zwecke Gebrauch gemacht, indem man einige gefährliche Heimatlose abconterfeite." 18 Und weiter meinte derselbe Professor: „Und wenn dann erst jeder Polizeibeamte einen Photographir-Apparat zur Hand hat, so wird die Macht der Polizei gar gross sein. "19 Diese Macht der Fotografie als Identifikationstechnologie kann indes nicht (nur) der Kamera selbst zugeschrieben werden, sondern der politischen Autorität, die hinter der Kamera steht. ${ }^{20}$

Der Glaube an die Evidenz der Fotografie zeigte sich einige Jahre später auch in einem anderen Bereich, und zwar in den bakteriologischen Labors, wo die Visualisierung die Identifizierung und anschlies-

16 Siehe dazu die Unterlagen im Schweizer Bundesarchiv BAR Bestand E 21, 20528, Akzession 9001. Siehe auch Gasser / Meier und Wolfensberger, 1998, S. 11. Gasser und Suter, 2007.

17 Gasser und Suter, 2007, S. 56. Dazu auch Leimgruber, 2004-2005.

18 Diese Aussage ist indes insofern inkorrekt, als dass Durheim nicht das Verfahren der Daguerrotypie verwendete - obwohl es anfänglich so vorgesehen war - sondern jenes der Kalotypie, siehe Gasser und Suter, 2007, S. 56.

19 Zitiert nach Gasser und Suter, 2007, S. 59. Die Polizei von San Francisco führte übrigens auch äusserst früh ein „mug book“, ein Verbrecheralbum ein. Es wäre interessant, diese Fotografien mit den Schweizer Fotografien der Fahrenden zu vergleichen, die aus der gleichen Zeit stammen. Unterlagen zum „mug book“ sind in der Bancroft Library und im San Francisco History Center vorhanden (die ich indes nicht einsehen konnte): Jesse Brown Cook Scrapebooks Documenting San Francisco History and Law Enforcement, Bancroft Library sowie Mug Book Collection, San Francisco Police Department, San Francisco History Center, San Francisco Public Library.

20 Tagg, 1988, S. 64. 
send die Bekämpfung der Bakterien ermöglichen sollte. ${ }^{21}$ Im Jahre 1877 publizierte Robert Koch als erster Wissenschaftler Fotografien von Bakterien. ${ }^{22}$ Berühmt wurde in diesem Zusammenhang die Aussage Robert Kochs von 1881: „Das photographische Bild eines mikroskopischen Gegenstands ist unter Umständen wichtiger als dieser selbst. ${ }^{23}$ Die Evidenz der Fotografie war allerdings von Anfang an nicht unumstritten, wie die Ausführungen zu Watkins gezeigt haben.

Interessanterweise ist allerdings Kochs Forderung, das fotografische Bild solle keine Illustration, sondern Beweisstück ${ }^{24}$ sein, nicht weit entfernt von den Postulaten, die im Zuge des iconic beziehungsweise pictorial turn geäussert werden. In Kochs Prozeduren war Fotografie jedenfalls nicht Endprodukt oder Illustration, sondern Agent der Forschungsarbeit geworden. ${ }^{25}$

\section{Sichtbarmachung der Sans-Papiers}

Nicht nur die Identifizierung, auch eine (In-)visibilisierung ist in Bezug auf die illegalisierte Immigration bedeutsam, wie die fotografierte Wandzeichnung auf dem Titelbild dieser Arbeit veranschaulicht, indem sie die Unsichtbarkeit der Sans-Papiers sichtbar macht. Auf einer weissen Mauer sind die schwarzen, skizzenhaften Umrisse einer fallenden Person gezeichnet. Die obere Hälfte des Körpers durchstösst eine Grenzlinie. Dabei werden die Körperkonturen „unsichtbar“. Die Finger erhalten ein skelettartiges Aussehen. „Immigration“ heisst es in der Bildunterschrift.

Das Bild befand sich während einiger Monate im öffentlichen Raum: Der rumänische Künstler Dan Perjovschi hatte es im Rahmen seines Projektes „I Am Not Exotic - I Am Exhausted“ im Winter 2007 auf die Rückwand der Kunsthalle Basel gezeichnet. Perjovschis mit wenigen Strichen und Linien ausgeführte Wandzeichnungen, an (illegali-

21 Sarasin, 2007. - Otis, 1999, S. 26. Breidbach, 2002.

22 Brons, 2004, S. 19.

23 Koch, 1912, S. 123. Dazu auch Schlich, 1995. Die Sichtbarmachung der Krankheitserreger wurde jedoch nicht von allen Forschern für so wichtig gehalten wie von Koch: „Diejenigen, die, wie Louis Pasteur und seine Schüler, die Infektionskrankheit durch Immunisierung zu kontrollieren suchten, zeigten zunächst wenig Interesse an der genauen Identifizierung des Krankheitserregers - und damit ebensowenig an der dafür erforderlichen visuellen Darstellung." Schlich, 1997, S. 182.

24 Koch, 1912, S. 126.

25 Brons, 2004, S. 27. 
sierte) Graffiti erinnernd, sind jeweils nur während einer begrenzten Zeit sichtbar. Anschliessend werden die Zeichnungen wieder übermalt. ${ }^{26}$ Doch werden einmal benutzte Motive andernorts wieder aufgenommen; so schafft der Künstler mit seinen Zeichnungen ein transitorisches und zugleich fortlaufendes Projekt, das sich auf jeder Wand neu manifestiert und das sowohl ortsgebunden wie ortsunabhängig ist. Der Künstler hatte einige Monate zuvor eine sehr ähnliche Zeichnung für eine Ausstellung im „Museum of Modern Art“ in New York angefertigt. Perjovschi verwendet ähnliche Motive auch deshalb, weil die Situation, die er beschreibt, an diesen Orten ähnlich ist, wie er selbst ausführt. ${ }^{27}$ Seine Werkzeuge sind billige Filzstifte. Indem seine Arbeiten nach einer bestimmten Zeit ausgelöscht werden, entzieht sich Dan Perjovschi den üblichen Kriterien des Marktes, wo ein bestimmtes Produkt den Profit generiert. ${ }^{28}$ Eine Verletzung der „Marktregeln“ wird auch den illegalisierten Immigrierenden vorgeworfen.

Diese Erfahrung der Invisibilisierung der so genannten Sans-Papiers wird auch von anderen Künstlerinnen und Künstlern thematisiert. ${ }^{29}$ Das Denkmal des Bildhauers Ousmane Sow für Sans-Papiers in Genf ${ }^{30}$ oder die Renovierung des Schweizer Bundeshauses mit Geld der SansPapier-Bewegung wollen den Sans-Papiers Sichtbarkeit verleihen. ${ }^{31}$ Bereits die Namensgebung "Sans-Papiers" kann als ein Versuch der Umbenennung beziehungsweise Sichtbarmachung gesehen werden. Der Begriff wurde Ende der 1980er Jahre eingeführt als „Gegenbegriff" zur vorher geläufigen Bezeichnung der Illegalen oder Klandestinen. Der Slogan „kein Mensch ist illegal“ wurde wiederum 1997 im Rahmen der documenta X lanciert. ${ }^{32}$ Durch die Begriffssetzung „SansPapiers" sollte betont werden, dass Sans-Papiers durch eine diskriminierende Migrationspolitik zu Illegalisierten gemacht werden. ${ }^{33}$

26 Dietrich, 2007.

27 Perjovschi und Solakov, 2008, S. 74.

28 Vielleicht ist es indes gerade auch dieser Entzug, der zum Erfolg von Perjovschi beigetragen hat: 2007 rangierte er auf dem Capital-Kunstkompass noch vor Sigmar Polke und Gerhard Richter auf Platz 2.

29 Dazu auch Nellen-Stucky, 2006, S. 201.

30 Siehe dazu Falk, 2010b.

31 Zur Bundeshausrenovierung siehehttp://www.andreja.org/1chf-1voice/slike/CHFflayer.pdf (8. Oktober 2008), zum Denkmal in Genf https://www.swisster.ch/en/ news/society/statue-pays-tribute-to-immigrants-without-papers_117-360475 (25.3.2009).

32 Müller, 2008, S.75. Dazu auch Triandafyllidou, 2010.

33 Schwager, 2006, S. 38. 
Organisationen, die sich für Sans-Papiers einsetzen, dürfen selbst nicht allzu sichtbar sein, damit sie nicht angreifbar werden. In ihrer Öffentlichkeitsarbeit versuchen sie, illegalisierte Immigrierende wahrnehmbar zu machen, ohne einzelne Individuen zu zeigen, um sie dadurch nicht zu gefährden. Denn eine Sichtbarmachung kann auch zu repressiven Zwecken dienen. ${ }^{34}$

Viele Sans-Papiers verfügen allerdings entgegen ihrer Bezeichnung über gültige Identitätspapiere; was ihnen fehlt, ist die Aufenthalts- und Arbeitsbewilligung. ${ }^{35}$ Die Staatsgrenze wird hier unter gewissen Aspekten zu einem Filter, der die rechtliche und politische Position dieser Immigranten schwächt. ${ }^{36}$

Illegalisierte sind indes keine homogene Gruppe, sie unterscheiden sich u. a. hinsichtlich ihrer Illegalisierungswege und der Aussichten bezüglich ihrer Lebensgestaltung. ${ }^{37}$ So hat eine südamerikanische Putzfrau bessere Arbeitsmöglichkeiten als ein abgewiesener Asylbewerber aus Afrika, der bereits registriert ist. ${ }^{38}$ Zudem ist die Illegalisierung auf der rechtlichen Ebene nicht deckungsgleich mit ihrer Durchsetzung.

Die grössten Berufsgruppen unter den weiblichen Sans-Papières sind Haushaltshilfen, Babysitter und Pflegekräfte, viele männliche Sans-Papiers arbeiten in der Landwirtschaft oder auf dem Bau. ${ }^{39} \mathrm{Be}-$ zeichnenderweise arbeiten illegalisierte Immigrantinnen und Immigranten meist in jenen Industrien, die sich nicht auslagern lassen. ${ }^{40}$ Werden Migrationsbestimmungen verschärft, so wird dabei die legale Migration oft durch eine illegalisierte ersetzt. ${ }^{41}$ Catherine Dauvergne spricht davon, dass wir gegenwärtig Zeugen von einer zunehmenden Illegalisierung der Immigration sind. Durch die Illegalisierung werde ein Ausschluss produziert, „even when physical borders fail to do so". 42

Diese Illegalisierung wird durch Gesetze produziert, in den medialen Darstellungen aber oft „naturalisiert" und beispielsweise als Naturkatastrophe inszeniert. In karikierender Absicht zeigt Chappatte eine

34 De Genova, 2009.

35 Niklaus und Schäppi, 2007, S. 6.

36 Schilliger, 2008, S. 166.

37 Karakayali, 2008, S. 25.

38 Eichenhofer, 1999. Zur Situation in der Schweiz in historischer Perspektive siehe Kreis, 1995.

39 Düvell, 2007, S.6.

40 Düvell, 2005a, S. 46.

41 Düvell, 2005a, S. 41. Dazu auch Düvell, 2006.

42 Dauvergne, 2008, S. 169, 2. 
solche Naturalisierung in der „NZZ am Sonntag“ vom 9. Oktober 2005, wo die Masse der Migrierenden als Tsunamiwelle die von der EU errichteten Dämme überspült. Wenige Tage davor wurden Menschen erschossen, weil sie versuchten, den Stacheldrahtzaun zu übersteigen, der bei Ceuta Afrika von Europa und Marokko von Spanien trennt; weitere starben in Melilla einige Tage darauf. ${ }^{43}$

Migration entsteht indes nicht zufällig: Migrationsbewegungen sind selektive Prozesse; nur bestimmte Gruppen von Menschen verlassen ihre Heimat, und sie treiben nicht blind auf irgendein Land zu. Migration ist eine Normalität; man denke etwa an die Binnenmigration innerhalb der bestehenden Staaten, die heute gar nicht mehr als Migration wahrgenommen wird. ${ }^{44}$ Migrationswege verfügen weiter über eine erkennbare Struktur, die mit Beziehungen und Interaktionen zwischen Herkunfts- und Zielländern zusammenhängt. ${ }^{45}$ So hatte beispielsweise 2009 aufgrund der Wirtschaftskrise auch die illegalisierte Einwanderung in die USA abgenommen. ${ }^{46}$

\section{Entgrenzung und Entbildlichung der Grenze}

Die Digitalisierung von Datenströmen und die so genannte Schleierfahndung - die, wie in einem früheren Kapitel gezeigt wurde, keine neue Erfindung ist - führen dazu, dass sich die Grenzkontrolle von der Grenzlinie löst und zunehmend flächendeckend funktioniert: „Grenzen sind nicht mehr Linien, sondern überziehen als Netze ganze Gebiete. “ ${ }^{47}$ Eine Verschleierung der Grenze führt u. a. in der Schleierfahndung zu einer Flexibilisierung, Virtualisierung und Entgrenzung ${ }^{48}$ der Grenze und damit auch zu einer Entbildlichung, was ich als Tendenz zur Grenztransparenz beschreibe. Auf die Risiken der Repräsentation kann mit einem Verzicht auf Sichtbarkeit reagiert werden. Bildmächtige Bauwerke können trotz der dabei aufgerufenen Undurchdringlichkeitssymbolik als Versagen gedeutet werden, wie es beispielsweise zumindest im Westen bei der Berliner Mauer und den Grenzbefestigungen der DDR der Fall war.

43 Del Grande, 2008, S. 159. Blanchard und Wender, 2007. Siehe auch http://www. sosf.ch/cms/front_content.php?idcatart $=1780 \&$ lang $=1 \&$ client $=1$ (19. 11.2008).

44 Wottreng, 2000.

45 Sassen, 1997.

46 Angst, 2009.

47 Heck, 2008, S. 241.

48 Dazu auch Euskirchen / Lebuhn und Ray, 2007. 
Mit der Formulierung „Tendenz zur Grenztransparenz“ will ich indes nicht einfach eine einseitige lineare Entwicklung postulieren. Denn dies schliesst nicht aus, dass gleichzeitig in einer sich globalisierenden Welt eine Rückkehr zu militarisierten Mauern und bewachten Grenzbefestigungen stattfindet: „The dismantling of borders, the great symbol and promise of globalization, has been replaced with the exploding industry of border surveillance from optical scanning and biometric IDs to the planned high-tech fence on the border between Mexico and the U.S. “49 Selbst dieses Bollwerk soll allerdings abschnittsweise - was bisher indes noch nicht richtig funktioniert - als digitaler Vorhang funktionieren.

Eine Tendenz zur Grenztransparenz lässt sich hier ausserdem in einer anderen Bedeutungsdimension beobachten, wie die Zeitungen selbst in der Schweiz berichteten: „Die texanischen Sheriffs setzen bei der Überwachung der Grenze zu Mexiko neuerdings auf das Internet - und den Massen-Voyeurismus. Über Webcams kann jedeR von zu Hause aus und rund um die Uhr zum virtuellen Grenzer werden. Fällt einem etwas Verdächtiges auf, ist per Klick auf einen roten Knopf sofort die Grenzpolizei alarmiert. "50 Ein „Transparentmachen“ der Verhältnisse an der Grenze soll also illegale Grenzübertritte verhindern. Hier wird die Ambivalenz des Transparenzbegriffs besonders deutlich; Grenztransparenz weist je nach Sichtweise eine positive wie negative Konnotation auf.

Die befestigte Grenze zwischen Israel und Palästina wird als Sicherheitszaun ${ }^{51}$ bezeichnet, was nicht ein Bollwerk aus Beton evoziert, sondern eine transparente Grenzarchitektur. Dies ist bekanntlich an vielen Stellen nicht der Fall ist: Durch die Mauer wird vielmehr der Blick auf palästinensische Dörfer versperrt, was auch von israelischen Friedensaktivistinnen kritisiert wird. „It is opaque [the wall, ff] in order to prevent the sight [...]. If it were transparent, we could actually see the troubling suffering of the people on the other side. " ${ }^{2}$

49 Klein, 2007, S. 303.

50 Bauer, 2009.

51 Pike, 2006.

52 Marton und Baum, 2005, S. 216. 


\section{Bildverbot und Grenzauratisierung}

Gerade in Bezug auf befestigte Grenzen herrscht oft ein Bildverbot. Goethe beispielsweise berichtete in der „Italienischen Reise“, dass er 1786 beim Zeichnen eines Turmes in Schwierigkeiten geriet, da es sich um eine Grenzfestung „zwischen dem Gebiete Venedigs und dem Österreichischen Kaiserstaate" handelte ${ }^{53}$ und er verdächtigt wurde, ein österreichischer Spion zu sein. ${ }^{54}$ In der DDR war es der Bevölkerung streng verboten, die Grenze aus der Nähe zu betrachten oder zu fotografieren. ${ }^{55}$ Bildverbote zeugen bekanntlich von der grossen Macht, welche den Bildern zugeschrieben wird. In diesem Falle wird aus sicherheitspolitischen Überlegungen Grenzbildern die Fähigkeit zugesprochen, ein Wissen zu produzieren, welches die militärisch befestigte Grenze und vor allem deren Kontrolle gefährdet. Zugleich bewirkt ein Bildverbot - das je nach Umständen die Konnotation des Göttlichen aufweisen kann - eine Auratisierung.

Mit dem Aufbau einer „Grenzaura“ werden Grenzen unberührbar, unverrückbar und unverfügbar gemacht. Grenzen erscheinen in einem solchen Licht als die „wahren Götter“. Die Grenze gebärdet sich dabei als numinose Macht: Ein Gott, der sich sträubt, durch ein Bild in Verfügbarkeit überführt zu werden, der sich jeder Repräsentation zu entziehen versucht, gleichzeitig aber auf Repräsentation angewiesen ist. Ein Gott, der die Welt ordnet: b/order. ${ }^{56}$ Ein Gott aber auch, dessen begriffliche Fixierung stets zirkulärer Operationen bedarf: Definieren bedeutet, die Grenzen eines Begriffs festzulegen. Wenn wir versuchen, den Begriff der Grenze zu bestimmen, dann ist die Vorstellung der Begrenzung im Begriff des Definierens bereits präsent, obwohl wir die Grenze als solche noch gar nicht begrifflich gefasst haben. ${ }^{57}$ Die Grenze lässt sich nicht gerne auf den Begriff bringen: Die sakrale Dimension der Grenze zeigt sich bereits in den Begrifflichkeiten; das aus dem Polnischen stammende Wort wird seit Mitte des 13. Jahrhunderts in die Geschäftssprache des Deutschordens übernommen, später findet es

53 Goethe, 1993, S. 36.

54 Falk, 2008b.

55 Ullrich, 2006, S. 25.

56 Herb, 2005, S. 178. Houtum / Kramsch und Zierhofer, 2005.

$57 \mathrm{Zu}$ einem ähnlichen Widerspruch siehe auch Wokart, 1995, S.280. - Balibar, 2006, S. 244. 
über Luther die Aufnahme in die Hochsprache. ${ }^{58}$ Der heilige Charakter der Grenze verweist dabei auf den heiligen Status der Macht. ${ }^{59}$

Als Remus die Mauer, die sein Bruder gezogen hatte, voller Spott übersprang, tötete ihn Romulus. Numa Pompilius, der sagenhafte zweite König von Rom, weihte dem Grenzgott Terminus einen Tempel und verordnete, ihm Opfergaben darzubieten. Zudem verabschiedete Numa ein Gesetz, dass jener, der Grenzsteine versetzte oder zerstörte, straflos umgebracht werden durfte, also ein homo sacer sei. ${ }^{60}$ Auch die Bibel ist unter anderem eine grosse Grenzgeschichte, ständig werden Grenzen verletzt und gesetzt: ${ }^{61}$ Die erste Beschäftigung Gottes war es, Grenzen zu ziehen, zwischen Himmel und Erde, Licht und Finsternis, Tag und Nacht, Land und Wasser, Mann und Frau, Tod und Leben. ${ }^{62}$ Es gibt im Buch Mose aber nicht nur die Auratisierung von Grenzen - „Du sollst die Grenze deines Nächsten, welche die Vorfahren gezogen haben, nicht verrücken in deinem Erbbesitze" ${ }^{\text {"63 }}$-, sondern auch die grosse Sehnsucht nach Grenzlosigkeit. „Der in seinem irdischen Leben durch Grenzen definierte Mensch wird, so die Verheissung, von den Grenzen befreit, an die er gebunden war. "64 Das Paradies ist somit eine Vorstellung des Grenzenlosen, des gänzlich ungeteilten Raumes, wobei es gleichzeitig oft auch als Garten, als begrenzter Bereich ohne interne Grenzen imaginiert wird. ${ }^{65}$

\section{Fazit}

Auf Grenzauratisierung kann mit Grenzprofanierung reagiert werden: „Wenn aber das, was nicht verfügbar und abgesondert war, einmal profaniert ist, verliert es seine Aura und wird dem Gebrauch zurückgegeben." "66 Das „gottgleiche Bild" der Grenze bedarf einer solchen Profanierung; denn es sind die Menschen, die politische Gemeinschaf-

58 Karp, 1989. Zur Etymologie der Grenze siehe Böckler, 2003. Medick, 1995. - Febvre, 1988. - Bauer und Rahn, 1997.

59 Foucher, 1988, S. 36.

60 Agamben, 2002. Ritchie, 1985, S. 589. Zur Sakralisierung der Grenzsteine siehe auch die interessante Arbeit von Warnke, 1992, S. 16.

61 Hecker, 2006, S. 10.

62 Zwingli-Bibel, 1966, S. 1 (Genesis, das erste Buch Mose).

63 Zwingli-Bibel, 1966, S. 208 (5. Buch Mose 19,14).

64 Hecker, 2006.

65 Goetz und Nancy, 2001, S. 27.

66 Agamben, 2005b, S. 74. 
ten definieren, die Grenzen selbst gesetzter Felder symbolisch markieren und diese manchmal auch als Götter inszenieren.

Die für Nichtbetroffene oft unsichtbaren Grenzen innerhalb Europas, welche Legalisierte von Illegalisierten trennt, zeigt, dass Grenzpotenz nicht nur auf Evidenz im Sinne der Erzeugung von Anschaulichkeit beruht, sondern auch auf Strategien der Unsichtbarmachung und des Blickentzugs. Denn die undurchdringbarste Grenze ist oft jene, die nicht als Grenze wahrnehmbar wird. Dies fasse ich u. a. unter den Begriff der Grenztransparenz, wobei diese - wie gesagt - perspektivabhängig ist. Die Sans-Papiers werden demnach ausgegrenzt, ohne dass ein klar zu bestimmender Akteur, der für diese Grenzziehung verantwortlich ist, sichtbar wird. Es handelt sich dabei oft um latente und deshalb „unsichtbare" Gewaltverhältnisse. ${ }^{67}$ Auch die Sans-Papiers selbst sind oft gezwungen, sich möglichst unsichtbar zu machen. ${ }^{68}$ Doch für die Sans-Papiers und die Verteidigung ihrer Interessen ist zuweilen eine Sichtbarkeitspolitik wichtig. ${ }^{69}$

Während Bootsflüchtlinge ein beliebtes Sujet der Berichterstattung zum Thema Migration darstellen, erhalten die Abschiebelager wenig mediale Aufmerksamkeit. Beim oft tödlich endenden Drama im Mittelmeer ist es schwierig zu sagen, wer dafür verantwortlich ist: Globale Probleme manifestieren sich an der Grenze, erhalten hier eine Sichtbarkeit - beispielsweise am Strand von Lampedusa ${ }^{70}$-, sind aber nicht dort entstanden.

Folglich sind die dafür Verantwortlichen nicht einfach zu bestimmen: "The responsibility for human rights violations surrounding migration control are therefore difficult to establish. "71 Die Abschiebelager fallen hingegen klar in die Verantwortung des Nationalstaats; hier ist ein Handlungsspielraum konkret vorhanden. Dies läuft darauf hinaus, dass Medienkonsumierende in Migrationsfragen regelmässig mit Verhältnissen konfrontiert werden, für die sie nicht direkt verantwortlich gemacht werden können, während ihnen die nationalen Zwangsmassnahmen relativ selten in Zeitungen oder Fernsehen begegnen. In

67 Zum Begriff der Latenz siehe u. a. Ellrich / Maye und Meteling, 2009. - Diekmann und Khurana, 2007.

68 Schroer, 2004, S. 156. Speziell in Bezug auf die Schweiz siehe auch Wicker, 2010.

69 Ich arbeite in meinem neuen Projekt zu einer visuellen Kulturgeschichte der Demonstration u. a. dazu.

70 Andrijasevic, 2006.

71 Pécoud und De Gucheteneire, 2006, S.74. Zum Zusammenhang von Tourismus und Migration siehe Holert und Terkessidis, 2006. 
künstlerischen Auseinandersetzungen werden diese Themen eher aufgegriffen. ${ }^{72}$

In der zweiten Hälfte des 19. Jahrhunderts verschwand vielerorts in Europa für Bessergestellte die Passkontrolle an der Grenze (was allerdings nicht gleichermassen für Handwerker und Lohnarbeiter galt). Dies war eine Folge der Freihandelsverträge der 1860er Jahre. ${ }^{73}$ Doch gleichzeitig wurden andernorts verstärkt auch Grenzen aufgebaut, so in den Vereinigten Staaten gegenüber Chinesen, in der Schweiz in Bezug auf die Fahrenden, in Deutschland gegenüber Polen und osteuropäischen Juden. Dies deckt sich mit der Diagnose von Eric Hobsbawm, der ab den 1870er Jahren einen Wendepunkt von einem inkludierenden hin zu einem exkludierenden Nationalismus ausgemacht hat. ${ }^{74}$

In den 1880er Jahren fand in verschiedenen Bereichen die Fotografie vermehrt Anwendung, so nebst der Medizin insbesondere in Wochen- und Monatszeitschriften. ${ }^{75}$ Visuelle Registrierungsmethoden wurden auch mit der Verschärfung der Immigrationsgesetze ausgebaut: Nur was identifizierbar ist, ist begrenzbar, auch in Bezug auf die Immigration. Indes war die Bedeutung von Bildern in Identifikationsprozessen nicht immer so wichtig. Valentin Groebner hält fest, dass in den erhaltenen Steckbriefen zwischen dem 13. und dem Ende des 16. Jahrhunderts Bilder beispielsweise keine Rolle spielten. ${ }^{76}$ Und heutzutage funktionieren biometrische und genetische Identifikationsverfahren nur teilweise über Visualisierungen.

Technologische Innovationen wie beispielsweise biometrische Verfahren sollen die Grenzkontrolle sicherer und effizienter gestalten. Je effizienter und effektiver die Grenzkontrollen allerdings verlaufen, umso höher sind die Profite für jene, die sich professionell auf Grenzumgehungen spezialisieren ${ }^{77}$ - und umso attraktiver wird dabei dieses

72 Vor allem möchte ich hier auf die sehr interessanten Arbeiten von Dié Fall Kane, Angela Sanders, Anna Voswinckel, Maria Iorio, Raphael Cuomo und Ursula Biemann hinweisen, sowie auf Fernand Melgars Dokumentarfilm „La Forteresse“ (2008) und auf Severin Kuhns Kurzfilm „Niemand nicht weiss“ (2008). Dazu Biemann, 2008.

73 Der "flächendeckende“ Zwang zum Ausweis wurde mit dem Ersten Weltkrieg wieder eingeführt. Dazu Groebner, 2004. Fahrmeir, 2008. Torpey, 2000.

74 Hobsbawm, 1990.

75 Am 4. März 1880 erschien im New Yorker „Daily Graphic“ offenbar das erste Foto in einer Zeitung, das mechanisch reproduziert wurde. Macias, 1990, S.6.

76 Groebner, 2004, S. 66.

77 Pécoud und De Gucheteneire, 2006, S. 81. Wie im Merkantilismus ist es hier die Grenze selbst, die einen Profit generiert. 
Feld für das organisierte Verbrechen. ${ }^{78}$ Das Bildverbot in Bezug auf die militärisch gesicherte Grenze soll Grenzverletzungen verhindern, produziert gleichzeitig aber auch eine Grenzauratisierung.

Der Umgang mit territorialen Grenzen wird durch verschiedene teilweise konfligierende Denktraditionen und Glaubenssysteme geprägt, in Europa unter anderem von dem, was üblicherweise als Liberalismus, Nationalismus, Konservatismus, Sozialismus oder Kosmopolitismus bezeichnet wird, aber ebenso durch die Religionen. Im Buch Mose heisst es beispielsweise: „Wenn ein Fremdling bei dir wohnt in eurem Lande, so sollt ihr ihn nicht bedrücken. Wie ein Einheimischer aus eurer eigenen Mitte soll euch der Fremdling gelten, der bei euch wohnt, und du sollst ihn lieben wie dich selbst - seid ihr doch auch Fremdlinge gewesen im Lande Ägypten; ich bin der Herr, euer Gott. "79 Das Kirchenasyl als Schutzmassnahme gegen eine potenzielle Abschiebung lässt sich - nebst der antiken Tradition des Tempelasyls - auch auf eine jüdisch-christliche Ethik zurückführen. ${ }^{80}$

Widersprüche, die sich in Bezug auf das Sehen und Denken von territorial-politischen Grenzen zeigen, sind auch auf Spannungsverhältnisse zwischen und in diesen Denktraditionen zurückzuführen. Andererseits konnte die Symbiose beispielsweise von Liberalismus und Nationalismus trotz des vorhandenen Spannungsverhältnisses auch Grenzevidenz generieren. ${ }^{81}$

78 Allerdings ist die Diskursverschränkung zwischen organisiertem Verbrechen und illegalisierter Immigration nicht unproblematisch, auch wird der hier involvierte Schmuggel oft professioneller imaginiert als er tatsächlich agiert.

79 Zwingli-Bibel, 1966, S. 127-128 (3. Buch Mose 19,33-34).

80 Düvell, 2005b, S. 179.

81 „Der Liberalismus erhielt eine Breitenwirkung weit über seine engere bürgerliche Hauptklientel hinaus; der Nationalismus entwickelte sein Reformprogramm, das mehr Demokratie versprach, und dies nicht nur politisch, sondern auch sozial." Langewiesche, 2003, S. 228. 


\section{Ein ReCHT AUf Migration}

„Die modernen Flüchtlinge sind nicht ver-

folgt, weil sie dies oder jenes getan oder gedacht hätten, sondern aufgrund dessen, was sie unabänderlicherweise von Geburt sind - hineingeboren in die falsche Rasse oder die falsche Klasse oder von der falschen Regierung zu den Fahnen geholt (wie im Falle der spanischen republikanischen Armee). ${ }^{\text {"1 }}$

Territoriale Grenzen haben heute Definitionsmacht über Lebenschancen wie kaum andere Institutionen. ${ }^{2}$ Und die Kontingenz der angeborenen Nationalität entscheidet in besonderem Ausmass über die Möglichkeiten der Lebensgestaltung. Joseph Carens vergleicht diese ungleiche Verteilung von Chancen mit Feudalrechten, die per Geburt weitergegeben werden: „Citizenship in the modern world is a lot like feudal status in the medieval world. It is assigned at birth; for the most part it is not subject to change by the individual's will and effort; and

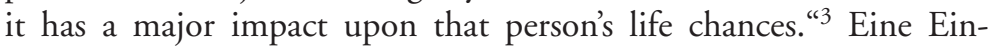
schränkung der Wahlmöglichkeit in Bezug auf den Arbeitsort widerspricht den Grundwerten liberaler Gesellschaften: Nach Adam Smith darf die Freiheit des Menschen, seinen Aufenthalts- und Arbeitsort selbst zu bestimmen, nicht eingeschränkt werden. Wenn eine solche Einschränkung dennoch geschieht, sei diese künstliche Grenze für arme Leute schwieriger zu überwinden als „die natürliche, von einem Meeresarm oder einem hohen Gebirgsrücken gezogene“. ${ }^{4}$ Dieses Problem bezeichnet Adam Smith als „vielleicht grösstes Übel in der englischen Wirtschaftspolitik" ${ }^{\text {“5 }}$. Selbst wenn sich Smith dabei auf Restriktionen innerhalb eines Nationalstaats (in diesem Falle Grossbritannien)

\footnotetext{
1 Arendt, 2008, S. 609.

2 Vobruba, 1998, S. 47.

3 Carens, 1992, S. 26. Zu dessen Position siehe auch Cohen, 2006, S. 198.

4 Smith, 2005, S. 123.

5 Smith, 2005, S. 118-119.
} 
bezieht, könnte die gleiche Argumentationslogik auch für einen globalen Bezugsrahmen in Anschlag gebracht werden.

Ein Recht auf Migration ${ }^{6}$ wird zuweilen als Menschenrecht verstanden: „le droit d'émigrer et d'immigrer n'est donc pas un privilège que seuls les états pourraient accorder; les migrants le voient comme un droit inaliénable dont nul ne saurait les priver. ${ }^{\text {"7 }}$ Heutzutage herrscht allerdings eine rege Diskussion darüber, ob es sinnvoll ist, hier auf die Instanz der Menschenrechte zu rekurrieren. Während beispielsweise Giorgio Agamben und Nicholas de Genova diesbezüglich kritisch eingestellt sind, ${ }^{8}$ befürworten andere eine solche Argumentationsweise. ${ }^{9}$ Kieran Oberman wiederum sieht eine internationale Bewegungsfreiheit in Analogie zur Bewegungsfreiheit innerhalb eines Staates; was das erstere begründe, begründet seiner Ansicht nach auch das zweitere: "If people have human rights to domestic freedom of movement, as it is conventionally thought they do, then they must also have a human right to international freedom of movement because the interests which ground the former right also ground the latter." ${ }^{10}$ Wird die Aufnahme von Migrierenden als Entscheidungsbefugnis souveräner Staaten betrachtet, ${ }^{11}$ erscheint "illegale Migration“ hingegen als Angriff auf die staatliche Souveränität. ${ }^{12}$ Inwieweit kann eine solche Denktradition auf Hobbes zurückgeführt werden, der in „De Cive“ die Freiheit als "die Abwesenheit von allem, was die Bewegung hindert", beschreibt? ${ }^{13}$ Wenn der Umkehrschluss gälte, wäre der Status der Souveränität durch eine Bewegungskontrolle charakterisiert, was so von Hobbes allerdings nicht artikuliert wird. Vielmehr gilt es hier anzumerken, dass die Maxime, der Staat habe ein (absolutes) Recht, Fremde aus seinem Territorium auszuschliessen, nach James Nafziger vor allem ein Produkt des späten 19. Jahrhunderts ist. Sie wurde in den Vereinigten Staaten u. a. gerade in Bezug auf den „Chinese Exclusion Act" formuliert, selbst wenn auch hier die Vordenker in der politischen Theorie zeitlich sehr viel weiter zurückreichen. Deshalb wäre es interessant, die rechtliche Kodifizierung mit historisch früheren Denksträngen der

6 Siehe dazu auch die sehr ausführliche Publikation Caloz-Tschopp / Dasen und Chetail, 2007. Dazu auch Caloz-Tschopp, 2004.

7 Rodier und Terray, 2008, S. 26.

8 Agamben, 2001a. - De Genova und Peutz, 2010.

9 Buckel und Wissel, 2010.

10 Oberman, Unveröffentlichtes Dissertations-Manuskript (2009).

11 Zurbuchen, 2007, S. 13. Dazu auch Gibney, 1988.

12 Pfau, 2008, S. 23.

13 Hobbes, 1994, S. 170. 
politischen Philosophie zusammenzudenken, was nach wie vor ein Forschungsdesiderat darstellt. ${ }^{14}$

"To the extent to which there is a global disorder of Hobbesian chaos, in which people's lives are all too nasty, brutish and short, then the way in which liberal capitalist states guard their borders and maintain their exclusivity is a major element of that disorder", schreibt Philipp Cole. ${ }^{15}$ Wenn eine Beschränkung der Bewegungsfreiheit überhaupt als nötig angesehen wird, meint Cole weiter, dann gäbe es keinen guten Grund dafür, dies nicht auf einer internationalen statt auf einer nationalen Ebene durchzusetzen. ${ }^{16}$

Während nun eine Machtausübung im Sinne einer „idealtypisch“ verstandenen Souveränität nach Foucault die Bewegung der Menschen streng kontrollieren will, wird unter den Bedingungen der Gouvernementalität gerade die Zirkulation ${ }^{17}$ und die Bewegungsfreiheit für einen gewissen Personenkreis ökonomisch fruchtbar gemacht, denn es gibt einen Bedarf nach flexiblen Arbeitskräften, die aus „eigenem Antrieb" 18 dahinziehen, wo es für sie Arbeit gibt. Der Prototyp der flexiblen Arbeitskraft sind die Sans-Papiers. Ihre Existenz resultiert aus der Tatsache, dass eine programmatisch dichte Grenze in der Tradition der Souveränität proklamiert wird, diese Grenze aber nicht hermetisch funktioniert. Gleichzeitig wird durch die drakonische Abschiebungshaft ein Strafexempel statuiert ${ }^{19}$, das wie der Hobbes'sche „Leviathan“ über einen Effekt der Abschreckung wirken soll, und zwar ebenfalls auf die „regularisierten“ Immigrantinnen und Immigranten, die selbst von Zwangsmassnahmen betroffen sein und ihre Aufenthaltsbewilligung verlieren können. ${ }^{20}$ Hier sind also Souveränität, Disziplinarmacht und Gouvernementalität gleichzeitig im Spiel. ${ }^{21}$ Oft dient dabei eine spektakuläre Inszenierung der Grenze dazu, einen kleiner werdenden

14 Nafziger, 1983, S.807-808. Dazu auch Chetail, 2007. Siehe auch Kanstroom, 2007, S. 6-16.

15 Cole, 2003, S. 205-206. Siehe auch Cole, 2000, S. 165-191.

16 Cole, 2003, S. 199.

17 Die Zirkulation bedarf indes immer irgendwo einer Schliessung, sonst kommt es nicht zum Kreislauf.

18 Die Konzeptionalisierung einer autonomen Migration sorgte bekanntlich für lebhafte Diskussionen, siehe dazu Bojadžijev / Karakayali und Tsianos, 2004. Pieper, 2004, Bd. 485. - Benz und Schwenken, 2005.

19 Schrover / Van der Leun / Lucassen und Quispel, 2008, S.21. Walters, 2002, S. 287.

20 Glick Schiller / Basch und Szanton Blanc, 1995, S.59. Dazu auch der sehr lesenswerte Artikel von Wicker, 2010.

21 Dazu auch Purtschert und Meyer, 2008. 
Handlungsspielraum der Nationalstaaten zu verdecken, wie Wendy Brown exemplarisch gezeigt hat. ${ }^{22}$

Insgesamt erscheint es mir allerdings wichtig, die heutige Migrationspolitik(en) nicht als Produkt einer bewussten Entscheidung eines monolithisch gedachten Akteurs zu begreifen, sozusagen ausgeführt nach einem Masterplan. ${ }^{23}$ Machtverhältnisse können lokal von Kalkülen durchsetzt und das Resultat bewusster Entscheidungen sein, dennoch entzieht sich oft der Gesamteffekt der Intention der Handelnden. ${ }^{24}$

In Bezug auf die heutige Migrationspolitik kann ein Spannungsverhältnis zwischen Souveränität, Disziplinarmacht, Gouvernementalität sowie einer biopolitischen Logik ausgemacht werden. So zeigt Didier Fassin, wie in Bezug auf die Asylpolitik eine Verlagerung von Legitimitätsgründen zu beobachten ist; der (hier allerdings individuelle) Körper fungiert nach Fassin vermehrt als Quelle politischer „Legitimität“. Fassins Argument lautet folgendermassen: In Frankreich sank seit den 1990er Jahren die Zahl der anerkannten Asylbewerber rapide, vor allem aufgrund der restriktiven Auslegung des Asylrechts. Im gleichen Zeitraum stieg die Zahl derjenigen Flüchtlinge stark an, die eine vorläufige Aufnahme erhielten aufgrund des Umstandes, dass sie an schweren Krankheiten litten, die in den Herkunftsländern nicht adäquat behandelt werden konnten: „The chronological association between the marked drop in political asylum and the increasing recognition of humanitarian reasons is not a coincidence. The two phenomena are linked. “25 Nach Fassin wird hierbei ein politisches zu einem medizinischen Problem umformuliert: „No situation could reveal more obviously the recent change in European politics of life than this shift from political asylum to humanitarian reasons." ${ }^{26}$ Dadurch aber erfährt das Asylverfahren eine „Entpolitisierung“: „The undocumented foreigner perceives him/herself as a victim reduced to soliciting compassion. "27 Ein Rückgriff auf den Körper als „Wahrheitsinstanz“ ist in Bezug auf die Asylpolitik auch anderwertig zu beobachten, wird doch neuerdings eine chemische Herkunftsanalyse für Asylsuchende gefordert. $^{28}$

22 Brown, 2009.

23 Karakayali, 2008, S. 17. - Euskirchen / Lebuhn und Ray, 2007.

24 Opitz, 2004, S. 35.

25 Fassin, 2005a, S.370. Siehe dazu auch Fassin, 2005b.

26 Fassin, 2005a.

27 Fassin, 2001, S. 5. Dazu auch Lemke, 2007, S. 114-115.

28 http://blogs.sciencemag.org/scienceinsider/nationality-swapping-DNA-testing. $\operatorname{pdf}(20.10 .2009)$. 


\title{
Aus- und Einwanderungsrechte
}

\begin{abstract}
"The border between who is illegal and legal is mutable, depending upon where the state decides to draw the line

between the two categories, and depending upon who the state allows to shift from one category to another. ${ }^{\text {“29 }}$
\end{abstract}

Die Verschiebung politischer Grenzen (wie etwa der Beitritt neuer Staaten zur Europäischen Union) kann dazu führen, dass gewissen Sans-Papiers quasi über Nacht Aufenthalts- und schrittweise auch Arbeitsrechte zugestanden werden, ${ }^{30}$ wird doch die Illegalisierung durch staatliche Gesetze produziert, die bestimmen, wer sich legal im Land aufhält und wer nicht. Gerade eine Verrechtlichung von Migration kann dabei zu einer zunehmenden Illegalisierung führen: „Not a loss of control, but the nationalization and standardization of U.S. immigration control is the proper premise for understanding the origins of illegal immigration. "31 In diesem Zusammenhang ist interessant, dass Locke - wie wir gesehen haben - die Exit-Option zwar einerseits als Prämisse von gewaltfrei verfassten Gesellschaften voraussetzt, andererseits aber für Vollbürger kein Auswanderungsrecht anerkennt (hier zeigt sich das Nachwirken merkantilistischer Denkweisen). Für eine Genealogie der postulierten Differenz zwischen Aus- und Einwanderungsrechten wäre Lockes Denken demnach ein interessanter Ausgangspunkt. Das bedingte Auswanderungsrecht könnte dabei gegen den Strich auch als Einwanderungsrecht gelesen werden: „Erst dann ist es ein freier Mensch, der auch die freie Entscheidung darüber hat, welcher Regierung er sich unterstellen will und welchem politischen Körper er sich anschliessen möchte", schreibt Locke. ${ }^{32}$ In einem merkantilistischen Referenzrahmen war indes wie gesagt die Emigration verboten, die Immigration hingegen erwünscht. Die Uno-Menschenrechtserklärung von 1948 kennt hingegen nur ein Auswanderungs-, aber kein Einwanderungsrecht. ${ }^{33}$ Da bestehende politische Grenzen

29 Volpp, 2005, S. 1611.

30 Düvell, 2007, S. 5.

31 Joppke, 1998, S. 272.

32 Locke, 1977, S. 275.

33 Bereits Grotius diskutierte ein Auswanderungsrecht: „Dass man nicht in Masse auswandern dürfe, ergiebt sich klar aus dem Zwecke, welcher dem Rechte seinen Inhalt giebt. Denn wäre dies gestattet, so könnte die bürgerliche Gesellschaft nicht bestehen. Anders verhält es sich mit der Entfernung Einzelner, so wie aus dem Flusse Wasser schöpfen nicht dasselbe ist, wie den Fluss ableiten. "Allerdings dürfe 
sowohl die von ihnen Ein- wie auch Ausgeschlossenen betreffen (wie im ersten Teil dieser Arbeit gezeigt wurde), sind Grenzregimes sowohl gegenüber den In- wie den Ausländern zu rechtfertigen. Eine von einer Seite eigenmächtig betriebene Grenzschliessung ist demnach aus einer bestimmten demokratietheoretischen Sicht problematisch: „Anyone who accepts a genuinely democratic theory of political legitimation domestically is thereby committed to rejecting the unilateral domestic right to control and close the state's boundaries, whether boundaries in the civic sense (which regulate membership) or in the territorial sense (which regulate movement)", schreibt Arash Abizadeh. ${ }^{34}$ Sandro Mezzadra spricht von der Grenze als dem undemokratischen Element der Demokratie. ${ }^{35}$ Vor dem Hintergrund der dargestellten Überlegungen zur nicht realisierten Bewegungsfreiheit im Liberalismus gilt es das Denken über Migration zu ändern. ${ }^{36}$ Dabei ist jene Prämisse zu überdenken, dass der Souverän - und sei er „demokratisch“ verfasst - über die Grenzen seines Staatskörpers eigenmächtig bestimme. In eine ähnliche Richtung argumentiert auch Martino Mona, wenn er in kritischer Anlehnung an Rawls festhält, dass im globalen Urzustand (also unter einem Schleier des Nichtwissens) niemand einem Vertrag zustimmen würde, der das Recht auf Migration verweigert, da er nicht wissen könne, welche zufälligen Umstände er antreffen beziehungsweise in welches Land er geboren werde. Mona möchte deshalb die Beweislast umkehren: Nicht Immigrierende sollen begründen müssen, weshalb ihnen ein Recht auf Migration zu gewähren sei, sondern es obliegt dem Staat, eine Einschränkung des individuellen Rechts auf Immigration in eng begrenzten Einzelfällen zu rechtfertigen. ${ }^{37}$ Diese Position vertritt auch Michael Dummett. ${ }^{38} \mathrm{Ihm}$ zufolge ist nicht der potenzielle Einreisende der Begründungsverpflichtete, sondern der Staat, der die Migration unter ganz bestimmten Umständen begrenzen könne: „Any country has the right to limit immigration if its indigenous population is in serious danger of being rapidly overwhelmed. “39

man dabei der Gesellschaft laut Grotius nicht schaden, wie es aber bei der Desertation beispielsweise der Fall sei. Schliesslich schlussfolgert er: „Diese Fälle ausgenommen, ist anzunehmen, dass die Völker die beliebige Auswanderung gestattet haben, weil aus dieser Freiheit ihnen von anderswärts her der gleiche Vortheil kommen kann." Grotius, 1869, S. 321, Buch II, Kapitel V, XXIV.

34 Abizadeh, 2008, S. 38.

35 Mezzadra, 2006, S. 148.

36 Dazu auch Rodier und Terray, 2008, S. 120. Siehe auch Lane, 2006.

37 Mona, 2007. Dazu auch Kirloskar-Steinbach, 2007.

38 Dummett, 2002, S. 57.

39 Dummett, 2002, S. 52. 
Diese Gefahr existiere aber, so Dummett, nur in kolonialen Kontexten und/oder bei Staaten, die sich illegal Land aneignen. Hingegen seien rassistisch motivierte Argumente, die vorgeben, dass ein Land von fremden Elementen überschwemmt werde, nicht legitim. ${ }^{40}$ Dummett führt weiter an, kein Staat könne behaupten, dass seine Pflichten sich nur auf seine Staatsbürger beschränkten, genauso wenig wie ein Familienoberhaupt erklären könne, dass er nur gegenüber seiner Familie Pflichten hätte, selbst wenn er gegenüber den Familienmitgliedern eine besondere Verantwortung trage. ${ }^{41}$ Gegenüber Mitmenschen hätten wir die Pflicht, in Notsituationen zu helfen und beispielsweise erste Hilfe zu leisten; dies gelte auch für Staaten, beispielsweise gegenüber Flüchtlingen. Tatsächlich verfügen anerkannte Flüchtlinge und Migrierende in den meisten Ländern über einen verschiedenen Status.

Allerdings entfällt der Rückgriff auf das Argument der Notsituation, wenn Bewegungsfreiheit als allgemeines Menschenrecht gefasst wird. Es stellt sich nach Dummett weiter die Frage, wie dieses Auswanderungsrecht zu qualifizieren sei. Handelt es sich dabei um ein absolutes oder ein konditionelles Recht? Um diesen Sachverhalt zu klären, führt Michael Dummett einen Vergleich an: „Everyone has a right to marry, but only if someone consents to be his wife or her husband: no one has an absolute right to be married. Does one have an absolute right to leave one's country, or only a right to do so conditionally upon some other country's willingness to accept one? "42 Wenn kein Land zur Aufnahme bereit ist, dann verhindert allerdings das fehlende Einwanderungsrecht eine Verwirklichung des Auswanderungsrechts: „Thus, emigration and immigration inextricably complement each other and the Universal Declaration of Human Rights has somehow stopped halfway in its recognition of a right to move", schreiben Antoine Pécoud und Paul de Gucheteneire dazu. ${ }^{43}$ Zudem könne ein Auswanderungsrecht einigen bereits existierenden Menschenrechten zur Verwirklichung verhelfen: Das Recht auf Arbeit und auf befriedigende Arbeitsbedingungen sei ohne die Möglichkeit der Migration oft kaum

40 Dummett, 2002.

41 Dummett, 2002, S. 49.

42 Dummett, 2002, S. 22.

43 Pécoud und De Gucheteneire, 2006, S.75. Dazu auch Bauböck, 2008. Zudem löst sich die Differenz zwischen Ein- und Auswanderungsrechten zunehmend auf: Afrikanische Bürger werden von ihren eigenen Staaten an der Ausreise gehindert. "Algerien hat in sein Strafrecht bereits das Delikt ,illegale Ausreise' eingeführt." Wiedemann, 2009, S. 12. 
zu erreichen. ${ }^{44}$ Werden hingegen für Illegalisierte fundamentale Rechte u. a. auch durch Notstandgesetze ausser Kraft gesetzt, hat das auch Rückwirkungen auf die Rechte der restlichen Bevölkerung. ${ }^{45}$ Giorgio Agamben spricht in diesem Zusammenhang von "noncitizens" 46 , Alessandro dal Lago von „non-persone “. ${ }^{47}$ Eine solche Migrationspolitik produziert eine Gruppe von Menschen, die, so Patricia Purtschert und Katrin Meyer, als „Nichtbevölkerung“ bezeichnet werden kann. ${ }^{48}$ Diese Nichtbevölkerung wird - wenn sie ins Abschiebelager kommt gerade nicht in ihrer Produktivität genutzt. Doch wird von diesen Prozessen der Illegalisierung und Entrechtlichung ökonomisch auch profitiert. Vielfach sind die Sans-Papiers gerade aufgrund ihrer tiefen Löhne und ihres fehlenden Arbeitsschutzes für ihre Arbeitgeber attraktiv. Das gilt indes nicht für alle Beschäftigungsverhältnisse, auch Solidarität kann ein Grund sein, Sans-Papiers zu beschäftigen.

\section{Sozialstaat und freie Migration: (K)eine Aporie?}

In einem Interview äusserte Milton Friedman kurz vor seinem Tod die Meinung, freie Migration und Wohlfahrtsstaat würden sich gegenseitig ausschliessen: "you can't have open immigration without largely the elimination of welfare. " ${ }^{49}$ Wenn diese Analyse zuträfe, dann wäre die Situation für jene, die sich für einen Sozialstaat und für ein Recht auf Migration einsetzen, aporetisch.

Tatsächlich könnte „freie Migration“ auch als ein Projekt des Freihandels realisiert werden, wenn dabei ein territorialer Zugang gestattet, gleichzeitig aber der Zugang zum Sozialstaat verweigert würde. Dies käme nicht einem Abbau von Grenzen, sondern einem Verschieben

44 Pécoud und De Gucheteneire, 2006, S. 76.

45 Dazu Marischka und Pflüger, 2006, S. 152. In Italien wird seit Jahren in Bezug auf ankommende Bootsflüchtlinge regelmässig der Notstand ausgerufen. Im Februar 2009 wurde ein Einwohner aus Sizilien aufgrund seiner dunkleren Hautfarbe für einen geflohenen illegalen Einwanderer gehalten. Der Polizist, der diesen einfangen wollte, verletzte ihn mit einem Schlagstock am Rücken. Er musste zur Behandlung nach Palermo ausgeflogen werden. Dazu http://www.studiocataldi.it/ ultimora.asp?id_notizia $=71386$ (18.2. 2009).

46 „We Refugee“ auf http://www.egs.edu/faculty/agamben/agamben-we-refugees. html (4. 4. 2009).

47 Dal Lago, 2006.

48 Purtschert und Meyer, 2008, S. 165.

49 Varadarajan, 2006. 
von Grenzen gleich. ${ }^{50}$ Zwischen der illegalisierten Immigration und dem Wohlfahrtsstaat besteht insofern ein gewisser Zusammenhang, als dass die Sozialversicherungssysteme es der einheimischen Bevölkerung bedingt ermöglichen, unattraktive Arbeit abzulehnen, welche die SansPapiers bereit sind zu übernehmen. Der Wohlfahrtsstaat alleine erklärt die Existenz illegalisierter Immigration aber nicht, ist diese doch auch in Nicht-Wohlfahrtsstaaten zu beobachten. ${ }^{51}$ Die Illegalisierung kann vielmehr eine allgemeine Prekarisierung, auch für legalisierte Arbeitskräfte, fördern. Für gewisse Arbeitgeber ist es deshalb vorteilhaft, sich für programmatisch dichte Grenzen, aber geringe Kontrollen einzusetzen. ${ }^{52}$ Auch können durch ein produziertes Überangebot an Arbeitskräften die Löhne gedrückt werden. Doch das Öffnen von territorialen Grenzen bedeutet jedoch nicht notwendigerweise den Abbau von sozialstaatlichen Leistungen.

Vielmehr kann Friedmans These sozusagen vom Kopf auf die Füsse gestellt werden. Aus einer solchen Perspektive wird gerade die Illegalisierung der Immigration - und die daraus resultierende Umgehung des Sozialversicherungssystems - für den Wohlfahrtsstaat zu einer Gefahr (wobei zuweilen eine Anmeldung bei den Sozialversicherungen theoretisch keinen legalen Aufenthaltsstatus voraussetzt). ${ }^{53}$ Der Sozialstaat könne deshalb von einer Legalisierung ${ }^{54}$ der Sans-Papiers, begleitet von entsprechenden gesetzlichen Massnahmen, profitieren, produziere Schwarzarbeit doch Ausfälle in den Steuer- und Sozialabgaben. Weiter könne eine Karenzpflicht für Sozialleistungen eingeführt werden: Nur wer als Neuzugezogener über eine festgelegte Dauer Beiträge bezahlt habe, wäre berechtigt, sozialstaatliche Leistungen zu beziehen. ${ }^{55} \mathrm{Be}-$ tont wird weiter, dass die meiste Schwarzarbeit von Inländerinnen und Inländern geleistet werde; die mediale Verschränkung von Schwarzarbeit mit Sans-Papiers sei in dieser Hinsicht problematisch. Die Strategie, soziale Sicherungssysteme und Migration als sich notwendigerwei-

50 Pécoud und De Gucheteneire, 2007, S. 20.

51 Düvell, 2007, S. 11.

52 Vobruba, 1998.

53 Allgemein zu dieser Problematik siehe Bommes und Geddes, 2000.

54 Allerdings kann eine Legalisierung auf Dauer nicht die Lösung sein: „Furthermore, every, legalization' has an inherently episodic and strictly partial character that never eliminates the field of ,illegality' but rather, in concert with the amassing of immense quantities of data for scrutinity by the authorities, simply refines and reconstitutes that field for the ineligible who will remain undocumented along with all subsequent ,illegal' arrivals." De Genova, 2002, S.429. Siehe auch De Genova, 2004.

55 Mona, 2007, S. 469. 
se ausschliessende Gegensätze zu portieren, gehe zudem gerade in Bezug auf die Finanzierung der Rentensysteme nicht auf. Denn diese können, wenn die Geburtenrate in Europa nicht wieder steigt, nur durch Zuwanderung gesichert werden. ${ }^{56}$ Die Illegalisierung bewirke zwar, dass Sans-Papiers nur in ganz bestimmten Bereichen arbeiten können; dadurch werde eine Konkurrenz zu „einheimischen Arbeitskräften" in anderen Sparten verhindert. Dies bedeute aber auch aus ökonomischer Perspektive mitnichten für alle Beteiligten eine WinWin-Situation: Während gewisse Wirtschaftsbereiche und Privathaushalte von einer Illegalisierung ökonomisch profitierten, produziere diese Politik der Illegalisierung hohe gesellschaftliche Kosten, müsse sie doch durch Druckmittel permanent aufrechterhalten werden. ${ }^{57}$ Durch ihre Herkunft Illegalisierte können für eine Dauer ins Gefängnis kommen, die üblicherweise einer Haftstrafe für schwere Delikte entspricht. ${ }^{58}$ Wenn also heute beispielsweise in der Schweiz die Haft für Illegalisierte mit der Vorbereitungs-, Ausschaffungs- und Durchsetzungshaft bis zu 18 Monaten beträgt (damit hat sich innerhalb zweier Jahrzehnte diese Dauer verzwanzigfacht), ${ }^{59}$ ist dies nicht nur aus einer menschenrechtlichen Perspektive kritisierbar, ${ }^{60}$ sondern auch aus einer ökonomischen. Die Wirksamkeit der Haft reduziert sich im Verlauf ihrer Dauer, da die Rückführungsraten dabei sehr viel geringer werden. ${ }^{61}$ Einige Kantone setzen die Ausschaffungshaft bewusst mit dem Ziel der Abschreckung ein, wie es in einer offiziellen Evaluation der Zwangsmassnahmen heisst, indem beispielsweise Personen einer bestimmten Nationalität in Haft genommen werden, um weggewiesene, aber (noch) nicht inhaftierte Landsleute zur Ausreise zu bewegen. ${ }^{62}$ Hier werden Menschen als Mittel benutzt. Dennoch trägt nach Ansicht der befragten Behörden die Ausschaffungshaft zu einer positiven Wahrnehmung der Asyl- und Ausländerpolitik des Bundes in der Bevölkerung bei. ${ }^{63}$

56 Hier wird ebenfalls ein Bild des „entleerten Europas“ aufgerufen, um Migration zu legitimieren.

57 Dies ist teuer; Baselland beispielsweise rechnet mit 300 Schweizer Franken pro Tag und Abschiebungsinsassen. Tobler, 2005, S.31.

58 Durch das Assoziierungsabkommen Schengen/Dublin muss die Schweiz bis 2010 die Abschiebungshaft von 24 auf 18 Monate verkürzen.

59 Zünd, 2007, S. 99.

60 Spescha, 2007.

61 Tobler, 2005, S. 2.

62 Tobler, 2005, S. 39.

63 Tobler, 2005, S. 39. 
Eine solche Repressionspolitik schafft selbstproduzierte Risiken. Hannah Arendt bemerkte treffend: „Wiewohl natürlich ein Mensch, der sich bereits durch die Tatsache, dass er existiert, strafbar macht, nur noch sein individuelles Gewissen zu befragen hat, um zu entscheiden, ob er sich zusätzlich noch einen Bankeinbruch leisten will oder nicht; denn die Strafe, die er für illegalen Grenzübertritt, illegalen Aufenthalt und illegale Arbeit zu erwarten hat, wird zumeist die, welche auf Einbruch steht, übertreffen." 64

\section{Grenzen anders sehen}

„Wir sind fünf Freunde, wir sind einmal hintereinander aus einem Haus gekommen, zuerst kam der eine und stellte sich neben das Tor, dann kam oder vielmehr glitt so leicht, wie ein Quecksilberkügelchen gleitet, der zweite aus dem Tor und stellte sich unweit vom ersten auf, dann der dritte, dann der vierte, dann der fünfte. Schliesslich standen wir alle in einer Reihe. Die Leute wurden auf uns aufmerksam, zeigten auf uns und sagten: ,Die fünf sind jetzt aus diesem Haus gekommen.' Seitdem leben wir zusammen, es wäre ein friedliches Leben, wenn sich nicht immerfort ein sechster einmischen würde. Er tut uns nichts, aber er ist uns lästig, das ist genug getan; warum drängt er sich ein, wo man ihn nicht haben will. Wir kennen ihn nicht und wollen ihn nicht bei uns aufnehmen. Wir fünf haben zwar früher einander auch nicht gekannt, und wenn man will, kennen wir einander auch jetzt nicht, aber was bei uns fünf möglich ist und geduldet wird, ist bei jenem sechsten nicht möglich und wird nicht geduldet. Ausserdem sind wir fünf und wir wollen nicht sechs sein. Und was soll überhaupt dieses fortwährende Beisammensein für einen Sinn haben, auch bei uns fünf hat es keinen Sinn, aber nun sind wir schon beisammen und bleiben es, aber eine neue Vereinigung wollen wir nicht, eben auf Grund unserer Erfahrungen. Wie soll man aber das alles dem sechsten beibringen, lange Erklärungen würden schon fast eine Aufnahme in unsern Kreis bedeuten, wir erklären lieber nichts und nehmen ihn nicht auf. Mag er noch so sehr die Lippen aufwerfen, wir stossen ihn mit dem Ellbogen weg, aber mögen wir ihn noch so sehr wegstossen, er kommt wieder." ${ }^{\text {"65 }}$

In eindrücklicher Weise wird in diesem Fragment von Kafka die Kontingenz von Gemeinschaftsgrenzen wie auch die Evidenz, die aus der

64 Arendt, 2008, S. 594. Dazu auch Caloz-Tschopp, 2000.

65 Kafka, 2003. Anzumerken ist, dass zwischen der handschriftlichen Fassung und den edierten Versionen von Kafkas „Erzählungen“ zum Teil beträchtliche Unterschiede bestehen. 
Existenz bereits bestehender Grenzen resultiert, sichtbar. ${ }^{66}$ Auch zeigt sich hier anschaulich die Unmöglichkeit einer abschliessenden unilateralen Abgrenzung: „aber mögen wir ihn noch so sehr wegstossen, er kommt wieder." Eine „demokratische“ Gesellschaft ist immer im Umbruch. Ihre Grenzlinien müssen verrückbar sein, sonst ist sie nicht mehr. ${ }^{67}$ Heute gilt es als „,natürlich“, Personen nach dem Kriterium der Staatszugehörigkeit Rechte zuzugestehen, indem ihnen der Zugang zu einem bestimmten Arbeitsmarkt erlaubt wird - oder eben nicht. ${ }^{68}$ Das Argument, ein Recht auf Immigration kollidiere mit der Vorstellung, dass eine politische Gemeinschaft eigene Kriterien der Mitgliedschaft ${ }^{69}$ festlegen soll, entspricht nicht den tatsächlichen Verhältnissen: Wir werden in politische Gemeinschaften hineingeboren und haben nicht die Möglichkeit, unsere Mitbürgerinnen und Mitbürger auszuwählen. Bei den Einbürgerungen ist dies zwar an manchen Orten teilweise der Fall, doch gerade weil dies nur für eine Minderheit gilt (bestimmte müssen sich auswählen lassen, andere gehören von Anfang an dazu), ist dieses einseitige Verhältnis problematisch. Ein solcher Anspruch erinnert zudem an jene Männer, die sich vor nicht allzu langer Zeit legitimiert fühlten, über das Frauenstimmrecht entscheiden zu dürfen: "There is something deeply disturbing in the claim that those who must decide the legitimacy of the distribution of liberal goods are those who already possess them. "70 Welche Konsequenzen sind aus den dargestellten Inkonsequenzen zu ziehen? Selbst wenn Nationalstaaten nicht im Alleingang von heute auf morgen ihre Zugangsbeschränkungen abschaffen können, so kann zumindest eines sofort in Angriff genommen werden: Grenzkontingenz sichtbar zu machen. Jean Nafziger schrieb schon vor bald dreissig Jahren: „Consequently, global discussions have only begun on one of the most serious issues of our era, the general admission of aliens. "71 "Considering mobility as a right is a provocative way of questioning the justification of policies that are now

66 Der Titel dieses Textes „Gemeinschaft“ stammt allerdings von Max Brod. Zum Verhältnis von Ästhetik und Politik siehe auch das sehr schöne Buch von Bleiker, 2009.

67 Dazu auch Bleiker, 2002.

68 Interessant dazu ist Pritchett, 2006. Allerdings teile ich dessen Argumentation nicht in allen Aspekten.

69 Chwaszcza, 1997, S. 39.

70 Cole, 2003, S. 203.

71 Nafziger, 1983, S. 845. 
taken for granted. Today's utopia may be tomorrow's reality and innovative debates and ideas are necessary to ensure new directions. "72

Allerdings sollte nicht vergessen werden, dass ein Öffnen von Grenzen nicht nur für Waren, sondern auch für Menschen jene ökonomischen Ursachen, die manche zur Migration zwingen, nicht aus der Welt schafft. Die zum „medialen Drama der Migration“ führenden Verhältnisse sind nicht zu ändern, wenn man nur auf die Grenze blickt. Um diese Probleme anzugehen, bedarf es nicht nur anderer Grenzregime $^{73}$, sondern beispielsweise auch einer grundsätzlich anderen Ausgestaltung der Ökonomie. Kurzsichtig erscheint dabei jene Sichtweise, die meint, durch eine zunehmende Entrechtlichung und Illegalisierung Probleme zu lösen, die sie selbst durch eine Verschärfung mitproduziert.

Die Geschichte ist bekanntlich keine Prophetin. Doch eine Historisierung macht (manchmal) die Begrenzungen der Gegenwart sichtbar: Sie antizipiert die Vergangenheit des Gegenwärtigen.

72 Pécoud und De Gucheteneire, 2006, S. 82. Dazu auch Geiselberger, 2007.

73 Hess und Kasparek, 2010. 
Urheberrechtlich geschütztes Material! @ 2011 Wilhelm Fink Verlag,

Paderborn, ein Imprint der Brill-Gruppe 


\section{ANSÄTZE EINER GESTISCHEN GESCHICHTE}

„Nicht so ist es, dass das Vergangene sein Licht auf das Gegenwärtige oder das Gegenwärtige sein Licht auf das Vergangene wirft, sondern Bild ist dasjenige, worin das Gewesene mit dem Jetzt blitzhaft zu einer Konstellation zusammentritt. “"

„Es ergibt sich daraus ein wichtiger Schluss: Gesten erhalten wir um so mehr, je häufiger wir einen Handelnden unterbrechen. "2

„Gestisch ist eine Sprache, wenn sie auf dem Gestus beruht, bestimmte Haltungen des Sprechenden anzeigt, die dieser andern Menschen gegenüber einnimmt. ${ }^{\text {"3 }}$

Eine gestische Geschichte zeichnet Bilder. Diese sind begrenzt, jedoch nicht abgeschlossen. Was mangelt, öffnet: Die Bilder sollen zeigen, dass sie nicht alles zeigen.

Erzeugt werden diese Bilder durch ein gestisches, öffnendes Schreiben, changierend zwischen Dichte und Leere, Präsenz und Absenz. Das Konstellieren von genau ausgearbeiteten und unbearbeiteten Stellen erzeugt Kontraste.

Diese Bilder wechselwirken; sie werden mit- und gegeneinander montiert. Ziel ist die Herstellung eines anderen Sehens. Eine solche Geschichtsschreibung inventarisiert nicht. Sie bezieht sich auf Konstellationen, die sich gegenseitig kommentieren.

1 Benjamin, 1983, Bd. I, S. 576-577. „Das aber heisst, dass die mythische Starre des Bildes hier zerbrochen worden ist, und man nicht eigentlich von Bildern, sondern von Gesten sprechen sollte." Agamben, 2001b, S. 58. Dazu auch Agamben, 2005a, S. 24 .

2 Benjamin, 1972, S. 521.

3 Brecht,1957, S. 252. 
Urheberrechtlich geschütztes Material! @ 2011 Wilhelm Fink Verlag,

Paderborn, ein Imprint der Brill-Gruppe 


\section{DANKSAGUNG}

Für meine Eltern. Und für M.F.

Gedanken entstehen im Dialog. Im Laufe dieser Untersuchung fand ich Gelegenheit zum Austausch mit zahlreichen Menschen. Besonderen Dank schulde ich Achatz von Müller; seine konstruktive Kritik und sein Rückhalt waren mir sehr wichtig. Mein Dank geht auch an Philipp Sarasin; er hat mir zu einem lehrreichen Einblick in die Funktionsweise von Denkstilen verholfen. Danken möchte ich weiter Sylwia Chomentowska, Marcel und Franz Falk, Hansjörg und Paola Höchner-Gallicani, Franziska Jenni, Rea Köppel, Sibylle Meyrat, Martin Mühlheim, Anja Rathmann-Lutz, Gerald Raunig, Dominique Rudin, Björn Schaub, Undine Stabrey und Armin Winiger. Sie haben zu verschiedenen Zeitpunkten das gesamte Manuskript gelesen und ihre Einsichten mit mir geteilt. Besonderen Dank schulde ich Richard Höchner, Benjamin Flückiger und Michael Lück für das Lektorat. Für alle Fehler und Ungenauigkeiten bin ich selbstverständlich alleine verantwortlich. Ich danke auch Giorgio Agamben, Helga Aichmaier, Emmanuel Alloa, Christine Bischoff, Roland Bleiker, Ina Boesch, Sabina Brandt, Matteo Burioni, Francis Cheneval, Maike Christadler, Harald Fischer-Tiné, Peter Geimer, Robert Girling, Tal Golan, Johannes Grave, Robin Grossinger, Carla Hesse, Gabriel Hürlimann, Kinch Hoekstra, Almut Höfert, Tom Holert, Christine Hult-Lewis, Sylvia Kafehsy, Othmar Keel, Sherry Keith, Xian Chu Kong, Alf Lüdtke, Barbara Lüthi, Paloma Lopez, Birigit Mersmann, W.J. Thomas Mitchell, Chantal Mouffe, Luise Müller, Roberto Nigro, Patricia Purtschert, Arno Schubbach, Ludger Schwarte, Susan Synder, Urs Stäheli, Jakob Tanner, Ute Tellmann, Tamar Tembeck, Doris Wastl-Walter, Cornelia Vismann ( $\mathrm{t}$ ) und Jack von Euw für Hinweise, Denkanstösse und Diskussionen. Beim nationalen Forschungsschwerpunkt „eikones“ fand ich ein intellektuell anregendes Umfeld. Mein weiterer Dank geht auch an die UC Berkeley, die mir einen Aufenthalt als „visiting scholar“ ermöglichte, sowie an das Istituto Svizzero in Venedig und das Haus am See in Kastanienbaum; geeignetere Schreiborte kann ich mir kaum vorstellen. Unverzichtbar war die Unterstützung durch die Mitarbeiterinnen und Mitarbeiter der Universitätsbibliothek Basel, der Bancroft Library in 
Berkeley, der British Library, der National Archives in San Bruno und des Warburg-Hauses Hamburg. Für die finanzielle Förderung der Arbeit beziehungsweise deren Publikation danke ich dem Schweizerischen Nationalfonds, der Schweizerischen Studienstiftung, der Janggen-Pöhn-Stiftung, der Christine Bonjour-Stiftung, der Hamasil Stiftung, dem Basler Dissertationsfonds und dem Max Geldner-Fonds. Wichtige Anregungen erhielt ich schliesslich vom Basler Solidaritätsnetz, von den Bleiberecht-Kollektiven, borderline-europe, Cserpe, kritnet, Migreurop, Solidarité sans frontières, PICUM und den Anlaufstellen für Sans-Papier; ihre Arbeit wird immer wichtiger. 


\section{SUMMARY $^{1}$}

\section{How liberalism reaches its limits at the border}

The plague doctors' masks on the frontispiece of the "Leviathan", John Locke's empty land, the photographs by Carleton Watkins, a military policeman's protective mask, the colonial history of the deportation camps, the plague policies and the Sans-Papiers - these are the seemingly disparate pieces that the author assembles into a mosaic to create a gestural history of the border. The mosaic lets territorial borders emerge from programmes of visualization and transparency, reveals their historicity and shows them as fault-lines of our society that produce violence.

Borders have for some years now dominated social and political debates and inspired numerous works of art as well as considerable scholarly research. Such studies tend to have a strong spatial, temporal, and factual focus. Francesca Falk has chosen to approach the subject from a different angle. Since the abstract cannot be considered without taking recourse to the graphic she sets out to investigate a number of specific constellations as well as significant interdependencies.

The two cornerstones of the author's study are the notions of borderline evidence and border contingency. She shows how visual and verbal premises that generate or have generated borderline evidence shape our thinking, thereby enabling us to identify border contingency in past and present. It is precisely because every border is in a sense contingent that there is a need for the social order to establish borderline evidence. If these effects of evidence fail, the borders are perceived as arbitrary, unnatural, constructed, not given, as contingent and not evident. Evidence and contingency are however by no means mutually exclusive pairs of opposites. On the contrary, they operate interactively. Every production of evidence can be questioned as to its inherent contingency. For this reason the study focusses on areas where despite apparently generated borderline evidence contingency is discernable. The power of borders does not however solely rely on evidence - in the sense of

1 Übersetzt von Matthias Müller. 
producing clarity - but also on the strategy of invisibilisation, of aniconism, and removal from view, which the author subsumes under the term border transparency. Because the most impermeable borders are those that are not perceivable as such.

The study's starting point is John Locke, the "father" of liberalism, and his social contract in the "Second Treatise". According to this theory individuals are called upon to enter voluntarily into a social contract. Falk's interest in this founding document of liberalism is directed to something often overlooked: namely, that those excluded from the socal contract are also affected by it. Not only are they subjected to constraints by their exclusion, but they are also unable to respond actively. Political borders are thus not the outcome of the free will of both sides. John Locke has to postulate an „empty land“ in America to legitimize his concept of state formation.

This emptiness was visualized by the photographer Carleton Watkins. In the 19th century he photographed the West of the USA and became famous with his pictures of what was later to be the Yosemite Park. The fact that the same photographer's pictures were also used in court to settle land disputes creates a constellation of paradoxes similar to the one inherent in John Locke's theory.

For Thomas Hobbes in contrast, America with its native Indians was not empty country but the representation of the state of nature. Thus on the first frontispiece of Hobbes” „De Cive“ the state of nature („Libertas“) and government („Imperium“) are set against each other as a dichotomically opposing pair. In her study, the author puts the frontispiece of the "Leviathan", the emblem of the Body Politic, into a radically new context, namely that of sanitation, sovereignty, selection and incipient biopolitics. The masks of the plague doctors, which have been largely ignored by research so far, occupy a pivotal position in Falk's interpretation. They point to the violence induced by the drawing of borders which was necessary to establish the sovereign totality and segregation of the body politic. Mechanisms of controlling and channelling the movement of citizens first emerged in the course of plague politics. Medical deployment was important for the establishment and legitimization of borders. The result was that plague measures produced new statal structures and new forms of border and migration control.

The plague doctor's mask makes a reappearance in the protective mask of the military policeman photographed „receiving“ boat refugees. The mask points to the fear of contamination. In such images 
territorial borders and corporal boundaries overlap: Migration here appears as an assault against one's physical integrity. Boat refugees coming ashore on Europe's borders are regularly visible in the media, whereas deportees remain largely invisible. Their camps are usually located on urban peripheries and media images of them are rarely circulated. A look at history shows that deportation camps were first used in a colonial context, which allows us to raise critical questions about the current illegalization of immigration from a post-colonial perspective.

Using historical case studies as a point of departure, Francesca Falk addresses pressing issues such as whether there should be a (human) right to migration. But today the admission of migrants is considered to be the domain of the discretionary authority of sovereign states: Seen from this perspective, „illegal migration“ is regarded as an attack against state sovereignty. While an exercise of power in the sense of sovereignty, according to Foucault, seeks to exert strict control over people's movements, governmentality tries to produce conditions that make circulation and freedom of movement economically rewarding for specific groups of people, because there is a demand for flexible workers who on their own accord are willing to move to wherever there is work for them.

The prototype of the flexible worker are the Sans-Papiers. Their existence results from the fact that they have managed to cross a programmatically closed border, proclaimed as such in the tradition of sovereignty, which in reality does not function hermetically. At the same time the state makes an example with the draconic custody pending deportation, which, like Hobbes' „Leviathan“, is designed to have a deterrent effect, in particular also on the „regularized“ immigrants who can themselves be affected by coercive measures and forfeit their residence permit.

In the tradition of Thomas Hobbes, political philosophy serves the production of the state's evidence. The basic question is how the state can be legitimized towards its citizens. In this tradition of thought the state is only required to justify itself to its own citizens. But precisely this is criticized in current political theory, a school of thought which this study, on the border between historical science, image analysis and political theory, adheres to. Falks argumentation with and against Giorgio Agamben, Michel Foucault, Thomas Hobbes and John Locke departs from the traditional history of political ideas and moves towards the iconism of political theory. Images provoke our thinking, limit it, organize our argumentation systems. This again affects how we see borders and consequently perceive migration. 
Francesca Falk has opted for a gestural historiography which is based on a strategy of reductionist writing, on the principles of condensation and interruption. Her study reveals how liberalism reaches its limits at the border. 


\section{BILDNACHWEISE}

Cover: Dan Perjovschi: „I Am Not Exotic - I Am Exhausted“, Digitalfotografie der Autorin, Basel Sommer 2007.

Bild 1: Carleton Watkins: „Yosemite Valley from the Best General View“, 1865/66, Albuminpapierabzug, 19,4 × 29,5 cm, J. Paul Getty Museum, Los Angeles.

Bild 2: Carleton Watkins: „Rancho San Antonio“, Watkins' court deposition in Land Case 100 ND, United States v. D. und V. Peralta, 1861, California Land Case Collection, 19xx.096:08-fff ALB digital scan, Courtesy of The Bancroft Library University of California, Berkeley.

Bild 3: Jean Matheus: Frontispiz von „De Cive“, 1642, Universitätsbibliothek Göttingen.

Bild 4: „America-Serie“ des Verlegers Theodor de Bry, Frontispiz des ersten Bandes von 1590, Herzog August Bibliothek, Wolfenbüttel.

Bild 5: Abraham Bosse: Frontispiz des „Leviathan“, 1651, Britisch Library.

Bild 6: Detailaufnahme Bild 5.

Bild 7: Detailaufnahme Frontispiz des „Leviathan“, 1750, Britisch Library.

Bild 8: Paulus Fürst nach I. Columbina: „Der Doctor Schnabel von Rom", 1656. Goldhahn, Richard: Spital und Arzt von einst bis jetzt. Stuttgart 1940, S. 103.

Bild 9: Luca Bruno, 18.03.1997 18:04:00, KEYSTONE AP, Bild 90792 (C), BRI110. 
Bild 10: Viktor Surbek, Plakat für die Schweizer Spende, $128 \times 271$ $\mathrm{cm}$, Lithografie schwarzweiss, 1945 oder 1946, Basler Plakatsammlung.

Bild 11: Franco Lannino, 20.10.2003, EPA/Keystone, Bild 15227285 (C), EPA: Image Number 00000400072473.

Bild 12: Giovanni Bellini, Polyptychon hl. Vincent Ferrer, $72 \times 67 \mathrm{~cm}$, Dominikanerkirche „Santi Giovanni e Paolo“ in Venedig, 1465-68. Olivari, Mariolina: Giovanni Bellini. Königstein im Taunus 1990. 


\section{INDEX}

Abizadeh, Arash 140

Abschiebung 105, 108, 110, 134

Abschiebelager 12, 14, 105, 106, $110,112,114,119,132,142$

Abschiebungsgefängnis 119

Abschiebungshaft 14, 74, 105, 106, 113, 114, 119, 137

Abschiebungsinsassen 12, 106, 114, 119

Agamben, Giorgio 33, 88, 108, 136, 142

Antisemitismus 112

Arendt, Hannah 108, 145

Armitage, David 78

Assmann, Aleida 100

Asyl

Asylpolitik 138, 144

Asylrecht 138

Asylsuchende 127, 138

Asylverfahren 138

Aufenthalt 105, 122, 145

Aufenthaltsbewilligung 14, 103, 127,137

Aufenthaltsort 135

Aufenthaltsrecht 15, 21, 139

Aufenthaltsstatus 143

Aufklärung 19, 60

Auswanderung 23, 29, 140

Auswanderungsrecht 139, 141

Bacon, Francis 77

Bashford, Alison 80

Bellini, Giovanni 70, 98, 100

Benhabib, Seyla 100

Benjamin, Walter 89

Bilder 11, 12, 15, 16, 19, 35, 37, $40,42,43,45,47,50,52,55$, $56,63,65,67,72,76$

Bildanalyse 15, 67
Bildbetrachter 63

Bilderarchiv 50

Bildkomposition 35

Bildlegende 91

bildliche Imagination 43

Bildlichkeit 15, 18, 19, 47, 83

Bildverbot 13, 130, 134

Boat people 95

Body Politic 11, 87, 88

bollettini di sanità 73

Boyle, Robert 21, 54

Brandt, Reinhard 67

Bredekamp, Horst 55, 63, 67, 82, 89

Brenner, Ernst 109

Brocker, Manfred 27

Brown, Wendy 138

Burghartz, Susanna 50

Carens, Joseph 135

Carmichael, Ann 73

Cheneval, Francis 33, 53

Chinese Exclusion Act 116, 121, 136

Christalder, Maike 50

Cole, Philipp 137

Criminal Tribes Acts 111

dal Lago, Alessandro 142

Dauvergne, Catherine 90, 127

Davenant, William 81

de Bry, Theodor 50

de Genova, Nicholas 136

de Gucheteneire, Paul 141

Demokratie 19, 140

Demokratiedefizite 16

Determinismus 78

Dhawan, Nikita 106

Diskurs 19, 43, 89, 96 
Dummett, Michael 140, 141

Durheim, Carl 123

Edkins, Jenny 85

Eggers, Daniel 57

Eigentum 21, 22, 26, 27, 30, 39

Eigentumsrecht 22, 26, 27, 28, 32

Einbürgerung 9, 15, 146

Einbürgerungsgesuch 9

Einwanderungsrecht 139

Ellis Island 115, 121

Engelspietà 98, 103

Evidenz 10, 12, 13, 16, 17, 18, 19, $21,38,45,47,93,104,124$, 132,145

Evidenzerzeugung 13

Exit-Option 22, 29, 32, 60

Fahrende 109, 110

Fassin, Didier 138

Filmer, Robert 27, 31

Fischer-Tiné, Harald 111

Flüchtlinge 93, 100, 102, 107, 135, 138, 141

(Boots)flüchtlinge 12, 14, 91, 92, 95, 96, 98, 100, 101, 102, 103, 132,142

Foucault, Michel 11, 15, 78, 79, $86,87,88,106,137$

Frauenstimmrecht 15, 146

Freiheitsentzug 114

Friedman, Milton 142

Frontier 35, 44

Frontispiz 11, 48, 50, 53, 55, 56, $61,65,67,69,70,72,79,80$, $82,84,87,88,89$

Fürst, Paulus 70

Geary Act 121

Geld 24, 25, 26, 31, 37, 43, 59, 70, $75,122,126$

Geldökonomie 24, 25, 27, 32, 60

Geldverkehr 24, 26

Gewalt 14, 22, 43, 52, 53, 54, 60, $61,65,76,83,86,102,108$
Gewaltanwendung 55, 59

Gewalterfahrung 105

Gewalt, politische 22

Gewalt, richterliche 22

Gewalt, sichtbare 82

Ginzburg, Carlo 69, 76

Goldrausch 37, 39

Grenze 9, 12, 13, 14, 15, 16, 25, $27,38,44,45,46,48,50,67$, $72,79,80,84,85,87,89,90$, 95, 96, 102, 103, 104, 105, 110, $111,112,113,114,118,128$, 129, 130, 131, 132, 133, 134, $135,137,140,142,143,145$, 146,147

Gemeinschaftsgrenze 145

Geschlechtergrenze 48

Grenzaura 130

Grenzauratisierung 131

Grenzbefestigung 14, 45, 128, 129

Grenze, politische 10, 32, 139

Grenze, staatsbürgerliche 9, 10

Grenze, territoriale 12, 101, 109, $110,134,135,143$

Grenzevidenz 10, 11, 12, 13, 14, 134

Grenzkontingenz 12, 13, 14

Grenzkontrolle 11, 73, 128, 133, 143

Grenzpotenz 13

Grenzprofanierung 131

Grenzstreitigkeit 11

Grenztransparenz 12, 13, 14, 132

Grenzverletzung 134

Grenzziehung 13, 14, 96

Grundstücksgrenze 27, 39, 40

Groebner, Valentin 133

Grotius, Hugo 29

Harriot, Thomas 50

Häsler, Alfred 93

Hobbes, Thomas 11, 14, 15, 23 , $24,30,31,32,33,47,48,50$, $52,53,54,55,56,57,58,59$, $60,61,65,69,75,76,79,80$, $81,82,83,85,86,88,136,137$ 
Hobsbawm, Eric 133

Horror Vacui 53

Ikone 45, 61, 63, 69, 95, 96, 115

Imhoof, Markus 93

Immigration $12,96,103,115,117$, $118,119,122,125,127,133$, $140,143,146$

Immigrationsgesetz 116, 133, 137

Immigrierende 12, 14, 90, 96, 100, $102,103,104,105,115,119$, $122,126,127,140$

Imperialismus 108

Johnson-Reid Act 115

Kafka, Franz 145

Kantorowicz, Ernst 72

Koch, Robert 125

Kolonialismus 12, 60, 102, 108

koloniale Herrschaft 12

Kolonialgeschichte 50

Konservatismus 134

Kontingenz 10, 12, 13, 14, 16, 18 , $19,120,135,145$

Konzentrationslager 106, 112, 113

Körper 26, 50, 75, 77, 79, 81, 85, $86,87,96,101,121,138$

Kosmopolitismus 134

Krieg 37, 38, 52, 54, 57, 65, 85, 87

Lange, Dorothea 100

Laslett, Peter 31

Leggewie, Claus 98

Legitimation der Abschiebung 109

Liberalismus 10, 16, 19, 60, 134, 140

Locke, John 10, 15, 21, 22, 23, 24, $25,26,27,28,30,31,32,34$, $35,43,45,54,55,58,59,60$, 75,79

Lott, Tommy L. 58

Lüthi, Barbara 115

Marin, Louis 83

Matheus, Jean 48
Meyer, Katrin 142

Mezzadra, Sandro 140

Michael, Mark 59

Migration 12, 14, 15, 33, 61, 73, $96,102,115,116,127,128$, $132,134,135,136,137,139$, 142,147

Migrationskontrolle 11

Migrationspolitik 126, 138, 142

Migrationswege 128

Mills, Charles W. 58

Mona, Martino 140

Monarchie 27

Morus, Thomas 29

Mundy, Barbara 40

Nafziger, James 136, 146

Nationalismus 133, 134

Nationalsozialismus 106, 108, 113

Naturzustand 11, 15, 22, 23, 29, $47,48,50,52,53,54,57,58$, $59,61,65,76,84,85,89$

Nietzsche, Friedrich Wilhelm 106

Oberman, Kieran 136

Osenbrüggen, Eduard 124

Palmer, Richard 74

Panofsky, Erwin 100

Paper Sons 116

Pateman, Carole 31

Pécoud, Antoine 141

Pennock, Roland 57

Perjovschi, Dan 125

Pest $69,70,72,73,76,77,80,88$

Pestarzt 11, 67, 70

Pestbrief 73

Pestpolitik 11, 73, 79, 80, 88

Petty, William 38, 76, 77, 78, 79, 88, 89

(Bio-)Politik 11, 76, 78, 80, 87, 88

politische Partizipation 15

Repressionspolitik 145

Provveditori alla Sanità 74,75

Purtschert, Patricia 52, 58, 142 
Quarantäne 73, 91, 115, 117

Repräsentation 18, 83, 128, 130

Rosen, George 73

Sanität 11, 62, 63, 69, 72, 73, 87

Sans-Papiers 14, 105, 119, 125, $126,127,132,137,139,142$, 143,144

Sarasin, Philipp 80, 101

Schaffer, Simon 54

Schmitt, Carl 53, 67

Shapin, Steven 54

Sichtbarkeit 14, 18, 45, 82, 83, $126,128,132$

Smith, Adam 135

Souveränität $11,14,60,61,62,63$, $69,72,73,74,75,78,81,87$, $88,116,136,137,138$

Sow, Ousmane 126

Sozialismus 91, 134

Spivak, Gayatri 106

Sqadrito, Kathy 29

Staat 22

Staatsbürgerschaft 9, 116, 141

Staatseintritt 22

Staatsgewalt 58

Staatsterritorium 23

Staatszugehörigkeit 10, 146

Subalternität 106

Symbolisierung 19
Taber, Isaiah West 123

Talbot, William Henry Fox 42

Toscani, Oliviero 93

Transparenz 12, 13, 16, 18, 19, 129

Turner, Frederick Jackson 44

Uzgalis, William 28

Vertrag 26, 27, 65, 140

Friedensvertrag 38

(Gesellschafts-)Vertrag 10, 22, 23, $24,29,30,32,43,47,55,59$, $60,82,85,88$

Vertragsgeneration 23

Vertragsschliessung 65

Vertragssubjekt 32

Vertrag von Tordesillas 37

von Guericke, Otto 21

von Müller, Achatz 63, 151

Voyeurismus 129

Watkins, Carleton 11, 45

Weed, Charles Leander 35

Zigeuner siehe Fahrende

Zivilisation 48

Dieser Index ist nicht erschöpfend und erfasst nur einen Teil der zitierten Autoren und Autorinnen. 


\section{BIBLIOGRAFIE}

Abizadeh, Arash: Democratic Theory and Border Coercion: No Rights to Unilaterally Control Your Own Borders. In: Political Theory, 36, 2008, S. 37-65.

Abizadeh, Arash Democratic Legitimacy and State Coercion: A Reply to David Miller. In: Political Theory, 38, 2010, S. 121-130.

Achermann, Christin und Gass, Stefanie: Staatsbürgerschaft und soziale Schliessung. Eine rechtsethnologische Sicht auf die Einbürgerungspraxis der Stadt Basel. Zürich 2003.

Adam, Hans Christian: Go West! Charles Leander Weed und Carleton E. Watkins im „Yosemite Valley“. In: Alles Wahrheit! Alles Lüge! Photographie und Wirklichkeit im 19. Jahrhundert. Die Sammlung Robert Lebeck. Hrsg. Bodo Von Dewitz und Roland Scotti. Amsterdam 1996, S. 401-412. Agamben, Giorgio: We Refugees. In: Symposium, 49, 1995, S. 114-119.

Agamben, Giorgio: Jenseits der Menschenrechte. Einschluss und Ausschluss im Nationalstaat. In: Jungle World, 28, 2001a.

Agamben, Giorgio: Noten zur Geste. In: Mittel ohne Zweck. Noten zur Politik. Hrsg. Giorgio Agamben. Zürich 2001b, S. 53-87.

Agamben, Giorgio: Homo sacer. Frankfurt am Main 2002.

Agamben, Giorgio: Was von Auschwitz bleibt. Das Archiv und der Zeuge. Frankfurt am Main 2003.

Agamben, Giorgio: Ausnahmezustand. Frankfurt am Main 2004.

Agamben, Giorgio: Nymphae. Berlin 2005a.

Agamben, Giorgio: Profanierungen. Frankfurt am Main 2005b.

Agamben, Giorgio: Herrschaft und Herrlichkeit. Über die theologischen Wurzeln von Wirtschaft und Herrschaft. Frankfurt am Main 2010.

Algazi, Gadi: Herrengewalt und Gewalt der Herren im späten Mittelalter. Herrschaft, Gegenseitigkeit und Sprachgebrauch. Frankfurt am Main 1996.

Andrijasevic, Rutvica: The Southern Gate to Fortress Europe. In: Policy Perspectives: Island and Tolerance in Wider Europe, 2006.

Angst, Ursula Schnyder: Illegale Einwanderung in die USA nimmt ab. In: Neue Zürcher Zeitung 14./15.3. 2009, S.3.

Arasse, Daniel: Le détail. Pour une histoire raprochée de la peinture. Paris 1992.

Aravamudan, Srinivas: Hobbes and America. In: The Postcolonial Enlightenment. Eighteenth-Century Colonialism and Postcolonial Theory. Hrsg. Daniel Carey und Lynn Festa. Oxford 2009, S. 37-70.

Arendt, Hannah: Elemente und Ursprünge totaler Herrschaft. Antisemitismus, Imperialismus, Totalitarismus. München 2008 [1951]. 
Argast, Regula, Binnenkade, Alexandra, Boller, Felix u.a. : Viele Wege - eine Welt. Erster Weltkrieg bis Globalisierung. Menschen in Zeit und Raum. Buchs 2005.

Aristoteles: Lehre vom Schluss oder Erste Analytik. Hrsg. Eugen Rolfes. Hamburg 1992.

Aristoteles: Die nikomachische Ethik. Hrsg. Olof Gigon und Rainer Nickel. Düsseldorf 2001.

Armitage, David: The Ideological Origins of the British Empire. Cambridge 2000.

Armitage, David: John Locke, Carolina, and the Two Treatises of Government. In: Political Theory 32, 2004, S. 602-627.

Arneil, Barbara: John Locke and America. The Defence of English Colonialism. Oxford 1996.

Asmussen, Tina: Experiment und die Vielschichtigkeit der Natur. Mikroskopie und die Deutung der Pest in Athanasius Kirchers „Scrutinium physicomedicum“. In: „Die Natur ist überall bey uns“. Mensch und Natur in der Frühen Neuzeit. Hrsg. Aline Steinbrecher und Sophie Ruppel. Zürich 2009, S. 157-170.

Assmann, Aleida: Frauenbilder im Männergedächtnis bei Pater, Proust und Joyce. In: Bildergedächtnis, Gedächtnisbilder. Hrsg. Marion Strunk. Zürich 1998, S. 24-65.

Auer, Andreas: Einbürgerungen durch Gemeindeversammlungen: Um- und Holzwege der bundesgerichtlichen Rechtssprechung. In: Schweizerisches Zentralblatt für Staats- und Verwaltungsrecht, 2, 2009, S. 69-91.

Azzelini, Dario und Gleitze, Judith: Italien. Legalisierung von Flüchtlingen Militarisierung der Grenzen? Berlin 2002.

Baecque, Antoine de: Le corps de l'histoire. Métaphores et politique (17701800). Paris 1993.

Baehr, Peter: City under Siege: Authoritarian Toleration, Mask Culture, and the SARS Crisis in Hong Kong. In: Networked Disease. Emerging Infections in the Global City. Hrsg. S. Harris Ali und Roger Keil. Oxford 2008, S. 138-151.

Balibar, Etienne: Der Schauplatz des Anderen. Formen der Gewalt und Grenzen der Zivilität. Hamburg 2006.

Balke, Friedrich: Tumulto. Regime des Bildes in Hobbes' Leviathan. In: Bildregime des Rechts. Hrsg. Jean-Baptiste Joly, Cornelia Vismann und Thomas Weitin. Stuttgart 2007, S. 62-82.

Balke, Friedrich: Figuren der Souveränität. München 2009.

Banner, Stuart: How the Indians Lost Their Land. Law and Power on the Frontier. Cambridge, Mass. 2005.

Bashford, Alison: Foreign Bodies: Vaccination, Contagion and Colonialim in the Nineteenth Century. In: Contagion: Historical and Cultural Studies. Hrsg. Alison Bashford und Claire Hooker. London 2001, S. 39-60.

Bashford, Alison und Strange, Carolyn: Asylum-Seekers and National Histories of Detention. In: Australian Journal of Politics and History, 48, 2002, S. 509-527. 
Bätschmann, Oskar: Giovanni Bellini: Meister der venezianischen Malerei. München 2008.

Bauböck, Rainer: Transnational Citizenship. Membership and Rights in International Migration. Aldershot Hants 1994.

Bauböck, Rainer: Migration. In: Handbuch der Politischen Philosophie und Sozialphilosophie. Hrsg. Stefan Gosepath, Wilfried Hinsch und Beate Rössler. Berlin 2008, S. 818-823.

Bauer, David: Im Visier von 33000 Hilfssheriffs. In: SonntagsZeitung 25.1. 2009, S. 85.

Bauer, Markus und Rahn, Thomas: Die Grenze. Begriff und Inszenierung. Berlin 1997.

Baur, Joachim: Commemorating Immigration in the Immigrant Society: Narratives of Transformation at Ellis Island and the Lower East Side Tenement Museum. In: Enlarging European Memory. Migration Movements in Historical Perspective. Hrsg. Mareike König und Rainer Ohliger. Ostfildern 2006, S. 137-146.

Bazin, Janine: Lévolution du costume de médicine de peste en Europe de 1348-1720. Paris 1971.

Becker, Robert H.: Designs on the land. Diseños of California ranchos and their makers. San Francisco 1969.

Benhabib, Seyla: The Rights of Others. Aliens, Residents, and Citizens. Cambridge 2004.

Benjamin, Walter: Was ist das episches Theater? Eine Studie zu Brecht. In: Walter Benjamin. Gesammelte Schriften. Hrsg. Rolf Tiedemann und Hermann Schweppenhäuser. Frankfurt am Main 1972, Bd. II, S. 519-539.

Benjamin, Walter: Das Passagen-Werk. Hrsg. Rolf Tiedemann. Frankfurt am Main 1983, Bd. I.

Benthien, Claudia: Haut. Literaturgeschichte, Körperbilder, Grenzdiskurse. Reinbek bei Hamburg 1999.

Benz, Martina und Schwenken, Helen: Jenseits von Autonomie und Kontrolle. Eigensinnige Migrationspraxis. In: Prokla - Zeitschrift für kritische Sozialwissenschaft, 35, 2005, S.363-377.

Benz, Wolfgang und Distel, Barbara: Der Ort des Terrors. Geschichte der nationalsozialistischen Konzentrationslager. München 2005-2009.

Berger, Martin A.: Overexposed: Whiteness and the Landscape Photography of Carleton Watkins. In: Oxford Art Journal, 26, 2003, S. 1-23.

Berger, Silvia: Bakterien in Krieg und Frieden. Eine Geschichte der medizinischen Bakteriologie in Deutschland, 1890-1933. Wissenschaftsgeschichte. Göttingen 2009.

Bernasconi, Robert und Maaza Mann, Anika: Race and Racism in Modern Philosophy. In: Hrsg. Andrew Valls. Ithaca, N.Y. 2005, S. 89-107.

Biemann, Ursula: Ursula Biemann Video Works 1998-2008. Conceptualizing Artistic Fieldwork. In: Mission Reports. Artistic Practice in the Field 19982008. Hrsg. Ursula Biemann und Jan-Erik Lundström. Umea 2008, S. $17-$ 111. 
Blanchard, Emmanuel und Wender, Anne-Sophie: Guerre aux migrants. Le livre noir de Ceuta et Melilla. Arguments et mouvements. Paris 2007.

Bleiker, Roland: Activism after Seattle: Dilemmas of the Anti-globalisation Movement. In: Pacifica Review, 14, 2002, S. 191-207.

Bleiker, Roland: Aesthetics and World Politics. Basingstoke 2009.

Bloch, Marc: Apologie pour l'histoire ou métier d'historien. Paris 1993.

Blumenkranz, Bernhard: Juden und Judentum in der mittelalterlichen Kunst. Stuttgart 1965.

Böckler, Stefan: Grenze: Allerweltswort oder Grundbegriff der Moderne? In: Archiv für Begriffsgeschichte 2003, S. 167-220.

Boehm, Gottfried: Botschaften ohne Worte. Vom Sprachcharakter der bildenden Kunst. In: Der Mensch und seine Sprache(n). Hrsg. Oswald Panagl, Hans Goebl und Emil Brix. Wien, Köln, Weimar 2001, S. 253-273.

Boesch, Ina: Grenzfälle: Von Flucht und Hilfe. Fünf Geschichten aus Europa. Zürich 2008.

Böhme, Hartmut: Das Volle und das Leere. Zur Geschichte des Vakuums. In: Luft. Hrsg. Bernd Busch, Kunst- und Ausstellungshalle der Bundesrepublik Deutschland. Köln 2003, S. 42-67.

Bohn, Cornelia: Passregime: Vom Geleitbrief zur Identifikation der Person. In: AWR-Bulletin. Viertelsjahrschrift für Flüchtlingsfragen, 53, 2006, S. 254269.

Bojadžijev, Manuela, Karakayali, Serhat und Tsianos, Vassilis: Das Gespenst der Migration. Krise des Nationalstaats und Autonomie der Migration. In: Fântomas - Magazin für linke Debatte und Praxis, 5, 2004.

Bommes, Michael und Geddes, Andrew: Immigration and Welfare. Challenging the Borders of the Welfare State. London 2000.

Boucher, David: The Limits of Ethics in International Relations. Natural Law, Natural Rights, and Human Rights in Transition. Oxford 2009.

Brandt, Reinhard: Eigentumstheorien von Grotius bis Kant. Stuttgart 1974.

Brandt, Reinhard: Das Titelblatt des Leviathan und Goyas El Gigante. In: Furcht und Freiheit. Leviathan. Diskussion 300 Jahre nach Thomas Hobbes. Hrsg. Udo Bermbach, Klaus-Michael Kodalle. Opladen 1982, S. 203231.

Brandt, Reinhard: Thomas Hobbes: Das Titelblatt des Leviathan. In: Philosophie in Bildern. Hrsg. Reinhard Brandt. Köln 2000, S. 312-330.

Brecht, Bertolt: Schriften zum Theater. Über ein nicht-aristotelische Dramatik. Berlin 1957.

Brecht, Bertolt: Flüchtlingsgespräche. Berlin 1961.

Bredekamp, Horst: Thomas Hobbes visuelle Strategien. Der Leviathan: Urbild des modernen Staates. Berlin 1999.

Bredekamp, Horst: Thomas Hobbes „Der Leviathan“. Das Urbild des modernen Staates und seine Gegenbilder 1651-2001. 2., stark verändert. Aufl., Berlin 2003.

Bredekamp, Horst: Thomas Hobbes's Visual Strategies. In: The Cambridge Companion to Hobbes's Leviathan. Hrsg. Patricia Springborg. Cambridge 2007, S. 29-60. 
Bredekamp, Horst: Behemoth als Partner und Feind des Leviathan. Zur politischen Ikonologie eines Monstrums. In: Leviathan. Berliner Zeitschrift für Sozialwissenschaft, 37, 2009, S. 429-475.

Breidbach, Olaf: Representation of the Microcosm - The Claim for Objectivity in the 19th Century Scientific Microphotography. In: Journal of the History of Biology, 35, 2002, S. 221-250.

Brett, Annabel S.: Liberty, Right and Nature. Individual Rights in Later Scholastic Thought. Cambridge 1997.

Brocker, Manfred: Arbeit und Eigentum. Der Paradigmenwechsel in der neuzeitlichen Eigentumstheorie. Darmstadt 1992.

Bröckling, Ulrich, Krasmann, Susanne und Lemke, Thomas: Gouvernementalität, Neoliberalismus und Selbsttechnologien. In: Gouvernementalität der Gegenwart. Studien zur Ökonomisierung des Sozialen. Hrsg. Ulrich Bröckling, Susanne Krasmann und Thomas Lemke. Frankfurt am Main 2000, S. 7-40.

Brons, Franziska: Das Versprechen der Retina. Zur Mikrofotografie Robert Kochs. In: Instrumente des Sehens. Bildwelten des Wissens. Kunsthistorisches Jahrbuch für Bildkritik. Hrsg. Angela Fischel, Horst Bredekamp und Gabriele Werner. Berlin 2004, S. 19-28.

Broquet, Ch.: Le masque dans la peste. Présentation d'un modèle de masque antipesteux. In: Bulletin de la société de pathologie exotique. Institut Pasteur, 1911, S. 636-645.

Brossollet, Jacqueline: Costume del medico della peste nei secoli XV et XVI. In: Venezia e la Peste 1348/1797. Hrsg. Jacqueline Brossollet. Venezia 1979, S. 63-65.

Brown, Wendy: Murs. Les murs de séparation et le déclin de la souveraineté étatique. Paris 2009.

Brusatin, Manlio: Il muro della peste: Spazio della pietà e governo del lazzaretto. Venezia 1981.

Buck-Morss, Susan: The Origin of Negative Dialectics: Theodor W. Adorno, Walter Benjamin, and the Frankfurt Institute. Hassocks 1977.

Buck-Morss, Susan: The Dialectics of Seeing: Walter Benjamin and the Arcades Project. Cambridge (Mass.) 1989.

Buck-Morss, Susan: Hegel, Haiti, and Universal History. Pittsburgh 2009.

Buckel, Sonja und Wissel, Jens: State Project Europe: The Transformation of the European Border Regime and the Production of Bare Life. In: International Political Sociology, 4, 2010, S.33-49.

Bundesverfassung der Schweizerischen Eidgenossenschaft, vom 12. Herbstmonat 1848. Bern 1848.

Burghartz, Susanna: Alt, neu oder jung? Zur Neuheit der „Neuen Welt“. In: Die Wahrnehmung des Neuen in Antike und Renaissance. Hrsg. Achatz von Müller, Jürgen Von Ungern-Sternberg. München 2004a.

Burghartz, Susanna: Inszenierte Welten/Staging New Worlds. Die west- und ostindischen Reisen der Verleger de Bry 1590-1630. Basel $2004 \mathrm{~b}$.

Burghartz, Susanna: Mehrdeutigkeit und Superioritätsanspruch. Inszenierte Welten im kolonialen Diskurs um 1600. In: zeitenblicke. BildGeschichten. 
Das Verhältnis von Bild und Text in Berichten über aussereuropäische Welten, 7, 2008.

Bürgin, Ariane: Die Gleichheit aller vor dem Tod. Das emanzipatorische Versprechen von Thomas Hobbes. In: Ordnung, Politik und Geselligkeit der Geschlechter im 18. Jahrhundert. Hrsg. Ulrike Weckel. Göttingen 1998, S. 229-258.

Bürgin, Ariane: Endliches Subjekt: Gleichheit und der Ort der Differenz bei Hobbes und Rousseau. München 2008.

Büttner, Frank, Wimböck, Gabriele und Friedrich, Markus: Evidentia. Reichweiten visueller Wahrnehmung in der Frühen Neuzeit. Berlin 2007.

Calame, Claude: Räumung des „Dschungels“ von Calais: Eine humanitäre Wohltat? In: Archipel 178, 2010.

Caloz-Tschopp, Marie-Claire: Les sans-Etat dans la philosophie d'Hannah Arendt. Les humains superflus, le droit d'avoir des droits et la citoyenneté. Lausanne 2000.

Caloz-Tschopp, Marie-Claire: Les Etrangers aux frontières de l'Europe et le Spectre des Camps. Paris 2004.

Caloz-Tschopp, Marie-Claire, Dasen, Pierre und Chetail, Vincent: Mondialisation, migration et droits de l'homme: un nouveau paradigme pour la recherche et la citoyenneté Bruxelles 2007.

Carens, Joseph H: Migration and morality: A liberal egalitarian perspective. In: Free movement. Ethical Issues in the Transnational Migration of People and of Money. Hrsg. Brian Barry, Robert E. Goodin. University Park 1992, S. 25-47.

Carmichael, Ann G.: Plague and the Poor in Renaissance Florence. Cambridge 1986.

Casalini, Brunella: Denisons, Aliens, and Citizens in Locke's Second Treatise of Government. In: Locke Studies, 2008, S. 107-124.

Casas Klausen, Jimmy: Room Enough: America, Natural Liberty, and Consent in Locke's Second Treatise. In: The Journal of Politics, 2007, S.760769.

Castro Varela, María Do Mar und Dhawan, Nikita: Postkoloniale Theorie. Eine kritische Einführung. Bielefeld 2005.

Castro Varela, María Do Mar und Dhawan, Nikita: Dekolonisierung und die Herausforderungen Feministisch-Postkolonialer Theorie. In: Bildpunkt. Zeitschrift für Bildende Kunst, 2009/2010, S. 22-27.

Castro Varela, María Do Mar und Dhawan, Nikita: Mission Impossible: Postkoloniale Theorie im deutschsprachigen Raum. In: Postkoloniale Soziologie. Empirische Befunde, theoretische Anschlüsse, politische Intervention. Hrsg. Julia Reuter und Paula-Irene Villa. Bielefeld 2010, S.303-329.

Cattaneo, Mario A.: La teoria della pena in Hobbes. In: Jus. Rivista di Scienze Giuridiche, 6, 1960, S. 478-498.

Chase, Marilyn: The Barbary Plague: The Black Death in Victorian San Francisco. New York 2003. 
Cheneval, Francis: Philosophie in weltbürgerlicher Bedeutung. Über die Entstehung und die philosophischen Grundlagen des supranationalen und kosmopolitischen Denkens der Moderne. Basel 2002.

Chetail, Vincent: Migration, droits de l'homme et souveraineté: le droit international dans tous ses états. In: Mondialisation, migration et droits de l'homme: le droit international en question. Hrsg. Vincent Chetail. Bruxelles 2007, S. 13-133.

Christadler, Maike: Die Sammlung zur Schau gestellt: Die Titelblätter der America-Serie. In: Inszenierte Welten/Staging New Worlds. Die west- und ostindischen Reisen der Verleger de Bry, 1590-1630. Hrsg. Susanna Burghartz. Basel 2004, S. 48-93.

Christadler, Martin: Amerikanische Landschaft: Geologie und Heilsgeschichte, Mart und Manifest Destiny. In: Pioniere der Landschaftsphotographie: Gustave Le Gray, Carleton E. Watkins. Hrsg. Margret Stuffmann. Mainz 1993, S. 107-127.

Chwaszcza, Christine: Grundprobleme einer liberalen Philosophie der internationalen Beziehungen. In: Internationale Gerechtigkeit. Rechtsphilosophische Hefte. Beiträge zur Rechtswissenschaft, Philsosophie und Politik, 7, 1997, S. 25-53.

Cohen, Robin: Migration and its Enemies. Global Capital, Migrant Labour and the Nation-State. Aldershot 2006.

Cole, Philip: Reply to Professor Brender and Professor Byrne. In: Truth and Objectivity in Social Ethics. Social Philosophy Today, 18, 2003, S. 197 206.

Cole, Phillip: Philosophies of Exclusion. Liberal Political Theory and Immigration. Edinburgh 2000.

Cole, Simon A.: Suspect Identities. A History of Fingerprinting and Criminal Identification. Cambridge, Mass. 2001.

Conrad, Sebastian und Randeria, Shalini: Geteilte Geschichten - Europa in einer postkolonialen Welt. In: Jenseits des Eurozentrismus. Postkoloniale Perspektiven in den Geschichts- und Kulturwissenschaften. Hrsg. Sebastian Conrad und Shalini Randeria. Frankfurt am Main 2002, S. 9-49.

Cornellise, Galina: Immigration Detention and Human Rights. Rethinking Territorial Sovereignty. Leiden, Boston 2010.

Craddock, Susan: City of Plagues: Disease, Poverty, and Deviance in San Francisco. Minneapolis 2000.

D’Amato, Gianni: Vom Ausländer zum Bürger. Der Streit um die politische Integration von Einwanderern in Deutschland, Frankreich und der Schweiz. Münster 2001.

Dal Lago, Alessandro: Non-persone. l'esclusione dei migranti in una società globale. Universale economica. Milano 2006.

Daston, Lorraine: Objectivity and the Escape from Perspective. In: The Science Studies Reader. Hrsg. Mario Biagioli. New York 1999, S. 110-123.

Daston, Lorraine J. und Park, Katharine: Wonders and the Order of Nature 1150-1750. New York 1998. 
Dauvergne, Catherine: Making People Illegal. What Globalization Means for Migration and Law. New York 2008.

Davenport, Frances Gardiner: European treaties bearing on the history of the United States and its dependencies. Washington, D. C. 1917.

De Genova, Nicholas: The Legal Production of Mexican/Migrant „Illegality“ In: Latino Studies, 2004, S. 160-185.

De Genova, Nicholas: Conflicts of mobility, and the mobility of conflicts: Rightlessness, presence, subjectivity, freedom. In: Subjectivity, 2009, S. 4445-466.

De Genova, Nicholas und Peutz, Nathalie: The Deporation Regime. Sovereignty, Space and the Freedom of Movement. Durham, London 2010.

De Genova, Nicholas P.: Migrant „Illegality“ and Deportability in Everyday Life. In: Annual Review of Anthropology 31, 2002, S. 419-447.

De Ketham, Johannes: The Fasciculo di medicina. Venice 1493. Florence 1925.

Del Grande, Gabriele: Mamadou va a morire. La strage dei clandestini nel mediterraneo. Manocalzati 2008.

Denevan, William M.: The Pristine Myth: The Landscape of the Americas in 1492. In: Annals of the Association of American Geographers, 82, 1992, S. 369-385.

Dhawan, Nikita: Can the Subaltern Speak German? And Other Risky Questions. In: http://translate.eipcp.net/strands/03/dhawan-strands01en, 10.2.2011.

Dhawan, Nikita: Postkoloniale Feministin und die Politik der Subalternität. In: Olympe. Feministische Arbeitshefte zur Politik, 2008, S.36-41.

Diekmann, Stefanie und Khurana, Thomas Latenz. Eine Einleitung. In: Latenz. 40 Annäherungen an einen Begriff. Hrsg. Stefanie Diekmann und Thomas Khurana. Berlin 2007, S. 9-14.

Dietrich, Nikola: Von Wand zu Wand. In: Dan Perjovschi. On the other hand 2006 (with a 2005 prologue). Frankfurt am Main 2007.

Dinges, Martin: Pest und Staat: Von der Institutionengeschichte zur sozialen Konstruktion? In: Neue Wege in der Seuchengeschichte. Hrsg. Thomas Schlich, Martin Dinges. Stuttgart 1995, S.71-104.

Dohrn-van Rossum, Gerhard: Politischer Körper, Organismus, Organisation. Zur Geschichte naturaler Metaphorik und Begrifflichkeit in der politischen Sprache. Bielefeld 1977.

Drechsel, Benjamin: Bilderwelten=Weltbilder? Fotojournalismus als Herausforderung für die visuelle politische Bildung. In: Foto + Text. Handbuch für die Bildungsarbeit. Hrsg. Alfred Holzbrecher, Ingelore Oomen-Welke und Jan Schmolling. Wiesbaden 2006, S. 407-417.

Dummett, Michael A. E.: On Immigration and Refugees. Thinking in action. London 2002.

Düvell, Franck: Illegale Migration: Soziales Konstrukt der Neuzeit, Charakteristikum von Ungerechtigkeit und Ausdruck politischen Versagens. In: Wer bestimmt denn unser Leben? Beiträge zur Entkriminalisierung von Men- 
schen ohne Aufenthaltsstatus. Hrsg. Klaus Jünschke und Bettina Paul. Karlsruhe 2005a, S. 41-56.

Düvell, Franck: Migration und Gerechtigkeit: Gerechtigkeitsvorstellungen und - gefühle von Migranten. In: Sinn für Ungerechtigkeit. Ethische Argumentationen im globalen Kontext. Hrsg. Ian Kaplow und Christoph Lienkam. Baden-Baden 2005b, S. 178-199.

Düvell, Franck: Europäische und internationale Migration. Einführung in historische, soziologische und politische Analysen. Hamburg 2006.

Düvell, Franck: Irreguläre Migrant/innen in den Städten Europas: wirtschaftliche, ethische und politische Implikationen. In: Zürcher Migrationskonferenz (Vortragsmanuskript). 2007.

Ebeling, Frank: Die Grenze in der Betrachtung der Geopolitik in Deutschland. In: Die Grenze. Begriff und Inszenierung. Hrsg. Markus Bauer und Thomas Rahn. Berlin 1997, S.73-81.

Eberl, Oliver: Demokratie und Frieden. Kants Friedensschrift in den Kontroversen der Gegenwart. Baden-Baden 2008.

Edkins, Jenny und Pin-Fat, Véronique: Introduction: Life, Power, Resistance. In: Sovereign Lives. Power in Global Politics. Hrsg. Jenny Edkins, Véronique Pin-Fat und Michael J. Shapiro. New York 2004.

Edkins, Jenny: Whatever Politics. In: Giorgio Agamben. Sovereignty and Life. Hrsg. Matthew Calarco und Steven DeCaroli. Stanford 2007, S. 70-91.

Egger, Franz: Der Bundesstaat und die fremden Zigeuner in der Zeit von 1848 bis 1914. Bern 1982.

Eggers, Daniel: Die Naturzustandstheorie des Thomas Hobbes. Eine vergleichende Analyse von The elements of law, De Cive und den englischen und lateinischen Fassungen des Leviathan. Berlin 2008.

Eichenhofer, Eberhard: Migration und Illegalität. Osnabrück 1999.

Ellrich, Lutz, Maye, Harun und Meteling, Arno: Die Unsichtbarkeit des Politischen. Theorie und Geschichte medialer Latenz. Bielefeld 2009.

Endfield, Georgina: „Pinturas“, Land and Lawsuits: Maps in Colonial Mexican Legal Documents. In: Imago Mundi, 53, 2001, S.7-27.

Erkens, Franz-Reiner: Busse in Zeiten des Schwarzen Todes: Die Züge der Geissler. In: Zeitschrift für Historische Forschung, 26, 1999, S. 483-513.

Erlanger, Simon: „Nur ein Durchgangsland“. Arbeitslager und Internierungsheime für Flüchtlinge und Emigranten in der Schweiz, 1940-1949. Zürich 2006.

Euskirchen, Markus, Lebuhn, Henrik und Ray, Gene: From Boderline to Borderland: The Changing European Border Regime. In: Monthly Review, 59, 2007.

Euskirchen, Markus, Lebuhn, Henrik, Ray, Gene: Wie Illegale gemacht werden. Das neue EU-Grenzregime. In: Blätter für deutsche und internationale Politik, 54, 2009, S. 72-80.

Fach, Wolfgang: Geschichten vom Leviathan. In: Frankfurter Allgemeine Zeitung 9.6. 2010, S.3.

Faciolince, Héctor Abad Die neuen Pestkranken. In: Neue Zürcher Zeitung 19.5. 2008, S. 21. 
Fahrmeir, Andreas: Klassen-Grenzen: Migrationskontrolle im 19. Jahrhundert. In: Rechtsgeschichte. Zeitschrift des Max-Planck-Instituts für europäische Rechtsgeschichte, 2008, S. 125-138.

Fairchild, Amy L.: Science at the Borders. Immigrant Medical Inspection and the Shaping of the Modern Industrial Labor Force. Baltimore 2003.

Falk, Francesca: Amerika als leere Augenweide. John Lockes Staatstheorie und die Grenzfotografie vor Gericht. In: Grenzbilder. Bildwelten des Wissens. Kunsthistorisches Jahrbuch für Bildkritik. Hrsg. Horst Bredekamp, Matthias Bruhn, Angela Fischel u.a. Berlin 2008a, S. 21-32.

Falk, Francesca: Grenzevidenz, Bildverbot und Grenzpotenz. In: Die Vermessung der Globalisierung. Hrsg. Ulfried Reichardt. Heidelberg 2008b, S. 125-138.

Falk, Francesca: Grenzverwischer. „Jud Süss“ und „Das Dritte Geschlecht“: Verschränkte Diskurse von Ausgrenzung. Innsbruck 2008c.

Falk, Francesca: Europa - der Blick auf die Ränder. Bootsflüchtlinge und Bildgedächtnis: Ikonen gefährdeter Grenzen. In: Bilder von Europa. Innenund Aussenansichten von der Antike bis zur Gegenwart. Hrsg. Benjamin Drechsel und Claus Leggewie. Bielefeld 2010a, S.333-342.

Falk, Francesca: Invasion, Infection, Invisibility: An Iconology of Illegalized Immigration. In: Images of Illegalized Immigration. Towards a Critical Iconology of Politics. Hrsg. Christine Bischoff, Francesca Falk und Sylvia Kafehsy. Bielefeld 2010b, S. 83-100.

Falk, Francesca: Stimm- und Wahlrecht. Das Recht auf geistige Mitarbeit. In: Basler Zeitung 31.08. 2010c, S.31-33.

Falk, Francesca: Arabischer Frühling. Runter mit der kolonialen Brille. In: Wochenzeitung 24.3. 2011a, S. 21.

Falk, Francesca: Postkoloniale Perspektiven auf die politische Philosophie. Thomas Hobbes' horror vacui und John Lockes leeres Land. In: Tierische (Ge)Fährten. Historische Anthropologie, 2011b, S. 292-310.

Falk, Francesca: Hobbes' Leviathan und die aus dem Blick gefallenen Schnabelmasken. In: Leviathan. Berliner Zeitschrift für Sozialwissenschaft, 39, 2011. S. 247-266.

Falk, Francesca: Eine postkoloniale Perspektive auf die illegalisierte Immigration in der Schweiz. Über Ausschaffungen, den „Austausch mit Afrika“, Alltagsrassismen und die Angst vor der umgekehrten Kolonisierung. In: Postkoloniale Schweiz. Hrsg. Patricia Purtschert, Barbara Lüthi und Francesca Falk. Bielefeld 2012.

Farr, James: Locke, Natural Law, and New World Slavery. In: Political Theory, 36, 2008, S. 495-522

Fassin, Didier: The biopolitics of otherness. In: Anthropology Today, 17, 2001, S.3-7.

Fassin, Didier: Compassion and Repression: The Moral Economy of Immigration Policies in France. In: Cultural Anthropology, 2005a, S.362-387.

Fassin, Didier: The Truth from the Body: Medical Certificates as Ultimate Evidence for Asylum Seekers. In: American Anthropologist, 107, 2005b, S. 597-608. 
Fazzini, Gerolamo: Venezia - Isola del Lazzaretto Nuovo. Guide archeologiche della Laguna di Venezia. Venezia 2004.

Febvre, Lucien: „Frontière“ - Wort und Bedeutung. In: Das Gewissen des Historikers. Hrsg. Ulrich Raulff. Berlin 1988, S. 27-37.

Fernandes, Jorge: Ebola Takes to the Road: Mobilizing Viruses in Defense of the Nation-State. In: Sovereign Lives. Power in Global Politics. Hrsg. Jenny Edkins, Véronique Pin-Fat und Michael J. Shapiro. New York 2004, S. 189-210.

Filmer, Robert: Patriarcha and Other Writings. Cambridge 1991 [1680].

Fink-Eitel, Hinrich: Die Philosophie und die Wilden. Über die Bedeutung des Fremden für die europäische Geistesgeschichte. Hamburg 1994.

Fisch, Jörg: Die europäische Expansion und das Völkerrecht. Die Auseinandersetzungen um den Status der überseeischen Gebiete vom 15. Jahrhundert bis zur Gegenwart. Stuttgart 1984.

Fischer-Tiné, Harald: Frauen - Tiger - Offiziere? Die europäische Gesellschaft in Britisch-Indien um 1860-1914. In: Das Zeitalter des Kolonialismus. Hrsg. Boris Barth. Darmstadt 2007a, S. 97-104.

Fischer-Tiné, Harald: Global Civil Society and the Forces of Empire: The Salvation Army, British Imperialism, and the „Prehistory“ of NGO's (ca. 1880-1940). In: Competing Visions of World Order: Global Moments and Movements, 1880s-1930s. Hrsg. Sebastian Conrad und Dominic Sachsenmaier. New York 2007b, S. 29-68.

Flam, Helena: Migranten in Deutschland. Statistiken - Fakten - Diskurse. Wissen und Studium. Sozialwissenschaften. Konstanz 2007.

Foucault, Michel: Überwachen und Strafen. Die Geburt des Gefängnisses. Frankfurt am Main 1977.

Foucault, Michel: Nietzsche, die Genealogie, die Historie. In: Von der Subversion des Wissens. Frankfurt am Main 1987.

Foucault, Michel: Dies ist keine Pfeife. München 1997.

Foucault, Michel: Les Anormaux. Cours au Collège de France (1974-1975). Paris 1999.

Foucault, Michel: Gespräch mit Michel Foucault. In: Schriften in vier Bänden. Dits et Ecrits. Hrsg. Daniel Defert und François Ewald. Frankfurt am Main 2001, Bd. III 1976-1979, S. 186-212.

Foucault, Michel: Geschichte der Gouvernementalität I. Sicherheit, Territorium, Bevölkerung. Vorlesung am Collège de France 1977-1978. Frankfurt am Main 2004a.

Foucault, Michel: Geschichte der Gouvernementalität II. Die Geburt der Biopolitik. Vorlesung am Collège de France 1978-1979. Frankfurt am Main 2004b.

Foucher, Michel: Fronts et Frontières. Un tour du monde géopolitique. Paris 1988.

Fox, Frances L.: Luis Maria Peralta and his adobe. San Jose 1975.

Franck, Georg: Ökonomie der Aufmerksamkeit. Ein Entwurf. München 1998. 
Futscher, Edith et. al.: Was aus dem Bild fällt. Figuren des Details in Kunst und Literatur. Friedrich Teja zum 60. Geburtstag. Paderborn 2007.

Gabrielatos, Costas und Baker, Paul: Fleeing, Sneaking, Flooding. In: Journal of English Linguistics 36, 2008, S. 5-38.

Gasser, Martin, Meier, Thomas und Wolfensberger, Rolf: Wider das Leugnen und Verstellen. Carl Durheims Fahndungsfotografien von Heimatlosen 1852/53. Zürich, Winterthur 1998.

Gasser, Martin und Suter, Meinrad: Mordfall Meidel. Frühe Polizeifotografie in Zürich 1853. In: Fotogeschichte. Beiträge zur Geschichte und Aesthetik der Fotografie, 27, 2007, S. 53-59.

Gassner, Markus: Wie schützen Masken bei Krankheiten - früher oder heute? In: Schweizerische Ärztezeitung, 2008, S. 250-254.

Gatti, Fabrizio: Bilal. Als Illegaler auf dem Weg nach Europa. München 2010.

Geimer, Peter: Was ist kein Bild? Zur „Störung und Verweisung“. In: Ordnungen der Sichtbarkeit. Fotografie in Wissenschaft, Kunst und Technologie. Hrsg. Peter Geimer. Frankfurt am Main 2002, S. 313-341.

Geiselberger, Heinrich: Und jetzt? Politik, Protest und Propaganda. Frankfurt am Main 2007.

Genz, Henning: Die Entdeckung des Nichts. Leere und Fülle im Universum. München 1994.

Gerhard, Ute: „Fluten“, „Ströme“, „Invasionen“- Mediendiskurs und Rassismus. In: Zwischen Nationalstaat und multikultureller Gesellschaft: Einwanderung und Fremdenfeindlichkeit in der Bundesrepublik Deutschland. Hrsg. Manfred Hessler. Berlin 1993, S. 239-253.

Gerwarth, Robert und Malinowski, Stephan: Der Holocaust als „kolonialer Genozid“? Europäische Kolonialgewalt und nationalsozialistischer Vernichtungskrieg. In: Geschichte und Gesellschaft, 33, 2007, S. 439-466.

Gibney, Mark: Open borders? Closed societies? The Ethical and Political Issues. New York 1988.

Ginzburg, Carlo: Spurensicherung. Die Wissenschaft auf der Suche nach sich selbst. Berlin 1995.

Ginzburg, Carlo: Welt der Leviathane. Furcht, Verehrung, Schrecken -Thomas Hobbes' Politische Theologie. In: Lettre International, 83, 2008, S. 2327.

Glausser, Wayne: Three Approaches to Locke and the Slave Trade. In: Journal of the History of Ideas, 51, 1990, S. 199-216.

Glick Schiller, Nina, Basch, Linda und Szanton Blanc, Cristina: From Immigrant to Transmigrant: Theorizing Transnational Migration. In: Anthropological Quarterly 68, 1995, S. 48-63.

Goetz, Benoît und Nancy, Jean-Luc: La dislocation. Architecture et philosophie. Paris 2001.

Golan, Tal: Sichtbarkeit und Macht: Maschinen als Augenzeugen. In: Ordnungen der Sichtbarkeit. Fotografie in Wissenschaft, Kunst und Technologie. Hrsg. Peter Geimer. Frankfurt am Main 2002, S. 171-210.

Gordon, Anna Pegler: In sight of America: Photography and U.S. Immigration Policy, 1880-1930. American Culture. Michigan 2002. 
Graus, František: Pest - Geissler - Judenmorde. Das 14. Jahrhundert als Krisenzeit. Göttingen 1987.

Green, Nancy L.: History at Large. A French Ellis Island? Museums, Memory and History in France and the United States. In: History Workshop Journal 2007, S. 239-253.

Greenblatt, Stephen Jay: Wunderbare Besitztümer. Die Erfindung des Fremden: Reisende und Entdecker. Darmstadt 1991.

Groebner, Valentin: Der Schein der Person. In: Quel corps? Eine Frage der Repräsentation. Hrsg. Hans Belting, Dietmar Kamper und Martin Schulz. München 2002, S. 307-323.

Groebner, Valentin: Der Schein der Person. Steckbrief, Ausweis und Kontrolle im Europa des Mittelalters. München 2004.

Grotius, Hugo: Drei Bücher über das Recht des Krieges und Friedens. Berlin 1869 [1625].

Guex, Sébastien: L'impérialisme suisse ou les secrets d'une puissance invisible. In: solidaritéS, 2007, S. 1-4.

Hahn, Sylvia, Komlosy, Andrea und Reiter, Ilse: Der Staat schiebt ab. Zur nationalstaatlichen Konsolidierung von Heimat und Fremde im 18. und 19. Jahrhundert. Ausweisung - Abschiebung - Vertreibung in Europa. 16.20. Jahrhundert. Innsbruck 2006.

Hall, Barbara: Race in Hobbes. In: Race and Racism in Modern Philosophy. Hrsg. Andrew Valls. Ithaca, N.Y. 2005, S. 43-57.

Hamacher, Werner: „Now“: Walter Benjamin on Historical Time. In: Walter Benjamin and History. Hrsg. Andrew E. Benjamin. London, New York 2005, S. 38-68.

Harley, J. B.: New England Cartography and the Native Americans. In: The new Nature of Maps: Essays in the History of Cartography. Hrsg. J. B. Harley und Paul Laxton. Baltimore 2001, S. 169-196.

Harrison, John und Laslett, Peter: The library of John Locke. London 1965.

Hartle, Johan Frederik: Der Philosoph an den Grenzen der Rechtsgemeinschaft. In: Literaturkritik.de, 11 http://www.literaturkritik.de/public/rezension.php?rez_id=6524\&ausgabe=200311 (08.08.2010), 2003.

Hartle, Johann F.: Die Spur der Gewalt bildhaft werden lassen. In: per imaginem. Bildllichkeit und Souveränität. Hrsg. Anne Von der Heiden. Zürich, Berlin 2005, S. 23-44.

Häsler, Alfred: Einen Baum pflanzen. Gelebte Zeitgeschichte. Zürich 1996.

Häsler, Alfred Adolf: Unser Boot ist nicht voll. In: Weltwoche, 1979, S. 37-38.

Häsler, Alfred Adolf, Dürrenmatt, Friedrich: Das Boot ist voll: Die Schweiz und die Flüchtlinge 1933-1945. Zürich 1989.

Hauser, Walter: Bitterkeit und Tränen. Szenen der Auswanderung aus dem Tal der Linth und die Ausschaffung des heimatlosen Samuel Fässler nach Amerika. Zürich 1995.

Heck, Gerda: „Illegale Einwanderung“. Eine umkämpfte Konstruktion in Deutschland und den USA. Münster 2008. 
Hecker, Hans: Grenze, Raum, Geschichte. Oder: Ist ein Leben ohne die andere Seite möglich? Eine Einführung. In: Grenzen: Gesellschaftliche Konstitutionen und Transfigurationen. Hrsg. Hans Hecker. Essen 2006, S.9-26.

Heid, Ludger: Maloche - nicht Mildtätigkeit. Ostjüdische Arbeiter in Deutschland 1914-1923. Hildesheim, Zürich 1995.

Herb, Guntram H: Von der Grenzrevision zur Expansion: Territorialkonzepte in der Weimarer Republik. In: Welt-Räume. Geschichte, Geographie und Globalisierung seit 1900. Hrsg. Iris Schröder und Sabine Höhler. Frankfurt am Main 2005, S. 175-203.

Herbert, Ulrich: Lagerleben. Über die Dynamik eines Provisoriums. In: Journal für Geschichte, 2, 1987, S. 27-35.

Hess, Sabine und Kasparek, Bernd: Grenzregime. Diskurse, Praktiken, Institutionen in Europa. Berlin 2010.

Hirschman, Albert O.: Exit, Voice, and Loyalty. Responses to decline in Firms, Organizations, and States. Cambridge 1970.

Hobbes, Thomas: The English Works of Thomas Hobbes of Malmesbury. Hrsg. William Molesworth. London 1839, Bd. I.

Hobbes, Thomas: The English Works of Thomas Hobbes of Malmesbury. Hrsg. William Molesworth. London 1840, Bd. IV.

Hobbes, Thomas: Leviathan oder, Stoff, Form und Gewalt eines kirchlichen und bürgerlichen Staates. Frankfurt am Main 1966 [1651].

Hobbes, Thomas: Leviathan. Erster und zweiter Teil. Stuttgart 1970 [1670].

Hobbes, Thomas: Thomas White's De mundo examined. London 1976 [1642].

Hobbes, Thomas und Warrender, Howard: De Cive. The Latin version, entitled in the first edition „Elementorum philosophiae sectio tertia de cive“ and in later editions „Elementa philosophica de cive“. Oxford 1983.

Hobbes, Thomas: Vom Menschen. Vom Bürger. Elemente der Philosophie II/ III. Hrsg. Günter Gawlick. Hamburg 1994 [1642/1647].

Hobbes, Thomas: Leviathan, or The Matter, Form, and Power of a Commonwealth Ecclesiastical and Civil. Oxford World's Classic. Hrsg. J.C.A. Gaskin. Oxford 1996 [1651].

Hobbes, Thomas: De Cive. Montana 2004 [1651].

Hobsbawm, Eric John: Nations and Nationalism since 1780. Programme, Myth, Reality. Cambridge 1990.

Höffe, Otfried: Ethik und Politik. Grundmodelle und -probleme der praktischen Philosophie. Frankfurt am Main 1979.

Holert, Tom und Terkessidis, Mark: Fliehkraft. Gesellschaft in Bewegung von Migranten und Touristen. Köln 2006.

Hölscher, Lucian: Semantik der Leere. Grenzfragen der Geschichtswissenschaft. Göttingen 2009.

Hoppe, Marcus: „Auf die freundliche oder hässliche Art und Weise. Illegale Immigranten müssen verjagt werden." Der Anti-Immigrationsdiskurs der Lega Nord. In: The Making of Migration. Repräsentationen - Erfahrungen - Analysen. Hrsg. Bartholomäus Figatowski, Kokebe Haile Gabriel, Malte Meyer. Münster 2007, S. 127-145. 
Hornbeck, David: The Patenting of California's Private Land Claims, 18511885. In: Geographical Review, 69, 1979, S. 434-448.

Houtum, Henk van, Kramsch, Olivier Thomas und Zierhofer, Wolfgang: B/ ordering space. Border regions series. Aldershot 2005.

Huber, Jörg und Stoellger, Philipp: Kontingenz als Figur des Dritten - zwischen Notwendigkeit und Beliebigkeit. In: Gestalten der Kontingenz. Ein Bilderbuch. Hrsg. Jörg Huber und Philipp Stoellger. Zürich 2008, S. 7-22.

Hunt, Lynn Avery: Symbole der Macht, Macht der Symbole. Die Französische Revolution und der Entwurf einer politischen Kultur. Frankfurt am Main 1989.

Huonker, Thomas: Schweizer Polizeiinstanzen, Interpol und die Verfolgung von Roma, Sinti und Jenischen im 20. Jahrhundert. In: Neue Wege. Beiträge zu Christentum und Sozialismus, 94, 2004, S. 295-302.

Huonker, Thomas, Ludi, Regula: Roma, Sinti und Jenische. Schweizerische Zigeunerpolitik zur Zeit des Nationalsozialismus. Zürich 2001.

Hürlimann, Brigitte: Vom richtigen Umgang mit Ausschaffungshäftlingen. Bundesgericht rügt zu restriktives Haftregime im Kanton Zürich. In: Neue Zürcher Zeitung 13.5. 2008.

Ivison, Duncan: Locke, Liberalism and Empire. In: The Philosophy of John Locke. New Perspectives. Hrsg. Peter R. Anstey. London 2003, S. 86-105.

Jabès, Edmond: Le Livre des Ressemblances, II. Galimard 1978.

Jäger, Ludwig: Störung und Transparenz. Skizze zur performativen Logik des Medialen. In: Performativität und Medialität. Hrsg. Sybille Krämer. München 2004, S. 35-73.

Jäger, Ludwig: Geht die Zeit der Entzauberung der Evidenz zu Ende? Oder beginnt sie erst? Ludwig Jäger im Interview mit Helmut Lethen. In: Zeitschrift für Kulturwissenschaften. Sehnsucht nach Evidenz, 1, 2009, S. 8994.

Jäger, Margarete, Jäger, Siegfried: Deutungskämpfe. Theorie und Praxis kritischer Diskursanalyse. Wiesbaden 2007.

Jahn, Beate: The Cultural Construction of International Relations. The Invention of the State of Nature. Basingstoke 2000.

Jeggle, Utz: „Glück und Glas...“ Anmerkungen eines Volkskundlers zur Metaphorik des Gläsernen. In: Der gläserne Mensch - eine Sensation. Zur Kulturgeschichte eines Ausstellungsobjekts. Hrsg. Rosmarie Beier, Martin Roth. Stuttgart 1990, S. 125-134.

Joppke, Christian: Why Liberal States Accept Unwanted Immigration. In: World Politics, 50, 1998, S. 266-293.

Jordan, Thomas Edward: Sir William Petty, 1623-1687. The Genius Entrepreneur of Seventeenth-Century Ireland. Lewiston, N.Y. 2007.

Jussen, Bernhard: Die "Geschichte" der Wissenschaft und die "Geschichte" der Kunst. Was die historischen Wissenschaften von der bildenden Kunst lernen können. In: Das Gedächtnis der Kunst. Geschichte und Erinnerung in der Kunst der Gegenwart. Hrsg. Kurt Wettengl und Aleida Assmann. Ostfildern 2000, S. 57-70. 
Jütte, Robert: Arme, Bettler, Beutelschneider. Eine Sozialgeschichte der Armut in der Frühen Neuzeit. Weimar 2000.

Kafka, Franz: Gemeinschaft, Niederschrift im Konvolut 1920. In: Die Erzählungen und andere ausgewählte Prosa. Hrsg. Roger Hermes. Frankfurt am Main 2003, S. 373-353.

Kanstroom, Daniel: Deportation Nation. Outsiders in American History. Cambridge, Mass. 2007.

Kantorowicz, Ernst Hartwig: Die zwei Körper des Königs. Eine Studie zur politischen Theologie des Mittelalters. Stuttgart 1992.

Karakayali, Serhat: Gespenster der Migration. Zur Genealogie illegaler Einwanderung in der Bundesrepublik Deutschland. Bielefeld 2008.

Karp, Hans-Jürgen: Zur Frühgeschichte des Wortes „Grenze“. In: Archiv für das Studium der neueren Sprachen und Literatur, 141, 1989, S. 344-356.

Keller, Robert H. und Turek, Michael F.: American Indians and National Parks. Tucson 1998.

Kersting, Wolfgang: Die politische Philosophie des Gesellschaftsvertrags. Darmstadt 1996.

Kesselring, Thomas: Unendlichkeit des Geldes - Endlichkeit der Natur. In: Neue Zürcher Zeitung 17.3. 2009, S.7.

Kiening, Christian: Das wilde Subjekt. Kleine Poetik der Neuen Welt. Göttingen 2006.

Kirloskar-Steinbach, Monika: Gibt es ein Menschenrecht auf Immigration? Politische und philosophische Positionen zur Einwanderungsproblematik. München 2007.

Klein, Naomi: The Shock Doctrine. The Rise of Disaster Capitalism. New York 2007.

Koch, Robert: Zur Untersuchung von pathogenen Organismen. In: Gesammelte Werke. Leipzig 1912, Bd. 1, S. 112-163.

König, Helmut: Zivilisation und Leidenschaften. Die Masse im bürgerlichen Zeitalter. Reinbek bei Hamburg 1992.

König, Helmut: Politik und Gedächtnis. Weilerswist 2008.

Kornhauser, Elizabeth Mankin und Fluck, Winfried: Neue Welt: Die Erfindung der amerikanischen Malerei. München 2007.

Kost, Mena: Im Ausschaffungsknast. In: Surprise, 2008, S. 10-13.

Kotek, Joël und Pierre, Rigoulot: Das Jahrhundert der Lager. Gefangenschaft, Zwangsarbeit, Vernichtung. Berlin 2001.

Krämer, Sybille: Karten-Kartenlesen-Kartografie. Kulturtechnisch inspirierte Überlegungen. In: Bild/Geschichte. Festschrift für Horst Bredekamp. Hrsg. Philine Helas, Maren Polte, Claudia Rückert u.a. . Berlin 2007, S. 73-82.

Kreis, Georg: Schweizerische Asylpolitik in Vergangenheit und Gegenwart. In: Asylland wider Willen. Flüchtlinge in Österreich im europäischen Kontext seit 1914. Hrsg. Gernot Heiss, Oliver Rathkolb. Wien 1995, S. 264-279.

Kreis, Georg: Europa und seine Grenzen. Bern 2004. 
Krüger, Gesine: Kriegsbewältigung und Geschichtsbewusstsein. Realität, Deutung und Verarbeitung des deutschen Kolonialkrieges in Namibia 1904 bis 1907. Göttingen 1999.

Krummenacher, Jürg: St. Gallen findet Lösung für Einbürgerungen. In: Neue Zürcher Zeitung 17.2. 2009a, S. 14.

Krummenacher, Jürg: St. Gallen verfügt Einbürgerungen. In: Neue Zürcher Zeitung 15.12. 2009b, S. 15.

Kuhlemann, Ute: Between Reproduction, Invention and Propaganda: Theodor de Bry's Engravings after John White's Watercolours. In: A new world. England's first view of America. Hrsg. Kim Sloan. London 2007, S. 79-92.

Laboulais-Lesage, Isabelle: Combler les blancs de la carte. Modalités et enjeux de la construction des savoirs géographiques (XVIe-XXe siècle). Strassburg 2004.

Landwehr, Achim: Die Erschaffung Venedigs. Raum, Bevölkerung, Mythos, 1570-1750. Paderborn 2007.

Lane, Melissa: A Philosophical View on States and Immigration. In: Globalizing Migration Regimes. New Challenges to Transnational Cooperation. Hrsg. Joakim Palme und Kristof Tamas. Aldershot 2006, S. 131-143.

Langewiesche, Dieter: Liberalismus heute - historisch gesehen. In: Liberalismus und Sozialismus. Gesellschaftsbilder - Zukunftsvisionen - Bildungskonzeptionen. Hrsg. Friedrich Lenger. Bonn 2003, S. 206-231.

Lanz, Anni: Erwartungen, Enttäuschungen, verunsichernde Debatten. In: Olympe. Feministische Arbeitshefte zur Politik, 2008, S. 107-115.

Latour, Bruno: Wir sind nie modern gewesen. Versuch einer symmetrischen Anthropologie. Berlin 1995.

Lebovics, Herman: The Uses of America in Locke's Second Treatise of Government. In: Journal of the History of Ideas, 47, 1986, S. 567-581.

Lebovics, Herman: Imperialism and the Corruption of Democracies. Durham 2006.

Lee, Erika: At America's Gates: Chinese immigration during the exclusion era, 1882-1943. Chapel Hill 2003.

Leggewie, Claus: Amerikas Welt: Die USA in unseren Köpfen. Hamburg 2000.

Leimgruber, Walter: Bilder vom Körper - Bilder vom Menschen. Kultur und Ausgrenzung um 1900 und heute. In: Zeitschrift für Volkskunde, 100, 2004-2005, S. 69-91.

Lemberg-Pedersen, Martin: Postcolonial Humanity at the African-European Borderlands: The Biopolitics of Forced Flows. In: http://cesem.ku.dk/papers/Postcolonial_Humanity_at_the_African-European_Borderlands. docx.pdf, 2010.

Lemke, Thomas: Biopolitik zur Einführung. Hamburg 2007.

Leuthardt, Beat: Festung Europa - Asyl, Drogen „Organisierte Kriminalität“. Die „Innere Sicherheit" der 80er und 90er Jahre und ihre Feindbilder. Zürich 1994.

Leuthardt, Beat: An den Rändern Europas. Berichte von den Grenzen. Zürich 1999. 
Leven, Karl-Heinz: Mensch - Umwelt - Seuchen: Wechselwirkungen zwischen Krankheit und Lebensumwelt seit der Antike. In: Ökohistorische Reflexionen. Mensch und Umwelt zwischen Steinzeit und Silicon Valley. Hrsg. Kurt W. Alt, Natascha Rauschenberger. Freiburg im Breisgau 2001, S.75-98.

Linklater, Andro: The Fabric of America. How our Borders and Boundaries shaped the Country and forged our National Identity. New York 2007.

Locke, John: Zwei Abhandlungen über die Regierung. Hrsg. Walter Euchner. Frankfurt am Main 1977 [1690].

Locke, John: Second Treatise of Government. Hrsg. C.B. Macpherson. Indianapolis 1980 [1690].

Locke, John: Two Treatises of Government. Hrsg. Peter Laslett. Cambridge 1988 [1690].

Lott, Tommy: Patriarchy and Slavery in Hobbes's Political Philosophy. In: Philosophers on Race. Critical Essays. Hrsg. Julie K. Ward. Oxford 2002, S. 63-80.

Lucassen, Leo: Zigeuner. Die Geschichte eines polizeilichen Ordnungsbegriffes in Deutschland 1700-1945. Köln 1996.

Ludwig, Bernd: John Lockes Eigentumstheorie. In: Was ist Eigentum? Philosophische Eigentumstheorien von Platon bis Habermas. Hrsg. Andreas Eckl. München 2005, S. 88-102.

Lüthi, Barbara: Invading Bodies. Medizin und Immigration in den USA 1880-1920. Frankfurt am Main 2009.

Macias, José: Die Entwicklung des Bildjournalismus. München 1990.

MacLachlan, Colin M.: Spain's Empire in the New World. The Role of Ideas in Institutional and Social Change. Berkeley 1988.

Macpherson, Crawford Brough: Die politische Theorie des Besitzindividualismus. Von Hobbe bis Locke. Frankfurt am Main 1973.

Malcolm, Noel: Hobbes, Sandys, and the Virginia Company. In: Aspects of Hobbes. Hrsg. Noel Malcolm. Oxford 2002a, S. 53-79.

Malcolm, Noel: The Title Page of Leviathan, seen in a curious Perspective. In: Aspects of Hobbes. Hrsg. Noel Malcolm. Oxford 2002b, S. 200-229.

Manow, Philip: Sexualität und Souveränität - Neue Nachrichten vom Vorund Nachleben des Leviathan-Frontispizes. In: Leviathan. Berliner Zeitschrift für Sozialwissenschaft, 35, 2007, S. 470-494.

Manow, Philip: Im Schatten des Königs. Die politische Anatomie demokratischer Repräsentation. Frankfurt am Main 2008.

Marin, Louis: Das Porträt des Königs. Berlin 2005.

Marischka, Christoph und Pflüger, Tobias: Das militarisierte Grenzregime der EU. In: Widerspruch, 26, 2006, S. 143-154.

Marton, Ruchama und Baum, Dalit: Transparent Wall, Opaque Gates. In: Against the Wall. Israel's Barrier to Peace. Hrsg. Michael Sorkin. New York 2005, S. 212-223.

Matala de Mazza, Ethel Grace: Der verfasste Körper. Zum Projekt einer organischen Gemeinschaft in der politischen Romantik. Freiburg im Breisgau 1999. 
Matheron, Alexandre: Hobbes, la trinité et les caprices de la représentation. In: Thomas Hobbes. Philosophie première, théorie de la science et politique. Hrsg. Yves Charles Zarka und Jean Bernhardt. Paris 1990, S. 380-390.

Maurer, Trude: Ostjuden in Deutschland 1918-1933. Hamburg 1986.

Mayer, Ruth: Diaspora. Eine kritsche Begriffsbestimmung. Bielefeld 2005.

Mbembé, Achille: Necropolitics. In: Public Culture, 15, 2003, S. 11-40.

McClain, Charles J.: In Search of Equality: The Chinese Struggle against Discrimination in Nineteenth-Century America. Berkeley 1994.

McCormick, Ted: Alchemy in the political arithmetic of Sir William Petty (1623-1687). In: Studies in History and Philosophy of Science, 37, 2006, S. 290-307.

Medick, Hans: Naturzustand und Naturgeschichte der bürgerlichen Gesellschaft. Die Ursprünge der bürgerlichen Sozialtheorie als Geschichtsphilosophie und Sozialwissenschaft bei Samuel Pufendorf, John Locke und Adam Smith. Göttingen 1973.

Medick, Hans: Grenzziehungen und die Herstellung des politisch-sozialen Raumes. Zur Begriffsgeschichte und politischen Sozialgeschichte der Grenzen in der frühen Neuzeit. In: Literatur der Grenze - Theorie der Grenze. Hrsg. Barbara Naumann und Richard Faber. Würzburg 1995, S. 211-224.

Mellinkoff, Ruth: Antisemitic Hate Signs in Hebrew Illuminated Manuscripts from Medieval Germany. Jerusalem 1999.

Mezzadra, Sandro: Nel Leviatano. Immagini del nemico all'origine della filosofia politica moderna. In: Lo straniero e il nemico. Materiali per l'etnografia contemporanea. Hrsg. Alessandro Dal Lago. Genova 1998, S. 27-44.

Mezzadra, Sandro: Diritto di fuga. Migrazioni, Cittadinanza, Globalizzazione. Cartografie. Verona 2006.

Michael, Mark A: Locke's Second Treatise and the Literature of Colonization. In: Interpretation, 25, 1998, S. 407-428.

Miller, David: Why Immigration Controls Are Not Coercive: A Reply to Arash Abizadeh. In: Political Theory, 38, 2010, S. 111-120.

Mills, Charles W.: The Racial Contract. Ithaca 1997.

Mirzoeff, Nicholas: Empire der Lager. In: Bilderpolitik in Zeiten von Krieg und Terror. Medien, Macht und Geschlechterverhältnisse. Hrsg. Linda Hentschel. Berlin 2008, S. 121-136.

Mitchell, W. J. Thomas: Picture Theory. Essays on Verbal and Visual Representation. Chicago 1994.

Mitchell, W. J. Thomas: Interdisziplinarität und visuelle Kultur. In: Diskurse der Fotografie. Fotokritik am Ende des fotografischen Zeitalters. Hrsg. Herta Wolf. Frankfurt am Main 2003, Bd. II, S. 38-50.

Mitchell, W. J. Thomas: There are No Visual Media. In: Journal of Visual Culture, 4, 2005a, S. 257-267.

Mitchell, W. J. Thomas: What do pictures want? The Lives and Loves of Images. Chicago 2005b.

Mitchell, W. J. Thomas: Bildtheorie. Frankfurt am Main 2008. 
Mitchell, W. J. Thomas: Migration, Law, and the Image: Beyond the Veil of Ignorance. In: Images of Illegalized Immigration. Towards a Critical Iconology of Politics. Hrsg. Christine Bischoff, Francesca Falk und Sylvia Kafehsy. Bielefeld 2010.

Mnookin, Jennifer L.: The Image of Truth: Photographic Evidence and the Power of Analogy. In: Yale Journal of Law, 10, 1998, S. 1-75.

Mokre, Monika: Imaginierte Kulturen - reale Kämpfe. Annotationen zu Huntingtons „Kampf der Kulturen“. Baden-Baden 2000.

Mona, Martino: Das Recht auf Immigration. Rechtsphilosophische Begründung eines originären Rechts auf Einwanderung im liberalen Staat. Basel 2007.

Motte, Jan und Ohliger, Rainer: Looking for „Lieux de Mémoire“ in Germany’s Immigration Society. In: Enlarging European Memory. Migration Movements in Historical Perspective. Hrsg. Mareike König und Rainer Ohliger. Ostfildern 2006, S. 148-160.

Mouffe, Chantal: The Return of the Political. London, New York 1993.

Muhle, Maria: Eine Genealogie der Biopolitik. Zum Begriff des Lebens bei Foucault und Canguilhem. Bielefeld 2008.

Mühlhahn, Klaus: The Concentration Camp in Global Historical Perspective. In: History Compass, 8, 2010, S. 544-561.

Müller, Gini: Possen des Performativen. Theater, Aktivismus und queere Politiken. Wien 2008.

Müller, Markus: Zwangsmassnahmen als Instrument der Krankheitsbekämpfung. Das Epidemiengesetz und die persönliche Freiheit. Basel 1992.

Mundy, Barbara E.: The mapping of New Spain: Indigenous cartography and the maps of the relaciones geográficas. Chicago 1996.

Münkler, Herfried: Thomas Hobbes. Frankfurt am Main 2001.

Münkler, Herfried: Strategien der Visualisierung. Verbildlichung als Mittel politischer Kommunikation. Frankfurt am Main 2009.

Naef, Weston und Wood, James: Era of Exploration: The Rise of Landscape Photography in the American West, 1860-1885. Boston 1975.

Nafziger, James A.R.: The General Admission of Aliens under International Law. In: American Journal of International Law, 77, 1983, S. 804-847.

Nellen-Stucky, Rachel: „Notre point commun, c'est le papier“ - Sans-Papiers als politische Akteure. In: Sans-Papiers in der Schweiz. Unsichtbar - Unverzichtbar. Hrsg. Schweizerisches Rotes Kreuz. Zürich 2006, S. 200-237.

Niklaus, Pierre-Alain und Schäppi, Hans: Zukunft Schwarzarbeit? Jugendliche Sans-Papiers in der Schweiz. Zürich 2007.

Noiriel, Gérard: Le creuset français. Histoire de l'immigration XIXe-XXe siècles. Paris 1988.

Oberman, Kieran: Immigration and Freedom of Movement. Unveröffentlichtes Dissertations-Manuskript (2009).

Odgen, Kate Nearpass: Yosemite Valley as Image and Symbol: Paintings and Photographs from 1855 to 1880 . Graduate School of Arts and Science. Ann Arbor 2002. 
Opitz-Belakhal, Claudia: Das Universum des Jean Bodin: Staatsbildung, Macht und Geschlecht im 16. Jahrhundert. Frankfurt am Main 2006.

Opitz, Sven: Gouvernementalität im Postfordismus. Macht, Wissen und Techniken des Selbst im Feld unternehmerischer Rationalität. Hamburg 2004.

Orland, Barbara und Gugerli, David: Ganz normale Bilder: Historische Beiträge zur visuellen Herstellung von Selbstverständlichkeit. Zürich 2002.

Orwin, Clifford: Stasis and Plague: Thucydides on the Dissolution of Society. In: Journal of Politics, 50, 1988, S. 831-847.

Osterhammel, Jürgen: Geschichtswissenschaft jenseits des Nationalstaats. Studien zu Beziehungsgeschichte und Zivilisationsvergleich. Göttingen 2001.

Osterhammel, Jürgen: Die Verwandlung der Welt. München 2009.

Otis, Laura: Membranes: Metaphors of Invasion in nineteenth-century Literature, Science, and Politics. Baltimore 1999.

Padoan Urban, Lina: Il carnevale veneziano nelle maschere incise da Francesco Bertelli. Milano 1986.

Pagenstecher, Cord: „Das Boot ist voll“. Schreckensvision des vereinten Deutschland. In: Das Jahrhundert der Bilder. 1949 bis heute. Hrsg. Gerhard Paul. Göttingen 2008, S. 606-613.

Palmer, Richard J.: The Control of Plague in Venice and Northern Italy 13481600. 1978.

Palmquist, Peter E.: Carleton E. Watkins's oldest surviving landscape photograph. In: History of Phtography, 5, 1981, S. 223-225.

Panagiotidis, Efhimia und Tsianos, Vassilis: Denaturalizing „Camps“: Überwachen und Entschleunigen in der Schengener Ägais-Zone. In: Turbulente Ränder. Neue Perspektiven auf Migration an den Grenzen Europas. Hrsg. Transit Migration Forschungsgruppe. Bielefeld 2007, S. 57-86.

Panofsky, Erwin: Ikonografie und Ikonologie. Eine Einführung in die Kunst der Renaissance. In: Sinn und Deutung in der bildenden Kunst. Köln 1975, S. 36-62.

Parekh, Bhikhu C.: Liberalism and Colonialism. A Critique of Locke and Mill. In: The Decolonization of Imagination. Culture, Knowledge and Power. Hrsg. Nederveen Pieterse, Bhikhu Jan und Bhikhu C. Parekh. London 1995, S. 81-98.

Pateman, Carole: The Sexual Contract. Cambridge 1988.

Pateman, Carole und Mills, Charles W.: Contract and Domination. Cambridge 2007.

Paul, Gerhard: Das Jahrhundert der Bilder. Die visuelle Geschichte und der Bilderkanon des kulturellen Gedächtnisses. Göttingen 2008.

Pécoud, Antoine und De Gucheteneire, Paul: International Migration, Border Controls and Human Rights: Assessing the Relevance of a Right to Mobility. In: Journal of Borderland Studies, 21, 2006, S. 69-86.

Pécoud, Antoine und De Gucheteneire, Paul: Introduction: the migration without borders scenario. In: Migration Without Borders. Essays on the Free Movement of People. Hrsg. Antoine Pécoud und Paul De Gucheteneire. Paris 2007, S. 1-30. 
Pegler-Gordon, Anna: Chinese Exclusion, Photography, and the Development of U.S. Immigration. In: American Quarterly, 58, 2006, S. 51-77.

Pennock, Roland J.: Hobbes' Confusing „Clarity“-The Case of „Liberty“. In: Hobbes Studies. Hrsg. Keith C. Brown. Oxford 1965, S. 101-116.

Perec, Georges und Bober, Robert: Geschichten von Ellis Island. Oder Wie man Amerikaner macht. Berlin 1997.

Perjovschi, Dan und Solakov, Nedko: Walls and Floor (Without the Ceiling). Nürnberg 2008.

Perlmutter, David D.: Photojournalism and Foreign Policy: Icons of Outrage in International Crises. Westport, Connecticut, London 1998.

Persram, Nalini: Postcolonialism and Political Theory. Global encounters. Lanham 2007.

Petty, William: The Political Anatomy of Ireland. In: The Economic Writings of Sir William Petty. Hrsg. Charles Henry Hull. Cambridge 1899, S. 121223.

Petty, William: A Treatise of Ireland. In: The Economic Writings of Sir William Petty. Hrsg. Charles Henry Hull. Cambridge 1986, Bd. 2, S. 546-621.

Pfaelzer, Jean: Driven out: The forgotten War against Chinese Americans. New York 2007.

Pfau, Jonas: Prekäre Migration und Ausschluss: Die gesellschaftliche Perzeption von illegaler Migration, Fluchthilfe und Menschenschmuggel in und nach Mitteleuropa. In: Subversion am Rande. Grenzverletzungen im 20. und 21. Jahrhundert. comparativ. Zeitschrift für Globalgeschichte und vergleichende Gesellschaftsforschung, 18, 2008, S. 23-41.

Pichler, Wolfram: Detaillierung des Bildes. Zur Einleitung in den Band. In: Was aus dem Bild fällt. Figuren des Details in Kunst und Literatur. Friedrich Teja zum 60. Geburtstag. Hrsg. Edith Futscher. Paderborn 2007, S. 9-41.

Pieper, Marianne und Gutiérrez Rodríguez, Encarnación: Gouvernementalität. Ein sozialwissenschaftliches Konzept im Anschluss an Foucault. Frankfurt am Main 2003.

Pieper, Marianne et. al.: Empire und die biopolitische Wende. Die internationale Diskussion im Anschluss an Hardt und Negri. Frankfurt am Main 2007.

Pieper, Tobias: Weder Gespenst noch autonom. Eine kritische Auseinandersetzung mit der „Autonomie der Migration“. In: ak - analye und kritik. Zeitung für linke Debatte und Praxis 2004.

Pieper, Tobias: Die Gegenwart der Lager. Zur Mikrophysik der Herrschaft in der deutschen Flüchtlingspolitik. Münster 2008.

Pike, Deborah: Sharon's Wall and the Dialectics of Inside/Outside. In: borderlands e-journal. http://www.borderlands.net.au/vol5no3_2006/pike_sharonswall.htm, 5, 2006.

Pitt, Leonard: The decline of the Californios: A social history of the Spanishspeaking Californians, 1846-1890. Berkeley 1998.

Platon: Apologie des Sokrates. Kriton. Stuttgart 1994.

Prantl, Heribert: Der Terrorist als Gesetzgeber. München 2008. 
Prescott, John Robert Victor: Boundaries and Frontiers. London 1978.

Priddat, Birger P.: Das Geld und die Vernunft. Die vollständige Erschliessung der Erde durch vernunftgemässen Gebrauch des Geldes. Über John Lockes Versuch einer naturrechtlich begründeten Ökonomie. Frankfurt am Main 1988.

Prins, Jan: Hobbes on light and vision. In: The Cambridge Companion to Hobbes. Hrsg. Tom Sorell. Cambridge 1996, S. 129-156.

Pritchett, Lant: Let Their People Come. Breaking the Gridlock on International Labor Mobility. Washington 2006.

Pugh, Michael: Drowning not Waving: Boat People and Humanitarism at Sea. In: Journal of Refugee Studies, 17, 2004, S. 50-69.

Purtschert, Patricia: Die postkoloniale Schweiz. „Heute bedankt sich Naresh Khan bei Silvia Hug für ihr Engagement." Notizen zur postkolonialen Schweiz. In: Olympe. Feministische Arbeitshefte zur Politik, 27, 2008a, S. 76-87.

Purtschert, Patricia und Meyer, Katrin: Migrationsmanagement und die Sicherheit der Bevölkerung. In: Gouvernementalität und Sicherheit. Zeitdiagnostische Beiträge im Anschluss an Focault. Hrsg. Patricia Purtschert, Katrin Meyer und Yves Winter. Bielefeld 2008, S. 149-172.

Purtschert, Patricia: Postkoloniale Diskurse in der Schweiz: „De Schorsch Gaggo reist uf Afrika“. In: Widerspruch 28, 2008b, S. 169-180.

Purtschert, Patricia: „De Schorsch Gaggo reist uf Afrika“: Postkoloniale Konstellationen und Schweizer Befindlichkeiten. In: Postkoloniale Schweiz. Hrsg. Patricia Purtschert, Barbara Lüthi und Francesca Falk. Bielefeld 2012.

Purtschert, Patricia: Jenseits des Naturzustandes: Hobbes, Rousseau und die Wilden. Unveröffentlichtes Manuskript (2009).

Ratzel, Friedrich: Politische Geographie oder die Geographie der Staaten, des Verkehrs und Krieges. München 1903.

Riha, Orthrun: Nächstenliebe und Ausgrenzung. Aussatz als soziale Krankheit im Mittelalter. In: Grenze und Grenzüberschreitung im Mittelalter. 11. Symposium des Mediävistenverbandes vom 14. bis 17. März 2005 in Frankfurt an der Oder. Hrsg. Ulrich Knefelkamp und Kristian Bosselmann-Cyran. Berlin 2007, S.400-413.

Ritchie, Charles Edward: The Athenian Boundary Stones of Public Domain. Ann Arbor 1985.

Ritter, Joachim und Gründer, Karlfried: Kontingenz. In: Historisches Wörterbuch der Philosophie. Basel 1971.

Rodier, Claire und Saint-Saëns, Isabelle: Contrôler et filtrer: Les camps au service des politiques migratoires de l'europe. In: Mondialisation, migration et droits de l'homme: le droit international en question. Hrsg. Vincent Chetail. Bruxelles 2007, S. 618-663.

Rodier, Claire und Terray, Emmanuel: Conclusion. Il faut en finir avec la fermeture des frontières. In: Immigration: fantasmes et réalités. Pour une alternative à la fermeture des frontières. Hrsg. Claire Rodier und Emmanuel Terray. Paris 2008, S. 119-130. 
Roesler, Sascha: Vom Glashaus zum gläsernen Menschen. Transparenz als Ideologie der Moderne. In: Kunst + Architektur in der Schweiz, 58, 2007.

Rogers, Graham: Locke's Enlightenment. Aspects of the Origin, Nature, and Impact of his Philosophy. Hildesheim 1998.

Rosen, George: A History of Public Health. New York 1958.

Ruskola, Teemu: Canton is not Boston: The invention of American Imperial Sovereignty. In: Legal borderlands: Law and the construction of American borders. Hrsg. Mary L. Dudziak und Leti Volpp. Baltimore, Md. 2006, S. 267-292.

Sahlins, Peter: Boundaries: The Making of France and Spain in the Pyrenees. Berkeley 1989.

Sahlins, Peter: Natural Frontiers Revisted: France's Boundaries since the Seventeenth Century. In: The American Historical Review, 95, 1990, S. 14231451.

Said, Edward W.: Orientalism. Reprinted with a new preface. London 2003 [1978].

Salzmann, C.: Masques portés par les Médecins en temps de Peste. In: Aesculape, 22, 1932, S. 5-14.

Sarasin, Philipp: Agamben - oder doch Foucault? In: Deutsche Zeitschrift für Philosophie, 81, 2003, S. 348-353.

Sarasin, Philipp: Abu Ghraib, terrorist vermin und der utopische Körper der Nation. In: Utopische Körper. Visionen künftiger Körper in Geschichte, Kunst und Gesellschaft. Hrsg. Kristiane Hasselmann, Sandra Schmidt und Cornelia Zumbusch. München 2004, S. 167-183.

Sarasin, Philipp: Michel Foucault zur Einführung. Hamburg 2005.

Sarasin, Philipp: „War of the Worlds“. Der Terrorismus und das Pocken-Modell. Anmerkungen über Liberalität nach Foucault. In: Lab. Jahrbuch für Künste und Apparate. Hrsg. Kunsthochschule für Medien Köln. Köln 2005/2006, S. 151-163.

Sarasin, Philipp: Anthrax. Bioterror as Fact and Fantasy. Cambridge, Mass. 2006.

Sarasin, Philipp: Die Visualisierung des Feindes. Über metaphorische Technologien der frühen Bakteriologie. In: Bakteriologie und Moderne. Studien zur Biopolitik des Unsichtbaren, 1870-1920. Hrsg. Philipp Sarasin, Silvia Berger, Marianne Hänseler u.a. . Frankfurt am Main 2007, S. 427-461.

Sarasin, Philipp: Vapors, Viruses, Resistance(s): The Trace of Infection in the Work of Michel Foucault. In: Networked Disease. Emerging Infections in the Global City. Hrsg. S. Harris Ali und Roger Keil. Oxford 2008, S. $267-$ 280.

Sassen, Saskia: Migranten, Siedler, Flüchtlinge. Von der Massenauswanderung zur Festung Europa. Frankfurt am Main 1997.

Scanlan, John A und Kent, O.T.: The Force of Moral Arguments for a Just Immigration Policy in a Hobbesian Universe. The Contemporary American Example. In: Open borders? Closed societies? The ethical and political issues. Hrsg. Mark Gibney. New York 1988, S. 61-107. 
Schäffner, Wolfgang et. al.: „Der liebe Gott steckt im Detail“. Mikrostrukturen des Wissens. München 2003.

Schär, Bernhard C.: Von „Vaganten“ zu Jenischen: Emanzipation der Fahrenden im Geist der Hippieromantik. In: Bern 68. Lokalgeschichte eines globalen Aufbruchs - Ereignisse und Erinnerungen. Hrsg. Bernhard C. Schär. Baden 2008, S. 180-190.

Schilliger, Sarah: Migration im Kontext der Globalisierung des Kapitals. In: Zukunft der Demokratie. Das postkapitalistische Projekt. Hrsg. Beat Ringger und Willi Eberle. Zürich 2008, S. 155-187.

Schlich, Thomas: „Wichtiger als der Gegenstand selbst“ - Die Bedeutung des fotografischen Bildes in der Begründung der bakteriologischen Krankheitsauffassung durch Robert Koch. In: Neue Wege in der Seuchengeschichte. Hrsg. Marin Dinges und Thomas Schlich. Stuttgart 1995, S. 143-174.

Schlich, Thomas: Die Repräsentation von Krankheitserregern. Wie Robert Koch Bakterien für Krankheitsursachen dargestellt hat. In: Räume des Wissens. Repräsentation, Codierung, Spur. Hrsg. Hans-Jörg Rheinberger, Michael Hagner und Bettina Wahrig-Schmidt. Berlin 1997, S. 165-190.

Schmale, Wolfgang: Geschichte Frankreichs. Stuttgart 2000.

Schmitt, Carl: Der Leviathan in der Staatslehre des Thomas Hobbes. Sinn und Fehlschlag eines politischen Symbols. Hamburg 1938.

Schmitt, Carl: Der Nomos der Erde im Völkerrecht des Jus Publicum Europaeum. Berlin 1997.

Schmitt, Carl: Der Leviathan in der Staatslehre des Thomas Hobbes. Sinn und Fehlschlag eines politischen Symbols. Stuttgart 2003 [1938].

Schneider, Ute: Tordesillas 1494 - Der Beginn einer globalen Weltsicht. In: Saeculum. Jahrbuch für Universalgeschichte, 54, 2003, S. 39-62.

Schochet, Gordon J.: The family and the origins of the state in Locke's political philosophy. In: John Locke: Problems and Perspectives. A Collection of News Essay. Hrsg. John W. Yolton. Cambridge 1969, S. 81-98.

Scholz, Susanne: „The blood of the Commonwealth“: Koloniale Kreisläufe und die Ethik des Empire im England des 17. und 18. Jahrhunderts. In: Geschlechterperspektiven: Forschungen zur frühen Neuzeit. Hrsg. Heide Wunder und Gisela Engel. Königstein 1998, S. 469-182.

Schreckenberg, Heinz: Die Juden in der Kunst Europas. Ein historischer Bildatlas. Göttingen 1996.

Schroer, Markus: Gewalt ohne Gesicht. Zur Notwendigkeit einer umfassenden Gewaltanalyse. In: Gewalt. Entwicklungen, Strukturen, Analyseprobleme. Hrsg. Wilhelm Heitmeyer und Hans-Georg Soeffner. Frankfurt am Main 2004, S. 151-173.

Schrover, Marlou, Van der Leun, Joanne, Lucassen, Leo u.a. : Introduction. In: Illegal Migration and Gender in a Global and Historical Perspective. Hrsg. Marlou Schrover, Joanne Van der Leun, Leo Lucassen u.a. . Amsterdam 2008, S. 9-37.

Schwager, Bea: Die Sans-Papiers - illegalisiert, aber nicht rechtlos. In: Widerspruch. Beiträge zu sozialistischer Politik, 2006, S. 5. 
Schwarte, Ludger: Auszug aus dem Lager. Zur Überwindung des modernen Raumparadigmas. Bielefeld 2007.

Schwenken, Helen: Rechtlos, aber nicht ohne Stimme. Politische Mobilisierungen um irreguläre Migration in die Europäische Union. Bielefeld 2006.

Schwennicke, Andreas: „Ohne Steuer kein Staat“. Zur Entwicklung und politischen Funktion des Steuerrechts in den Territorien des Heiligen Römischen Reiches (1500-1800). Frankfurt am Main 1996.

Sengoopta, Chandak: Imprint of the Raj. How fingerprinting was born in colonial India. London 2003.

Sexton, Nanette Margret: Carleton E. Watkins: Pioneer California Photographer (1829-1916). The Fine Arts Department. Cambridge Mass. 1982.

Shachar, Ayelet: The Birthright Lottery. Citizenship and Global Inequality. Cambridge, Mass. 2009.

Shapin, Steven und Schaffer, Simon: Leviathan and the Air-Pump. Hobbes, Boyle, and the Experimental Life. Princeton 1985.

Shogimen, Takashi: Liberty. In: New dictionary of the history of ideas. Hrsg. Maryanne Cline Horowitz. Detroit 2005, S. 1272-1279.

Short, Bradford William: The healing philosopher: John Locke's Medical Ethics. In: Issues in Law \& Medicine, 22. September, 2004, S. 103-154.

Shuler, Benjamin: Shampoo trinken gegen die Ohnmacht. In: WOZ. Die Wochenzeitung 10.1. 2008.

Siebenpfeiffer, Hania: Video, ergo scio. Neue Untersuchungen zur Evidenz in der Frühen Neuzeit. Rezension über: Gabriele Wimböck, Karin Leonhard, Markus Friedrich [Hrsg.]: Evidentia. Reichweiten visueller Wahrnehmung in der Frühen Neuzeit. Münster: Lit 2007. In: IASLonline (03.01.2009), 2009.

Sieber-Lehmann, Claudius: „Regna colore rubeo circumscripta“. Überlegungen zur Geschichte weltlicher Herrschaftsgrenzen im Mittelalter. In: Grenzerfahrung und Raumvorstellungen. Hrsg. Guy Paul Marchal. Zürich 1996, S. 79-92.

Skenderovic, Damir und D'Amato, Gianni: Mit dem Fremden politisieren. Rechtspopulistische Parteien und Migrationspolitik in der Schweiz seit den 1960er Jahren. Zürich 2008.

Skinner, Quentin: The foundations of modern political thought. Cambridge 1978.

Skinner, Quentin: Reason and Rhetoric in the Philosophy of Hobbes. Cambridge 1996.

Skinner, Quentin: Hobbes and Republican Liberty. Cambridge 2008.

Slack, Paul: The Impact of Plague in Tudor and Stuart England. London, Boston 1985.

Smith, Adam: Lectures on Jurisprudence. Oxford 1978, Bd. VIII.

Smith, Adam: Der Wohlstand der Nationen. Eine Untersuchung seiner Natur und seiner Ursachen. Hrsg. Horst Claus Recktenwald. München 2005 [1776].

Spescha, Marc: Migrationsabwehr im Fokus der Menschenrechte. Zürich 2007. 
Spivak, Chakravorty: Achtung: Postkolonialismus. In: Inklusion : Exklusion. Probleme des Postkolonialismus und der globalen Migration. Hrsg. Peter Weibel und Slavoj Zizek. Wien 1997, S. 117-130.

Spivak, Gayatri: Can the Subaltern speak? In: Marxism and the Interpretation of Culture. Hrsg. Lawrence Grossberg und Cary Nelson. Urbana, Chicago 1988, S. 271-316.

Spyk, Benedikt van: Vertragstheorie und Völkerrecht im Werk des Hugo Grotius. Hamburg 2005.

Sqadrito, Kathy: Locke and the Dispossession of the American Indian. In: Philosophers on Race. Critical essays. Hrsg. Julie K. Ward und Tommy L. Lott. Oxford 2002, S. 101-124.

Statt, Daniel: The City of London and the Controversy Over Immigration, 1660-1722. In: The Historical Journal, 33, 1990, S. 45-61.

Steiner, Pascale und Wicker, Hans-Rudolf: Paradoxien im Bürgerrecht. Sozialwissenschaftliche Studien zur Einbürgerungspraxis in Schweizer Gemeinden. Zürich 2004.

Stern, Alexandra Minna: Gebäude, Grenzen und Blut. Medikalisierung und Nation-Building an der amerikanisch-mexikanischen Grenze 1910-1930. In: Bakteriologie und Moderne. Studien zur Biopolitik des Unsichtbaren, 1870-1920. Hrsg. Philipp Sarasin, Silvia Berger, Marianne Hänseler u.a. . 2007, S. 375-423.

Stollberg-Rilinger, Barbara: Der Staat als Maschine. Zur politischen Metaphorik des absoluten Fürstenstaats. Berlin 1986.

Studer, Brigitte, Arlettaz, Gérald und Argast, Regula: Das Schweizer Bürgerrecht. Erwerb, Verlust, Entzug von 1848 bis zur Gegenwart. Zürich 2008.

Tagg, John: The Burden of Representation: Essays on Photographies and Histories. Amherst 1988.

Talbot, Ann: „The Great Ocean of Knowledge“. The influence of Travel Literature on the Work of John Locke. Brill's studies in intellectual history. Leiden 2010.

Talbot, William Henry Fox: The Pencil of Nature. New York 1969 (1844-46).

Thränhardt, Dietrich Offene Grenzen in der EU - Todesmauer in der NAFTA. Entwicklungen, Strukturen und Diskurse In: Leviathan. Berliner Zeitschrift für Sozialwissenschaft, 38, 2010, S. 65-88.

Thumfart, Johannes: Die Begründung der globalpolitischen Philosophie. $\mathrm{Zu}$ Francisco de Vitorias „Relectio de Indis recenter inventis“ von 1539. Berlin 2010.

Tobler, Andreas: Evaluation der Zwangsmassnahmen im Ausländerrecht zuhanden der Geschäftsprüfungskommission des Nationalrates. Bern 2005.

Tomes, Nancy: The Gospel of Germs. Men, Women, and the Microbe in American Life. Cambridge, Mass. 1999.

Torpey, John C.: The Invention of the Passport: Surveillance, Citizenship and the State. Cambridge 2000.

Triandafyllidou, Anna: Irregular migration in Europe in the Early 21st Century. In: Irregular migration in Europe. Myths and Realities. Farnham 2010, S. $1-21$. 
Triulzi, Alessandro: Dispacing the Colonial Event. Hybrid Memories of Postcolonial Italy. In: Interventions, 8, 2006, S. 430-443.

Tully, James: Rediscovering America: The Two Treatises and Aboriginal Rights. In: An Approach to Political Philosophy: Locke in Contexts. Hrsg. James Tully. Cambridge 1993, S. 137-176.

Türke, Andras Istvan: La crise albanaise en 1997 et l'Opération ALBA. In: Frontières et Sécurité de l'Europe: Territoires, identités et espace européens. Hrsg. Christine Manigand. Paris 2008, S. 159-178.

Turner, Frederick Jackson: Rereading Frederick Jackson Turner: „The Significance of the Frontier in American History" and other Essays. New Haven, London 1998 [1893].

Ulbricht, Otto: Angst und Angstbewältigung in den Zeiten der Pest 15001720. In: Gotts verhengnis und seine straffe. Zur Geschichte der Seuchen in der Frühen Neuzeit. Hrsg. Petra Feuerstein. Wiesbaden 2005, S.101112.

Ullrich, Maren: Geteilte Ansichten. Erinnerungslandschaft Deutsch-Deutsche Grenze. Berlin 2006.

Uzgalis, William: „An Inconsistency not be Excused“: On Locke and Racism. In: Philosophers on Race. Critical Essays. Hrsg. Julie K. Ward und Tommy L. Lott. Oxford 2002, S. 81-100.

Van Gorp, Baldwin: Where is the Frame? Victims and Intruders in the Belgian Press Coverage of the Asylum Issue. In: European Journal of Communication, 2005, S. 484-507.

Varadarajan, Tunku: The Romance of Economics. In: Wall Street Journal, www.opinionjournal.com/editorial/feature.html?id=110008690, 22.07., 2006.

Vattimo, Gianni, Engelmann, Peter: Die transparente Gesellschaft. Wien 1992.

Vaughan-Williams, Nick: Border Politics. The Limits of Sovereign Power. Edinburgh 2009.

Vismann, Cornelia: Terra nullius. Zum Feindbegriff im Völkerrecht. In: Übertragung und Gesetz. Gründungsmythen, Kriegstheater und Unterwerfungstechniken von Institutionen. Hrsg. Martin Stingelin und Adam Armin. Berlin 1995, S. 159-176.

Vobruba, Georg: Grenz-Beobachtungen. In: Ästhetik \& Kommunikation. Gesellschaft grenzenlos?, 29, 1998, S. 47-52.

Volpp, Leti: Impossible Subjects: Illegal Aliens and Alien Citizen. In: Michigan Law Review, 103, 2005, S. 1595-1630.

Von Euw, Jack: Pictorial Collection. In: Exploring the Bancroft Library. Hrsg. Charles Faulhaber und Stephen Vincent. Salt Lake City, Berkeley 2006, S. 68-87.

Von Müller, Achatz: Der venezianische Karneval. In: Karneval in Venedig. Hrsg. Rolf D. Schwarz. Dortmund 1984, S. 123-138.

Von Müller, Achatz und Von Ungern-Sternberg, Jürgen: Die Wahrnehmung des Neuen: Zwischen Selbstverortung und Flucht aus der Geschichte. In: 
Die Wahrnehmung des Neuen in Antike und Renaissance. Hrsg. Achatz Von Müller. München 2004, S. VII-XVII.

Von Osten, Marion: Eine Bewegung der Zukunft. Die Bedeutung des Blickregimes der Migration für die Produktion der Ausstellung Projekt Migration. In: Turbulente Ränder. Neue Perspektiven auf Migration an den Grenzen Europas. Hrsg. Transit Migration Forschungsgruppe. Bielefeld 2007, S. 169-186.

Voss, Julia: Darwins Bilder. Ansichten der Evolutionstheorie 1837-1874. Fischer-Taschenbuch. Frankfurt am Main 2007.

Walter, Dirk: Antisemitische Kriminalität und Gewalt. Judenfeindschaft in der Weimarer Republik. Bonn 1999.

Walters, William: Deportation, Expulsion, and the International Police of Aliens. In: Citizenship Studies, 6, 2002, S. 265-292.

Walzer, Michael: Sphären der Gerechtigkeit. Ein Plädoyer für Pluralität und Gleichheit. Frankfurt am Main 1998.

Warnke, Martin: Politische Landschaft. Zur Kunstgeschichte der Natur. München 1992.

Weiand, Kerstin: Tagungsbericht HT 2010: Der Topos des leeren Raumes als narratives Konstrukt mittelalterlicher und neuzeitlicher Einwanderergesellschaften. In: H-Soz-u-Kult, http://hsozkult.geschichte.hu-berlin.de/tagungsberichte/id=3364 13.11. 2010.

Weizman, Eyal: Hollow Land. Israel's Architecture of Occupation. London 2007.

Wenk, Silke und Krebs, Rebecca: Analysing the Migration of People and Images: Perspectives and Methods in the Field of Visual Culture. In: http:// www.york.ac.uk/res/researchintegration/Integrative_Research_Methods/ Wenk\%20Visual\%20Culture\%20April\%202007.pdf (20.1.2010).

Whelan, Frederick G.: Citizenship and the Right to Leave. In: The American Political Science Review, 75, 1981, S.636-653.

Wicker, Hans-Rudolf, Fibbi, Rosita und Haug, Werner: Migration und die Schweiz. Ergebnisse des Nationalen Forschungsprogramms „Migration und interkulturelle Beziehungen“. Zürich 2004.

Wicker, Hans-Rudolf: Deportation at the Limits of „Tolerance“: The Juridical, Institutional, and Social Construction of „Illegality“ in Switzerland. In: The Deportation Regime. Sovereignty, Space, and the Freedom of Movement. Hrsg. Nicholas De Genova und Nathalie Peutz. Durham, N.C. 2010, S. 224-244.

Wiedemann, Charlotte: Mythen der Migration. In: Le Monde diplomatique, Juni, 2009, S. 12-13.

Wiesing, Lambert: Die Sichtbarkeit des Bildes. Geschichte und Perspektiven der formalen Ästhetik. Reinbek 1997.

Wiesing, Lambert: Phänomene im Bild. München 2000.

Wieviorka, Annette: L'expression „camp de concentration“ au 20e siècle. In: Vingtième Siècle. Revue d'histoire, 54, 1997, S. 4-12. 
Windisch, Martin: Staatstheorie und Bildform bei Thomas Hobbes. In: Zeitsprünge. Forschungen zur Frühen Neuzeit. Zentrum zur Erforschung der Frühen Neuzeit, 1, 1997, S. 117-165.

Wippermann, Wolfgang: Konzentrationslager. Geschichte, Nachgeschichte, Gedenken. Berlin 1999.

Wokart, Norbert: Differenzierungen im Begriff „Grenze“. Zur Vielfalt eines scheinbar einfachen Begriffs. In: Literatur der Grenze - Theorie der Grenze. Hrsg. Richard Faber und Barbara Naumann. Würzburg 1995, S. 275289.

Wottreng, Willi: Ein einzig Volk von Immigranten. Die Geschichte der Einwanderung in die Schweiz. Zürich 2000.

Zimmer, Carl: Soul made Flesh.The Discovery of the Brain - and how it changed the World. New York 2004.

Zumbusch, Cornelia: Wissenschaft in Bildern. Symbol und dialektisches Bild in Aby Warburgs Mnemosyne-Atlas und Walter Benjamins Passagen-Werk. Berlin 2004.

Zünd, Andreas: Von den alten zu den neuen Zwangsmassnahmen. In: Jahrbuch für Migrationsrecht 2006/2007. Hrsg. Alberto Achermann. Bern 2007, S. 97-105.

Zurbuchen, Simone: Einleitung. In: Bürgerschaft und Migration. Einwanderung und Einbürgerung aus ethisch-politischer Perspektive. Hrsg. Simone Zurbuchen. Zürich 2007, S.7-21.

Zwingli-Bibel: Die Heilige Schrift des Alten und des Neuen Testaments. Zürich 1966. 